RUY SCANHO MARQUES DE QUEIROZ

\begin{abstract}
AVALIAÇÃO DE REATOR UASB ASSISTIDO QUIMICAMENTE PARA REMOÇÃO DE FÓSFORO
\end{abstract}


RUY SCANHO MARQUES DE QUEIROZ

\title{
AVALIAÇÃO DE REATOR UASB ASSISTIDO QUIMICAMENTE PARA REMOÇÃO DE FÓSFORO
}

\author{
Dissertação apresentada à Escola \\ Politécnica da Universidade de São \\ Paulo para obtenção do título de Mestre \\ em Engenharia. \\ Área de Concentração: \\ Engenharia Hidráulica e Sanitária \\ Orientador: \\ Prof. Dr. Roque Passos Piveli
}


RUY SCANHO MARQUES DE QUEIROZ

\title{
AVALIAÇÃO DE REATOR UASB ASSISTIDO QUIMICAMENTE PARA REMOÇÃO DE FÓSFORO
}

\author{
Dissertação apresentada à Escola \\ Politécnica da Universidade de São \\ Paulo para obtenção do título de Mestre \\ em Engenharia. \\ Área de Concentração: \\ Engenharia Hidráulica e Sanitária \\ Orientador: \\ Prof. Dr. Roque Passos Piveli
}


AUTORIZO A REPRODUÇÃO E DIVULGAÇÃO TOTAL OU PARCIAL DESTE TRABALHO, POR QUALQUER MEIO CONVENCIONAL OU ELETRÔNICO, PARA FINS DE ESTUDO E PESQUISA, DESDE QUE CITADA A FONTE.

VOLUME REVISADO: Esta versão difere da Dissertação depositada e aprovada na defesa, à qual foram incorporadas modificações sugeridas pela comissão examinadora, devidamente verificadas e aprovadas pelo orientador.

Prof. Dr. Roque Passos Piveli

\section{FICHA CATALOGRÁFICA}

Queiroz, Ruy Scanho Marques de

Avaliação de reator UASB assistido quimicamente para remoção de fósforo / R.S.M. de Queiroz. - São Paulo, 2007.

$181 \mathrm{p}$.

Dissertação (Mestrado) - Escola Politécnica da Universidade de São Paulo. Departamento de Engenharia Hidráulica e Sanitária.

1.Esgotos sanitários (Tratamento) 2.Reatores anaeróbios 3.Fósforo (Remoção) I.Universidade de São Paulo. Escola Politécnica. Departamento de Engenharia Hidráulica e Sanitária II.t. 
A Clara, pelo companheirismo e carinho que tanto ajudaram no desenvolvimento deste trabalho. 


\section{AGRADECIMENTOS}

A Deus, por permitir que eu percorresse este caminho tão gratificante.

Ao Professor Doutor Roque Passos Piveli, orientador, por tudo que transmitiu de conhecimento, pelas sugestões e pelo estabelecimento das diretrizes deste trabalho.

Ao Professor Doutor Pedro Alem Sobrinho, pelos conselhos e ensinamentos passados em inúmeras ocasiões.

Ao Professor Doutor Sidney Seckler Ferreira Filho, por toda a ajuda e pelo desenvolvimento inicial do assunto ora abordado.

À Professora Doutora Dione Mari Morita, pela contribuição com idéias e pelo treinamento, indispensável para a execução das determinações analíticas deste trabalho.

A José Marques de Queiroz e Ophélia Scanho Marques de Queiroz, meus pais, pela formação, educação e conceitos ensinados, sem os quais não teria sido possível chegar a este ponto.

A Manoel Rodrigues Escanho, meu avô, pelas sempre sábias palavras.

À minha irmã, Elizabeth Scanho Marques de Queiroz, pelo companheirismo e acolhida nos momentos mais difíceis.

Aos colegas Aline Akabochi Fabreti, Ari Caraver, Érica Myho Matsumura, Gilberto Carlos Sundefeld Jr., Hilton Alexandre de Oliveira, Lúcia Naomi Asada, Luciano Matos Queiroz, Manoel Paulo de Toledo e Osvaldo Americano Godoy, pelo coleguismo e ajuda mútua que conduziu, nos momentos devidos, ao sucesso de cada um. 
Aos funcionários do Laboratório de Saneamento da Escola Politécnica Ângela Mizuta, Fábio Campos e Laerte Carvalho, que em muito contribuíram para a conclusão desta Dissertação.

Aos funcionários do Departamento de Hidráulica e Saneamento da Escola Politécnica, por toda ajuda.

Às empresas CBC Indústrias Pesadas, Hidrogesp Hidrogeologia, Sondagens e Perfurações e Centroprojekt do Brasil e seus funcionários, pelo incentivo e compreensão.

À empresa Kemwater do Brasil, pela ajuda no desenvolvimento do estudo.

À Companhia de Saneamento Básico do Estado de São Paulo - Sabesp, que além de toda experiência que me foi passada enquanto seu funcionário, cedeu sua estação de tratamento de Ribeirão Pires e forneceu mão de obra e todos os insumos, sem os quais este experimento não teria existido.

Aos funcionários da Sabesp, André Gois, Ronaldo Matoso e Sérgio Aparecido, pela grande ajuda na operação e manutenção do sistema montado para o experimento.

Ao Conselho Nacional de Desenvolvimento Científico e Tecnológico - CNPq, pela bolsa de mestrado.

À FAPESP, pela ajuda na implantação do estudo experimental.

Aos engenheiros Aldo Takahashi e Kouji Kitahara, pelas lições de saneamento e de bom senso, que me fizeram dar início a uma carreira tão recompensadora.

A todos que colaboraram direta ou indiretamente na execução deste trabalho. 
Quem não desconfia de si mesmo, não merece a confiança dos outros!

Mestre Nô-Elin 


\section{RESUMO}

Queiroz, R. S. M. Avaliação de reator uasb assistido quimicamente para remoção de fósforo. 2007.180 p. Dissertação (Mestrado) - Escola Politécnica da Universidade de São Paulo. Departamento de Engenharia Hidráulica e Sanitária. São Paulo, 2007.

Este trabalho visou avaliar a remoção de fósforo solúvel e total, carga orgânica, sulfetos e sólidos num esgoto doméstico fraco, ao qual se adicionou como coagulante o cloreto férrico, atravessando o manto de lodo de um tratamento anaeróbio UASB. A ETE Ribeirão Pires, aonde este estudo foi desenvolvido, conta com 4 reatores com capacidade para tratar $70 \mathrm{~L} / \mathrm{s}$, dos quais 2 foram utilizados, num deles (reator $\mathrm{B}$ ) foram dosados 25 e $50 \mathrm{mg} \mathrm{FeCl} / 3$ e no outro (reator $\mathrm{C}$ ) não houve dosagem, servindo como referência. Em cada uma das fases, foram realizadas 20 amostragens para $\mathrm{DQO}$, fósforo total e solúvel, alcalinidade, $\mathrm{pH}$ e sólidos suspensos. Para $\mathrm{DBO}_{5,20^{\circ} \mathrm{C}}$, sulfetos, sólidos totais e sedimentáveis foram obtidos 10 valores em cada dosagem. Os pontos de coleta foram: esgoto bruto e esgoto tratado dos reatores $\mathrm{B}$ e $\mathrm{C}$. Foram coletadas amostras em 3 alturas do manto de lodo e realizadas as séries de sólidos em cada dosagem. Quanto à secagem desse lodo, os itens ciclo de desaguamento, espessura da camada e teor de sólidos foram comparados em descartes aos leitos de secagem da ETE. Da avaliação, pode-se concluir que a adição de cloreto férrico gera aumento considerável de remoção de carga orgânica (de $55 \%$ para $73 \%$ da $\mathrm{DQO}$ e de $63 \%$ para $82 \%$ da $\mathrm{DBO}_{5,20^{\circ} \mathrm{C}}$, com $50 \mathrm{mg} \mathrm{FeCl} / \mathrm{L}$ ). Quanto ao fósforo, as eficiências foram menores, sendo mais notadas nos ortofosfatos (de $28 \%$ para $36 \%$ de fósforo total e de $0 \%$ para $59 \%$ de solúvel com $50 \mathrm{mg} \mathrm{FeCl} / / \mathrm{L}$ ). Com relação ao lodo gerado, houve diminuição do ciclo de secagem e do volume da torta (do lodo com adição) em relação àquela gerada no reator sem adição de cloreto férrico. $O$ manto de lodo se mostrou mais espesso e com menor concentração de sólidos no reator com aplicação de cloreto férrico, sugerindo uma tendência a maior perda de sólidos com o efluente clarificado.

Palavras-chave: Anaeróbio. Coagulante. UASB. Fósforo. Cloreto Férrico $\left(\mathrm{FeCl}_{3}\right)$. 


\section{ABSTRACT}

Queiroz, R. S. M. UASB reactor chemically assisted evaluation for phosphorus removal. 2007. 180 p. Thesis (Master's degree) - Escola Politécnica da Universidade de São Paulo. Departamento de Engenharia Hidráulica e Sanitária. São Paulo, 2007.

The presented work intended to evaluate the removal of soluble and total phosphorus, organic matter $\left(\mathrm{BOD}_{5,20^{\circ} \mathrm{C}}\right.$ and $\left.\mathrm{COD}\right)$, sulfides and solids in a weak domestic wastewater, to which it was added ferric chloride as precipitant, crossing an UASB sludge blanket. The Ribeirão Pires wastewater treatment plant, where this study took place, is composed by 4 UASB reactors. In one of them (reactor B), 25 and $50 \mathrm{mg} \mathrm{FeCl} / \mathrm{L}$ were dosed, and in another (reactor $\mathrm{C}$ ) there were no dosage, serving as a reference. In each of the stages, it had been carried through around 20 samplings for COD, total and soluble phosphorus, alkalinity, $\mathrm{pH}$ and suspended

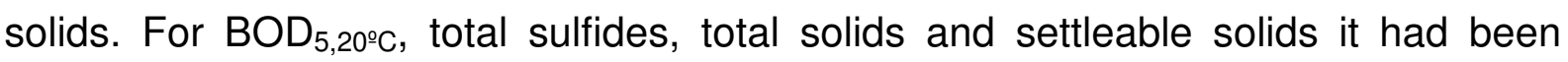
gotten 10 values in each dosage. The collection points had been: raw wastewater and treated wastewater from reactors B and C. Samples in 3 heights of the sludge blanket had been collected and carried through the solid series analysis in each dosage. About the sludge dewatering, items as dewatering period, layer thickness and total solids had been compared in some discharges to the drying beds. From this evaluation, it can be concluded that the ferric chloride addition generates an increase of organic matter removal (from $55 \%$ to $73 \%$ of the COD and from $63 \%$ to $82 \%$ of the $\mathrm{BOD}_{5,20^{\circ} \mathrm{C}}$, with $\left.50 \mathrm{mg} \mathrm{FeCl} / \mathrm{L}\right)$. For phosphorus, the removal efficiencies had been lower, more noticed in the soluble portion (from $28 \%$ to $36 \%$ of total and from $0 \%$ to $59 \%$ of soluble phosphorus at $50 \mathrm{mg} \mathrm{FeCl} / \mathrm{L}$ ). Improvement in the dewatering capacity and in sludge cake volume were also noticed. The sludge blanket showed thicker and with a lower solid concentration in the reactor with ferric chloride application, suggesting a trend to solids loss in the clarified effluent.

Keywords: Anaerobic. Precipitant. Uasb. Phosphorus. Ferric chloride $\left(\mathrm{FeCl}_{3}\right)$. 


\section{SUMÁRIO}

1. INTRODUÇÃO

PÁG. 01

2. OBJETIVOS

PÁG. 04

2.1. Objetivos Gerais

PÁG. 04

2.2. Objetivos Especificos

PÁG. 04

3. REVISÃO BIBLIOGRÁFICA

PÁG. 05

3.1. Importância do Fósforo

PÁG. 05

3.2. Digestão Anaeróbia

PÁG. 06

3.3. Reatores Anaeróbios tipo UASB

PÁG. 10

3.4 Fósforo nos Esgotos

PÁG. 20

3.5. Processos de Remoção de Fósforo

PÁG. 23

3.5.1. Processos Biológicos de Remoção de Fósforo

PÁG. 23

3.5.1.1. Processos Aeróbios de Remoção de Fósforo

PÁG. 24

3.5.1.2. Processos Anaeróbios de Remoção de Fósforo

PÁG. 24

3.5.2. Processos Físico-Químicos de Remoção de Fósforo

PÁG. 25

3.6. Reatores Anaeróbios Conjugados a Processos

Físico-Químicos

PÁG. 26

4. MATERIAIS E MÉTODOS

PÁG. 30

4.1. Considerações Gerais

PÁG. 30

4.2. Descrição da ETE Ribeirão Pires

PÁG. 30

4.3. Alterações Propostas para a Operação do Sistema

e Instalações Complementares

PÁG. 40

4.3.1. Dados considerados

PÁG. 41

4.3.2. Verificações iniciais

PÁG. 41

4.3.3. Cálculo da produção de lodo por módulo

PÁG. 42 
4.3.4. Cálculo da produção de lodo devido à adição de coagulante por módulo de reator UASB

PÁG. 43

4.3.5. Sistema de dosagem de cloreto férrico

PÁG. 45

4.4. Operação dos Reatores UASB, antes da Adição Química

PÁG. 45

4.5. Operação do Sistema com um dos Reatores UASB

recebendo Cloreto Férrico

PÁG. 46

4.6. Estudo do Manto de Lodo e das suas Características

PÁG. 48

4.7. Determinação das Velocidades Reais de Passagem

nos Reatores

PÁG. 48

4.8. Metodologias Analíticas

PÁG. 50

5. RESULTADOS E DISCUSSÃO

PÁG. 51

5.1. Resultados da $1^{a}$ Fase - Sem Adição de Cloreto Férrico

PÁG. 51

5.1.1. DQO Total

PÁG. 51

5.1.2. DQO Filtrada

PÁG. 53

5.1.3. $D B O_{5,20 \circ \mathrm{C}}$ Total

PÁG. 55

5.1.4. $D B O_{5,20^{\circ} \mathrm{C}}$ Filtrada

PÁG. 57

5.1.5. Fósforo Total

PÁG. 59

5.1.6. Ortofosfatos

PÁG. 59

5.1.7. Sulfetos

PÁG. 61

5.1.8. Sólidos Totais

PÁG. 62

5.1.9. Sólidos Suspensos Totais

PÁG. 63

5.1.10. Sólidos Suspensos Voláteis

PÁG. 65

5.1.11. Sólidos Sedimentáveis

PÁG. 67

5.2. Resultados da 2a Fase - Com Adição de $25 \mathrm{mg} / \mathrm{L}$ de

Cloreto Férrico

PÁG. 68

5.2.1. DQO Total

PÁG. 70

5.2.2. DQO Filtrada

PÁG. 71

5.2.3. $\mathrm{DBO}_{5,20^{\circ} \mathrm{C}}$ Total

PÁG. 73

5.2.4. $\mathrm{DBO}_{5,20^{\circ} \mathrm{C}}$ Filtrada

PÁG. 75

5.2.5. Fósforo Total

PÁG. 76 
5.2.6. Ortofosfatos

PÁG. 78

5.2.7. Sulfetos

PÁG. 80

5.2.8. Sólidos Totais

PÁG. 81

5.2.9. Sólidos Suspensos Totais

PÁG. 83

5.2.10. Sólidos Suspensos Voláteis

PÁG. 85

5.2.11. Sólidos Sedimentáveis

PÁG. 87

5.2.12. $\mathrm{pH}$

PÁG. 88

5.2.13. Alcalinidade

PÁG. 90

5.3. Resultados da $3^{a}$ Fase - Com Adição de 50 mg/L de Cloreto Férrico

PÁG. 92

5.3.1. DQO Total

PÁG. 92

5.3.2. DQO Filtrada

PÁG. 94

5.3.3. $D B O_{5,20^{\circ} \mathrm{C}}$ Total

PÁG. 96

5.3.4. $D B O_{5,20^{\circ} \mathrm{C}}$ Filtrada

PÁG. 97

5.3.5. Fósforo Total

PÁG. 99

5.3.6. Ortofosfatos

PÁG. 100

5.3.7. Sulfetos

PÁG. 102

5.3.8. Sólidos Totais

PÁG. 104

5.3.9. Sólidos Suspensos Totais

PÁG. 105

5.3.10. Sólidos Suspensos Voláteis

PÁG. 106

5.3.11. Sólidos Sedimentáveis

PÁG. 108

5.3.12. $p H$

PÁG. 110

5.3.13. Alcalinidade

PÁG. 111

5.4. Estudo Comparativo

PÁG. 112

5.5. Acompanhamento do Manto de Lodo

PÁG. 116

5.6. Comportamento dos Reatores

PÁG. 117

5.7. Características de Desaguamento do Lodo Descartado

PÁG. 119

5.8. Informações Adicionais

PÁG. 122

6. CONCLUSÕES

PÁG. 125

7. ANEXOS

PÁG. 127 
A. Planilhas dos dados levantados para o experimento

PÁG. 128

B. Planilhas de dados anteriores ao experimento

PÁG. 164

C. Desenhos da ETE Ribeirão Pires

PÁG. 169

D. Planilhas de dados de sólidos nas alturas do manto de lodo

PÁG. 174

E. Hidrograma de vazões de esgoto sanitário afluente à ETE Ribeirão Pires

PÁG. 178

8. LISTA DE REFERÊNCIAS

PÁG. 179 


\section{INTRODUÇÃO}

O lançamento de efluentes, ainda que tratados, contendo compostos com nitrogênio e fósforo tem causado problemas para os mananciais de água para abastecimento público. Com a característica de servirem como nutrientes para as algas, cuja floração produz conseqüências como geração de toxinas, aumento de gastos com tratamento (com aplicação de carvão ativado, pré-cloração, etc.), entre outros, sua remoção passou a ser tão importante quanto à redução da carga orgânica carbonácea. Por um outro lado, os reatores anaeróbios de fluxo ascendente (conhecidos como UASB's - upflow anaerobic sludge blanket - ou RAFA's) representam uma forma de tratamento bastante compacta, de simples operação e monitoramento e, como conseqüência, com custos de implantação e operação bastante competitivos diante de outros processos que hoje tem-se conhecimento. Em contrapartida, essa forma de tratamento tem como pontos negativos a baixa eficiência na remoção de $\mathrm{DBO}_{5,20^{\circ} \mathrm{C}}$ (carga orgânica), atingindo valores de $65 \%$, em boas condições de operação com efluentes domésticos, e a incapacidade de remoção de nitrogênio e fósforo, fatores que costumam inviabilizar sua aplicação sem outro tratamento complementar.

A estação aonde este estudo se deu é localizada no Município de Ribeirão Pires, região Metropolitana de São Paulo, e lança o efluente tratado no Reservatório Billings. Deste manancial (braço do Rio Grande) é captada água para a ETA Rio Grande, responsável pelo abastecimento dos municípios do ABC Paulista, produzindo $4,7 \mathrm{~m}^{3} / \mathrm{s}$ de água potável para 1.600 .000 habitantes. Inaugurada em agosto de 1994, a ETE Ribeirão Pires é dotada de 4 reatores tipo UASB com capacidade para tratar $70 \mathrm{~L} / \mathrm{s}$.

O município de Ribeirão Pires, situado na altitude de $750 \mathrm{~m}$ a.n.m., longitude $46^{\circ} 25^{\prime}$ e latitude $23^{\circ} 43^{\prime}$, a $33 \mathrm{~km}$ da Sé, na capital paulista. Tem uma área de 107 km², sendo $100 \%$ urbanizada e dentro integralmente inserida na área da Lei de Proteção dos Mananciais. A população tem apresentado uma taxa geométrica de crescimento anual de 2,01\%, chegando a 115.195 habitantes no ano de 2005. A taxa de 
mortalidade infantil é 17,4 por mil nascidos vivos. O IDHM (Índice de Desenvolvimento Humano Municipal) foi avaliado em 0,807 (ano de 2002). Os níveis de atendimento em saneamento, ano de 2000 , eram $91,67 \%$, para abastecimento de água, e 81,34\%, para esgoto sanitário.

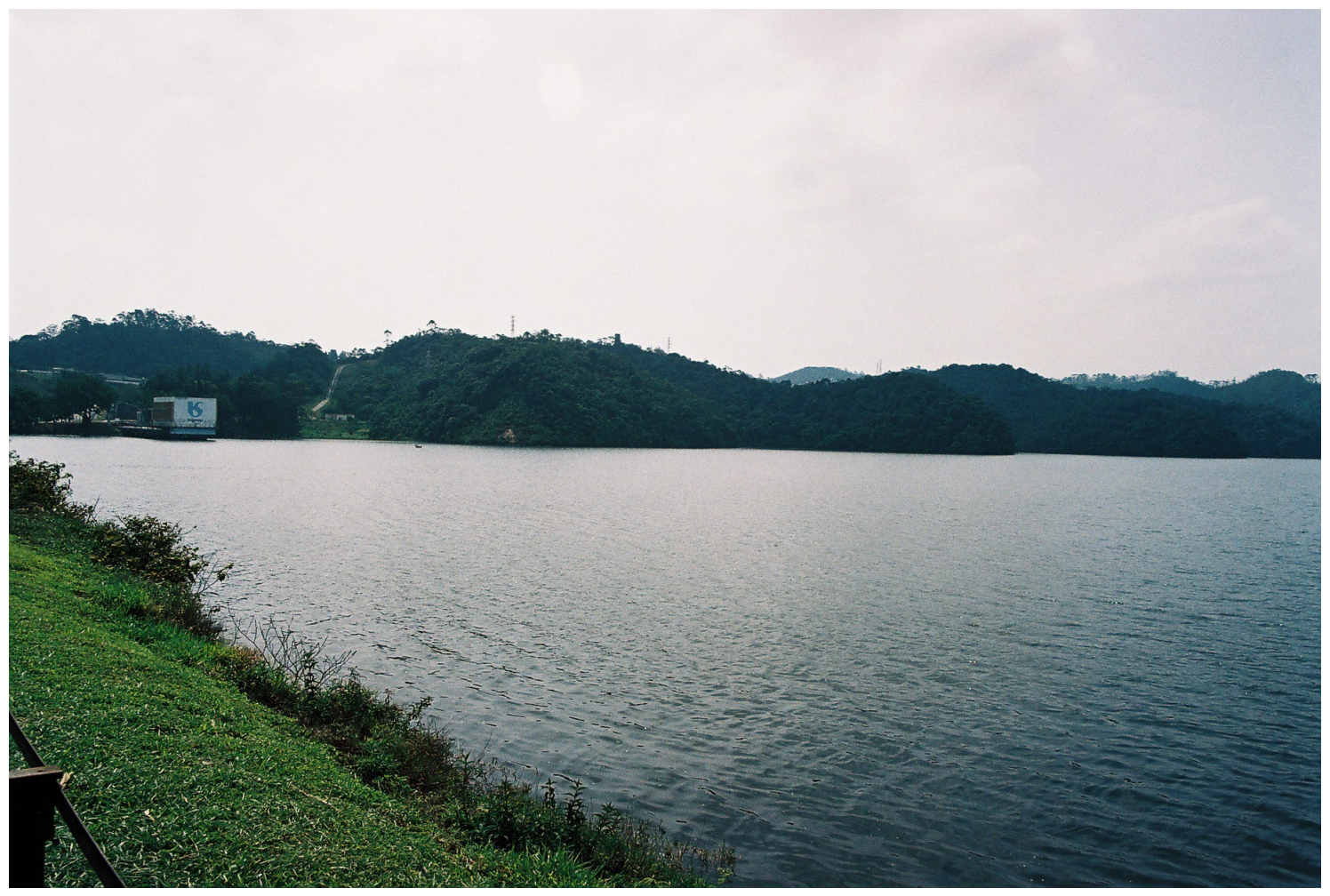

FIGURA 1.1 - Captação de Água Bruta no Reservatório Billings.

O município de Ribeirão Pires insere-se no Comitê da Bacia Hidrográfica do Alto Tietê, com uma área de drenagem total de $5.650 \mathrm{~km}^{2}$. Os municípios limítrofes são Suzano, Mauá, Rio Grande da Serra e Santo André. Seu relevo é acidentado, com morros e serras. Seus principais acessos são a SP-31 (Rodovia Índio Tibiriçá) e a SP 122 (Rodovia Deputado Antônio Adib Chamas).

Segundo os documentos "Relatório de Qualidade das Águas Interiores do Estado de São Paulo" - dos anos 2001 a 2005, da CETESB (site Relatórios, http://www.cetesb.sp.gov.br/Agua/rios/relatorios.asp, as estações de monitoramento RGDE02200 e RGDE02900, situadas no Reservatório Billings, respectivamente, próxima à ETE e junto à captação da ETA Rio Grande, a concentração de 
ortofosfatos média foi $0,03 \mathrm{mg} / \mathrm{L}$ e total de 0,40 e $0,05 \mathrm{mg} / \mathrm{L}$. Os valores do IQA (Índice de Qualidade das Águas) em 2005 foram 65 e 75 (classificada como "boa").

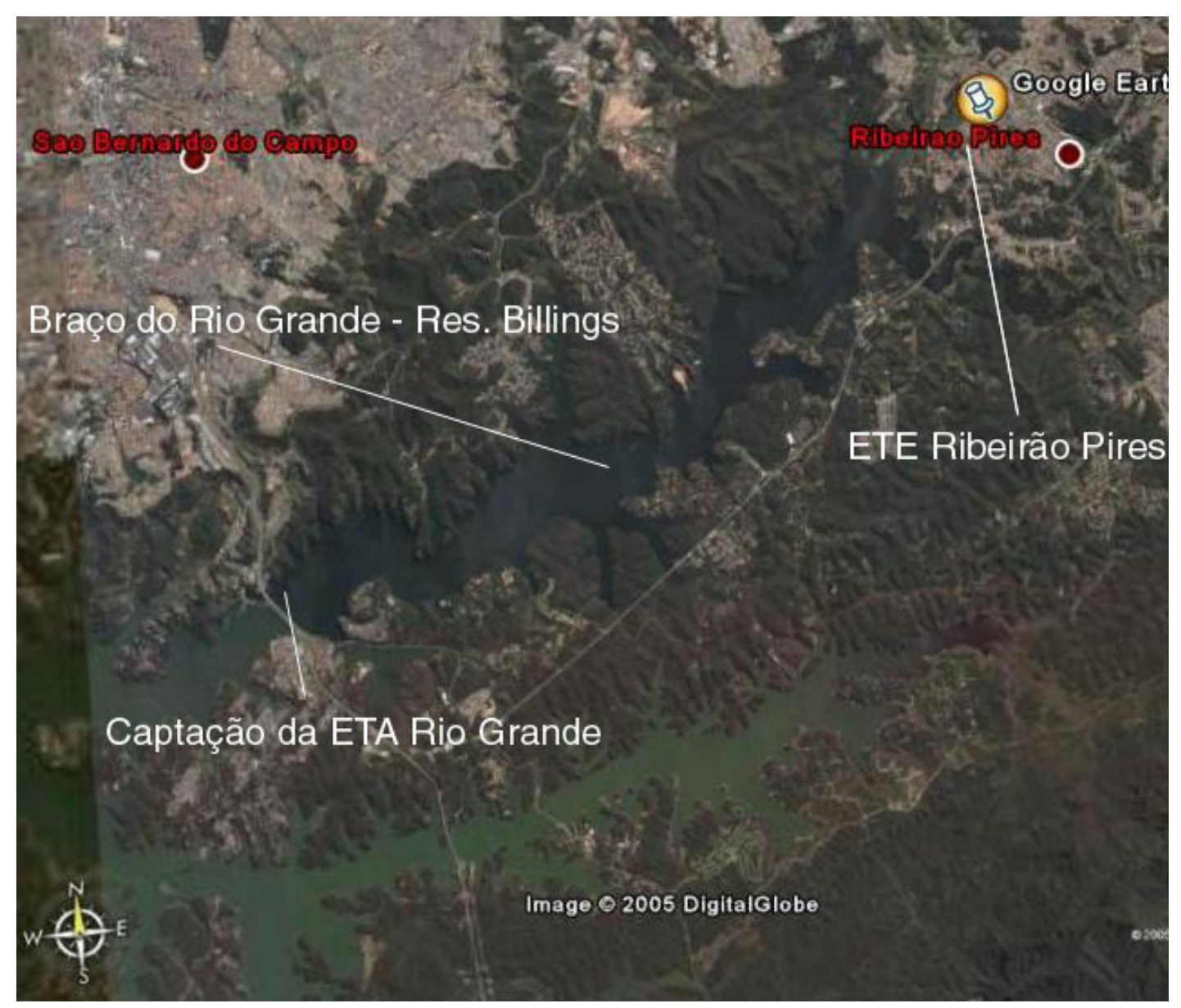

FIGURA 1.2 - ETE Ribeirão Pires, Braço do Rio Grande e Captação de Água Bruta. 


\section{OBJETIVOS}

\subsection{Objetivos Gerais}

O estudo proposto visou avaliar a capacidade de remoção de fósforo e de matéria orgânica na operação dos reatores tipo UASB com a injeção de coagulantes (neste caso, cloreto férrico) na entrada do esgoto bruto na unidade, atravessando juntamente com o mesmo o manto de lodo.

Por se tratar de um processo simples, compacto e com produção de lodo relativamente baixa se comparado a outros processos aeróbios, caso se verifique 0 aumento na capacidade de tratamento nos UASB's com a simples adição de coagulantes, essa alternativa poderá se apresentar como opção para diversos sistemas com condições semelhantes.

\subsection{Objetivos Específicos}

A intenção foi comparar 2 dos 4 reatores existentes na estação (ETE Ribeirão Pires), num deles aplicando cloreto férrico e no outro operando nem qualquer adição, nas condições de $25 \mathrm{mg} \mathrm{FeCl}_{3} / \mathrm{L}$ e $50 \mathrm{FeCl}_{3} / \mathrm{L}$. Os parâmetros dessa comparação foram $\mathrm{DQO}, \mathrm{DBO}_{5,20^{\circ} \mathrm{C}}$, fósforo solúvel, fósforo total, sulfetos, $\mathrm{pH}$, alcalinidade, sólidos totais, em suspensão e sedimentáveis. O manto de lodo, suas concentrações e altura também mereceram a atenção dessa análise.

Ainda objetivou-se estudar a produção de lodo nessas condições e suas características obtidas nas diferentes situações da adição do coagulante, principalmente no que se refere ao seu desaguamento, promovido em leitos de secagem.

Também a avaliação de custo operacional com a adição de cloreto férrico em comparação com os eventuais benefícios obtidos dessa aplicação foram objeto de interesse neste trabalho. 


\section{REVISÃO BIBLIOGRÁFICA}

O sistema de tratamento proposto para estudo foi composto por um sistema de tratamento anaeróbio (UASB) antecedido por uma etapa de tratamento físicoquímico, visando aumentar a eficiência de remoção da matéria orgânica e do fósforo, em suas formas de ortofosfatos, polifosfatos e o fosfato orgânico.

\subsection{Importância do Fósforo}

Como já foi dito anteriormente, a remoção do fósforo presente no esgoto doméstico visa, além do atendimento à legislação ambiental, a redução do lançamento de nutrientes aos corpos d'água, limitando o crescimento exagerado de algas.

De acordo com METCALF \& EDDY, 1991, o fósforo é essencial ao crescimento das algas e outros organismos vivos. Devido ao florescimento nocivo de algas em águas superficiais, há atualmente grande interesse em se controlar a quantidade de compostos de fósforo encaminhados às águas superficiais nos lançamentos de efluentes domésticos e industriais e nas águas de drenagem superficial. No caso dos esgotos domésticos, por exemplo, as concentrações de fósforo podem variar de 4 a $16 \mathrm{mg} \mathrm{P/L}$. As formas mais comuns de fósforo encontradas nas soluções aquosas incluem os ortofosfatos, os polifosfatos e o fosfato orgânico. Os ortofosfatos $\left(\mathrm{PO}_{4}{ }^{-3}, \mathrm{HPO}_{4}{ }^{-2}, \mathrm{H}_{2} \mathrm{PO}_{4}{ }^{-}\right.$e $\mathrm{H}_{3} \mathrm{PO}_{4}$ ), por exemplo, são disponíveis para o metabolismo biológico sem a necessidade de uma posterior dissociação. Os polifosfatos incluem aquelas moléculas com 2 ou mais átomos de fósforo e, em alguns casos, átomos de hidrogênio combinados numa molécula complexa. Os polifosfatos sofrem hidrólise em solução aquosa e são convertidos às formas de ortofosfatos; entretanto, essa hidrólise é normalmente lenta. As formas orgânicas de fósforo são geralmente de menor importância na maioria dos efluentes domésticos mas podem ser um constituinte importante em efluentes industriais e em lodos de ETEs.

O ortofosfato pode ser determinado pela adição direta de uma substância como o molibdato de amônia, que irá formar um complexo colorido com o fosfato. Os 
polifosfatos e os fosfatos orgânicos devem ser convertidos pela digestão com ácido antes da determinação por forma similar que as dos ortofosfatos (METCALF \& EDDY, 1991).

\subsection{Digestão Anaeróbia}

O tratamento anaeróbio, ou seja, aquele baseado na digestão anaeróbia, se incumbe, entre outros, da estabilização da matéria orgânica e da redução do volume do lodo (através da liquefação, gaseificação e adensamento) (JORDAO, E. P, PESSOA, C. A, 1975). Trata-se de um processo fermentativo, ao qual podem ser submetidos diversos tipos de resíduos (urbanos, rurais ou industriais), com uma ou mais das seguintes finalidades: tratamento dos resíduos (remoção de matéria orgânica poluente e dos microorganismos patogênicos), produção de biogás e produção de biofertilizantes mais estáveis, mais ricos em nutrientes assimiláveis e com melhores qualidades sanitárias em relação ao material original (SOUZA, MARCOS EDUARDO, 1982).

De uma forma simplificada, o processo ocorre em duas etapas. Na primeira etapa, a matéria orgânica complexa é transformada em compostos simples, como ácidos orgânicos voláteis, $\mathrm{CO}_{2}, \mathrm{H}_{2}$, etc., pela ação de enzimas extra-celulares, das bactérias acidogênicas e das baterias acetogênicas (que transformam os demais ácidos voláteis em acido acético, $\mathrm{H}_{2}$ e $\mathrm{CO}_{2}$ ). $\mathrm{Na}$ segunda etapa, estes produtos são transformados principalmente em $\mathrm{CH}_{4}$ e $\mathrm{CO}_{2}$, pela ação das bactérias metanogênicas (SOUZA, MARCOS EDUARDO, 1982).

Nesse tipo de tratamento, tem-se a participação de bactérias fermentativas, bactérias acetogênicas produtoras de hidrogênio; bactérias acetogênicas consumidoras de hidrogênio; bactérias metanogênicas redutoras de $\mathrm{CO}_{2}$ e bactérias metanogênicas acetoclásticas (PARKIN \& OWEN, 1986 apud MANGIERI, L.,2002).

De acordo com LETTINGA \& van HAANDEL (1994), o tratamento anaeróbio de esgotos oferece vantagens significativas com relação aos tratamentos aeróbios. Porém, não é somente a estequiometria intrinsecamente favorável aos processos 
anaeróbios que fazem deles uma alternativa adequada ao tratamento de águas residuárias. Existem outros dois fatores que também são fundamentais: a eficiência de remoção de matéria orgânica, que deve ser elevada, de forma que se tenha uma baixa concentração de matéria orgânica no efluente e a taxa de remoção, que deve ser alta, para que se tenha um pequeno tempo de detenção, resultando em unidades pequenas de reatores. Fatores como a natureza do efluente, o projeto do reator e o tempo de retenção hidráulico são fundamentais.

A hidrólise pode se tornar um fator limitante do processo de estabilização se as condições ideais, como a presença de uma população bacteriana ativa, substrato orgânico concentrado, temperatura correta e homogeneidade no reator, não estiverem presentes (PARKIN \& OWEN, 1986 e LETTINGA \& van HAANDEL, 1994 apud MANGIERI,2002),. Ainda que todas essas condições sejam satisfeitas, uma parcela da matéria orgânica não será hidrolisada. Trata-se da fração não biodegradável ou refratária da matéria orgânica, cujo percentual em esgotos sanitários varia entre 35 e $80 \%$ da matéria volátil, em função da origem do esgoto e do tratamento prévio. (PARKIN \& OWEN, 1986 apud MAGIERI, L., 2002).

A transformação de moléculas complexas presentes no esgoto em gás requer a participação de vários grupos de microorganismos. Proteínas, carboidratos e lipídios são digeridos em diferentes etapas, aonde se identificam quatro fases distintas: hidrólise, acidogênese, acetogênese e metanogênese.

$\mathrm{Na}$ hidrólise, a matéria particulada complexa é transformada em componentes dissolvidos de menor peso molecular. As exo-enzimas, produzidas pelas bactérias fermentativas têm papel importante nesta etapa. As proteínas são degradadas (através dos polipeptídios) em aminoácidos. Os carboidratos passam a mono e dissacarídeos e os lipídios se convertem a ácidos graxos e glicerina de cadeias longas. Esta etapa pode se tornar muito lenta em temperaturas abaixo dos $20^{\circ} \mathrm{C}$ (LETTINGA \& van HAANDEL, 1994).

$\mathrm{Na}$ acidogênese, os componentes dissolvidos gerados na liquefação são secretados já na forma de compostos mais simples como ácidos orgânicos voláteis, álcoois, 
ácidos láticos e compostos minerais, como dióxido de carbono, hidrogênio, amônia e gás sulfídrico. Um grupo diferente de bactérias promove essa etapa, cuja maioria é anaeróbia. Há, porém, uma parcela facultativa que pode metabolizar a matéria orgânica pela via oxidativa. É uma etapa importante, na qual o oxigênio dissolvido se torna tóxico aos organismos anaeróbios.

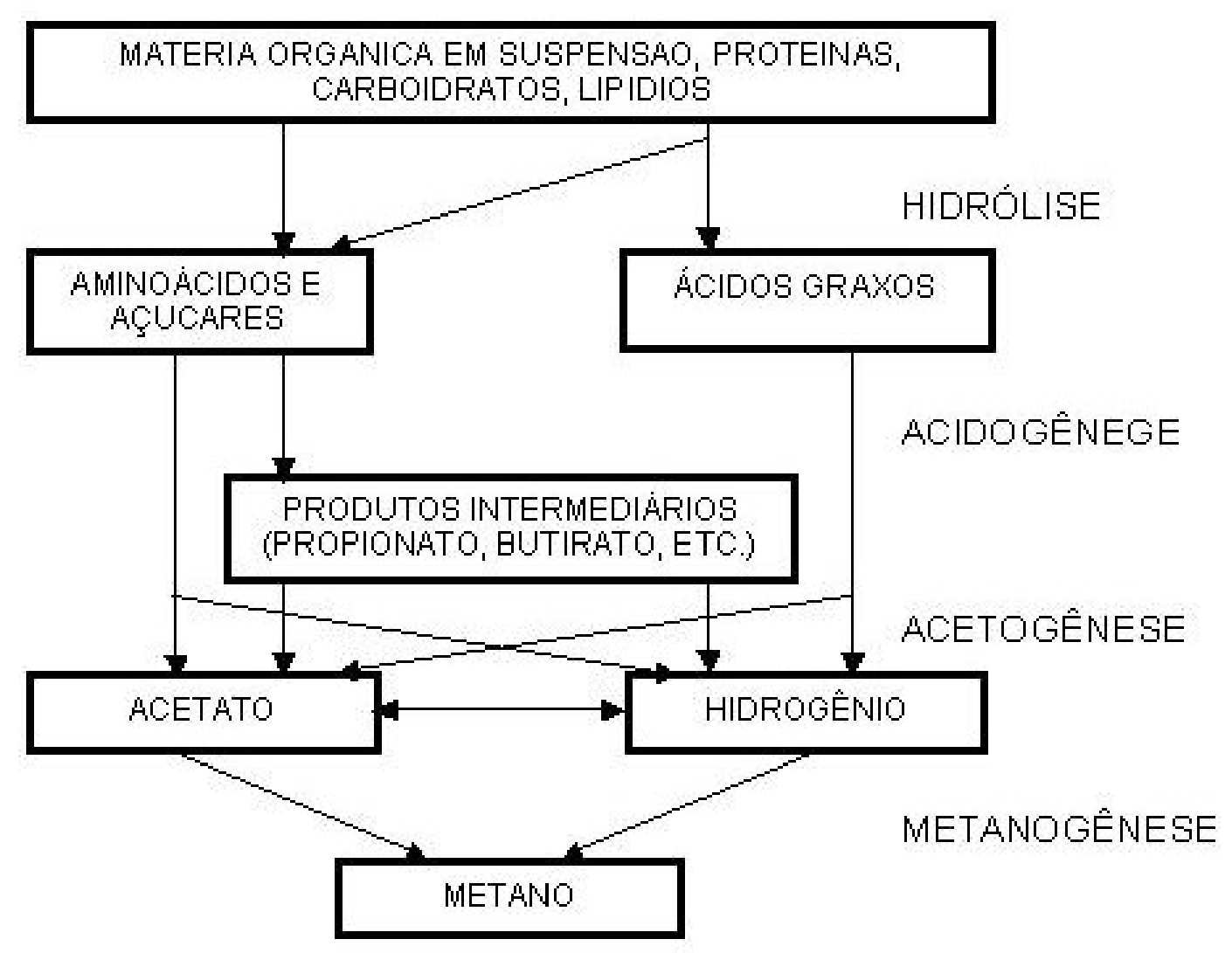

Figura 3.1 - Seqüência de reações da digestão anaeróbia (adaptado de LETTINGA \& van HAANDEL, 1994).

Com a acetogênese, os produtos da acidogênese são convertidos em acetato, hidrogênio e gás carbônico. Cerca de $70 \%$ da DQO afluente é transformada em ácido acético e o restante da capacidade de acepção de elétrons é concentrada na forma de hidrogênio. Dependendo do estado de oxidação da matéria orgânica original, a formação de acido acético pode ser acompanhada da geração de gás carbônico e hidrogênio. Na mistura esperada de diferentes poluentes orgânicos de um esgoto, é possível se ter esses processos ocorrendo de maneira simultânea, mas geralmente é produzido mais hidrogênio que gás carbônico, devido ao número 
médio de elétrons disponível na matéria orgânica ser normalmente maior que 4 por átomo de carbono. A conseqüência é a geração de acido acético ser acompanhada pela produção de hidrogênio.

Por fim, vem a metanogênese, que freqüentemente é a etapa limitante do processo global de digestão, apesar de, a baixas temperaturas, ser a hidrólise a fase limitante. A partir do acetato ou da redução do dióxido de carbono, é produzido o metano, através das bactérias acetotróficas e hidrogenotróficas, respectivamente.

As bactérias produtoras de metano a partir do hidrogênio crescem mais rapidamente que aquelas que se utilizam do acetato (LETTINGA \& van HAANDEL, 1994 apud Henzen et al, 1983), de modo que a metanogênese acetotrófica geralmente é a fase limitante no que se refere à transformação das macromoléculas dos esgotos em biogás.

Os diferentes grupos de bactérias envolvidos nas conversões da matéria orgânica presente no esgoto bruto exercem tanto atividades anabólicas como catabólicas. Com isso, concomitantemente à liberação de diferentes produtos inerentes à fermentação, há a formação de nova biomassa associada aos quatro processos de conversão descritos anteriormente. Por conveniência, a hidrólise, a acidogênese e a acetogênese são algumas vezes agrupadas, chamando-se de processo de fermentação ácida, assim como a etapa de metanogênese é chamada de fermentação metanogênica.

Dois fatores importantes devem ser enfatizados com relação aos diferentes processos desenvolvidos durante a digestão anaeróbia: - a remoção de matéria orgânica é limitada pela liberação de hidrogênio. Com isso, um requisito para uma alta eficiência de remoção de matéria orgânica é de que se tenha um bom desempenho da metanogênese acetotrófica; - a fermentação ácida tende a promover uma queda no $\mathrm{pH}$ pela produção de ácidos orgânicos voláteis e produtos intermediários que se dissociam e geram prótons. Como a metanogênese somente se desenvolve bem em pHs neutros, pode haver instabilidade se, por algum motivo, a taxa de remoção de ácidos pela produção de metano cair para níveis inferiores 
aos da taxa de produção de ácidos. Haverá uma produção líquida de ácidos, baixando $\circ \mathrm{pH}$, ० que reduzirá a atividade metanogênica (LETTINGA \& van HAANDEL, 1994).

\subsection{Reatores Anaeróbios tipo UASB}

Os reatores tipo UASB são reatores anaeróbios nos quais o esgoto afluente é distribuído pelo fundo de um tanque e, ao subir, atravessa um "leito" concentrado de lodo e, em seqüência, outro "manto" de lodo, com concentrações menores. É nesses locais que ocorre a remoção de substrato. Acima se encontra o separador trifásico, no qual o gás produzido é separado e encaminhado para o sistema de coleta e tratamento. Já o líquido, ainda com sólidos, passa à câmara de decantação, aonde as partículas maiores tem a possibilidade de sedimentar e atravessam o separador trifásico em sentido contrário, incorporando-se ao manto de lodo e sofrendo a degradação anaeróbia. O esgoto, então já clarificado, verte para canaletas, de onde é encaminhado para o lançamento final ou qualquer outra etapa de tratamento.

No processo com reatores de manto de lodo (UASB's), o esgoto a receber tratamento é introduzido no fundo do reator destinado a este fim. O despejo flui no sentido ascendente através de um manto de lodo composto de grânulos e partículas biológicos. O tratamento se dá na medida em que há o seu contato com esses grânulos. Os gases produzidos nas condições anaeróbias (principalmente metano e dióxido de carbono) promovem a circulação interna, o que auxilia na formação e manutenção dos grânulos biológicos. Parte do gás gerado no manto de lodo adere aos grãos, enquanto o gás livre e as partículas menores nas quais há gás aderido sobem até o topo do reator. Estas últimas, em dada altura, chocam-se contra o defletor, liberando as bolhas de gás e caem, incorporando-se ao manto de lodo. $O$ gás livre e aquele que é liberado das partículas são capturados em campânulas posicionadas na parte superior do reator. O líquido, contendo um residual de sólidos e grânulos biológicos segue para a câmara de sedimentação, aonde se dá a separação sólido/líquido. Os sólidos descem para o fundo do separador e caem até também serem agregados ao manto de lodo. A fim de manter o manto de lodo em suspensão, têm sido utilizadas velocidades ascensionais na faixa entre 0,6 e $0,9 \mathrm{~m} / \mathrm{h}$ 
(METCALF \& EDDY, 1991). Dados típicos de processo são mostrados na Tabela 3.1.

Tabela 3.1 - Valores Típicos de Processo e Performance para Processos Anaeróbios Empregados para Tratamento de Despejos Industriais (adaptado de METCALF \& EDDY, 1991).

\begin{tabular}{l|cccc}
\hline \multicolumn{1}{c|}{ Processo } & $\begin{array}{c}\text { DQO de } \\
\text { entrada [mg/L] }\end{array}$ & $\begin{array}{c}\text { Tempo de } \\
\text { Detenção } \\
\text { Hidráulico [h] }\end{array}$ & $\begin{array}{c}\text { Taxa de } \\
\text { Aplicação [kg } \\
\text { DQO/m }{ }^{3} \text {.dia] }\end{array}$ & $\begin{array}{c}\text { Eficiência de } \\
\text { Remoção de } \\
\text { DQO [\%] }\end{array}$ \\
\hline $\begin{array}{l}\text { Processo Anaeróbio de } \\
\text { Contato }\end{array}$ & $1.500 \sim 5.000$ & $2 \sim 10$ & $0,48 \sim 2,40$ & $75 \sim 90$ \\
UASB & $5.000 \sim 15.000$ & $4 \sim 12$ & $4,00 \sim 12,00$ & $75 \sim 85$ \\
Leito Fixo & $10.000 \sim 20.000$ & $24 \sim 48$ & $0,96 \sim 4,81$ & $75 \sim 85$ \\
& & & & \\
Leito Expandido & $5.000 \sim 10.000$ & $5 \sim 10$ & $4,81 \sim 9,61$ & $80 \sim 85$ \\
\hline
\end{tabular}

Os reatores anaeróbios de manto de lodo foram desenvolvidos nos anos 70 por Lettinga e seu grupo na Universidade de Wageningen, Holanda. Esse tipo de reator é de longe, o mais utilizado sistema de alta taxa para o tratamento anaeróbio de efluentes. Várias estações já foram colocadas em operação e inúmeras outras estão sendo construídas. Todas as plantas em escala real operam em condições tropicais e sub-tropicais e estações piloto foram desenvolvidas em regiões de clima moderado.

O dispositivo mais característico dos reatores UASB é o separador trifásico. Este item é localizado na parte superior do reator, dividindo o mesmo em zona de digestão (parte inferior) e zona de decantação (parte superior). O esgoto é distribuído da forma mais uniforme possível pelo fundo do reator, passando através do manto de lodo e adentrando a zona de decantação pela abertura existente no separador de fases (separador trifásico). 
Devido à inclinação das paredes do separador, há um aumento da área de decantação conforme o líquido se aproxima da superfície, causando a diminuição da velocidade. Conseqüentemente, os flocos de lodo arrastados até a zona de sedimentação podem flocular e/ou decantar. Em um determinado momento, o peso do lodo acumulado no separador de fases excede a força de atrito que o mantém sobre a superfície, provocando seu deslizamento de volta até a zona de digestão. Portanto, a presença de um sedimentador acima da zona de digestão permite ao sistema manter uma grande massa de lodo, enquanto o efluente sai praticamente isento de partículas de sólidos.

As bolhas de gás sobem até a interface líquido-gás sob o separador. Esse nível é algo próximo ao nível de líquido na câmara de sedimentação ou ligeiramente menor, caso haja alguma pressurização devida ao selo hidráulico do sistema de gás. Flocos de lodo com bolhas de gás aderidas a si podem elevar-se essa interface, mas caem novamente ao liberar esse gás. Para prevenir a passagem de gás para a zona de sedimentação, são instalados defletores (LETTINGA \& HAANDEL, 1994).

Existem vários reatores UASB de pequena escala instalados no estado do Paraná. Porém, nessas unidades (RALF) não há o separador de fases, apesar de contarem com um decantador interno às unidades. O separador trifásico foi eliminado por questões de redução de custos e simplificação de construção. Com isto, a eficiência de remoção sofre um decréscimo, como as expressões advindas de experimentos com as duas modalidades mostram:

Para reatores tipo RALF: $\quad E=1-1,53 \cdot(\mathrm{TDH})^{-0,64}$

Para reatores UASB: $\quad E=1-0,68 \cdot(\mathrm{TDH})^{-0,68}$

onde E significa a eficiência (em \%) de remoção de DQO (matéria orgânica) e TDH o tempo de detenção hidráulica na unidade, em horas.

As vantagens dos reatores tipo UASB em relação aos processos aeróbios convencionais, principalmente quando utilizados em climas quentes, condição de 
nosso país, são muitas, como: - sistema compacto; - baixo custo de implantação e operação; - reduzida produção de lodo; - pequeno consumo de energia; - remoção de carga orgânica na ordem de $65 \%$ a $75 \%$; - lodo descartado com alto teor de sólidos e boas características de desaguamento (PROSAB, 1999).

Como pontos desfavoráveis aos reatores UASB, tem-se: - possibilidade de exalação de maus odores; - vulnerabilidade a cargas tóxicas; - start-up elevado até que se tenha uma operação com boas eficiências; - requisição de etapa de pós-tratamento, a fim de atendimento à legislação para lançamento de efluentes tratados em corpos d'água.

No que se refere à partida desses reatores, o período esperado é de 4 a 6 meses, desde que não se empreguem inóculos. Este período porém, tem sido reduzido, através de procedimentos operacionais e metodologias, entre outros, atrelados ao uso de sementes, para partidas envolvendo entre 2 a 3 semanas.

O projeto desse tipo de reator é bastante simples, apesar de ainda não haver no Brasil um roteiro de dimensionamento claro acessível aos projetistas.

A operação do reator tem inicio com sua inoculação com um volume suficiente de lodo anaeróbio seguida de alimentação em baixa taxa no sentido ascendente. A medida em que se tem uma resposta favorável do sistema, deve-se aumentar essa taxa de alimentação, o que, após alguns meses de funcionamento, se reflete na formação de um leito de lodo concentrado (entre $40.000 \mathrm{mg} \mathrm{ST/L}$ e $100.000 \mathrm{mg}$ ST/L, ou seja, teor de sólidos de 4\% a 10\%). Com isto, grânulos de lodo entre $1 \mathrm{~mm}$ e $5 \mathrm{~mm}$ são desenvolvidos.

Acima desse leito de lodo, tem lugar uma zona mais dispersa, chamada de manto de lodo, aonde os sólidos têm velocidades de sedimentação mais baixas. A concentração de sólidos apresenta valores entre $1 \%$ e 3\%, com uma certa homogeneização devida ao movimento das bolhas de gás com movimento ascendente. Como no período de start-up há uma baixa produção desse gás, pode ser aconselhável empregar uma forma de mistura adicional, como a recirculação de 
gás ou do efluente. No que se refere a remoção de substrato, esta ocorre tanto no leito como no manto de lodo, embora seja mais pronunciada no leito (PROSAB, 1999).

Com a subida das bolhas de gás e do liquido, o lodo acaba por ser carreado, aonde se requer a presença do separador trifásico, a fim de permitir a separação e o retorno do lodo. Acima desse separador fica a câmara de sedimentação, aonde ocorre a separação do lodo mais denso, que retorna ao compartimento de digestão.

O separador trifásico garante o retorno do lodo e a alta capacidade de retenção de grades quantidades de biomassa, sem o emprego de qualquer tipo de meio suporte. Uma conseqüência é o elevado tempo de residência celular, muito maior que o tempo de detenção hidráulico, o que é uma característica de reatores anaeróbios de alta taxa. Num UASB, essas idades de lodo normalmente ultrapassam os 30 dias, o que confere ao lodo em excesso uma qualidade excelente, com alto grau de estabilização e boas condições de desidratação.

Os princípios mais importantes que governam a operação de um reator de manto de lodo são: - o fluxo ascendente deve propiciar o máximo contato entre biomassa e substrato; - deve-se evitar a existência de curto-circuitos, a fim de assegurar tempo suficiente para a degradação da matéria orgânica; - o separador de fases deve ser projetado adequadamente, com áreas de passagem que possibilitem velocidades dos sólidos, líquidos e do gás que liberem os dois últimos e retenham os sólidos; - o lodo do manto deve ser adaptado e apresentar altas atividade metanogênica especifica (AME) e sedimentabilidade (que, neste caso, é bem melhor que a sedimentabilidade dos lodos floculentos) (PROSAB, 1999).

Os reatores UASB foram criados inicialmente para o tratamento de efluentes industriais e apresentavam formas cilíndricas ou retangulares, aonde se tinham áreas de digestão e de decantação iguais, levando a se ter unidades com paredes externas verticais. O emprego desse processo para o tratamento de esgotos domésticos (com baixas concentrações de carga orgânica) fez com que se construíssem unidades com diferentes configurações da idéia original. Para esse 
caso (efluentes domésticos de baixa concentração), o dimensionamento é pela carga d e aplicação hidráulica, em lugar de se utilizar a carga orgânica. Assim, as velocidades ascendentes nas zonas de digestão e de sedimentação têm grande relevância: velocidades altas implicam em perda de biomassa do manto e no efluente clarificado. Resulta daí a necessidade de diminuição da altura do reator com o aumento de sua seção transversal (PROSAB, 1999).

Os reatores podem apresentar formas circulares ou retangulares em planta. Para pequenas vazões de esgotos domésticos, a forma circular, mais econômica é a mais utilizada. Para populações maiores, torna-se necessária a criação de módulos, o que, por questões de lay-out, conduz ao formato retangular. O corte típico de um reator é apresentado na Figura 3.2.

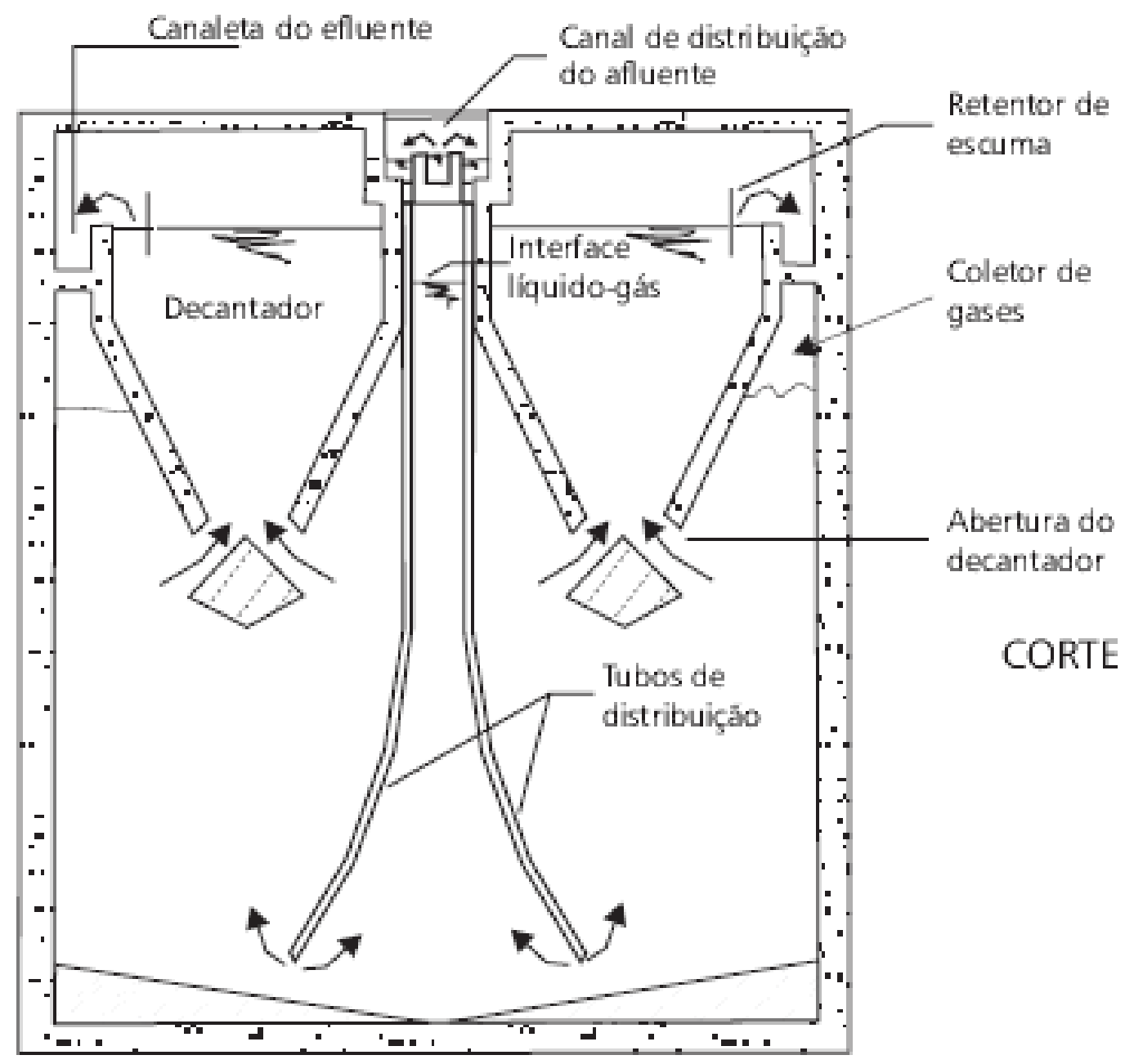

Figura 3.2 - Corte de um reator UASB (PROSAB, 1999). 
Como critérios de dimensionamento, conforme PROSAB (1999), para esgotos domésticos tem-se:

Carga hidráulica volumétrica ( $\mathrm{CHV}$ ) e tempo de detenção hidráulica: A carga hidráulica volumétrica representa o volume de esgotos aplicados por unidade de tempo (dia), por unidade de volume de reator. O tempo de detenção hidráulico é o inverso da $\mathrm{CHV}$

$$
\begin{aligned}
& \mathrm{CHV}=\mathrm{Q} / \mathrm{V} \text {, onde } \mathrm{Q}=\text { vazão }\left[\mathrm{m}^{3} / \mathrm{dia}\right] \text { e } \mathrm{V}=\text { volume do } \\
& \text { reator }\left[\mathrm{m}^{3}\right] \\
& \theta_{\mathrm{h}}=1 / \mathrm{CHV} \text {, ou: } \theta_{\mathrm{h}}=\mathrm{V} / \mathrm{Q}
\end{aligned}
$$

A experiência demonstrou que a carga hidráulica não deve exceder o valor de 5,0 $\mathrm{m}^{3} / \mathrm{m}^{3}$.dia, incorrendo num tempo de detenção hidráulico recomendável de 4,8 h. A não observação desses parâmetros pode levar à perda de sólidos no efluente, redução da idade do lodo (diminuindo o grau de estabilização) e instabilidade do processo, com a eventual diminuição do tempo de residência dos sólidos a valores abaixo do seu tempo de crescimento no interior do reator.

Para temperaturas em torno de $20^{\circ} \mathrm{C}$, o tempo de detenção hidráulica pode variar entre 6 e 16 horas, dependendo do tipo de despejo. Experimentos em escala piloto a $25^{\circ} \mathrm{C}$, com esgoto doméstico, demonstraram que tempos de 4 horas não trazem prejuízos ao desempenho ou à estabilidade desses reatores (PROSAB, 1999 apud van HAANDEL \& CATUNDA, 1998).

Para esses esgotos domésticos a $20^{\circ} \mathrm{C}$, o recomendável é o valor de 8 a 10 horas, para vazão media e não inferior a 4 horas para a vazão máxima, por períodos inferiores a 6 horas.

Na Tabela 3.2 são indicados tempos recomendados para projeto de reatores de manto de lodo tratando esgotos domésticos. 
Tabela 3.2 - Tempos de detenção hidráulica em reatores UASB (adaptado de PROSAB, 1999 apud LETTINGA \& HULSHOFF, 1991).

\begin{tabular}{c|cc}
\hline \multirow{2}{*}{$\begin{array}{c}\text { Temperatura do } \\
\text { esgoto }\left[{ }^{\circ} \mathrm{C}\right]\end{array}$} & \multicolumn{2}{|c}{ Tempo de Detenção Hidráulico [h] } \\
\cline { 2 - 3 } & Média Diária & Mínimo (durante 4 a 6 h) \\
\hline $16 \sim 19$ & $>10 \sim 14$ & $>7 \sim 9$ \\
\hline $20 \sim 26$ & $>6 \sim 9$ & $>4 \sim 6$ \\
\hline$>26$ & $>6$ & $>4$ \\
\hline
\end{tabular}

Assim, a partir da vazão de esgoto a ser tratado, admitindo um valor de tempo de detenção é possível determinar o volume do reator:

$$
V=Q \cdot \theta_{h}\left[m^{3}\right]
$$

- Carga orgânica volumétrica: É a relação entre a massa de matéria orgânica aplicada ao reator e o volume deste:

$$
\begin{aligned}
& \text { COV }=\mathrm{Q} . \mathrm{S} / \mathrm{V} \text {, onde } \mathrm{S}=\text { concentração do } \\
& \text { substrato afluente }\left[\mathrm{kg} \mathrm{DQO} / \mathrm{m}^{3}\right] .
\end{aligned}
$$

Apesar de já terem sido utilizadas em estudos com pilotos carga orgânicas bastante elevadas (45 $\mathrm{kg} \mathrm{DQO} / \mathrm{m}^{3} . \mathrm{d}$ ), adota-se nos projetos de estações em escala real valores limitados a $15 \mathrm{~kg} \mathrm{DQO} / \mathrm{m}^{3} . \mathrm{d}$. O volume do reator pode ser determinado a partir da vazão afluente e da carga orgânica volumétrica escolhida:

$$
V=Q . S / \operatorname{cov}\left[m^{3}\right]
$$

Para efluentes domésticos, com concentrações de $1.000 \mathrm{mg} \mathrm{DQO} / \mathrm{L}$, é comum se ter cargas orgânicas volumétricas de 2,5 a $3,5 \mathrm{~kg} \mathrm{DQO} / \mathrm{m}^{3} . \mathrm{d}$, uma vez que o parâmetro de dimensionamento mais crítico é o de carga hidrálica. Por esse fato é que se recomenda dimensionar reatores para tratamento de esgotos domésticos utilizando a carga hidráulica volumétrica. 
- Carga biológica: A carga de lodo, que é a quantidade de matéria orgânica aplicada por dia ao reator, por unidade de biomassa presente no mesmo.

$$
\begin{aligned}
& \mathrm{CB}=\mathrm{Q} . \mathrm{S} / \mathrm{M} \text {, onde } \mathrm{M}=\text { massa de microorganismos } \\
& \text { presentes no reator [kg SVT]. }
\end{aligned}
$$

Na partida de reatores anaeróbios, recomenda-se valores de carga biológica entre 0,05 e 0,15 kg DQO/kg SVT.d, em função do efluente a receber tratamento. Com a evolução da eficiência do tratamento, as mesmas devem ser gradualmente aumentadas.

Seus valores máximos, já com o processo estabilizado, variam em torno de 2,0 kg DQO/kg SVT.d

- Velocidade ascendente do fluxo: é a relação entre a vazão de alimentação e a área de seção transversal do reator:

$$
\mathrm{v}=\mathrm{Q} / \mathrm{A}\{\mathrm{m} / \mathrm{s}]
$$

Ou, a razão entre altura do reator e o tempo de detenção hidráulico:

$$
\begin{aligned}
& \mathrm{v}=\mathrm{Q} . \mathrm{H} / \mathrm{V} \text {, onde } \mathrm{H}=\text { altura do reator }[\mathrm{m}] \\
& \mathrm{v}=\mathrm{H} / \theta_{\mathrm{h}}
\end{aligned}
$$

Seus valores recomendados dependem das características do lodo e das cargas aplicadas.

Na Tabela 3.3 são apresentados valores indicados para esgotos domésticos. 
Tabela 3.3 - Velocidades ascendentes recomendadas para o projeto de reatores UASB tratando esgotos domésticos. (adaptado de PROSAB, 1999 apud LETTINGA \& HULSHOFF, 1991).

\begin{tabular}{c|c}
\hline Vazão Afluente & Velocidade Ascendente $[\mathrm{m} / \mathrm{h}]$ \\
\hline Vazão média & $0,5 \sim 0,7$ \\
\hline Vazão máxima & $0,9 \sim 1,1$ \\
\hline $\begin{array}{c}\text { Picos temporários } \\
\text { (duração de 2 a 4 horas) }\end{array}$ & $<1,5$ \\
\hline
\end{tabular}

As eficiências de remoção de matéria orgânica são feitas a partir de relações empíricas, a partir de estudos experimentais de reatores em operação, uma vez que a modelagem matemática tem sido pouco utilizada a esse tipo de reator.

Estudos com reatores operando na faixa de 20 a $25^{\circ} \mathrm{C}$ (PROSAB, 1999), produziram curvas de eficiência representadas pelas equações abaixo:

Para DQO: $E_{D Q O}=100 \cdot\left(1-0,68 \cdot \theta_{h}^{-0,35}\right)$

$\mathrm{E}$, para $\mathrm{DBO}_{5,20^{\circ} \mathrm{C}}: \mathrm{E}_{\mathrm{DBO}}=100 \cdot\left(1-0,70 \cdot \theta_{\mathrm{h}}{ }^{-0,50}\right)$

As concentrações de $\mathrm{DQO}$ e de $\mathrm{DBO}_{5,20^{\circ} \mathrm{C}}$ no efluente final podem ser estimadas com a equação: $S=S_{0}-E . S_{0} / 100$, onde $S_{0}$ é a concentração afluente de $D Q O$ ou de $\mathrm{DBO}_{5,20^{\circ} \mathrm{C}}[\mathrm{mg} / \mathrm{L}]$, S é a concentração efluente de $\mathrm{DQO}$ ou de $\mathrm{DBO}_{5,20^{\circ} \mathrm{C}}[\mathrm{mg} / \mathrm{L}]$ e $\mathrm{E}$ a eficiência de remoção de $\mathrm{DQO}$ ou de $\mathrm{DBO}_{5,20^{\circ} \mathrm{C}}$ (PROSAB, 1999).

Quanto à produção de gás, um dos fatores de avaliação da boa operação dos reatores UASB, uma estimativa pode ser obtida a partir da DQO afluente ao sistema. De forma simplificada, a determinação da parcela de DQO convertida em gás metano pode ser conforme descrito abaixo:

$$
\mathrm{DQO}_{\mathrm{CH} 4}=\mathrm{Q} \cdot\left(\mathrm{S}_{0}-\mathrm{S}\right)-\mathrm{Y}_{\mathrm{obs}} \cdot \mathrm{Q} \cdot \mathrm{S}_{0}
$$


Onde, $\mathrm{DQO}_{\mathrm{CH} 4}$ é a carga de $\mathrm{DQO}$ afluente que é transformada em metano [kg $\left.D Q O_{\mathrm{CH} / \mathrm{d}}\right], Q$ a vazão afluente $\left[\mathrm{m}^{3} / \mathrm{d}\right], \mathrm{S}_{0}$ a concentração de DQO afluente [kg $\left.\mathrm{DQO} / \mathrm{m}^{3}\right]$, S a concentração de DQO efluente $\left[\mathrm{kg} \mathrm{DQO} / \mathrm{m}^{3}\right]$ e $\mathrm{Y}_{\text {obs }}$ o coeficiente de produção de sólidos do sistema em termos de DQO $\left(0,11\right.$ a $0,23 \mathrm{~kg}$ DQO $_{\text {lodo }} / \mathrm{kg}$ $\left.\mathrm{DQO}_{\mathrm{apl}}\right)$.

Em termos de produção volumétrica $\left[\mathrm{m}^{3} \mathrm{CH}_{4} / \mathrm{d}\right]$, tem-se: $\mathrm{Q}_{\mathrm{CH}_{4}}=\mathrm{DQO}_{\mathrm{CH}_{4}} / \mathrm{K}(\mathrm{t}) . \mathrm{K}(\mathrm{t})$ é o fator de correção para temperatura operacional do reator $\left[\mathrm{kg} D Q O / \mathrm{m}^{3}\right]$ e é obtido por: $K(t)=P . K /[R .(273+t)]$, em que $P$ é a pressão atmosférica (1 atm), $K$ é a DQO correspondente a $1 \mathrm{~mol}$ de metano $(64 \mathrm{~g} \mathrm{DQO} / \mathrm{mol}), \mathrm{R}$ a constante dos gases $(0,08206 \mathrm{~atm} . \mathrm{L} / \mathrm{mol} . \mathrm{K})$ e t é a temperatura de operação do reator $\left[{ }^{\circ} \mathrm{C}\right]$.

Com essa estimativa de produção de metano, pode-se prever a vazão de produção de gás dos reatores, uma vez que a parcela de metano corresponde de $60 \%$ a $80 \%$ desse total (PROSAB, 1999).

\subsection{Fósforo nos Esgotos}

O fósforo ocorre nos esgotos sob várias formas de fosfatos. Os fosfatos são classificados de acordo com suas características físicas em frações dissolvida e particulada (normalmente com base na filtração em membrana com abertura de 0,45 micron) e características químicas em ortofosfatos, fosfatos condensados e frações orgânicas (baseando-se na hidrólise e digestão).

Na Tabela 3.4 é apresentado um resumo dessa classificação com valores médios dos esgotos tipicamente domésticos nos Estados Unidos, aonde não há regulação das concentrações de fósforo nos detergentes sintéticos (SEDLAK, 1991). 
Tabela 3.4 - Formas de fosfato em esgotos domésticos (adaptado de SEDLAK, 1991).

\begin{tabular}{l|c}
\hline \multicolumn{1}{c|}{ Forma de Fosfato } & $\begin{array}{c}\text { Concentrações Típicas } \\
\text { [mg P/l] }\end{array}$ \\
\hline Ortofosfato & $3 \sim 4$ \\
\hline $\begin{array}{l}\text { Fosfatos condensados (pirofosfato, tru- } \\
\text { polifosfato, tri-metafosfato, etc.) }\end{array}$ & $2 \sim 3$ \\
\hline $\begin{array}{l}\text { Fosfatos orgânicos (nucleotídeos, } \\
\text { fosfolipídeos, etc.) }\end{array}$ & 1 \\
\hline
\end{tabular}

As fontes de fósforo nos esgotos são: - águas de drenagem superficial; - dejetos domésticos e industriais; - utilização doméstica e industrial de detergentes e produtos de limpeza. As contribuições per capita aproximadas das maiores fontes de fósforo são: - dejetos domésticos: 0,6 kg P/habitante.ano; - lavanderias: 0,3 kg P/habitante.ano; - outros produtos de limpeza domésticos: 0,1 kg P/habitante.ano. Contribuições devidas à fontes industriais, institucionais e comerciais são muito variáveis. Portanto, estimativas precisas da quantidade de fósforo afluente a uma estação de tratamento devem se basear em caracterizações feitas especificamente para cada local (SEDLAK, 1991).

Atualmente, a maior preocupação com o fósforo é com o fosfato dissolvido nas águas interiores, em função da de sua qualidade, pois desempenha papel relevante na produção de algas (eutrofização), com conseqüências negativas para o abastecimento público de águas. As fontes principais de fósforo são as rochas sedimentares, os fertilizantes, os despejos líquidos domésticos, os detergentes, as águas de chuva, os aditivos anticorrosivos e aqueles no controle de incrustações (DERISIO, 1992).

A respeito do ciclo do fósforo, substâncias químicas (nutrientes) são também necessárias para os depósitos e processos de um ecossistema. Um dos nutrientes mais importantes para a construção de organismos é o fósforo. Geralmente o fósforo é mais escasso que outros nutrientes, tais como o nitrogênio e o potássio. Se o sistema florestal não reciclasse o fósforo, este poderia ficar tão escasso, que 
limitaria o crescimento das plantas da floresta. Na Figura 3.3 mostra os caminhos e depósitos restantes como o diagrama do ciclo do fósforo.

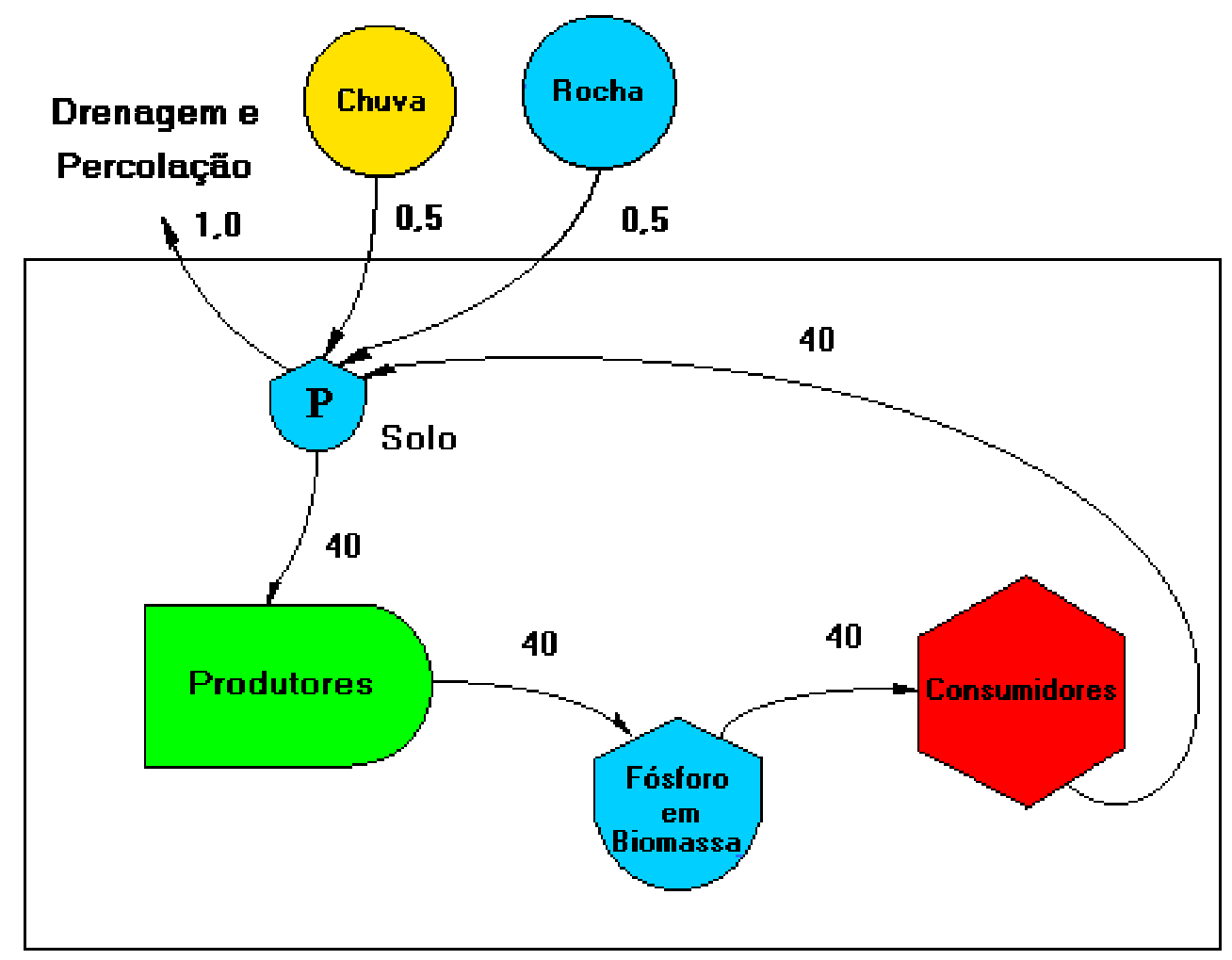

Gramas/m2/ano

Figura 3.3. Ciclo do fósforo (adaptado de ENVIRONMENTAL AND SOCIETY IN FLORIDA, 1997).

O diagrama mostra a chuva e as rochas como fontes externas de fósforo. O fósforo está presente como fosfatos inorgânicos que as plantas usam para produzir compostos orgânicos necessários para a vida. O fósforo nestes compostos, participa da biomassa que regressa a formas inorgânicas mediante os consumidores, quando eles usam a biomassa como alimento. O fósforo inorgânico liberado se torna parte do depósito de nutrientes no solo. Assim, o fósforo se move em um ciclo como mostra a Figura 3.3. Parte flui para fora do sistema com as águas que saem pela superfície do solo ou percolam para o lençol freático. O fósforo não tem fase gasosa em seu ciclo.

Para esgotos tipicamente domésticos, os valores apresentados na Tabela 3.5 são referência ao estudo realizado, uma vez que se refere a ETE Barueri, com uma composição muito próxima aos esgotos afluentes à ETE Ribeirão Pires. 
Tabela 3.5 - Concentrações de fósforo total no esgoto afluente à ETE Barueri (SINELLI, 2002).

Esgoto Afluente à ETE Barueri

\begin{tabular}{c|c}
\hline Data da Análise & $\begin{array}{c}\text { Concentração de Fósforo } \\
\text { [mg P/L] }\end{array}$ \\
\hline $27 / 03 / 01$ & 3,41 \\
\hline $24 / 04 / 01$ & 5,52 \\
\hline $22 / 05 / 01$ & 4,43 \\
\hline $19 / 06 / 01$ & 5,97 \\
\hline $17 / 07 / 01$ & 5,30 \\
\hline $21 / 08 / 01$ & 6,80 \\
\hline $16 / 10 / 01$ & 5,43 \\
\hline $20 / 11 / 01$ & 5,16 \\
\hline
\end{tabular}

\subsection{Processos de Remoção de Fósforo}

O fósforo presente nos esgotos pode ser removido pela forma biológica ou físicoquímica. Os processos biológicos podem ser aeróbios, como os lodos ativados ou anaeróbios, como os digestores anaeróbios. E os processos físico-químicos, que consistem de coagulação/floculação seguidas de decantação, ou qualquer outro tratamento.

\subsubsection{Processos Biológicos de Remoção de Fósforo}

Conforme METCALF \& EDDY, 1991, os microorganismos utilizam o fósforo durante a síntese celular e o transporte de energia. Como resultado, 10 a 30\% do fósforo afluente é removido durante o tratamento biológico secundário. Uma remoção adicional para a manutenção e síntese celular é requerida para que se obtenha uma baixa concentração no efluente tratado. Sob determinadas condições aeróbias, uma parcela maior pode ser removida pelos microorganismos. O fósforo pode ser 
liberado pelas células em ambientes anóxicos. A remoção biológica de fósforo é realizada alinhando reatores com as condições ambientais adequadas.

\subsubsection{Processos Aeróbios de Remoção de Fósforo}

Basicamente, existem os processos Phostrip e Bardenpho, que empregam seqüências de contato anaeróbio-aeróbio com pequenas diferenças entre si. No processo Phostrip, a liberação biológica do fósforo, sob condições anóxicas, é utilizada para concentrar esse nutriente em uma corrente paralela para tratamento físico-químico, aonde a cal é normalmente empregada para a precipita-lo. No processo Bardenpho, uma seqüência de etapas anaeróbia, anóxica e aeróbia é utilizada com a finalidade de se remover nitrogênio e fósforo. $O$ fósforo é removido com a descarga de excesso de lodo do sistema (METCALF \& EDDY, 1991).

\subsubsection{Processos Anaeróbios de Remoção de Fósforo}

Conforme relatado por LETTINGA \& van HAANDEL, 1994, a eficiencia de remoção encontrada no reator UASB de Pedregal foi relativamente baixa (em torno de $50 \%$ ), o que, isoladamente, não atende às exigências para lançamento em corpos d'água.

A Tabela 3.6 apresenta um comparativo das eficiências de remoção de fósforo esperadas em diversos processos de tratamento de esgotos domésticos. Pode-se ver que as opções mais eficientes são as variadas formas de infiltração. Os reatores UASB apresentam somente entre 10 e $20 \%$ de remoção o que, para um esgoto doméstico médio, significa muito pouco para que as concentrações após a diluição num corpo receptor atendam os padrões exigidos para, por exemplo, a Classe 2. 
Tabela 3.6 - Comparativo das eficiências de remoção de fósforo nos diversos processos de tratamento (SPERLING, 1996)

\begin{tabular}{cc}
\hline Processos e Operaçães de Tratamento & Remoção do Fósforo (\%) \\
\hline Tratamento preliminar & $\sim 0$ \\
\hline Tratamento Primário & $10 \sim 20$ \\
\hline Lagoa Facultativa & $20 \sim 60$ \\
\hline Lagoa Anaeróbia - Lagoa Facultativa & $20 \sim 60$ \\
\hline Lagoa Aerada Facultativa & $20 \sim 60$ \\
\hline Lodos Ativados Convencional & $30 \sim 45$ \\
\hline Lodos Ativados Aeração Prolongada & $10 \sim 20$ \\
\hline Lodos Ativados Fluxo Intermitente & $30 \sim 45$ \\
\hline Filtro Biológico (Baixa Carga) & $30 \sim 45$ \\
\hline Filtro Biológico (Alta Carga) & $30 \sim 45$ \\
\hline Biodiscos & $30 \sim 45$ \\
\hline UASB & $10 \sim 20$ \\
\hline Fossa Séptica - Filtro Anaeróbio & $10 \sim 20$ \\
\hline Infiltração Lenta & $75 \sim 99$ \\
\hline Infiltração Rápida & $30 \sim 99$ \\
\hline Infiltração Subsuperficial & $85 \sim 95$ \\
\hline Infiltração Superficial & $85 \sim 95$ \\
\hline Escoamento Superficial & $20 \sim 50$ \\
\hline
\end{tabular}

\subsubsection{Processos Físico-Químicos de Remoção de Fósforo}

A precipitação química do fósforo é obtida através da adição de um metal, o que provoca a formação de fosfatos precipitados pouco solúveis. Este metal pode ser ou o ferro ( $\mathrm{Fe}^{2+}$ ou $\mathrm{Fe}^{3+}$ ) ou alumínio $\left(\mathrm{Al}^{3+}\right)$. Os sais normalmente empregados são o sulfato de alumínio $\left.\left(\mathrm{Al}_{2}\left(\mathrm{SO}_{4}\right)_{3}\right) .18 \mathrm{H}_{2} \mathrm{O}\right)$, o aluminato de sódio $\left(\mathrm{NaAlO}_{2}\right)$, o cloreto férrico $\left(\mathrm{FeCl}_{3}\right)$, o sulfato férrico $\left(\mathrm{Fe}_{2}\left(\mathrm{SO}_{4}\right)_{3}\right)$, o sulfato ferroso $\left(\mathrm{FeSO}_{4}\right)$ e o cloreto ferroso $\left(\mathrm{FeCl}_{2}\right)(\mathrm{METCALF} \&$ EDDY, 1991).

$\mathrm{Na}$ remoção físico-química de fósforo, a adição de certos produtos químicos às águas residuárias produz sais insolúveis ou de baixa solubilidade quando combinados com fosfato. Os principais compostos químicos utilizados são: sulfato de alumínio, aluminato de sódio, cloreto férrico, sulfato férrico e cal. Produtos como sulfato ferroso e cloreto ferroso, recuperados de subprodutos provenientes de fábrica de aço, podem também ser usados. Outros produtos eficientes são os polímeros que, juntamente com o sulfato de alumínio, cloreto férrico e cal, funcionam como auxiliares de floculação. (METCALF \& EDDY, 1991) 
Ainda segundo METCALFF \& EDDY, os fatores que afetam a escolha do produto químico para a remoção de fósforo são:

- Concentração de fósforo do afluente;

- Concentração de sólidos em suspensão da água residuária;

- Alcalinidade de água residuária;

- Custo econômico do produto químico, incluindo seu transporte;

- Garantia de fornecimento do produto químico;

- Instalações de armazenamento do lodo gerado na estação e sua disposição final;

- Compatibilidade com outros processos de tratamento.

Segundo a USEPA (1987), sistema com remoção química de fósforo através da adição de sais de metais podem alcançar eficiência de remoção de 80 a 95\% de fósforo total.

\subsection{Reatores Anaeróbios Conjugados a Processos Físico-Químicos}

O tema ora abordado, remoção de fósforo através da associação de processos físico-químico e anaeróbio, já foi estudado em algumas de suas possibilidades. De acordo com ALEM SOBRINHO \& JORDÃO (2001), a aplicação de coagulantes a base de sais de metais trivalentes seguida de clarificação por decantação ou flotação por ar dissolvido tem se mostrado eficiente na remoção de sólidos suspensos, matéria coloidal e fósforo dos esgotos. Já em termos de matéria orgânica solúvel, a remoção é quase nula. Valores usuais de eficiência de remoção de $\mathrm{DBO}_{5,200 \mathrm{c}}$ e $\mathrm{DQO}$ não ultrapassam $60 \%$ a $65 \%$, em relação à concentração do esgoto bruto afluente.

Quando se tem o tratamento biológico anaeróbio seguido do físico-químico, nota-se uma maior redução da matéria orgânica solúvel acompanhada do mesmo bom desempenho em relação ao fósforo citado acima (ALEM SOBRINHO \& JORDÃO, 2001). 
Como exemplos dessa associação de processos de tratamento, ALEM SOBRINHO \& JORDÃO (2001), citam os casos de Uberlândia, MG e Cascavel, PR. Em Uberlândia tem-se um reator UASB e, na seqüência, flotação por ar dissolvido com aplicação de coagulante cloreto férrico nas dosagens de 50 a $80 \mathrm{mg} / \mathrm{L}$, gerando um efluente tratado com $\mathrm{DBO}_{5,200 \mathrm{c}}$ menor que $30 \mathrm{mg} / \mathrm{L}$ e fósforo total abaixo de 1,0 $\mathrm{mg} / \mathrm{L}$. Em Cascavel, numa ETE de vazão nominal $75 \mathrm{~L} / \mathrm{s}$ e vazão de operação 30 $\mathrm{L} / \mathrm{s}$, composta de UASB a montante e tratamento físico-químico (com cloreto férrico) com decantador lamelar, o efluente também tem $\mathrm{DBO}_{5,200 \mathrm{C}}<30 \mathrm{mg} / \mathrm{L}$ e $\mathrm{P}_{\text {TOT }}<1,0$ $\mathrm{mg} / \mathrm{L}$. Há também estudos do PROSAB com essa mesma configuração (UASB + físico-químico) em escala piloto na EESC-USP e em escala real na PUC-PR, num trabalho em conjunto com a SANEPAR no sistema implantado na cidade de Campo Largo, PR.

Em ensaios desenvolvidos descritos em (FRANCl et al., 2004) chegou-se a conclusão, através de ensaios do tipo jar-test, que, para a condição de aplicação após um filtro aerado submerso, antecedido de um UASB, as melhores faixas de dosagem foram entre 10 e $40 \mathrm{mg} / \mathrm{L}$ para coagulantes baseados em sulfato de alumínio e entre 20 e $70 \mathrm{mg} / \mathrm{L}$ para coagulantes a base de cloreto férrico, sendo que somente com estes últimos a condição de atendimento aos padrões de lançamento.

Outro trabalho desenvolvido nessa linha avaliou a possibilidade de remoção de fósforo em efluente de tratamento em reatores tipo UASB (SINELLI et al., 2002). Ali se concluiu que a remoção físico-química de fósforo de efluente de reator tipo UASB se mostrou eficiente com a aplicação de cloreto férrico, para obtenção de efluente com concentração de fósforo total e $\mathrm{P}_{\mathrm{PO} 4}$ abaixo de $1 \mathrm{mg} / \mathrm{L}$, a importância da relação estequiométrica em massa $\mathrm{Fe} / \mathrm{P}$, sendo afetada pelas reações de competição, que dependem das características momentâneas da água residuária, e de que a produção de lodo depende principalmente da dosagem de cloreto férrico utilizada e da concentração de sólidos presentes no afluente ao tratamento físico-químico (naquele caso, após o tratamento no UASB).

Já dentro da mesma linha da pesquisa proposta, SANTOS (2001) desenvolveu estudo de aplicação de coagulantes no afluente de reator anaeróbio de leito 
expandido. Ali, através de diversos ensaios jar-test se verificou que praticamente não há interferências devidas à dosagem de cloreto férrico na atividade metanogênica específica do reator, mesmo operando com dosagens de $500 \mathrm{mg} / \mathrm{L}$. E obteve bons resultados, numa faixa de dosagem avaliada entre 40 e $200 \mathrm{mg} / \mathrm{L}$ de cloreto férrico, sendo $40 \mathrm{mg} / \mathrm{L}$ em conjunto com 1,0 mg/L de polímero aniônico, no tocante a remoção de DQO (elevação de 64\% para 71\%), turbidez (de $47 \%$ para $59 \%$ ), fósforo (de 17\% para 31\%) e sólidos em suspensão totais (de 52\% para 77\%). É interessante ainda ressaltar que, diante de alterações nas condições de aplicação do(s) coagulante(s) notou-se respostas rápidas dos valores de remoções.

Por outro lado, tem-se o alerta a respeito da manutenção da atividade metanogênica específica (que é um "termômetro" do bom funcionamento de um reator anaeróbio, dando respostas relativas a qualquer efeito tóxico que a aplicação de um sal metálico, como o cloreto férrico, possa causar) feito por SEDLAK (1991). Nesse trabalho, tem-se que a performance da digestão anaeróbia pode ser afetada pela adição de sais metálicos ao esgoto com a finalidade de remoção de fósforo. O efeito sobre a digestão é normalmente a redução da destruição de sólidos voláteis e a diminuição da produção de gás (USEPA, 1987 e Dentel e Gossett, 1987). A magnitude desse impacto sobre a digestão depende da quantidade de sal metálico adicionado e de qual metal esse sal é (cloreto férrico ou de alumínio). Dosagens mais altas reduzem a destruição de voláteis e a produção de gás. O hidróxido de alumínio pode se aglomerar em (ou depositar sobre) partículas em dosagens mais altas. O recobrimento das partículas orgânicas poderia ser o motivo dessa redução na biodegradabilidade (Dentel e Gossett, 1987).

Em outro artigo, baseado em experimentos desenvolvidos para tratamento de efluentes gerados na indústria de parboilização de arroz (SILVA et al., 2003) tem-se outra alternativa nesse sentido. Através do pós-tratamento físico-químico de efluente de parboilização do arroz, previamente tratado em reator UASB, utilizando agitação (onde diversos tempos foram avaliados) e com cloreto de cálcio como precipitante $\left(\mathrm{CaCl}_{2}\right)$, obteve-se a máxima eficiência com tempo de contato de 60 minutos e $\mathrm{CaCl}_{2}$ a $200 \mathrm{mg} / \mathrm{L}$, atingindo uma concentração mínima de $\mathrm{P}$ de $32,9 \mathrm{mg} / \mathrm{L}$ de um efluente que possui alta concentração de fósforo (em torno de $100 \mathrm{mg} / \mathrm{L}$, devido ao processo 
de produção, baseado no encharcamento dos grãos, o que promove a hidrólise da fitina (substância presente nos grãos, rica em fósforo). 


\section{MATERIAIS E MÉTODOS}

\subsection{Considerações Gerais}

A parte experimental deste trabalho foi desenvolvida na estação de tratamento de esgotos do município de Ribeirão Pires, pertencente à Companhia de Saneamento Básico do Estado de São Paulo, SABESP. Nessa unidade foi instalado um sistema de dosagem de cloreto férrico, composto de reservatório, bomba dosadora e mangueiras para condução de coagulante até a caixa de divisão de vazões da ETE, alimentando um de seus reatores. Durante o período em que houve acompanhamento dos reatores, entre abril de 2005 e junho de 2006, foram feitas 2 coletas por semana, cujas análises eram realizadas no laboratório de saneamento da Escola Politécnica, na Cidade Universitária.

\subsection{Descrição da ETE Ribeirão Pires}

Os esgotos sanitários coletados na cidade de Ribeirão Pires seguem, através do conjunto de 10 elevatórias até 2 delas, finais, estação elevatória EE-5 e estação elevatória EE-10, de onde os esgotos seguem até a entrada da ETE Ribeirão Pires. A EE-10 é responsável pelo recalque de cerca de $20 \%$ da vazão coletada no sistema, enquanto que a EE-5 se encarrega do bombeamento da maior parte dos esgotos, coletados na região central da cidade. Pelas características apresentadas pelo esgoto bruto durante o período de acompanhamento da ETE, pode-se afirmar que o esgoto é de característica fraca, com uma considerável contribuição de infiltração na rede coletora. Da elevatória EE-5, situada próxima ao centro da cidade, parte uma linha de recalque com Ø200 mm. Já da EE-10, localizada dentro da área da ETE, segue outra linha de recalque, também com Ø200 mm. Ambas as tubulações descarregam na caixa de entrada da ETE, a montante de seu prétratamento. A vazão afluente é da ordem de $40 \mathrm{~L} / \mathrm{s}$, sofrendo alterações com a ocorrência de chuvas. Um exemplo da variação diária de vazão é mostrado no hidrograma da Figura E.1, do Capítulo 7 - ANEXOS, relativo ao dia 30/05/05. 
A estação de tratamento de esgotos de Ribeirão Pires conta com gradeamento mecanizado (2 canais de grades circulares com raspadores mecanizados e abertura de passagem de $10 \mathrm{~mm}$, sendo um operante e o outro de reserva).

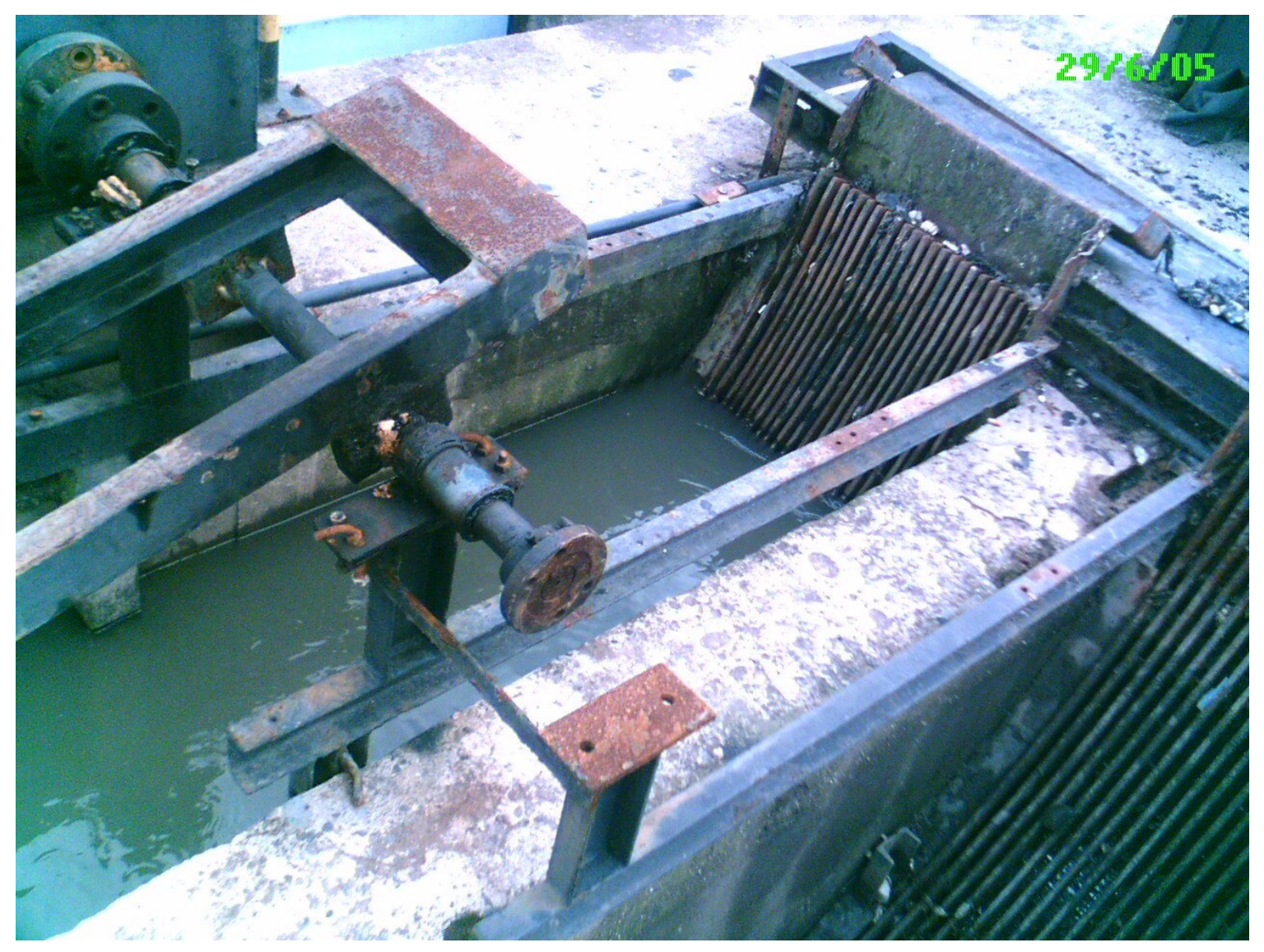

Figura 4.1 - Gradeamento mecanizado da ETE.

Em seguida, existe uma calha Parshall com largura de garganta $w=9$ " para medição das vazões afluentes e manutenção das velocidades nos canais das unidades de gradeamento. No ponto de medição está instalado um medidor ultrassônico, que envia sinal de alturas de líquido a um CLP (controlador lógico programável), situado na sala de controle da ETE. Para esse medidor, a equação que fornece o valor de vazão em função da altura da água é: $Q=0,535 . H^{1,530}$, com $Q$ em $\left[\mathrm{m}^{3} / \mathrm{s}\right]$ e $\mathrm{H}$ em [m]. Nesse equipamento, as alturas medidas na calha Parshall são transformadas em valores de vazão, que são armazenados a cada 1 hora pelo período de 1 semana. Com isto, se obteve, em parte deste estudo, os valores de volume recebido para tratamento ao longo das semanas acompanhadas. Após uma "desprogramação" do citado CLP, este registro deixou de ser feito, passando-se a 
ter a anotação semanal do registrador de volume na entrada para determinar a vazão tratada nos reatores.

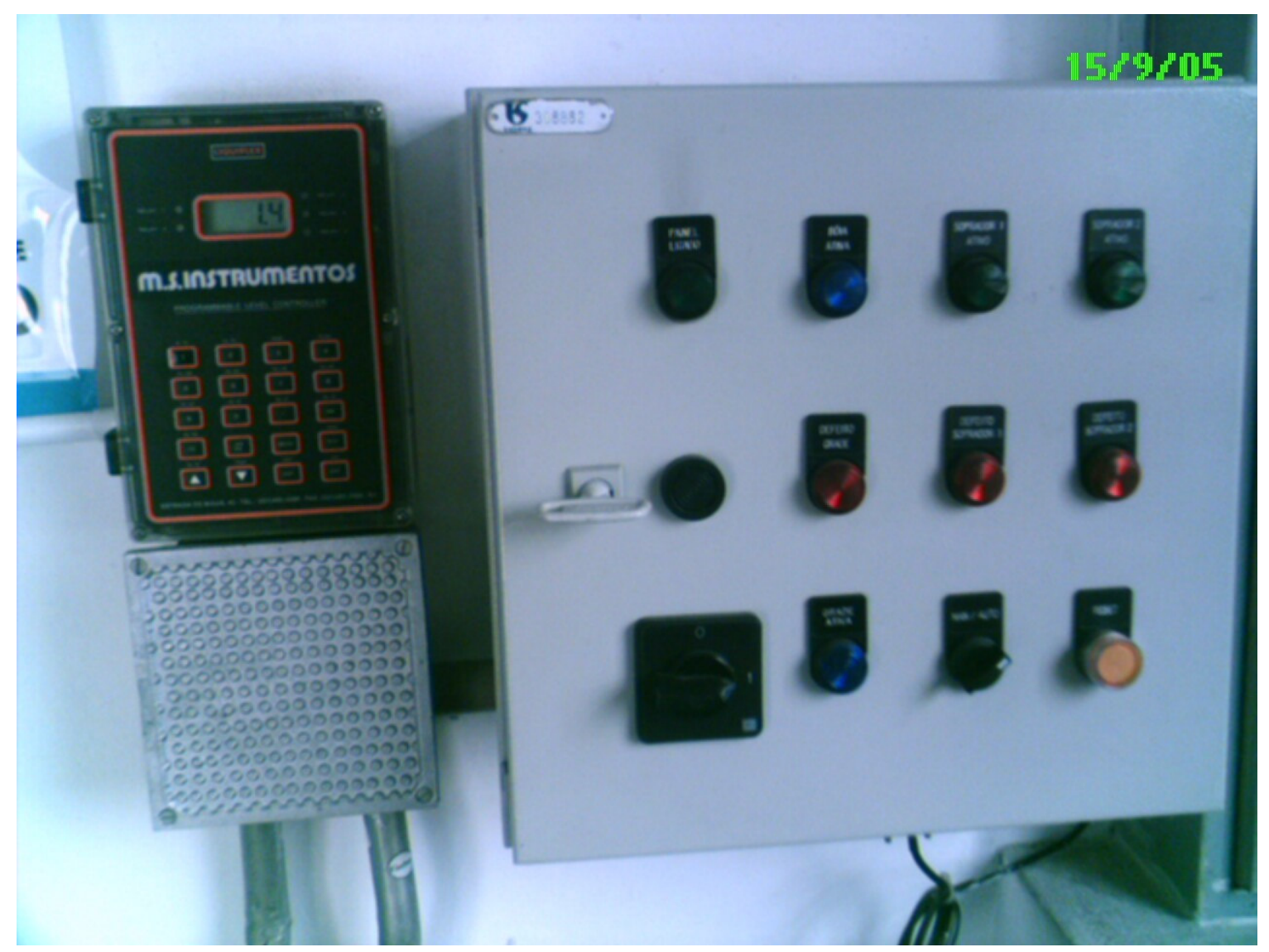

Figura 4.2 - Indicador de vazão de esgoto afluente e CLP (sala de operação da ETE)

Os esgotos seguem então para a unidade de desarenamento, uma caixa de areia aerada. Dois sopradores de ar (um operante e outro reserva) injetam ar, através de uma tubulação no fundo do canal da mesma, criando um fluxo espiral, retendo a areia do esgoto bruto. Por questões de falhas no sistema de ar, um volume de areia não retido desta unidade se depositou no fundo dos reatores UASB ao longo dos cerca de 13 anos de funcionamento da ETE, o que pode ser notado nas amostras coletadas nas alturas de lodo dentro destes, apresentadas adiante. Pode-se dizer que em torno de 1,0 m de altura desses reatores estão ocupados com areia.

Do desarenamento, o esgoto flui para a caixa de divisão de vazões da estação. Nesta, a vazão é dividida, através de vertedores retangulares para os 4 reatores existentes. Há ainda 4 comportas, permitindo a retirada de operação de qualquer 
reator que se julgue necessário. Esta operação, apesar de possível, normalmente não é feita, pois, hidraulicamente, em condições de vazão alta, com as elevatórias finais (EE-5 e EE-10) funcionando continuamente, pode haver o transbordamento a montante da referida caixa, caso um dos reatores esteja fechado. Durante o experimento, tentou-se operar com apenas 3 reatores, a fim de trabalhar com vazões mais elevadas que as normalmente observadas na ETE. Porém, quando da ocorrência de chuvas fortes (devido à alta contribuição de infiltração na rede), todas as comportas eram abertas, deixando dúvidas de qual a vazão real passou pelo sistema.

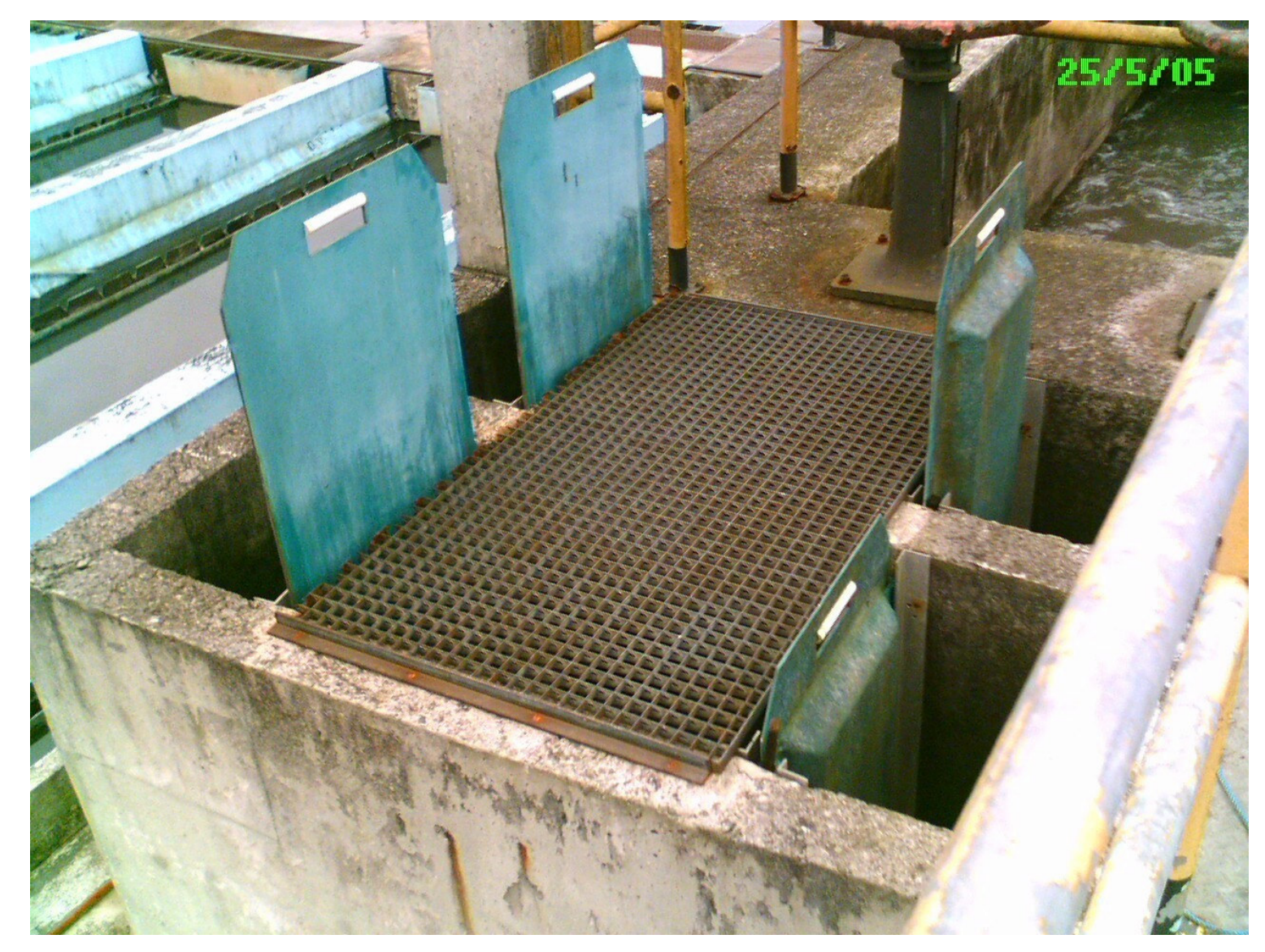

Figura 4.3 - Caixa de divisão de vazões da ETE

Essa caixa, dotada de vertedores retangulares, foi o ponto escolhido para se fazer a dosagem do produto coagulante (cloreto férrico). A grande agitação gerada nesses vertedores produzia as melhores condições de mistura, com o gradiente de velocidade determinado abaixo (DI BERNARDO, 1993). 
$\mathrm{Na}$ condição em que se deu a operação, a vazão afluente foi de $40 \mathrm{~L} / \mathrm{s}$, cabendo para cada reator $10 \mathrm{~L} / \mathrm{s}$. Os vertedores têm, cada um, largura de 0,60 m.

Altura crítica: $y_{c}=\left[Q^{2} /\left(b^{2} \cdot g\right)\right]^{(1 / 3)}=\left[0,01^{2} /\left(0,60^{2} \cdot 9,81\right)\right]^{(1 / 3)}=0,0305 \mathrm{~m}$, onde $Q$ é a vazão $\left\{\mathrm{m}^{3} / \mathrm{s}\right]$, b é a largura do vertedor [m] e g a aceleração da gravidade $(9,81$ $\left.\mathrm{m} / \mathrm{s}^{2}\right)$.

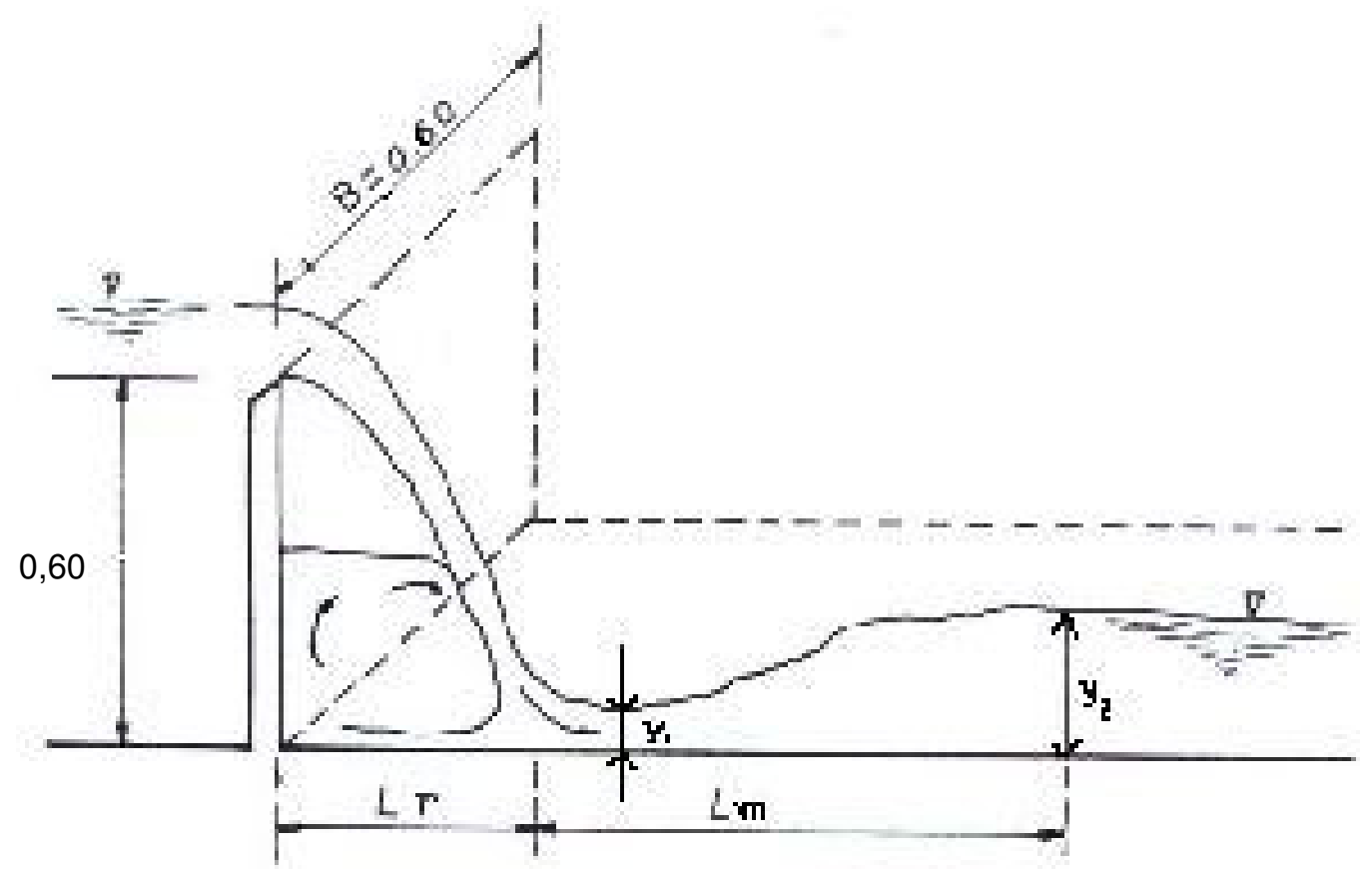

Figura 4.4 - Corte esquemático de vertedor retangular

Altura de ressalto mínimo: $y_{1}=y_{c} \cdot 1,414 /\left[\left(2,56+p_{v r} / y_{c}\right)^{(1 / 2)}\right]$, onde $p_{v r}$ é a altura do vertedor (0,60 m). Então: $y_{1}=0,0305.1,414 /\left[(2,56+0,60 / 0,0305)^{(1 / 2)}\right]=0,009 \mathrm{~m}$

Velocidade no ressalto mínimo: $U_{1}=Q /\left(b \cdot y_{1}\right)=0,01 /(0,60.0,009)=1,82 \mathrm{~m} / \mathrm{s}$

Número de Froude de montante: $F_{r 1}=U_{1} /\left[\left(y_{1} \cdot g\right)^{(1 / 2)}\right]=1,82 /\left[(0,009.9,81)^{(1 / 2)}\right]=$ $=\mathrm{F}_{\mathrm{r} 1}=6,13$

Altura do ressalto $2: \mathrm{y}_{2}=\mathrm{y}_{1} / 2 \cdot\left[\left(1+8 \cdot \mathrm{F}_{\mathrm{r} 1}{ }^{2}\right)^{(1 / 2)}-1\right]$

$\mathrm{y}_{2}=0,009 / 2 \cdot\left[\left(1+8 \cdot 6,13^{2}\right)^{(1 / 2)}-1\right]=0,074 \mathrm{~m}$ 
Velocidade no final do ressalto: $U_{2}=Q /\left(b \cdot y_{2}\right)=0,01 /(0,60$. 0,074) $=0,23 \mathrm{~m} / \mathrm{s}$

Perda de energia: $E_{n}=\left[\left(y_{2}-y_{1}\right)^{3}\right] /\left(4 \cdot y_{1} \cdot y_{2}\right)$

$E_{n}=\left[(0,074-0,009)^{3}\right] /(4.0,009.0,074)=0,103 m$

Comprimento do ressalto: $L_{r}=5 \cdot\left(y_{2}-y_{1}\right)=5 \cdot(0,074-0,009)=0,325 \mathrm{~m}$

Altura da lâmina sobre o vertedor: $Q=1,838 \cdot b \cdot H_{v r}^{(3 / 2)}$

$\mathrm{H}_{\mathrm{vr}}=0,043 \mathrm{~m}$

Distância entre o vertedor e o ressalto: $L_{m}=1,45 . H_{v r} \cdot\left[\left(p_{v r} / H_{v r}\right)^{0,54}\right]=0,26 m$

Tempo médio de mistura: $T_{m r}=L_{r} / U_{\text {médio }}=0,325 /[(1,82+0,23) / 2]=0,32 \mathrm{~s}$

Gradiente de velocidade médio: $G_{m r}=\left[\left(9800 . E_{n}\right) /\left(0,001 . T_{m r}\right)\right]^{(1 / 2)}$

$G_{m r}=[(9800 \cdot 0,103) /(0,001.0,32)]^{(1 / 2)}=1776 \mathrm{~s}^{-1}\left(>1000 \mathrm{~s}^{-1}:\right.$ ok $)$

Para uma boa condição de mistura, deve-se ter gradiente de velocidade acima de $1000 \mathrm{~s}^{-1}$. Portanto, a aplicação de coagulante neste ponto é adequada.

O tratamento principal da ETE de Ribeirão Pires é composto de 4 reatores UASB em paralelo, sem tratamento complementar. Após a divisão de vazões, o esgoto gradeado e desarenado segue para cada um desses reatores. Antes de adentrá-los, há uma divisão em 3 partes iguais, nas caixas de divisão, também por meio de vertedores, o que assegura uma partição eqüitativa de fluxos. Destas (há umas caixa para cada reator), o esgoto ainda sofre mais uma divisão, em 8 partes, cada uma delas correspondente a um tubo de alimentação, que conduz até o fundo dos reatores. Por questões de acúmulo de areia e períodos de baixas vazões, ocorre a obstrução de alguns destes tubos, o que provoca falhas de distribuição de vazões, curto-circuitos e zonas mortas. Tal condição pesa negativamente no que se refere à eficiência do tratamento, reduzindo o tempo de detenção e provocando o arraste de sólidos. Na ETE Ribeirão Pires, nos reatores estudados, cerca de $30 \%$ dessa 
distribuição de vazão estava deficiente, mesmo após 2 operações de limpeza. As figuras 4.5 e 4.6 mostram as caixas de partição de vazões citadas acima.

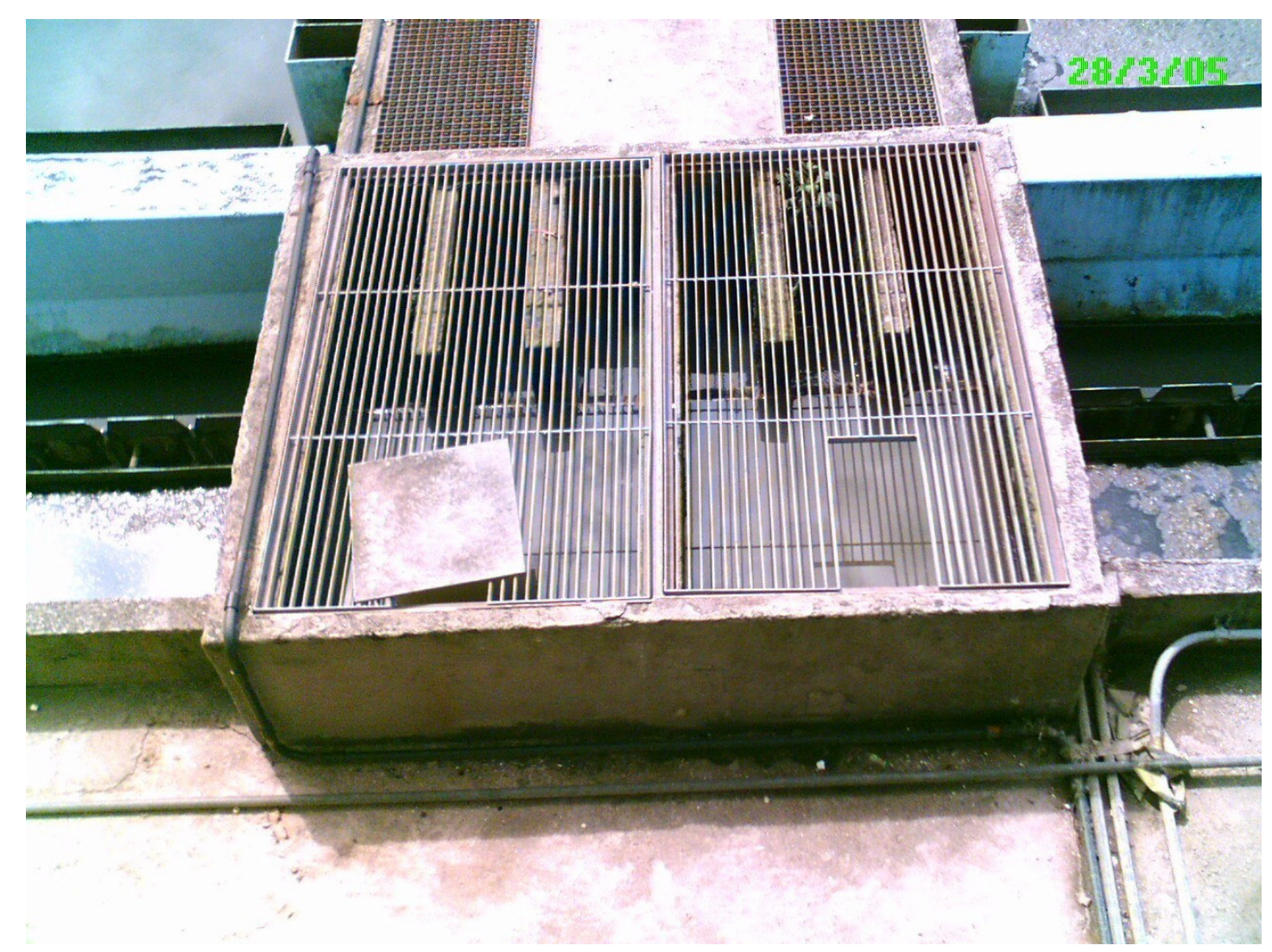

Figura 4.5 - Caixa de divisão de vazões

Após a alimentação, pelo fundo do reator, o esgoto atravessa o manto de lodo, de onde segue para a câmara de sedimentação. $O$ gás é captado nas campânulas e os sólidos retidos descem, agregando-se ao manto de lodo. Cada Reator UASB possui 12,0 $\mathrm{m} \times 8,0 \mathrm{~m}$ de dimensões em planta e profundidade útil de 4,25 m, perfazendo um volume útil de $408 \mathrm{~m}^{3}$ cada um. O líquido clarificado é coletado na superfície em calhas coletoras longitudinais e dali conduzidos por canais (de concreto) e tubulações de ferro fundido até o ponto de lançamento final. $O$ desnivelamento das calhas coletoras, com desbalanceamento das vazões captadas é outro motivo para o surgimento de curto-circuitos e zonas mortas. Percebe-se ainda que os materiais não são os mais adequados para um ambiente anaeróbio. As paredes internas dos canais e as tubulações de efluente tratado sofreram, desde o início da operação, ataque, mostrado por baixa resistência da superfície do concreto e vários pontos de 
corrosão na tubulação. A saída de efluente tratado é composta de tubulação de ferro fundido $\varnothing 200 \mathrm{~mm}$ e, após reunião com os demais reatores, noutra tubulação, também em ferro fundido e com $\varnothing 400 \mathrm{~mm}$. A corrosão no sistema fez com que esse trecho fosse "consumido" parcialmente pela corrosão, ocasionando a paralisação da estação por mais de uma vez durante o período do trabalho de pesquisa. Da tubulação, o esgoto é lançado num canal, afluindo por fim a um dos braços da Represa Billings.

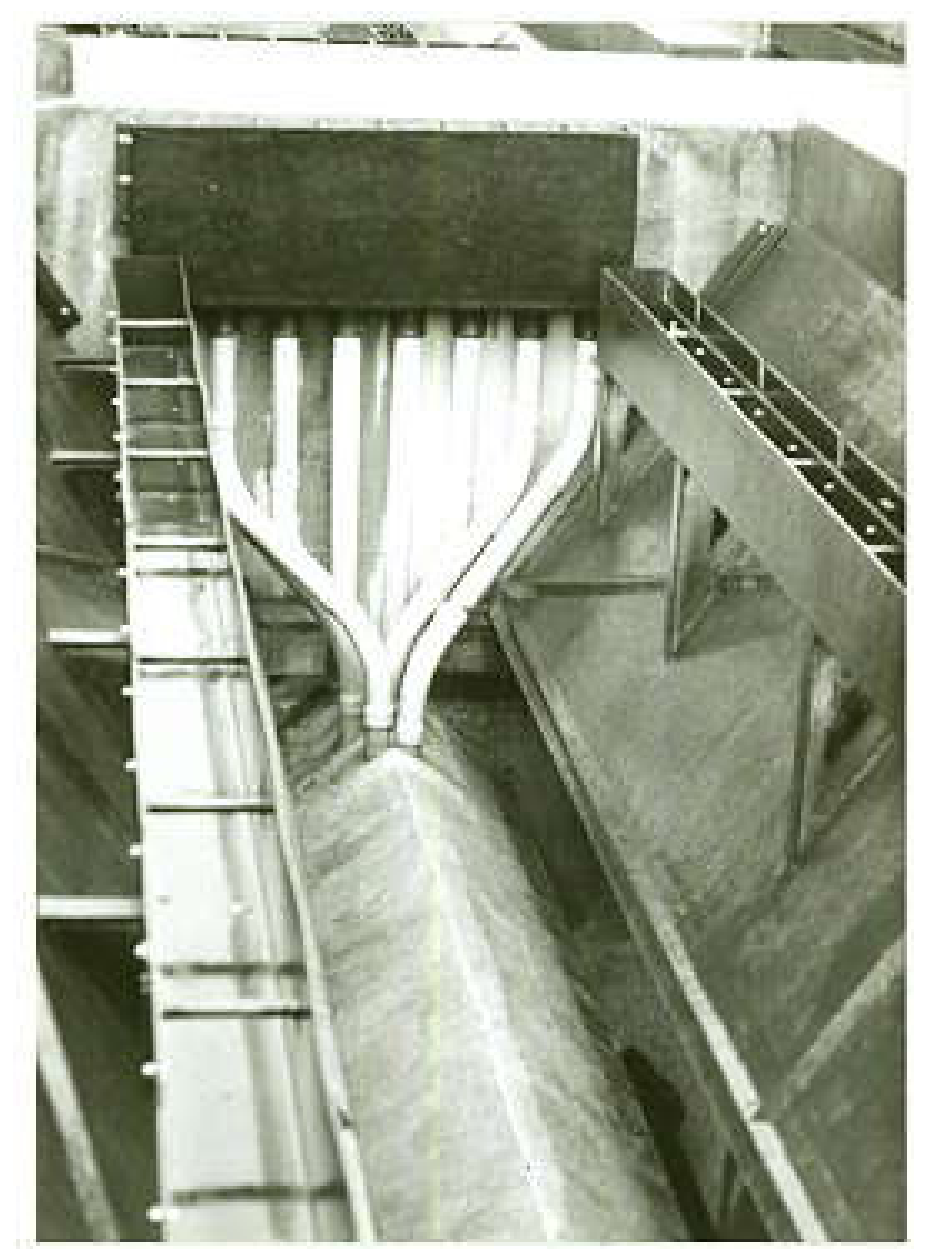

Figura 4.6 - Sistema de Distribuição de Esgoto no Fundo do Reator

O lodo é descarregado dos reatores através do acionamento manual de 4 registros gaveta situados na tubulação de coleta com saídas próximas ao fundo das unidades (cada reator tem 4 saídas de $\varnothing 150 \mathrm{~mm}$ na altura de 1,30 $\mathrm{m}$ acima do fundo do tanque). Dessa tubulação, o lodo segue até a caixa de alimentação dos leitos de secagem, que abastece um sistema de canaletas e, pela manobra de comportas 
manuais, pode-se optar por qual dos 8 leitos de secagem usar, cada um deles com área de $50 \mathrm{~m}^{2}(5,0 \times 10,0 \mathrm{~m})$. Pelas características devidas ao processo de digestão anaeróbia, o lodo tem grande capacidade de desaguamento, o que resulta em ciclos de secagem inferiores a 3 semanas. O filtrado é coletado na face oposta dos leitos. A retirada da torta "seca" é feita pelos operadores e o transporte e disposição final é realizado por empresas terceirizadas. A Figura 4.7 mostra os leitos de secagem da ETE Ribeirão Pires.

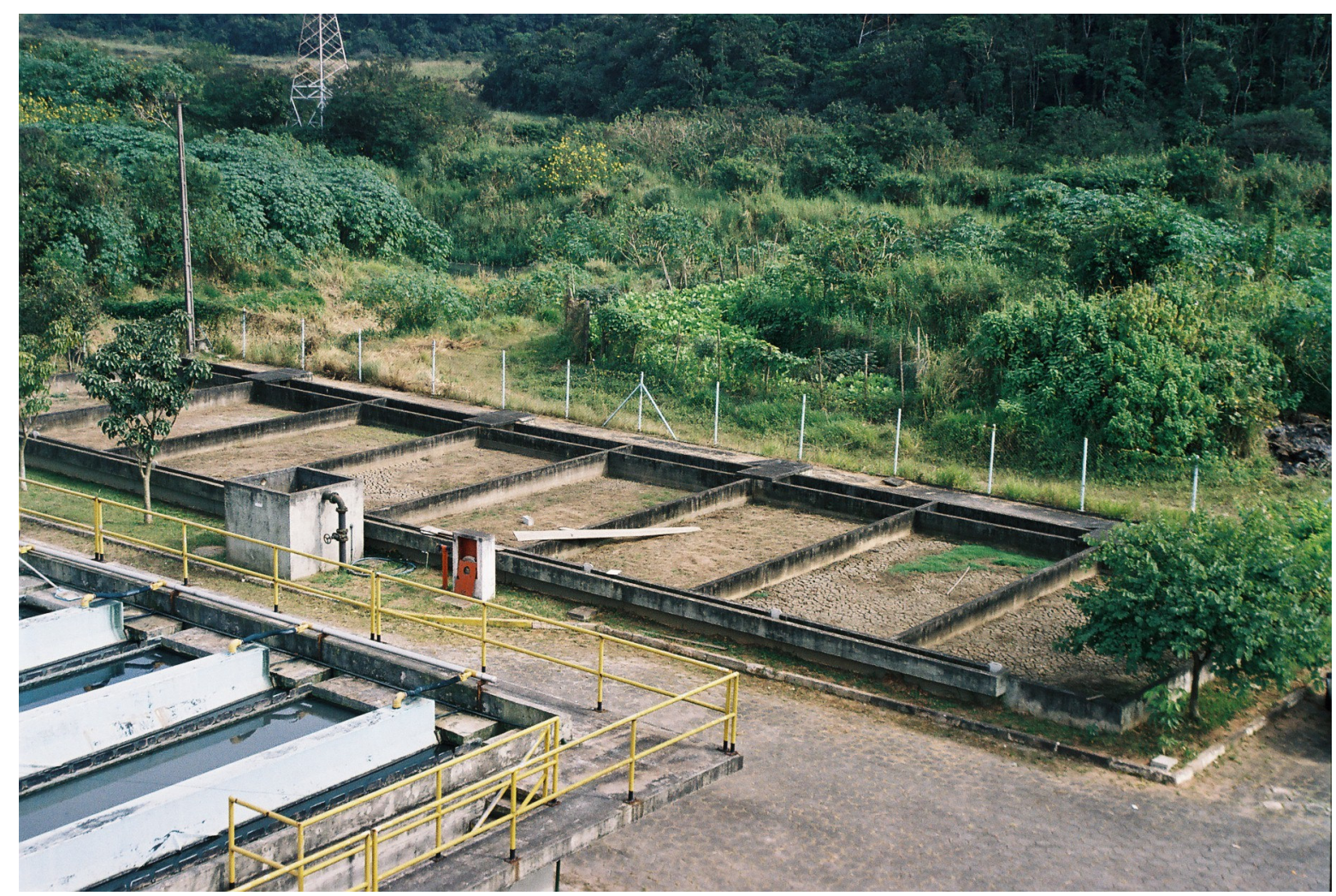

Figura 4.7 - Leitos de secagem

O gás produzido nos reatores é coletado nos separadores trifásicos e enviado para um sistema de queima. Há ainda instrumentação que registra o volume de gás gerado, atualmente fora de operação.

Em virtude da proximidade com residências e a geração de sub-produtos da digestão anaeróbia, foi instalado sistema de desodorização, que, de forma intermitente, faz a nebulização de produto, o que reduz o impacto desses gases. 
A ETE conta ainda com um laboratório com capacidade para a execução de determinações de DBO, DQO, sólidos totais, suspensos, fixos, voláteis e sedimentáveis, fósforo total, $\mathrm{pH}$, acidez, alcalinidade e temperatura.

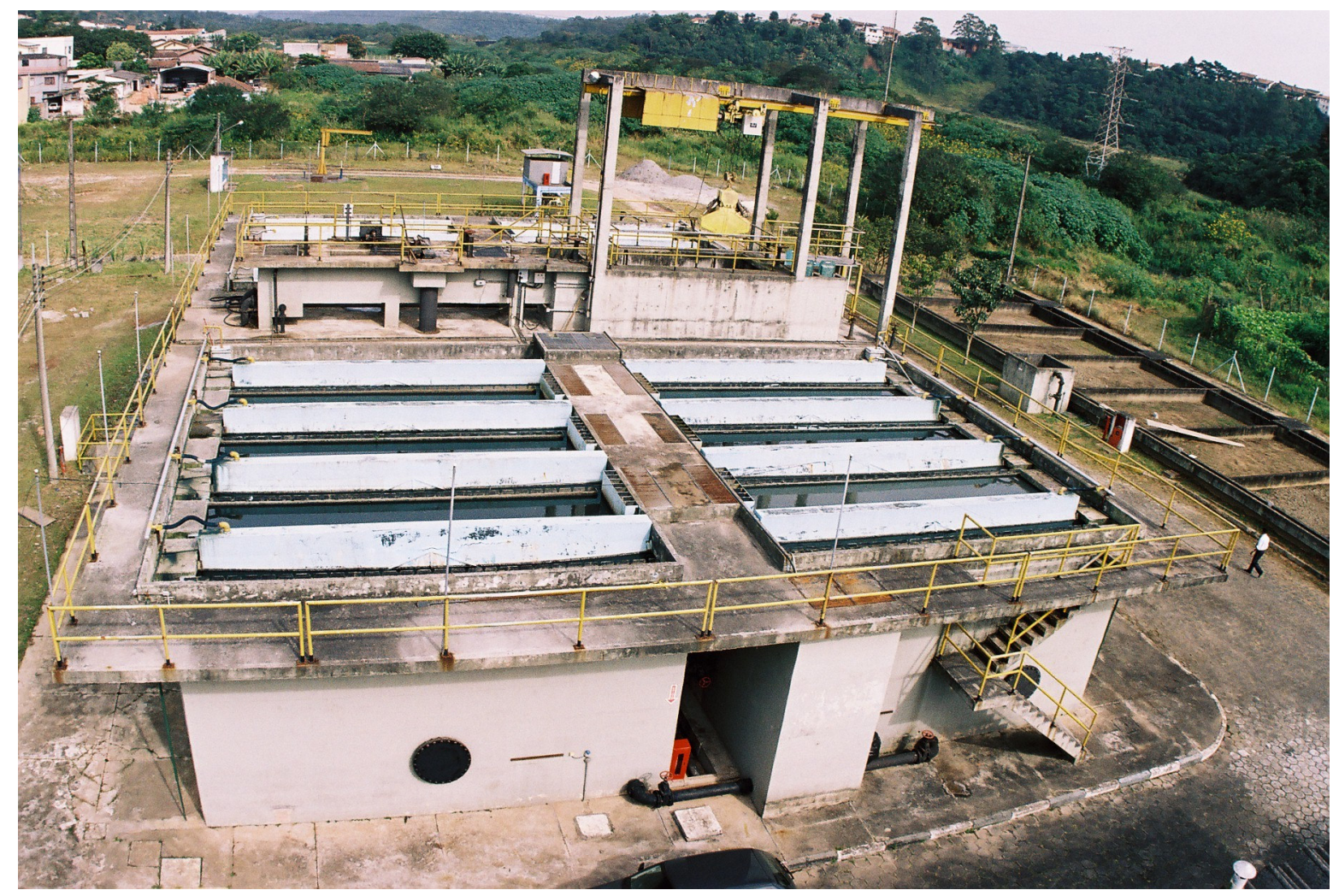

Figura 4.8 - Vista Geral da ETE Ribeirão Pires e EE-10

Na tabela 4.1 apresentam-se os resultados médios do monitoramento efetuado pela Sabesp nos meses que antecederam a pesquisa ora em curso. Os valores dos meses mais recentes que antecederam o experimento estão indicados nas planilhas das Tabelas B.1 a B.5, no Capítulo 7 - ANEXOS.

Tabela 4.1: Monitoramento da ETE Ribeirão Pires / Sabesp - Resumo (fonte: SABESP)

\begin{tabular}{|c|c|c|c|c|c|c|c|c|c|c|c|c|}
\hline & \multicolumn{3}{|c|}{ DQO } & \multicolumn{2}{|c|}{ Turbidez } & \multicolumn{2}{|c|}{ Sol. Susp. Totais } & \multicolumn{3}{|c|}{ DBO } & \multicolumn{2}{|c|}{$\mathrm{P}$ total } \\
\hline & Afluente: & Saída: & $\begin{array}{l}\text { Efic. } \\
\text { [\%]: }\end{array}$ & Afluente: & Saída: & Afluente: & Saída: & Afluente: & Saída: & $\begin{array}{l}\text { Efic. } \\
\text { [\%]: }\end{array}$ & Afluente: & Saída: \\
\hline média & 320 & 97 & 68 & 252 & 83 & 135 & 48 & 102 & 25 & 68,2 & 4,3 & 3,5 \\
\hline mínima: & 158 & 66 & 43,7 & 97 & 45 & 46 & 8 & 18,36 & 1 & 7,1 & 2,2 & 2,1 \\
\hline máxima: & 716 & 147 & 83,0 & 416 & 174 & 812 & 132 & 395 & 72 & 97,8 & 6,3 & 5,8 \\
\hline
\end{tabular}


Observa-se que o esgoto afluente à ETE Ribeirão Pires pode ser classificado como variando entre médio e diluído, em função da contribuição relativamente elevada de águas de infiltração.

Nota-se que os tempos de retenção hidráulica impostos aos reatores são maiores que a média de 8 horas recomendada na literatura, fazendo que a concentração de matéria orgânica à saída dos reatores seja mais baixa que os valores obtidos em outros reatores UASB, tanto em termos de DBO quanto DQO.

\subsection{Alterações Propostas para a Operação do Sistema e Instalações Complementares}

O estudo impôs que se instalasse o sistema de dosagem de cloreto férrico, constituído de reservatório de 2000 litros, para armazenamento do produto recebido na forma líquida (com concentração de 38\%) e bomba dosadora, para a transferência da solução para o compartimento de entrada de um dos reatores UASB, na caixa de distribuição.

Como os reatores UASB da ETE Ribeirão Pires não possuem dispositivos de coleta de lodo ao longo de sua profundidade e dada a importância da caracterização do perfil do manto de lodo nessa pesquisa, a amostragem nas diversas alturas foi feita com uma mangueira dotada de peso em uma de suas extremidades e marcada de metro em metro, a fim de se conhecer a altura em que se extrai o lodo. A retirada da amostra era então realizada através de sifão (com a mangueira previamente preenchida com água imersa no reator, a partir da zona de decantação), levando-se a mesma até um frasco, posicionado no nível do terreno e com a outra extremidade da mangueira emborcada em seu interior. As coletas foram realizadas nos níveis de 1,2, 2,0 e 3,0 metros acima do nível da laje de fundo dos reatores. A intenção inicial era de se obter amostras mais profundas, o que se mostrou inviável por 2 motivos: ausência de conexões para coleta e excessivo acúmulo de areia no fundo dos mesmos. Esta última revela a importância de se realizar o correto desarenamento do esgoto bruto, já que, como pôde ser constatado, a areia ocupou cerca de 1,0 metro de cada reator, diminuindo seu volume útil em torno de $25 \%$. Outra conseqüência 
desse acúmulo é a baixa velocidade que se obtém na tubulação de distribuição de esgoto no fundo do reator, o que provoca o entupimento desse dispositivo e causa uma distribuição não uniforme no fluxo, com o aparecimento de zonas mortas e curto-circuito.

Em termos de dimensionamento do sistema para o experimento proposto tem-se abaixo um estudo para algumas dosagens de cloreto férrico e suas conseqüências:

\subsubsection{Dados considerados}

- 4 módulos de reator UASB com vazão média de esgotos de $10 \mathrm{l} / \mathrm{s}$ cada, perfazendo um total de $40 \mathrm{l} / \mathrm{s}$;

. DQO afluente: $500 \mathrm{mg} / \mathrm{l}$;

. Eficiência de remoção: 70 \%;

. Aplicação de cloreto férrico no afluente ao reator com dosagens de $100 \mathrm{mg} \mathrm{FeCl} / \mathrm{l}$ a $200 \mathrm{mg} \mathrm{FeCl} / /$;

. Dimensões de cada módulo de reator UASB:

- comprimento: 8,0 m;

- largura: 12,0 m;

- $\quad$ altura total: 4,4 m (altura útil);

- altura do manto de lodo: 3,0 m;

- $\quad$ altura da zona de decantação: 1,4 m;

- quantidade de tubos distribuidores: 24 unidades.

\subsubsection{Verificações iniciais:}

. Cálculo do tempo de detenção hidráulico:

$\theta=V / Q=\frac{8,0.12,0.4,4 m^{3} .1000 l / m^{3}}{10 l / s .86400 \mathrm{~s} / \mathrm{dia}}=0,489 \mathrm{dia}=11,7$ horas

. Cálculo da velocidade ascensional no manto de lodo: 
$v=Q / A=\frac{864 \mathrm{~m}^{3} / \mathrm{dia}}{8,0.12,0 \mathrm{~m}^{2}}=9,0 \mathrm{~m} / \mathrm{dia}=0,375 \mathrm{~m} /$ hora

. Número de tubos por $\mathrm{m}^{2}$ de reator:

$N=\frac{24 t u b o s}{8,0.12,0 m^{2}}=0,25 t u b o / m^{2}=1 t u b o / 4 m^{2}$

\subsubsection{Cálculo da produção de lodo por módulo:}

Admitindo-se um coeficiente de síntese celular de 0,12 $\mathrm{kgSST}$ produzido $/ \mathrm{kgDQO}_{\text {aplicada, }}$ tem-se que:

$\Delta X=y \cdot \Delta D Q O_{\text {aplic }}$

$\Delta D Q O_{\text {aplic. }}=864 \mathrm{~m}^{3} /$ dia. $0,5 \mathrm{kgDQO} / \mathrm{m}^{3}=432 \mathrm{kgDQO} / \mathrm{dia}$

Portanto: $\Delta X=0,12 \mathrm{kgSST} / \mathrm{kgDQO} O_{\text {aplic. }} .432 \mathrm{kgDQO} / \mathrm{dia}=51,84 \mathrm{kgSST} / \mathrm{dia}$

Que é a produção de lodo por módulo.

Admitindo um teor de sólidos no lodo do reator igual a $3,0 \%\left(30000 \mathrm{~g} / \mathrm{m}^{3}\right.$ ou 30 $\mathrm{kg} / \mathrm{m}^{3}$ ) o acréscimo de volume no período de um dia será de:

$\Delta V=\frac{51,84 \mathrm{~kg} / \mathrm{dia}}{30 \mathrm{~kg} / \mathrm{m}^{3}}=1,73 \mathrm{~m}^{3} / \mathrm{dia}$

Admitindo que o volume de lodo ocupado no reator seja correspondente a uma altura de 3,0 m, tem-se que:

$\mathrm{V}_{\text {LODO }}=8,0 \cdot 12,0 \cdot 3,0 \mathrm{~m}^{3}=288 \mathrm{~m}^{3}$

Portanto, a idade do lodo aproximada para o sistema atualmente em operação pode ser calculada por: 
$\theta_{C}=\frac{V X}{\Delta X}=\frac{288 \mathrm{~m}^{3} \cdot 30 \mathrm{~kg} / \mathrm{m}^{3}}{51,84 \mathrm{~kg} / \mathrm{dia}}=167 \mathrm{dias}$

4.3.4. Cálculo da produção de lodo devido à adição de coagulante por módulo de reator UASB:

$\mathrm{Fe}^{+3} \rightarrow \mathrm{Fe}(\mathrm{OH})_{3} \cdot 3 \mathrm{H}_{2} \mathrm{O}$

Portanto, 1 mol de Fe ${ }^{+3}$ produz 1 mol de $\mathrm{Fe}(\mathrm{OH})_{3} \cdot 3 \mathrm{H}_{2} \mathrm{O}$ e,

$56 \mathrm{~g}$ de $\mathrm{Fe}^{+3}$ produz $161 \mathrm{~g}$ de $\mathrm{Fe}(\mathrm{OH})_{3} \cdot 3 \mathrm{H}_{2} \mathrm{O}=161 \mathrm{~g}$ de lodo.

Mas, 1 mol de $\mathrm{Fe}^{+3}$ corresponde a $1 \mathrm{~mol}$ de $\mathrm{FeCl}_{3} \mathrm{e}$,

$56 \mathrm{~g}$ de $\mathrm{Fe}^{+3}$ correspondem a $162,5 \mathrm{~g}$ de $\mathrm{FeCl}_{3}$. Logo, tem-se:

$162,5 \mathrm{mg} \mathrm{FeCl}_{3} / \mathrm{l} \quad \rightarrow 161 \mathrm{mg}$ de lodo/l

$1 \mathrm{mg} \mathrm{FeCl} / \mathrm{l} \rightarrow \mathrm{X} \mathrm{mg} \mathrm{de} \mathrm{lodo/l}$

$\mathrm{X}=0,99 \mathrm{mg}$ de lodo gerado/mg $\mathrm{FeCl}_{3}$ adicionado

Daí, chega-se a:

- Quantidade de coagulante adicionado para a dosagem de $100 \mathrm{mgFeCl} / \mathrm{l}$ :

$\Delta$ Coag $=\frac{864,0 \mathrm{~m}^{3} / \mathrm{dia} .100 \mathrm{gFeCl}_{3} / \mathrm{m}^{3}}{1000 \mathrm{~g} / \mathrm{kg}}=86,4 \mathrm{kgFeCl}_{3} / \mathrm{dia}$

e a quantidade gerada de lodo adicional devido ao coagulante será:

Prod. lodo $=86,4 \mathrm{~kg} / \mathrm{dia} .0,99=85,6 \mathrm{~kg} / \mathrm{dia}$.

- Quantidade de coagulante adicionado para a dosagem de $150 \mathrm{mg} \mathrm{FeCl} / \mathrm{l}$ : 
$\Delta$ Coag $=\frac{864,0 \mathrm{~m}^{3} / \mathrm{dia} .150 \mathrm{gFeCl} / \mathrm{m}^{3}}{1000 \mathrm{~g} / \mathrm{kg}}=129,6 \mathrm{kgFeCl} / \mathrm{dia}$

e a quantidade gerada de lodo adicional devido ao coagulante será:

Prod.. lodo $=129,6 \mathrm{~kg} / \mathrm{dia} .0,99=128,3 \mathrm{~kg} / \mathrm{dia}$.

- Quantidade de coagulante adicionado para a dosagem de $200 \mathrm{mgFeCl} / \mathrm{l}$ :

$\Delta$ Coag $=\frac{864,0 \mathrm{~m}^{3} / \mathrm{dia} .200 \mathrm{gFeCl}_{3} / \mathrm{m}^{3}}{1000 \mathrm{~g} / \mathrm{kg}}=172,8 \mathrm{kgFeCl}_{3} / \mathrm{dia}$

e a quantidade gerada de lodo adicional devido ao coagulante será:

Prod. lodo $=172,8 \mathrm{~kg} / \mathrm{dia} .0,99=171 \mathrm{~kg} / \mathrm{dia}$.

Portanto, admitindo-se uma dosagem média de $150 \mathrm{mg} \mathrm{FeCl}_{3} / \mathrm{l}$, temos uma produção total de lodo em torno de:

$\Delta \mathrm{X}_{\mathrm{T}}=\Delta \mathrm{X}_{0}+\Delta \mathrm{X}_{\mathrm{c}}=51,84+128,3=180,0 \mathrm{~kg} / \mathrm{dia}$

Admitindo um teor de sólidos no lodo do reator igual a 2,5\% (25000 mg/l ou 25 $\mathrm{kg} / \mathrm{m}^{3}$ ), o acréscimo de volume no período de um dia será:

$\Delta \mathrm{V}=180 \mathrm{~kg} / \mathrm{dia} / 25 \mathrm{~kg} / \mathrm{m}^{3}=7,2 \mathrm{~m}^{3} / \mathrm{dia}$

Portanto, a nova idade do lodo aproximada para o sistema poderá ser calculada por:

$\theta_{C}=\frac{V X}{\Delta X}=\frac{288 \mathrm{~m}^{3} \cdot 25 \mathrm{~kg} / \mathrm{m}^{3}}{180 \mathrm{~kg} / \mathrm{dia}}=40$ dias 


\subsubsection{Sistema de dosagem de cloreto férrico:}

A aplicação deverá ser efetuada na forma líquida. Admitindo uma porcentagem em massa de $\mathrm{FeCl}_{3}$ de $38 \%$ e massa específica de $1400 \mathrm{~kg} / \mathrm{m}^{3}$, teremos:

0,38 massa de $\mathrm{FeCl}_{3} /$ massa de solução

$\rightarrow m_{\mathrm{SOLUÇÃO}}=\mathrm{m}_{\mathrm{FeCl} 3} /$ 0,38 $=129,6 \mathrm{~kg} \mathrm{FeCl} /$ dia $/$ 0,38 = 341,1 kg de solução/dia

$\rightarrow \mathrm{V}_{\text {SOLUÇÃO }}=341,1 \mathrm{~kg} / \mathrm{dia} / 1400 \mathrm{~kg} / \mathrm{m}^{3}=0,244 \mathrm{~m}^{3} / \mathrm{dia}$

Vazão da bomba dosadora $=0,244 \mathrm{~m}^{3} / \mathrm{dia}=10,2 \mathrm{l} / \mathrm{hora}($ para $150 \mathrm{mg} / \mathrm{l})$

Na Figura 4.9 é mostrada a bomba dosadora de $\mathrm{FeCl}_{3}$, instalada no local do experimento.

Cuidados a serem considerados:Variação de $\mathrm{pH}$. Caso a alcalinidade não seja suficiente para a manutenção do pH, este deverá ser corrigido mediante à aplicação de $\mathrm{Na}_{2} \mathrm{CO}_{3}$.

\subsection{Operação dos Reatores UASB, antes da Adição Química}

O experimento foi delineado de forma a utilizar-se apenas 2 (dois) dos quatro reatores UASB, sendo que um deverá receber adição contínua de cloreto férrico e o outro não, sendo também monitorado para servir como referência. Portanto, fez-se necessário um período de operação monitorada dos dois reatores, sem adição de cloreto férrico. Estimou-se um período de 4 meses de operação controlada dos dois reatores UASB, prevendo-se o seguinte programa de coletas de amostras e análises laboratoriais: 
a) Esgoto à Entrada e Saída dos Reatores

Parâmetro:

Freqüência:

Demanda Bioquímica de Oxigênio, $\mathrm{DBO}_{5,20}$ (total e filtrada)

$1 \times$ semana

Demanda Química de Oxigênio, DQO (total e filtrada)

$2 \times$ semana

Sólidos Totais, Fixos e Voláteis

$1 \times$ semana

Sólidos em Suspensão Totais, Fixos e Voláteis

$2 \times$ semana

Sólidos Sedimentáveis

$1 \mathrm{x}$ semana

Fósforo Total e Ortofosfato Solúvel

$2 \times$ semana

Sulfeto

$1 \times$ semana

$\mathrm{pH}$

$2 \times$ semana

Alcalinidade

$2 \times$ semana

b) Lodo ao Longo da Profundidade dos Reatores UASB

Sólidos Totais, Fixos e Voláteis

$3 \times$ dosagem

Sólidos em Suspensão Totais, Fixos e Voláteis

$3 \times$ dosagem

Além das análises laboratoriais indicadas, deverá ser exercido o controle da quantidade de lodo descartado dos dois reatores UASB, medindo-se o volume descartado de cada reator e determinando-se a concentração de sólidos em suspensão em cada oportunidade que este evento venha a ocorrer.

\subsection{Operação do Sistema com um dos Reatores UASB recebendo Cloreto Férrico}

Foi realizado um período de 10 (dez) meses de operação dos dois reatores UASB, um sem qualquer adição química e, o outro, recebendo cloreto férrico segundo a seguinte programação: 
Período:

Setembro/2005 a janeiro/2006

Fevereiro/2006 a junho/2006

\section{Dosagem:}

$25 \mathrm{mg} \mathrm{FeCl} / 3$

$50 \mathrm{mg} \mathrm{FeCl} / 3 / \mathrm{L}$

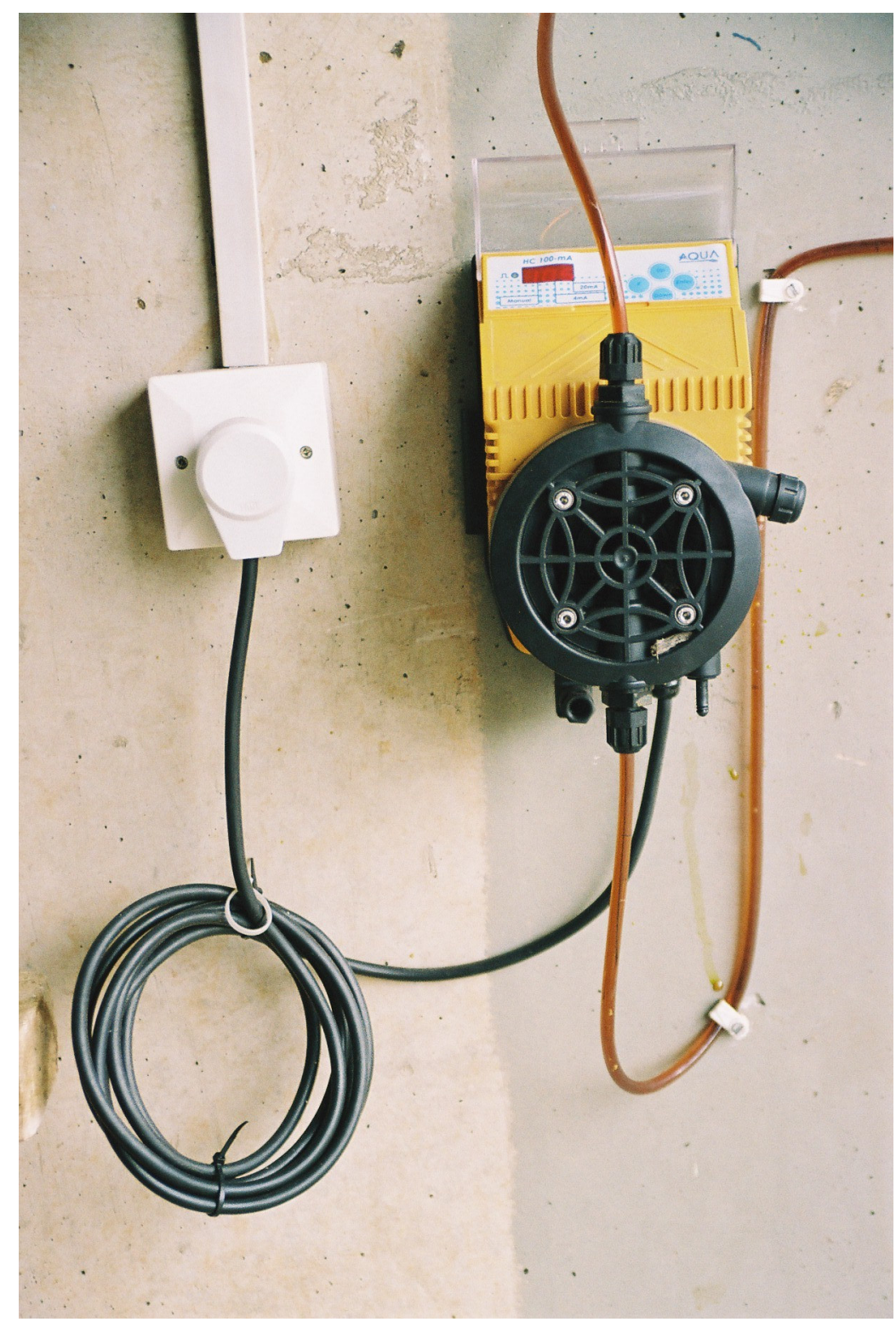

Figura 4.9 - Bomba Dosadora de $\mathrm{FeCl}_{3}$ 


\subsection{Estudo do Manto de Lodo e das suas Características}

Os reatores não contam com pontos de amostragem intermediários em sua altura. Com isto, se torna mais difícil acompanhar operacionalmente o perfil do manto de lodo. A solução encontrada foi fazer um sifão, transferindo o lodo de uma certa altura para um frasco de coleta posicionado no nível 0,0, ao lado dos reatores. Com uma mangueira flexível e com o comprimento suficiente, na qual se amarrou um peso na ponta e sobre a qual se anotou distâncias de metro em metro, foi possível baixar sua extremidade até as alturas de 1,0 m,2,0 m e 3,0 m acima do nível do fundo do reator (tomando por base o nível de água no reator, de 4,25 m, abaixava-se a ponta da mangueira 1,25 $\mathrm{m}$ para posiciona-la na altura 3,0 $\mathrm{m}$ acima do fundo; para coletar lodo a 2,0 m, baixava-se mais $1,0 \mathrm{~m}$ e para coletar a 1,0 de altura, descia-se mais 1,0 m. Das amostras coletadas eram realizados os ensaios da série de sólidos (ST, STF, STV, SST, SSF e SSV).

\subsection{Determinação das Velocidades Reais de Passagem nos Reatores}

A ETE Ribeirão Pires foi projetada para operar com vazão de $70 \mathrm{~L} / \mathrm{s}$. Entretanto, as condições em que o experimento se desenvolveu foram com vazões da ordem de 40 L/s. Esta diferença implica em novos valores de velocidades de passagem para zona de decantação e ascensional, entre outros, os quais são determinados abaixo:

- velocidade de passagem para a zona de decantação:

vazão por reator: $Q_{R}=40 \mathrm{~L} / \mathrm{s} / 4$ reatores $=10 \mathrm{~L} / \mathrm{s}=36 \mathrm{~m}^{3} / \mathrm{h}$

$v_{P}=Q_{R} / A_{P}=36 \mathrm{~m}^{3} / \mathrm{h} /(0,4 \mathrm{~m} \times 8,0 \mathrm{~m} \times 8)=1,41 \mathrm{~m} / \mathrm{h}(<4,0 \mathrm{~m} / \mathrm{h}:$ ok $)$

onde $A_{P}=$ área de passagem para a zona de decantação (8 passagens,com $8,0 \mathrm{~m}$ de comprimento e largura 0,4 m).

- taxa de escoamento superficial na zona de decantação: 
$q_{A}=Q_{R} / A_{S}=36 \mathrm{~m}^{3} / \mathrm{h} /[(0,65 \times 2+1,50 \times 3) \times 8,0]=0,78 \mathrm{~m} / \mathrm{h}\left(<1,2 \mathrm{~m}^{3} / \mathrm{m}^{2} \cdot \mathrm{h}:\right.$ ok $)$

onde $A_{S}=$ área da superfície na zona de decantação (2 larguras de 0,65 m e 3 de $1,5 \mathrm{~m}$, por comprimento de $8,0 \mathrm{~m}$ )

- velocidade ascencional:

$v_{a}=Q_{R} / A_{f}=36 \mathrm{~m}^{3} / \mathrm{h} /(12,0 \times 8,0)=0,375 \mathrm{~m} / \mathrm{h}(<0,7 \mathrm{~m} / \mathrm{h}:$ ok $)$

onde $A_{f}=$ área do fundo do reator (12,0 m de comprimento por 8,0 m de largura)

- tempo de detenção hidráulico:

$t_{d}=V_{u} / Q_{R}=(12,0 \times 8,0 \times 4,25) / 36 \mathrm{~m}^{3} / \mathrm{h}=408 \mathrm{~m}^{3} / 36 \mathrm{~m}^{3} / \mathrm{h}=11,3 \mathrm{~h}(>6,0 \mathrm{~h}:$ ok $)$

onde $\mathrm{V}_{\mathrm{u}}=$ volume útil do reator $(12,0 \mathrm{~m}$ de comprimento por 8,0 $\mathrm{m}$ de largura por 4,25 de lâmina líquida)

Percebe-se que todos os parâmetros de dimensionamento são atendidos com grande folga, em virtude da baixa vazão atual em comparação com a vazão de projeto. 


\subsection{Metodologias Analíticas}

Todas as análises físico-químicas e biológicas dos efluentes nas diversas etapas de tratamento foram desenvolvidas de acordo com os preceitos da $20^{a}$ Edição do "Standard Methods for Examination of Water and Wastewater" (AWWA - 1998).

Tabela 4.2 - Metodologias Analíticas

\begin{tabular}{|c|c|}
\hline Parâmetro & Método \\
\hline Demanda Bioquímica de Oxigênio $\left(\mathrm{DBO}_{5,20}\right)$ & $\begin{array}{l}\text { Técnica das diluições e incubação a } 20^{\circ} \mathrm{C} \text {. } \\
\text { Concentrações de oxigênio dissolvido medidas } \\
\text { pelo método eletrométrico (oxímetro marca YSI). }\end{array}$ \\
\hline Demanda Química de Oxigênio (DQO) & $\begin{array}{l}\text { Oxidação com dicromato de potássio } \\
\text { (catalisada) em refluxo aberto e titulação com } \\
\text { sulfato ferroso amoniacal. }\end{array}$ \\
\hline $\begin{array}{l}\text { Nitrogênio Total Kjeldhal (NTK) e Nitrogênio } \\
\text { Amoniacal }\end{array}$ & $\begin{array}{l}\text { Digestão química, destilação da amônia e } \\
\text { titulação final. }\end{array}$ \\
\hline Nitrato & Eletrodo de íon seletivo. \\
\hline Fósforo Total e Ortofosfatos & $\begin{array}{l}\text { Digestão química e colorimetria em } \\
\text { espectrofotômetro UV - Visível marca Shimadzu } \\
\text { (método do ácido ascórbico). }\end{array}$ \\
\hline $\begin{array}{l}\text { Sólidos Totais, Suspensos, Dissolvidos, Fixos e } \\
\text { Voláteis }\end{array}$ & $\begin{array}{l}\text { Filtração, secagem (estufa), calcinação (forno } \\
\text { mufla) e gravimetria. }\end{array}$ \\
\hline $\mathrm{PH}$ & Método eletrométrico (pH-metro marca Orion) \\
\hline Ácidos Voláteis & Titulação Potenciométrica \\
\hline Alcalinidade & Titulação Potenciométrica \\
\hline Turbidez & Nefelometria com Turbidímetro marca Hach. \\
\hline Cor Aparente & Aparelho comparador de cor marca Policontrol. \\
\hline Temperatura & Termômetro de Mercúrio \\
\hline Sulfeto & Método lodométrico. \\
\hline
\end{tabular}




\section{RESULTADOS E DISCUSSÃO}

O monitoramento da estação de tratamento de Ribeirão Pires se deu entre abril de 2005 e junho de 2006, avaliando parâmetros do esgoto afluente à ETE e os efluentes tratados pelos reatores $B$ (com aplicação de cloreto férrico) e C (sem adição de cloreto férrico). Esse estudo foi dividido em 3 fases: - 1a fase: sem aplicação de coagulante em nenhum dos reatores, com o objetivo de comparar os desempenhos dos dois reatores; - 2ª fase: aplicação de 25,0 mg FeCl $3 / L$ no esgoto afluente ao reator $\mathrm{B}$; - $3^{\text {a }}$ fase: aplicação de $50,0 \mathrm{mg} \mathrm{FeCl} / 3 / \mathrm{L}$ no esgoto afluente ao reator B. Uma 4a fase, com a dosagem de $100,0 \mathrm{mg} \mathrm{FeCl}_{3} / \mathrm{L}$ no esgoto afluente ao reator $B$, que estava prevista, não pôde ser realizada, pois a linha de recalque que conduz boa parte dos esgotos afluentes à ETE, proveniente da EE- 5 , se rompeu em junho de 2006, causando uma grande redução de vazão no sistema, com os tempos de detenção hidráulicos passando de $11 \mathrm{~h}$ para $19 \mathrm{~h}$, trazendo condições diferentes daquelas em que o experimento de desenvolveu anteriormente. Outro fato ocorrido foi a retirada temporária de operação do reator $\mathrm{C}$, do qual se obteve todos os parâmetros de comparação com o reator onde se aplicou o coagulante.

\subsection{Resultados da 1a Fase - Sem Adição de Cloreto Férrico}

Com o intuito de comparar as performances dos dois reatores empregados neste experimento, houve uma etapa inicial de análises de matéria orgânica, ortofosfatos, sulfetos e série de sólidos, da qual os resultados são apresentados a seguir.

\subsubsection{DQO Total}

Nesta fase foram realizadas 32 análises, entre abril e setembro de 2005, mostradas no Capítulo 7. ANEXOS, na Tabela A.1. Da observação da Figura 5.1 pode-se concluir que não há diferenças significativas entre os efluentes dos 2 reatores. Notase ainda a característica fraca do esgoto bruto. $O$ aumento da carga afluente é amortecido pelos reatores, como se vê no ponto relativo à data 8/8/05. 


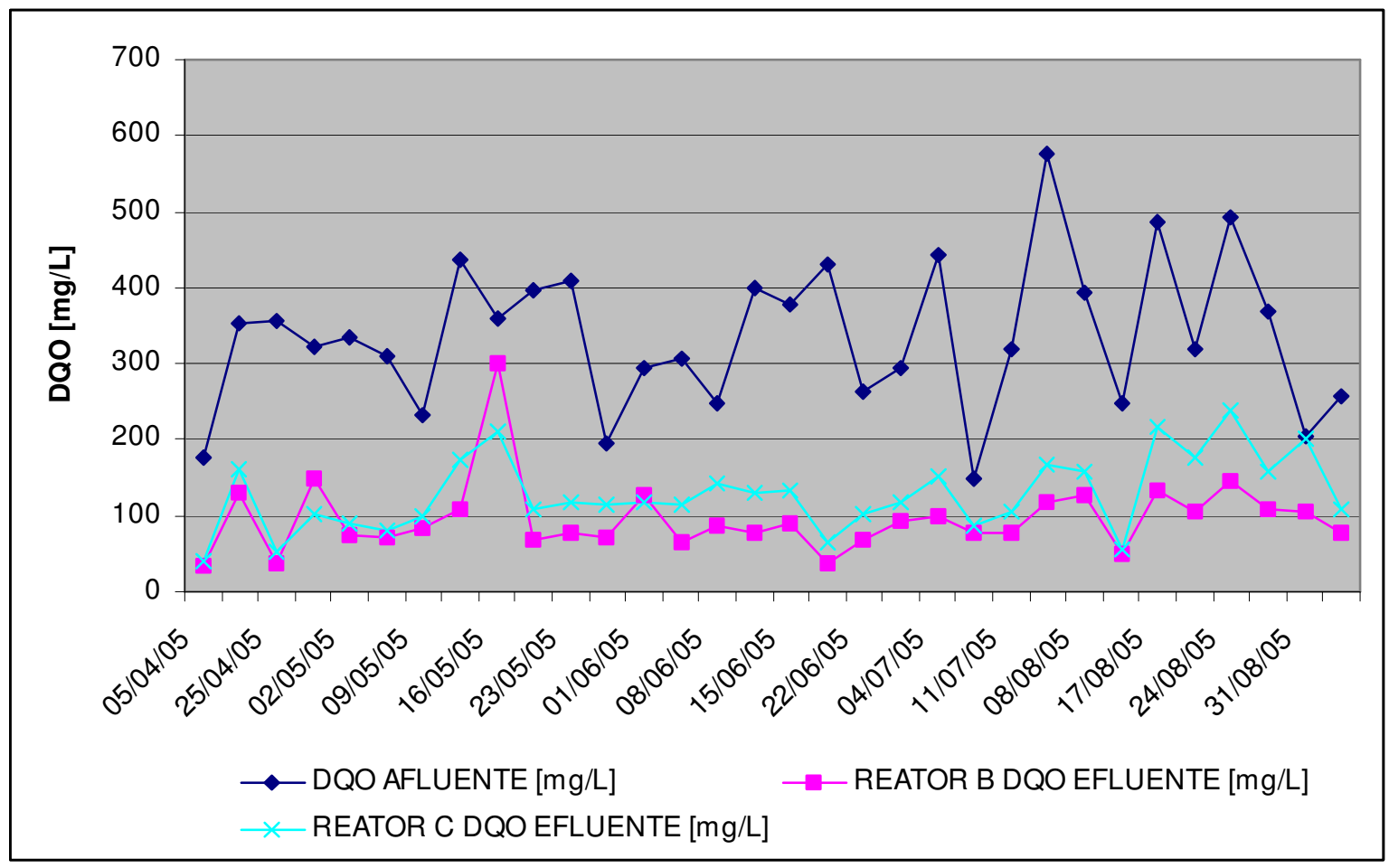

Figura 5.1 - Valores de DQO total afluente e nas saídas dos reatores B e C: 1a Fase

Os valores médios obtidos estão apresentados na Tabela 5.1, com os respectivos dados estatísticos. Existe de fato uma pequena vantagem do reator $\mathrm{B}$ (valor médio do reator $B=96 \mathrm{mg} / \mathrm{L}$, enquanto o valor médio do reator $C=128)$, sendo, porém sua diferença menor que os desvios padrões (respectivamente 48 e 49 mg/L). As maiores diferenças apareceram no final da $1^{\underline{a}}$ fase, com pode-se observar também na Figura 5.1. Na Figura 5.2 apresentam-se as representações gráficas dessa análise estatística.

Tabela 5.1 - Índices estatísticos da DQO total afluente e da saída dos reatores B e C: $1^{\text {a }}$ Fase

\begin{tabular}{lccc}
\hline $\begin{array}{c}\text { PONTO DE } \\
\text { COLETA }\end{array}$ & ESGOTO BRUTO & $\begin{array}{c}\text { EFLUENTE } \\
\text { REATOR B }\end{array}$ & $\begin{array}{c}\text { EFLUENTE } \\
\text { REATOR C }\end{array}$ \\
\hline $\begin{array}{l}\text { VALOR MÉDIO } \\
\text { [mg/L] }\end{array}$ & 336 & 96 & 128 \\
\hline MÍNIMO [mg/L] & 148 & 35 & 39 \\
\hline MÁXIMO [mg/L] & 575 & 302 & 238 \\
\hline $\begin{array}{l}\text { DESVIO } \\
\text { PADRÃO }\end{array}$ & 98 & 48 & 49 \\
\hline VARIANÇA & 0,29 & 0,50 & 0,38 \\
\hline $\begin{array}{l}\text { EFICIÊNCIA DE } \\
\text { REMOÇÃO [\%] }\end{array}$ & - & 71,4 & 61,9 \\
\hline
\end{tabular}


Como pode-se ver, a faixa de variação dos resultados do reator B é mais ampla, mas as concentrações médias foram menores.

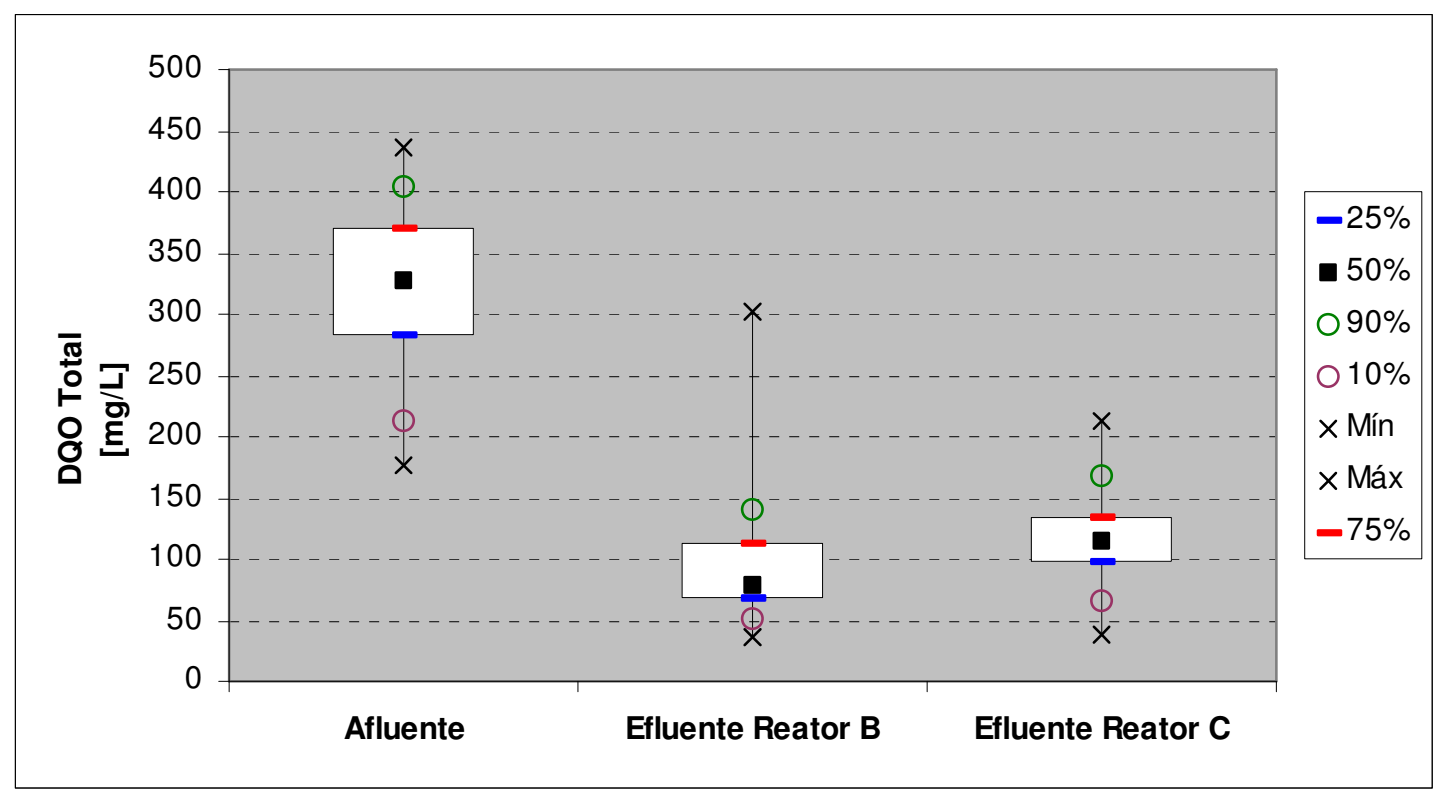

Figura 5.2 - DQO total da 1르 Fase: análise estatística

\subsubsection{DQO Filtrada}

Aqui foram realizadas 24 análises, mostradas no Capítulo 7. ANEXOS, na Tabela A.2. Da Figura 5.3 percebe-se que também não há diferenças expressivas na DQO filtrada dos efluentes dos reatores.

Assim como se vê na DQO total, as concentrações do efluente do reator B se apresentaram com uma contínua diferença para menor no final desta fase. Já a diferença entre os valores médios (50 e $64 \mathrm{mg} / \mathrm{L}$, para B e C) aqui foi também menor que os desvios padrões das distribuições (18 e $28 \mathrm{mg} / \mathrm{L}$, respectivamente).

Esses valores indicam que há uma pequena vantagem de remoção de matéria orgânica no reator B mas, diante das incertezas envolvidas nessas determinações, essa interpretação não se comprova com os números extraídos das determinações. 


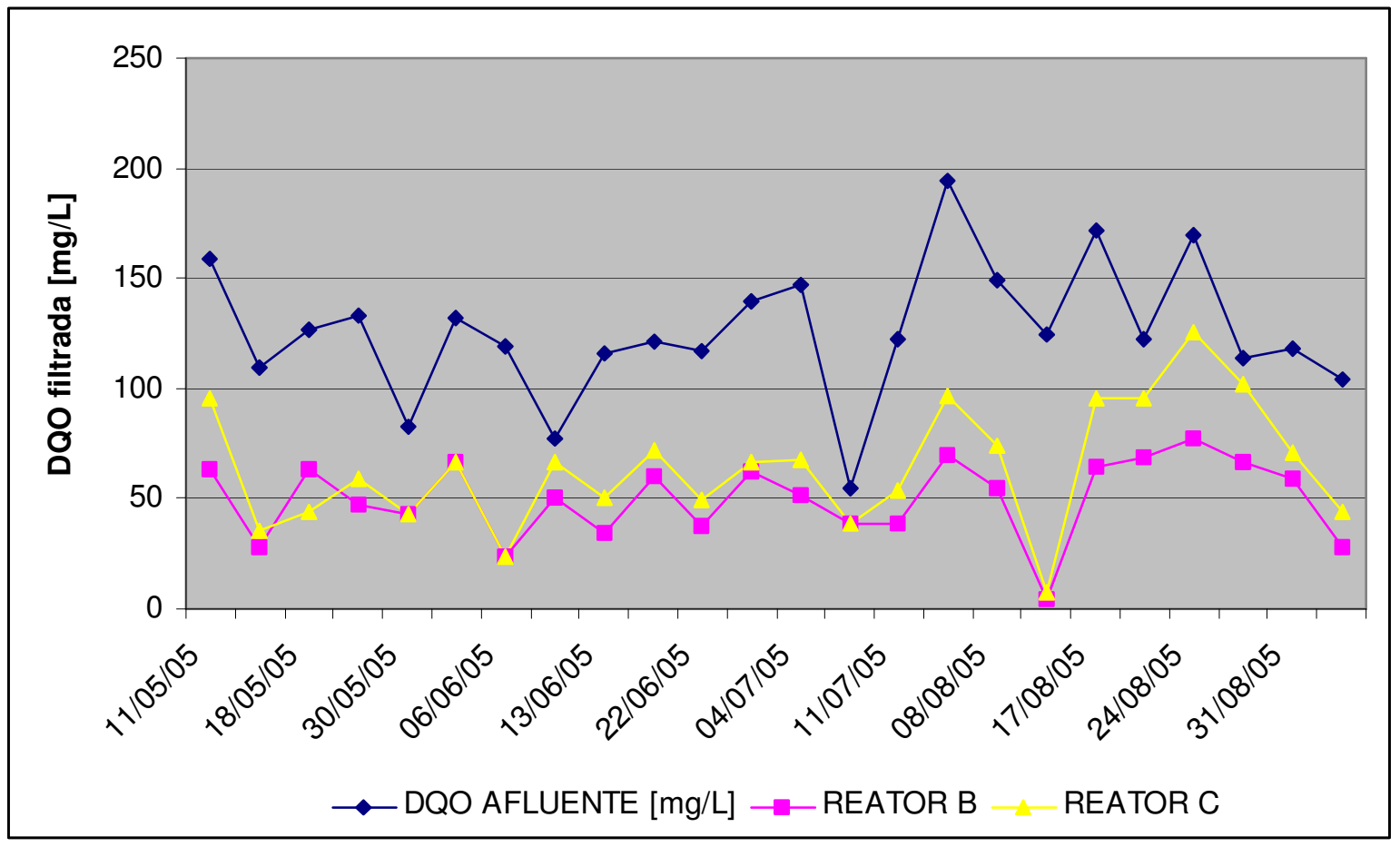

Figura 5.3 - Valores de DQO filtrada afluente e na saída dos reatores B e C: 1르 Fase

Pela análise da Tabela 5.2, chega-se que as eficiências de remoção foram melhores para o reator B $(60,3 \%$, contra $49,1 \%$ no reator C). A distribuição dos valores foi mais restrita para os valores do reator $\mathrm{B}$, refletida no menor número de seu desvio padrão (18 mg/L).

Tabela 5.2 - Índices estatísticos da DQO filtrada afluente e de saída nos reatores B e C: 1a Fase

\begin{tabular}{lccc}
\hline $\begin{array}{c}\text { PONTO DE } \\
\text { COLETA }\end{array}$ & ESGOTO BRUTO & $\begin{array}{c}\text { EFLUENTE } \\
\text { REATOR B }\end{array}$ & $\begin{array}{c}\text { EFLUENTE } \\
\text { REATOR C }\end{array}$ \\
\hline $\begin{array}{l}\text { VALOR MÉDIO } \\
\text { [mg/L] }\end{array}$ & 126 & 50 & 64 \\
\hline MÍNIMO [mg/L] & 54 & 4 & 8 \\
\hline MÁXIMO [mg/L] & 194 & 77 & 125 \\
\hline $\begin{array}{l}\text { DESVIO } \\
\text { PADRÃO }\end{array}$ & 31 & 18 & 28 \\
\hline VARIANÇA & 0,24 & 0,36 & 0,43 \\
\hline $\begin{array}{l}\text { EFICIÊNCIA DE } \\
\text { REMOÇÃO [\%] }\end{array}$ & - & 60,3 & 49,1 \\
\hline
\end{tabular}


Pelo estudo da Figura 5.4 pode-se ver que as distribuições dos dados de esgoto afluente e efluente do reator $C$ foram mais espalhadas, o que é confirmado pelos desvios padrão mais altos.

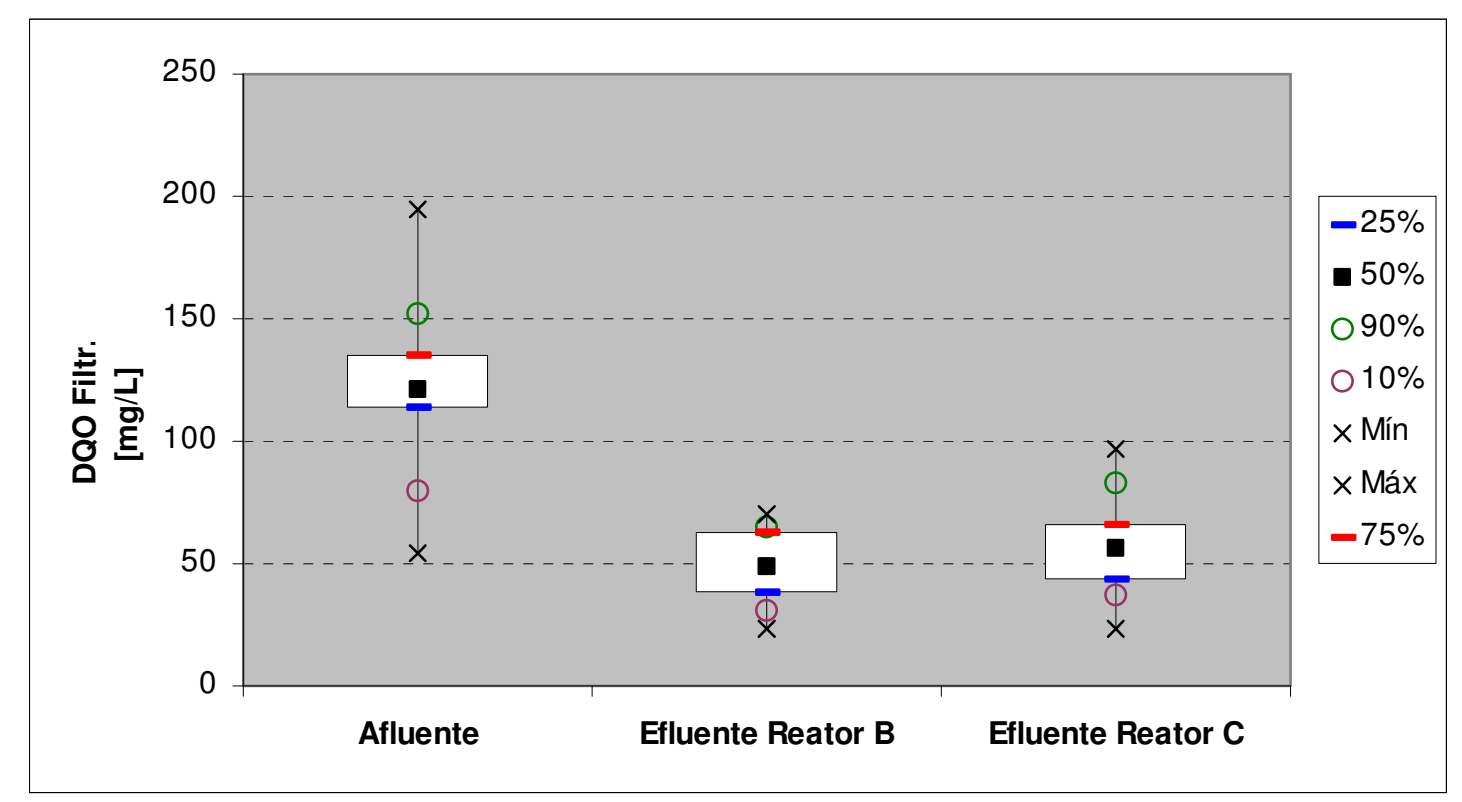

Figura 5.4 - DQO filtrada da 1ª Fase: análise estatística

\subsection{3. $\mathrm{DBO}_{5,20^{\circ} \mathrm{C}}$ Total}

Foram realizadas 8 análises, mostradas no Capítulo 7. ANEXOS, na Tabela A.3. Observando a Figura 5.5 pode-se concluir que as remoções nos 2 reatores são muito próximas. Mais uma vez é notada a característica de esgoto bruto fraco.

Os dois reatores apresentaram o mesmo desempenho, apesar do reduzido número de amostras. Os valores de entrada e saída obtidos no dia 01/06/05 indicam a capacidade de amortecimento das 2 unidades de tratamento, reduzindo-a de 514 $\mathrm{mg} / \mathrm{L}$ para menos de $100 \mathrm{mg} / \mathrm{L}$ no reator B (uma eficiência de $~ 80 \%$ ) e para uma concentração ainda menor no reator $\mathrm{C}$, sugerindo, para este ponto uma eficiência entre 90 e 95\%. Nos demais pontos vê-se uma alternância entre os tratamentos, sempre produzindo um efluente com $\mathrm{DBO}_{5,20^{\circ} \mathrm{C}}$ menor que $100 \mathrm{mg} / \mathrm{L}$. 
As médias obtidas estão apresentadas na Tabela 5.3, com os respectivos dados estatísticos dessa amostragem. Na Figura 5.6 estão as representações gráficas dessa distribuição.

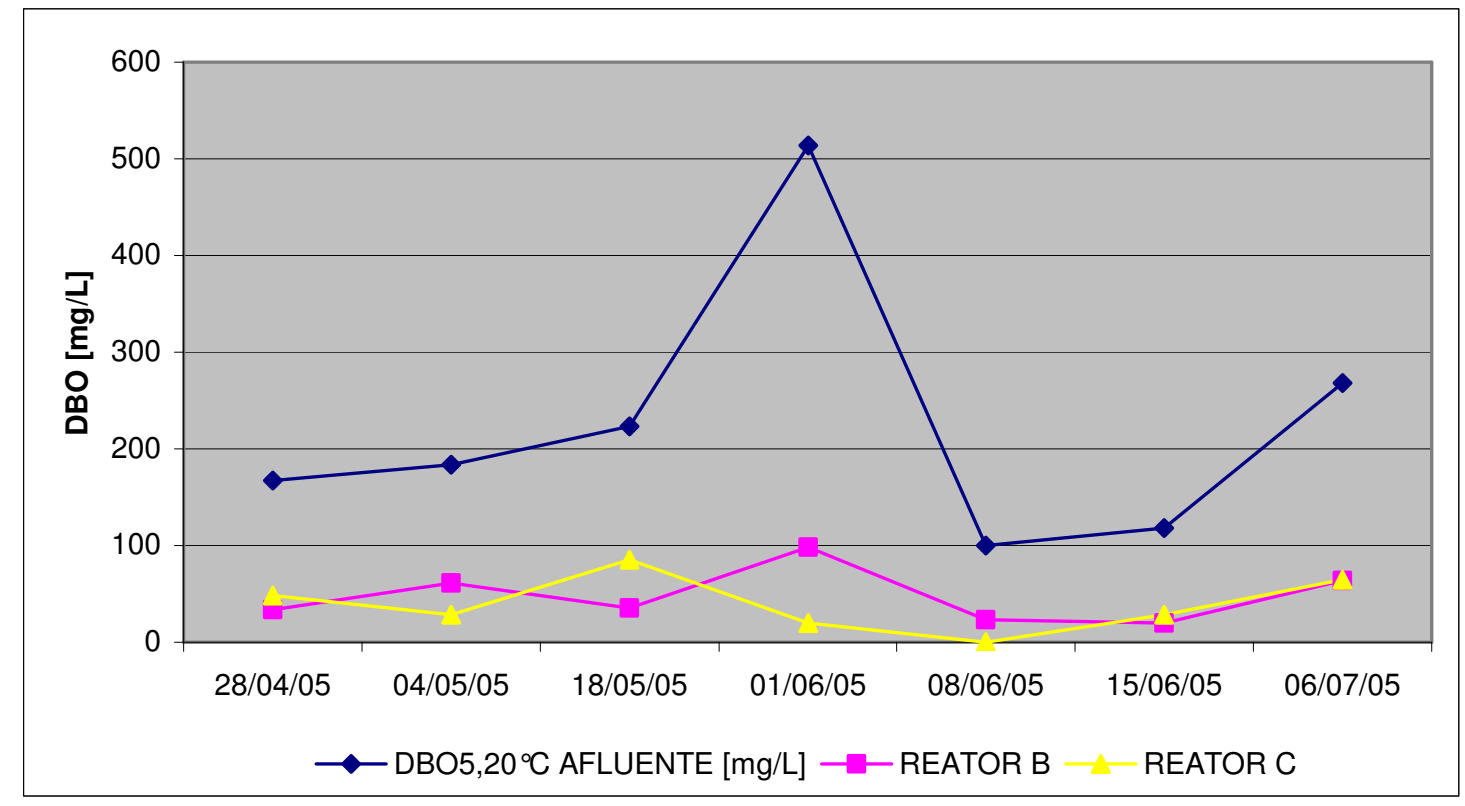

Figura 5.5 - Valores de $\mathrm{DBO}_{5,20^{\circ} \mathrm{C}}$ total afluente e na saída dos reatores $\mathrm{B}$ e C: $1^{\text {a }}$ Fase

Ao observar a Tabela 5.3, identifica-se a similaridade dos dois reatores, que tiveram os mesmos valores médios de concentração de matéria orgânica em seus efluentes. Padrão de Emissão (60 mg/L) é, na maior parte do tempo, atendido.

Tabela 5.3 - Índices estatísticos da $\mathrm{DBO}_{5,20^{\circ} \mathrm{C}}$ total afluente e de saída nos reatores $\mathrm{B}$ e C: 1ํ $^{\mathrm{a}}$ Fase

\begin{tabular}{lccc}
\hline $\begin{array}{c}\text { PONTO DE } \\
\text { COLETA }\end{array}$ & ESGOTO BRUTO & $\begin{array}{c}\text { EFLUENTE } \\
\text { REATOR B }\end{array}$ & $\begin{array}{c}\text { EFLUENTE } \\
\text { REATOR C }\end{array}$ \\
\hline $\begin{array}{l}\text { VALOR MÉDIO } \\
\text { [mg/L] }\end{array}$ & 225 & 48 & 48 \\
\hline MíNIMO [mg/L] & 100 & 20 & 28 \\
\hline MÁXIMO [mg/L] & 514 & 98 & 85 \\
\hline $\begin{array}{l}\text { DESVIO } \\
\text { PADRÃO }\end{array}$ & 140 & 28 & 20 \\
\hline VARIANÇA & 0,62 & 0,59 & 0,42 \\
\hline $\begin{array}{l}\text { EFICIÊNCIA DE } \\
\text { REMOÇÃO [\%] }\end{array}$ & - & 78,7 & 78,6 \\
\hline
\end{tabular}


A Figura 5.6 dá uma visão da baixa dispersão dos valores de concentrações efluentes.

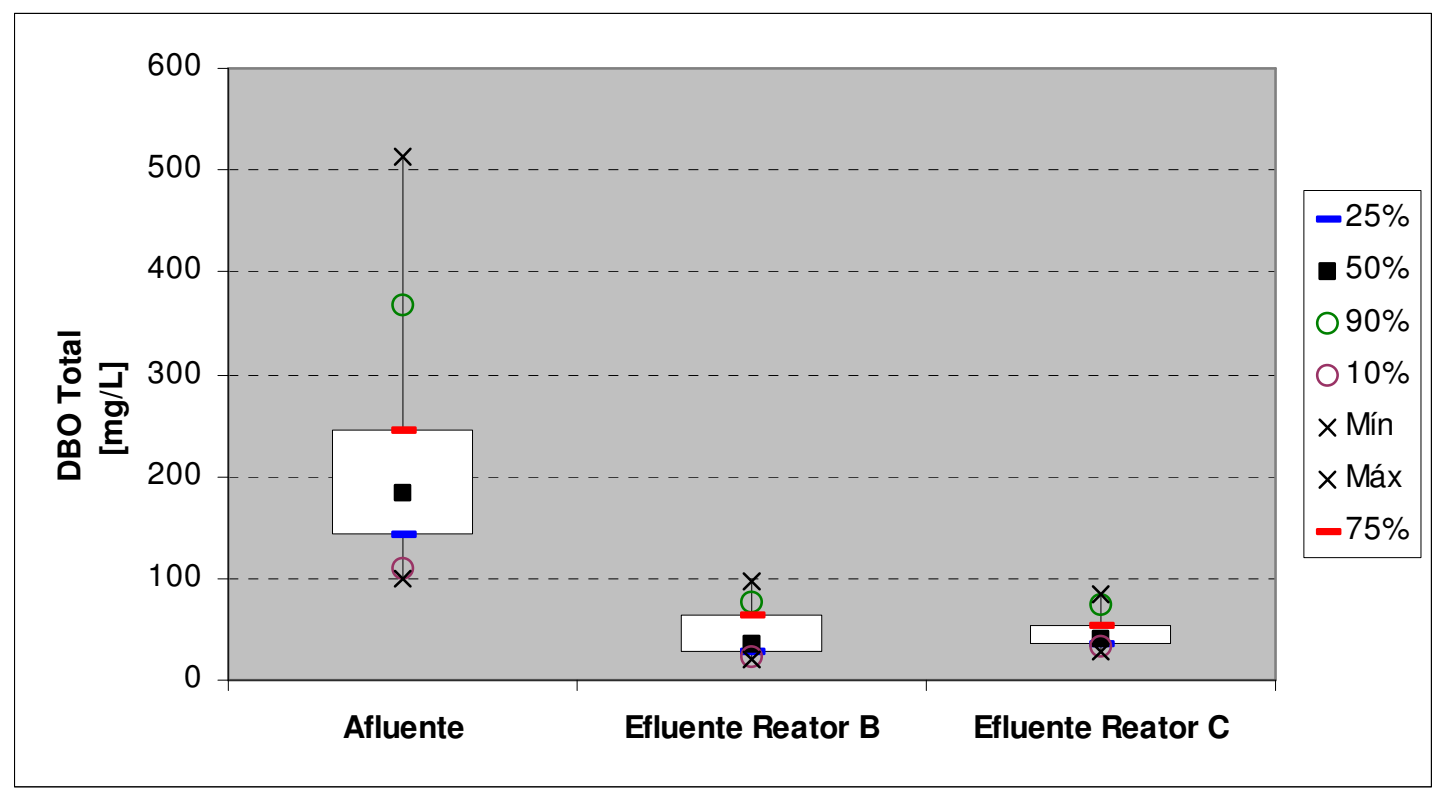

Figura $5.6-\mathrm{DBO}_{5,20^{\circ} \mathrm{C}}$ total da $1^{\mathrm{a}}$ Fase: análise estatística

\subsection{4. $\mathrm{DBO}_{5,20^{\circ} \mathrm{C}}$ Filtrada}

Foram realizadas 5 análises, listadas no Capítulo 7. ANEXOS, na Tabela A.4. Na Figura 5.7 estão apresentados os valores de carga orgânica afluentes e das saídas dos 2 reatores, estas últimas, muito próximas.

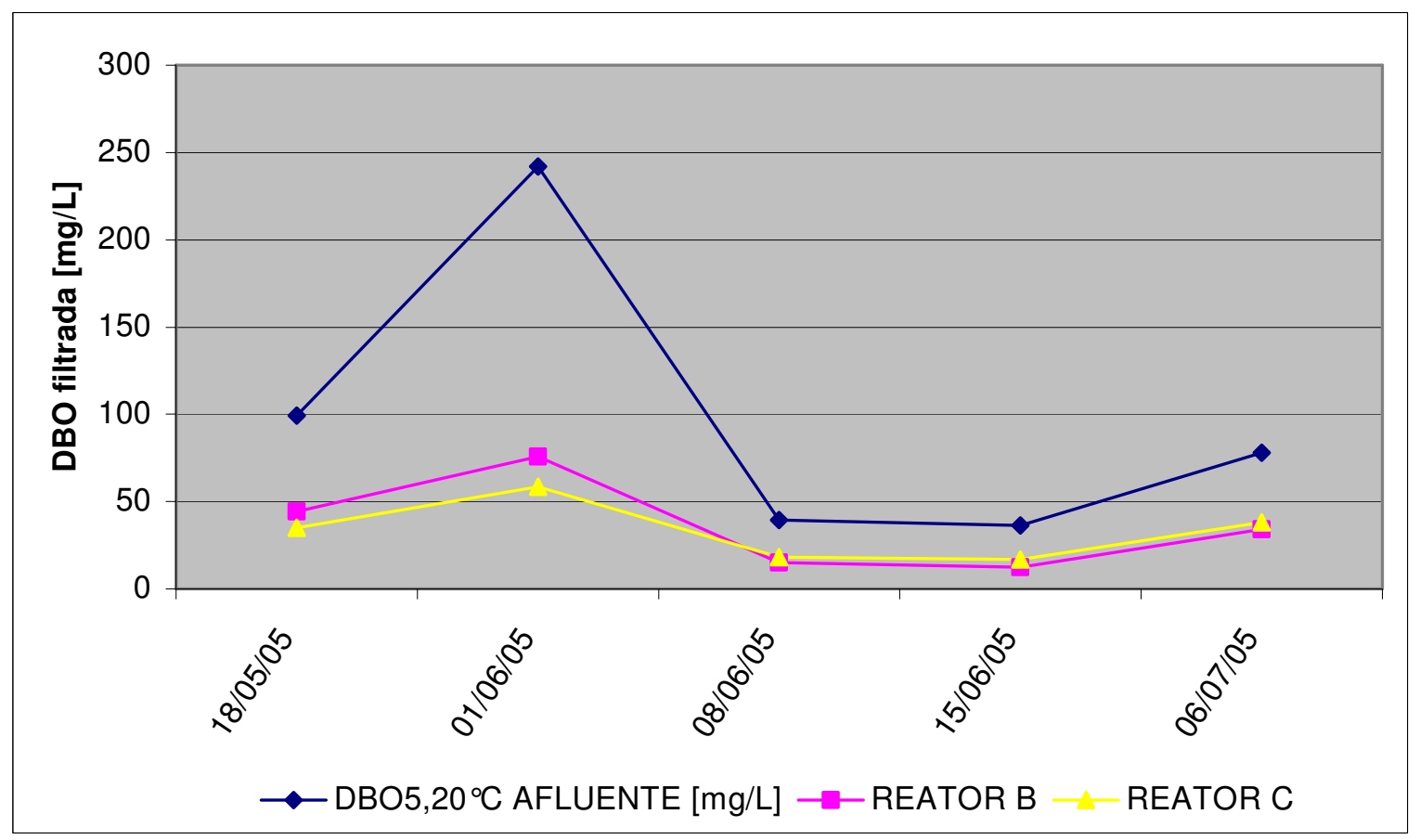

Figura 5.7 - Valores de $\mathrm{DBO}_{5,20^{\circ} \mathrm{C}}$ filtrada afluente e na saída dos reatores $\mathrm{B}$ e C: $1^{\underline{a}}$ Fase 
É possível visualizar que as 2 saídas fornecem concentrações muito parecidas e que acompanham, de forma amortecida, as variações do esgoto afluente.

As médias estão mostradas na Tabela 5.4, com os respectivos dados estatísticos da amostragem. Como se vê, os valores médios (reator B com $36 \mathrm{mg} / \mathrm{L}$ e retor $\mathrm{C}$ com $33 \mathrm{mg} / \mathrm{L}$ ) são bastante próximos, assim como os desvios padrão correspondentes.

Tabela 5.4 - Índices estatísticos da $\mathrm{DBO}_{5,20^{\circ} \mathrm{C}}$ filtrada afluente e de saída nos reatores $\mathrm{B}$ e C: 1ํㅡㄹ $^{\text {a }}$ Fase

\begin{tabular}{lccc}
\hline $\begin{array}{c}\text { PONTO DE } \\
\text { COLETA }\end{array}$ & ESGOTO BRUTO & $\begin{array}{c}\text { EFLUENTE } \\
\text { REATOR B }\end{array}$ & $\begin{array}{c}\text { EFLUENTE } \\
\text { REATOR C }\end{array}$ \\
\hline $\begin{array}{l}\text { VALOR MÉDIO } \\
\text { [mg/L] }\end{array}$ & 99 & 36 & 33 \\
\hline MÍNIMO [mg/L] & 36 & 12 & 17 \\
\hline MÁXIMO [mg/L] & 242 & 76 & 58 \\
\hline $\begin{array}{l}\text { DESVIO } \\
\text { PADRÃO }\end{array}$ & 84 & 26 & 17 \\
\hline VARIANÇA & 0,85 & 0,71 & 0,51 \\
\hline $\begin{array}{l}\text { EFICIÊNCIA DE } \\
\text { REMOÇÃO [\%] }\end{array}$ & - & 63,4 & 66,3 \\
\hline
\end{tabular}

Na Figura 5.8 estão as representações gráficas dessa análise estatística, aonde se verifica uma repetição do comportamento das distribuições de $\mathrm{DBO}_{5,20^{\circ} \mathrm{C}}$ total.

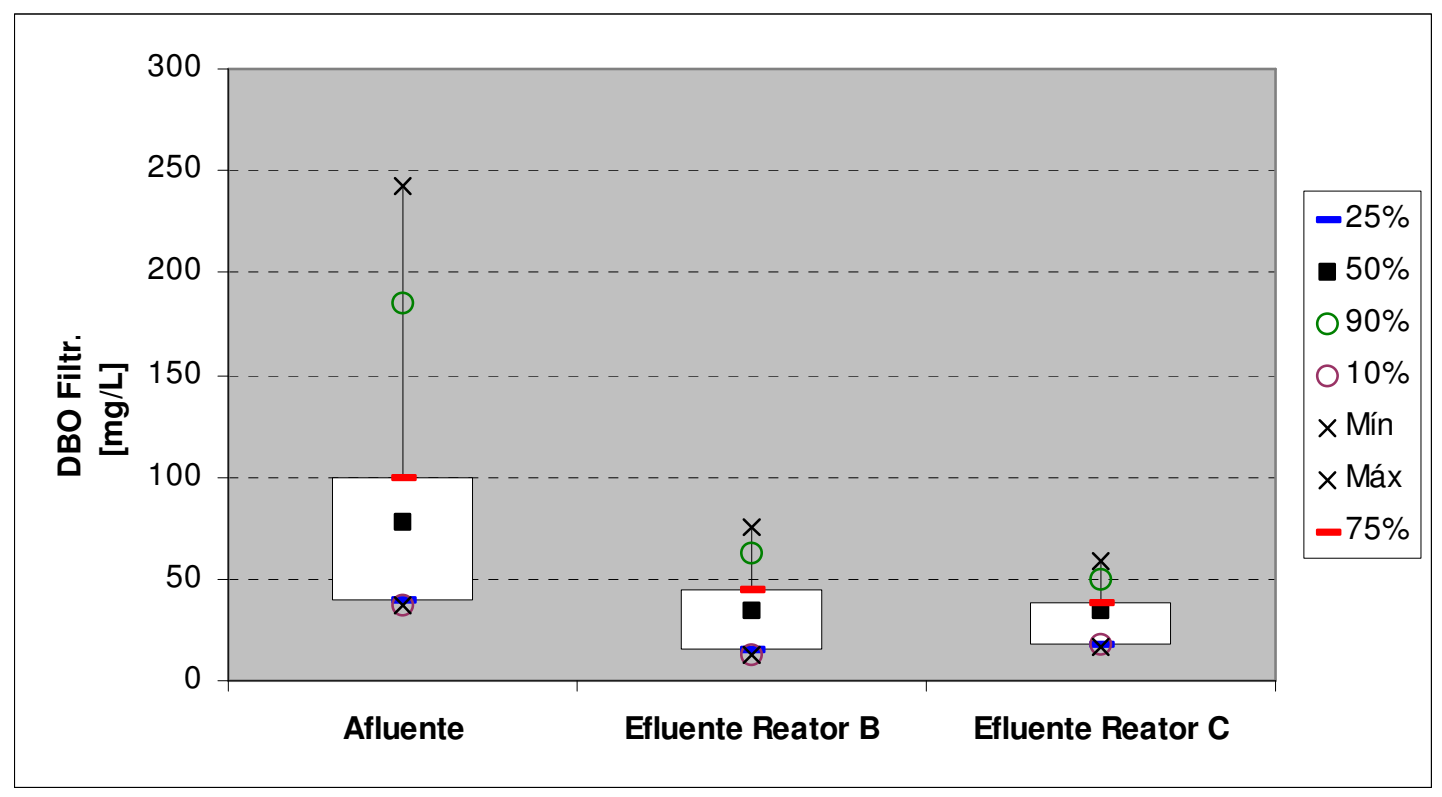

Figura 5.8 $-\mathrm{DBO}_{5,20^{\circ} \mathrm{C}}$ filtrada da $1^{\mathrm{a}}$ Fase: análise estatística 


\subsubsection{Fósforo Total}

Foram realizadas apenas 2 análises, listadas no Capítulo 7. ANEXOS, na Tabela A.5. Na Tabela 5.5 estão os valores médios de fósforo total afluentes e das saídas dos 2 reatores.

Tabela 5.5 - Índices estatísticos do Fósforo total afluente e de saída nos reatores B e C: $1^{\text {a }}$ Fase

\begin{tabular}{lccc}
\hline $\begin{array}{c}\text { PONTO DE } \\
\text { COLETA }\end{array}$ & ESGOTO BRUTO & $\begin{array}{c}\text { EFLUENTE } \\
\text { REATOR B }\end{array}$ & $\begin{array}{c}\text { EFLUENTE } \\
\text { REATOR C }\end{array}$ \\
\hline $\begin{array}{l}\text { VALOR MÉDIO } \\
\text { [mg/L] }\end{array}$ & 4,2 & 1,7 & 2,2 \\
\hline MÍNIMO [mg/L] & 3,6 & 0,9 & 1,7 \\
\hline MÁXIMO [mg/L] & 4,7 & 2,5 & 2,6 \\
\hline $\begin{array}{l}\text { DESVIO } \\
\text { PADRÃO }\end{array}$ & 0,8 & 1,1 & 0,6 \\
\hline VARIANÇA & 0,19 & 0,67 & 0,30 \\
\hline $\begin{array}{l}\text { EFICIÊNCIA DE } \\
\text { REMOÇÃO [\%] }\end{array}$ & - & 59,0 & 48,2 \\
\hline
\end{tabular}

\subsubsection{Ortofosfatos}

Nesta etapa foram feitas 29 análises, indicadas no Capítulo 7. ANEXOS, na Tabela A.6. Na Figura 5.9 vê-se a proximidade nos valores de concentração de ortofosfatos nos efluentes dos 2 reatores estudados. Percebe-se ainda que, na prática, não há remoção.

Os valores representados pelo diagrama ilustram a alternância de desempenho dos 2 tratamentos e também do esgoto bruto, que em muitas oportunidades foi mais baixo que as saídas, decorrente da baixa eficiência de remoção dos sistemas e das defasagens causadas pelo tempo de detenção hidráulico (o valor obtido no efluente é resultado da concentração do esgoto bruto de 11 horas antes). 


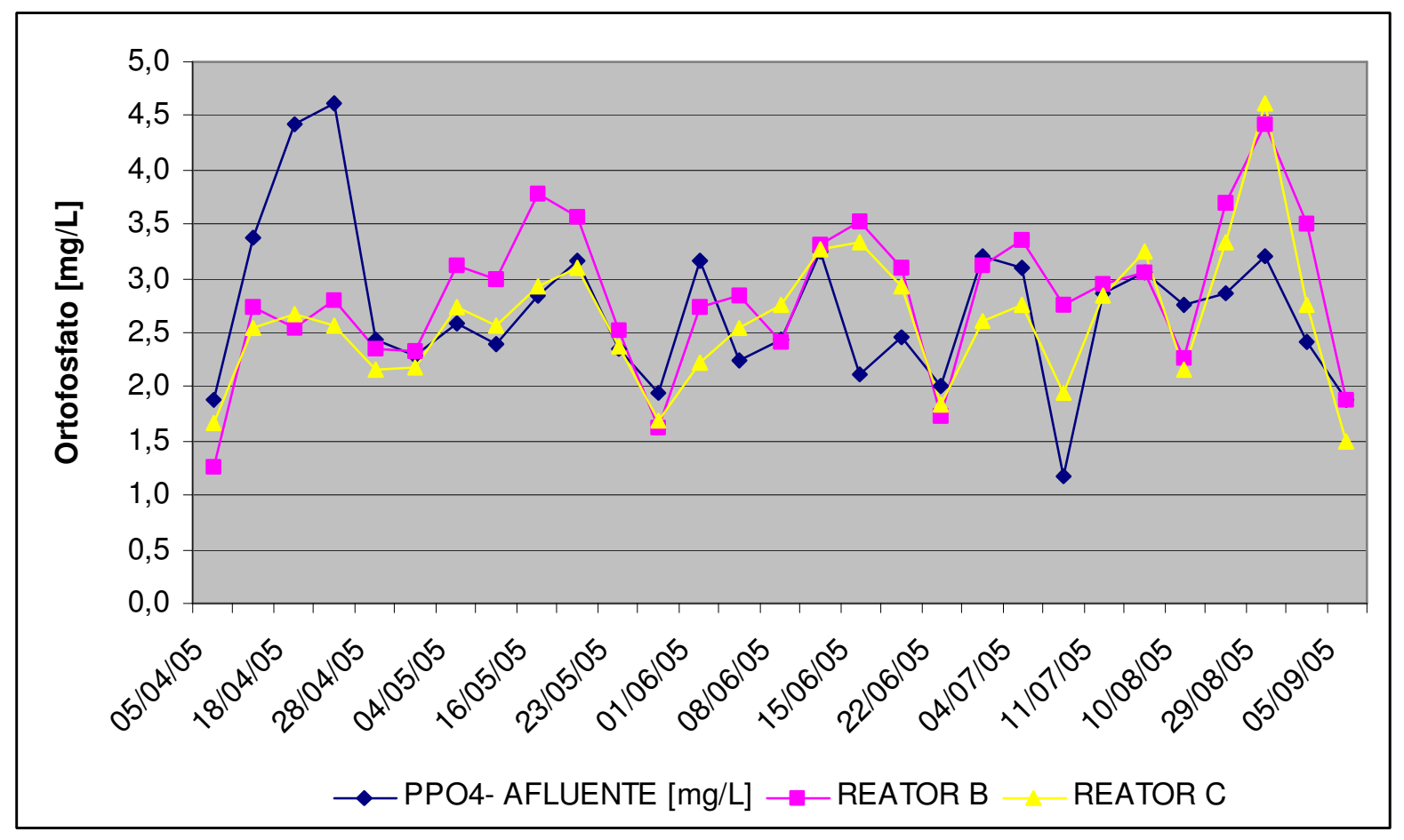

Figura 5.9 - Valores de concentração de ortofosfatos afluente e na saída dos reatores B e C: 1르 Fase

Os valores médios estão apresentados na Tabela 5.6, com os dados estatísticos dessa amostragem. A comparação das médias são a melhor indicação de que não havia vantagem entre os reatores nem também, na prática, qualquer remoção.

Tabela 5.6 - Índices estatísticos de ortofosfatos afluente e de saída nos reatores B e C: $1^{\underline{a}}$ Fase

\begin{tabular}{lccc}
\hline \multicolumn{1}{c}{$\begin{array}{c}\text { PONTO DE } \\
\text { COLETA }\end{array}$} & ESGOTO BRUTO & $\begin{array}{c}\text { EFLUENTE } \\
\text { REATOR B }\end{array}$ & $\begin{array}{c}\text { EFLUENTE } \\
\text { REATOR C }\end{array}$ \\
\hline $\begin{array}{l}\text { VALOR MÉDIO } \\
\text { [mg/L] }\end{array}$ & 2,7 & 2,8 & 2,6 \\
\hline MÍNIMO [mg/L] & 1,2 & 1,3 & 1,5 \\
\hline MÁXIMO [mg/L] & 4,6 & 4,4 & 4,6 \\
\hline $\begin{array}{l}\text { DESVIO } \\
\text { PADRÃO }\end{array}$ & 0,7 & 0,7 & 0,6 \\
\hline VARIANÇA & 0,27 & 0,25 & 0,24 \\
\hline $\begin{array}{l}\text { EFICIÊNCIA DE } \\
\text { REMOÇÃO [\%] }\end{array}$ & - & - & 3,4 \\
\hline
\end{tabular}

Na Figura 5.10 estão os gráficos da análise estatística. Nota-se o espalhamento semelhante das 3 amostragens e da inexistente diferença dos desempenhos. 


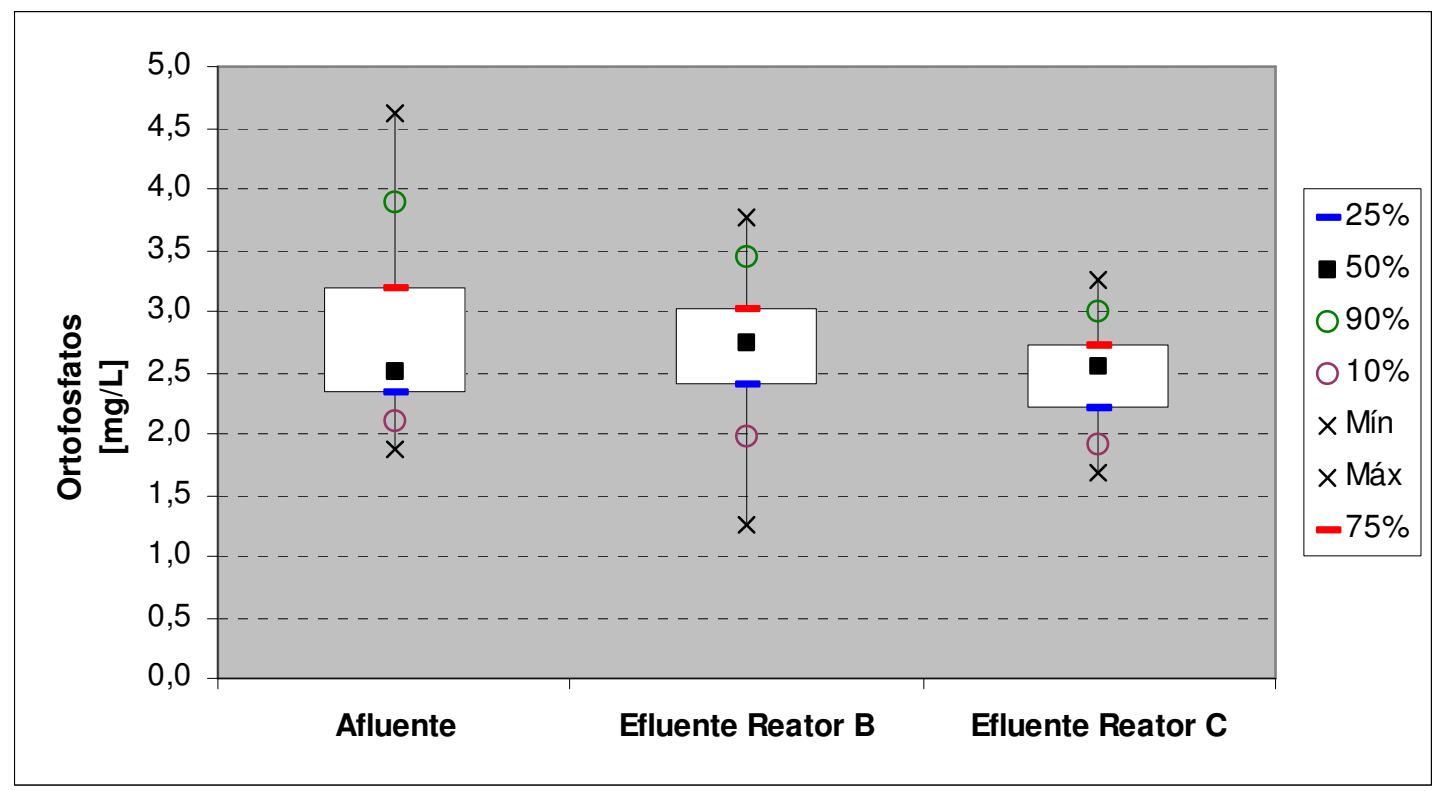

Figura 5.10 - Ortofosfatos da 1ª Fase: análise estatística

\subsubsection{Sulfetos}

Foram realizadas somente 3 análises, indicadas no Capítulo 7. ANEXOS, na Tabela A.7. Os valores médios estão apresentados na Tabela 5.7, com os dados estatísticos dessa amostragem. Aqui também se tem uma grande similaridade entre os reatores, com as concentrações médias de $3,1 \mathrm{mg} / \mathrm{L}$ e 2,7 mg/L para os reatores B e C, respectivamente.

Tabela 5.7 - Índices estatísticos da concentração de sulfetos nas saídas dos reatores B e C: $1^{1}$ Fase

\begin{tabular}{lccc}
\hline \multicolumn{1}{c}{$\begin{array}{c}\text { PONTO DE } \\
\text { COLETA }\end{array}$} & ESGOTO BRUTO & $\begin{array}{c}\text { EFLUENTE } \\
\text { REATOR B }\end{array}$ & $\begin{array}{c}\text { EFLUENTE } \\
\text { REATOR C }\end{array}$ \\
\hline $\begin{array}{l}\text { VALOR MÉDIO } \\
\text { [mg/L] }\end{array}$ & - & 3,1 & 2,7 \\
\hline MÍNIMO [mg/L] & - & 1,6 & 1,7 \\
\hline MÁXIMO [mg/L] & - & 4,7 & 3,8 \\
\hline $\begin{array}{l}\text { DESVIO } \\
\text { PADRÃO }\end{array}$ & - & 1,5 & 1,1 \\
\hline VARIANÇA & - & 0,51 & 0,39 \\
\hline EFICIÊNCIA DE & - & - & - \\
REMOÇÃO [\%] & & & \\
\hline
\end{tabular}




\subsubsection{Sólidos Totais}

Para este parâmetro foram feitas 20 análises, mostradas no Capítulo 7. ANEXOS, na Tabela A.8. Na Figura 5.11 observa-se a pouca diferença dos valores de sólidos nos efluentes dos 2 reatores estudados.

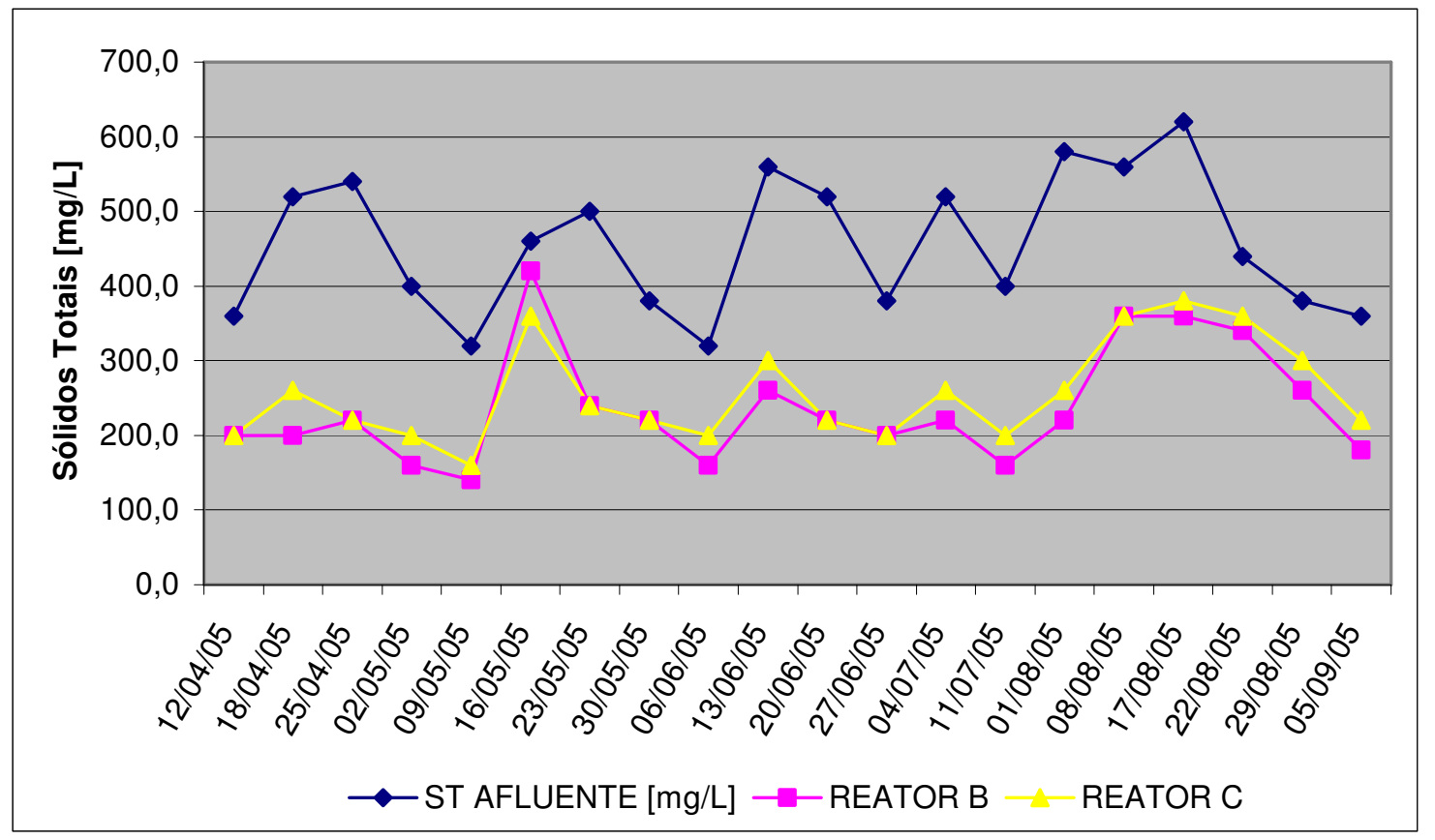

Figura 5.11 - Valores de sólidos totais afluentes e na saída dos reatores B e C: $1{ }^{\text {a }}$ Fase

As concentrações de ambos reatores variaram igualmente, acompanhando as variações da entrada.

Tabela 5.6 - Índices estatísticos de sólidos totais afluente e de saída nos reatores B e C: 1a Fase

\begin{tabular}{lccc}
\hline $\begin{array}{c}\text { PONTO DE } \\
\text { COLETA }\end{array}$ & ESGOTO BRUTO & $\begin{array}{c}\text { EFLUENTE } \\
\text { REATOR B }\end{array}$ & $\begin{array}{c}\text { EFLUENTE } \\
\text { REATOR C }\end{array}$ \\
\hline $\begin{array}{l}\text { VALOR MÉDIO } \\
\text { [mg/L] }\end{array}$ & 456,0 & 237,0 & 256,0 \\
\hline MíNIMO [mg/L] & 320,0 & 140,0 & 160,0 \\
\hline MÁXIMO [mg/L] & 620,0 & 420,0 & 380,0 \\
\hline $\begin{array}{l}\text { DESVIO } \\
\text { PADRÃO }\end{array}$ & 93,0 & 76,6 & 65,7 \\
\hline VARIANÇA & 0,20 & 0,32 & 0,26 \\
\hline $\begin{array}{l}\text { EFICIÊNCIA DE } \\
\text { REMOÇÃO [\%] }\end{array}$ & - & 48,0 & 43,9 \\
\hline
\end{tabular}


Na Figura 5.12 mostram-se os gráficos dessa análise estatística. Os valores médios estão apresentados na Tabela 5.8, com os dados estatísticos da amostragem.

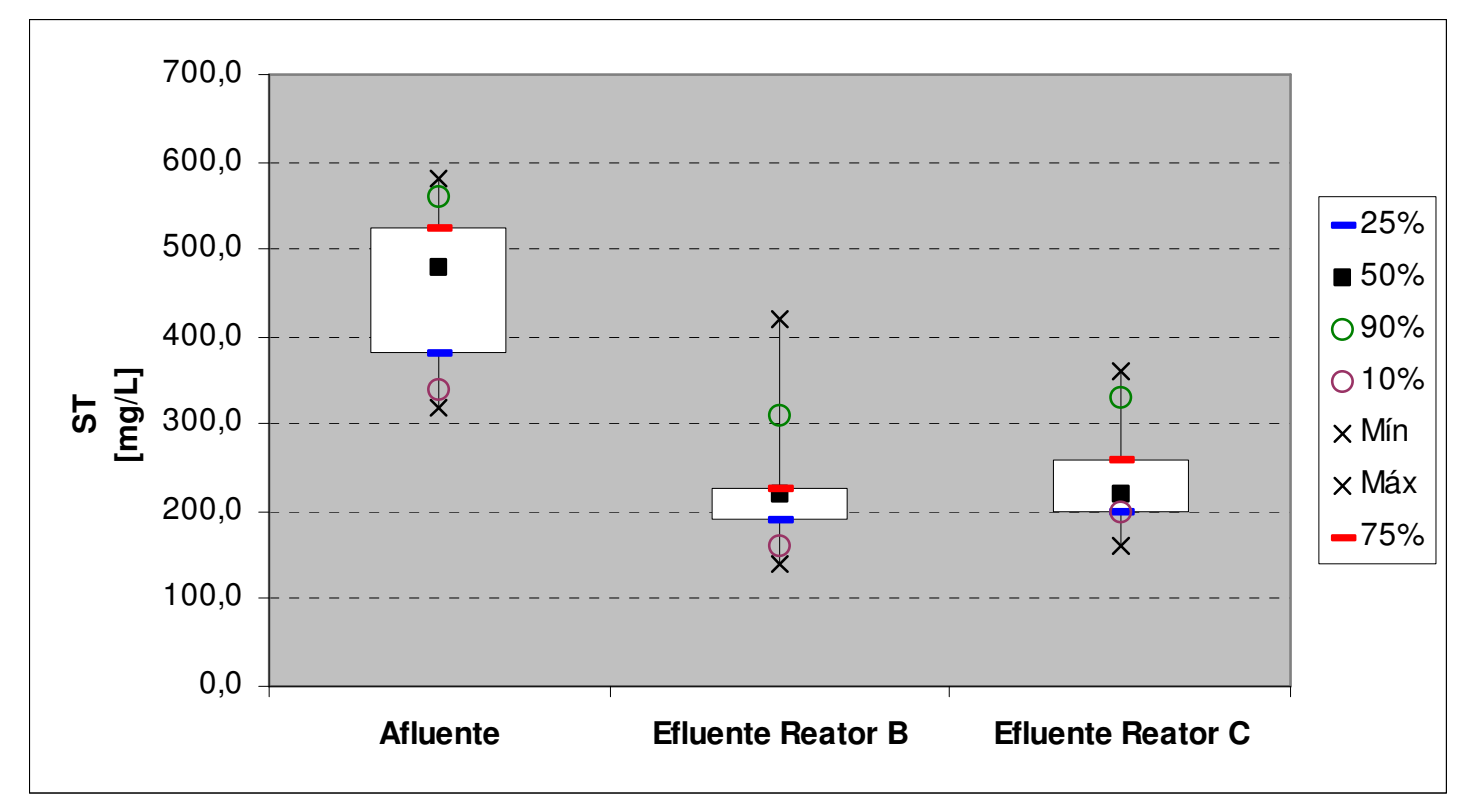

Figura 5.12 - Sólidos totais da 1ํㅡㄹ Fase: análise estatística

\subsubsection{Sólidos Suspensos Totais}

Nesta etapa foram executadas 22 análises, mostradas no Capítulo 7. ANEXOS, na Tabela A.11. Na Figura 5.13 observa-se a pequena diferença dos valores de sólidos nos efluentes dos 2 reatores estudados, com uma pouco pronunciada vantagem do reator $\mathrm{B}$.

Novamente, o aumento desse parâmetro na entrada repercute num maior valor nas saídas das unidades de tratamento. Em 16/05/05 e 20/06/05 ocorreram desequilíbrios, expressados pelas altas concentrações obtidas nos efluentes dos dois reatores.

Em média, conclui-se uma redução de cerca de 150 mg/L nos 2 reatores. 


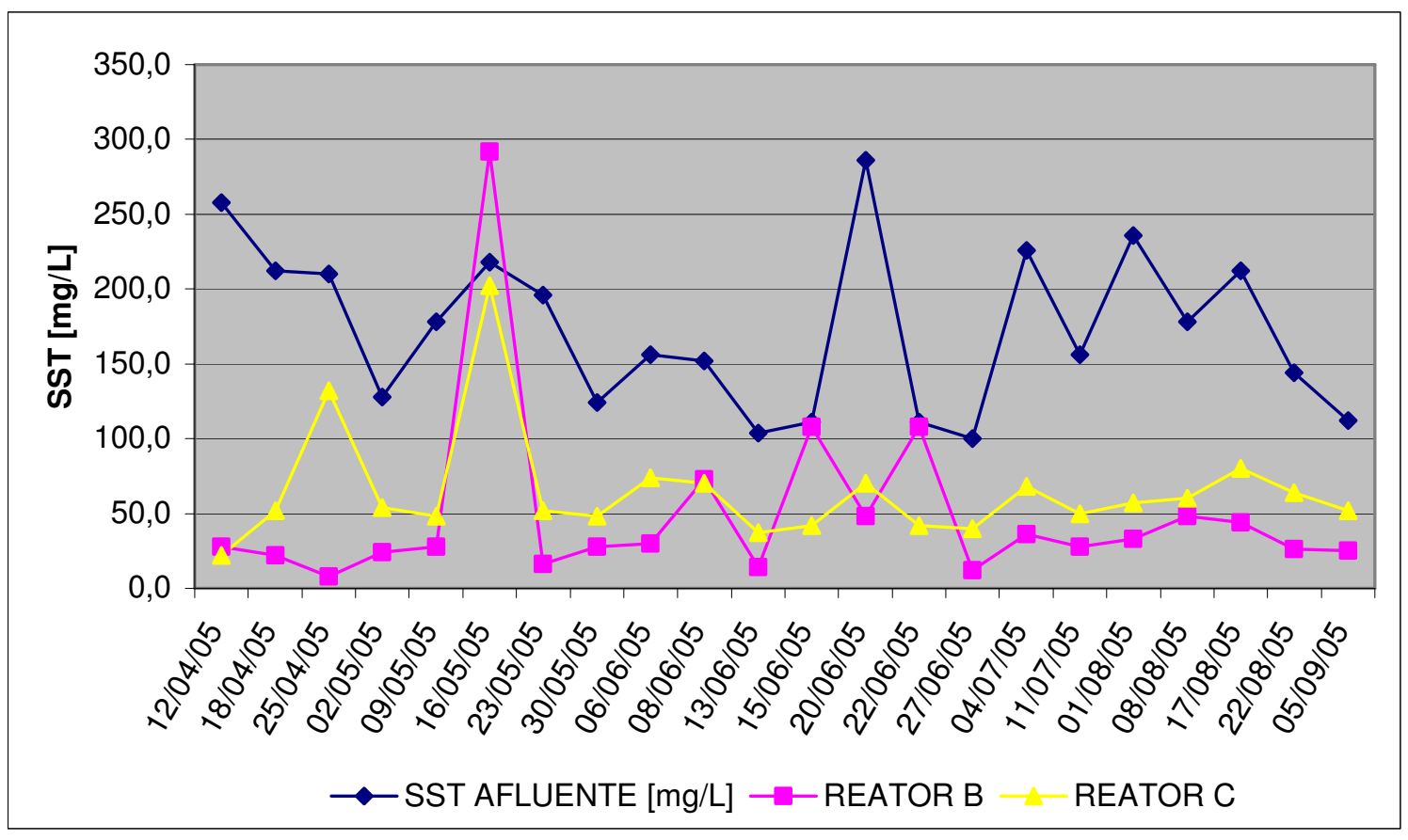

Figura 5.13 - Valores de sólidos suspensos totais afluentes e na saída dos reatores B e C: 1ª Fase

Os valores médios estão apresentados na Tabela 5.9, com os dados estatísticos dessa amostragem. Na Figura 5.14 mostram-se os gráficos dessa análise estatística. A média do reator $\mathrm{B}$ é inferior à do reator $\mathrm{C}$, coincidindo com a leve melhor eficiência do reator $B$.

\begin{tabular}{|c|c|c|c|}
\hline $\begin{array}{l}\text { PONTO DE } \\
\text { COLETA }\end{array}$ & ESGOTO BRUTO & $\begin{array}{l}\text { EFLUENTE } \\
\text { REATOR B }\end{array}$ & $\begin{array}{l}\text { EFLUENTE } \\
\text { REATOR C }\end{array}$ \\
\hline $\begin{array}{l}\text { VALOR MÉDIO } \\
\text { [mg/L] }\end{array}$ & 173,1 & 49,0 & 64,4 \\
\hline MÍNIMO [mg/L] & 100,0 & 8,0 & 22,0 \\
\hline MÁXIMO [mg/L] & 286,0 & 292,0 & 202,0 \\
\hline $\begin{array}{l}\text { DESVIO } \\
\text { PADRÃO }\end{array}$ & 54,1 & 60,5 & 37,4 \\
\hline VARIANÇA & 0,31 & 1,23 & 0,58 \\
\hline $\begin{array}{l}\text { EFICIÊNCIA DE } \\
\text { REMOÇÃO [\%] }\end{array}$ & - & 71,7 & 62,8 \\
\hline
\end{tabular}

$\mathrm{Na}$ Figura 5.14 percebe-se que houve grande variação dessas concentrações, ocupando uma faixa de $\sim 300 \mathrm{mg} / \mathrm{L}$ para o reator $\mathrm{B}$, fato refletido no desvio padrão 
dessa amostragem, maior que as demais, implicando em uma dificuldade maior para se concluir a respeito de sua comparação com o outro reator estudado.

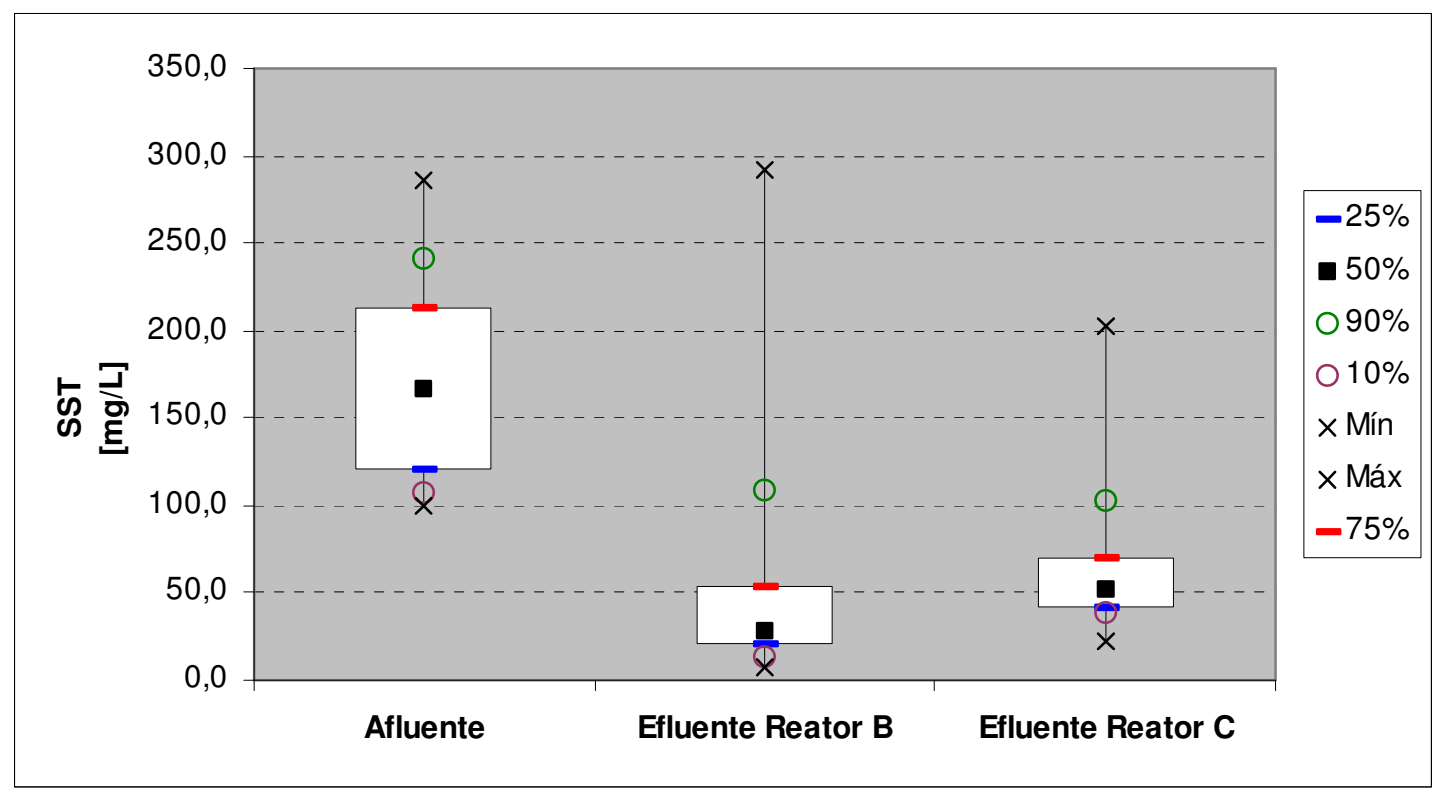

Figura 5.14 - Sólidos suspensos totais da $1^{\text {a }}$ Fase: análise estatística

\subsubsection{Sólidos Suspensos Voláteis}

Nesta etapa foram executadas 23 análises, mostradas no Capítulo 7. ANEXOS, na Tabela A.13.

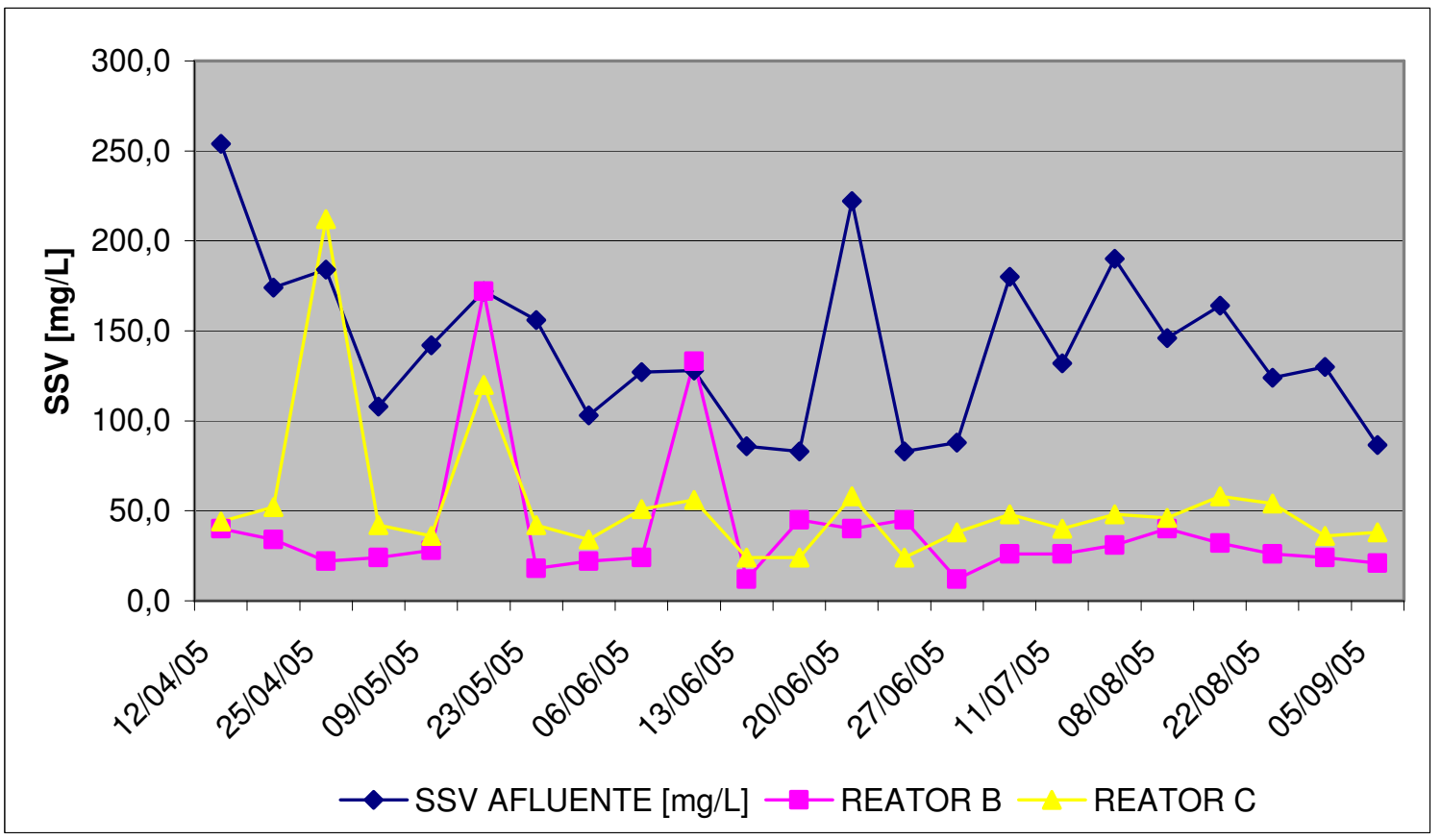

Figura 5.15 - Valores de sólidos suspensos voláteis afluentes e na saída dos reatores B e C: 1르 Fase 
Na Figura 5.15 observa-se que, com a exceção de 2 ocasiões, não houve diferença significativa dos valores de SSV nos efluentes dos 2 reatores estudados.Numa das amostras, quando houve uma carga mais elevada na entrada, o reator $\mathrm{C}$ não teve boa eficiência, enquanto que em outras duas oportunidades, essa característica foi apresentada pelo reator $\mathrm{B}$.

Tabela 5.10 - Índices estatísticos de SSV afluente e de saída nos reatores B e C: 1aㅡ Fase

\begin{tabular}{lccc}
\hline $\begin{array}{c}\text { PONTO DE } \\
\text { COLETA }\end{array}$ & ESGOTO BRUTO & $\begin{array}{c}\text { EFLUENTE } \\
\text { REATOR B }\end{array}$ & $\begin{array}{c}\text { EFLUENTE } \\
\text { REATOR C }\end{array}$ \\
\hline $\begin{array}{l}\text { VALOR MÉDIO } \\
\text { [mg/L] }\end{array}$ & 141,9 & 39,0 & 53,3 \\
\hline MíNIMO [mg/L] & 83,0 & 12,0 & 24,0 \\
\hline MÁXIMO [mg/L] & 254,0 & 172,0 & 212,0 \\
\hline $\begin{array}{l}\text { DESVIO } \\
\text { PADRÃO }\end{array}$ & 46,1 & 37,4 & 39,5 \\
\hline VARIANÇA & 0,33 & 0,96 & 0,74 \\
\hline EFICIÊNCIA DE & - & 72,5 & 62,5 \\
REMOÇÃO [\%] & & &
\end{tabular}

Os valores médios estão apresentados na Tabela 5.10, com os dados estatísticos dessa amostragem. A Figura 5.16 mostra os gráficos estatísticos. Os desvios padrão das 3 amostragens foram muito próximos, enquanto as médias indicaram melhor retenção no reator $B(39,0 \mathrm{mg} / \mathrm{L}$, contra $53,3 \mathrm{mg} / \mathrm{L}$ do reator $\mathrm{C})$.

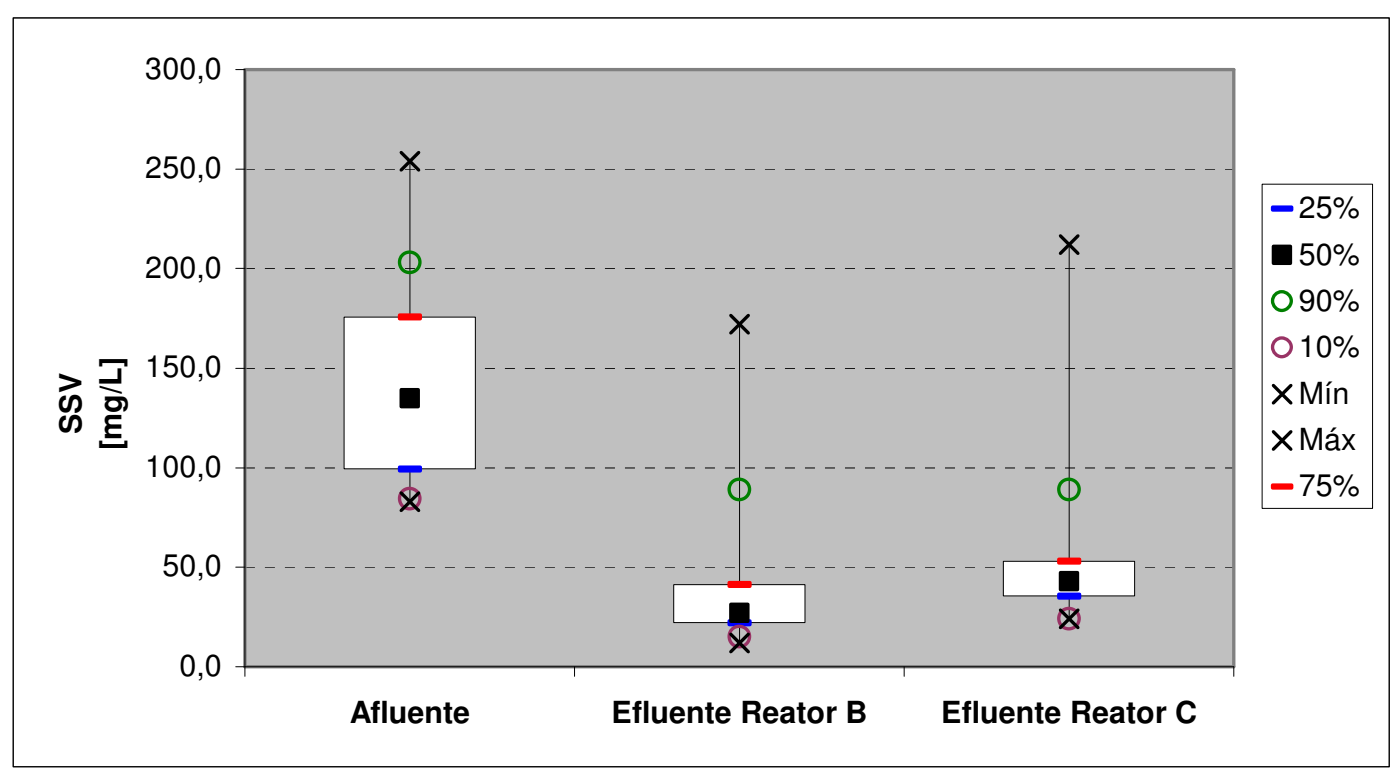

Figura 5.16 - Sólidos suspensos voláteis da 1ํㅡㄹ Fase: análise estatística 


\subsubsection{Sólidos Sedimentáveis}

Para este parâmetro eram feitas análises semanais, num total de 20 , mostradas no Capítulo 7. ANEXOS, na Tabela A.14. Na Figura 5.17 tem-se a evolução dos resultados nos 4 meses de avaliação, sendo que os valores nos efluentes dos 2 reatores sempre estiveram próximos a 0 (zero $\mathrm{mL} / \mathrm{L}$ ).

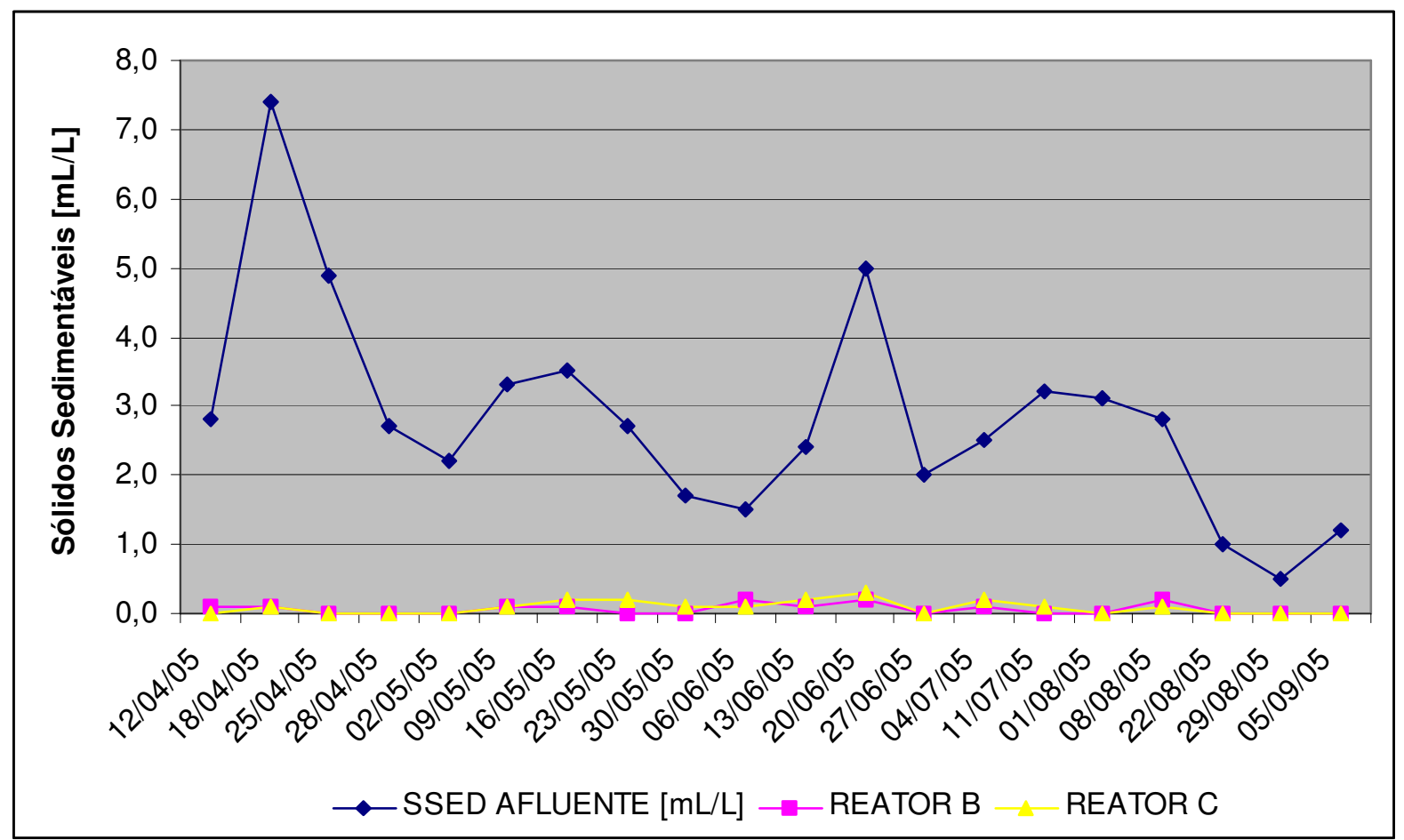

Figura 5.16 - Valores de sólidos sedimentáveis afluentes e na saída dos reatores B e C: $1^{\text {a }}$ Fase

Os valores médios estão apresentados na Tabela 5.11, aonde se tem ainda os dados estatísticos dessa amostragem. Os sólidos sedimentáveis variaram, para os dois reatores entre 0,0 e $0,3 \mathrm{~mL} / \mathrm{L}$, de maneira quase independente dos valores de entrada, que oscilaram de 0,5 a $7,4 \mathrm{~mL} / \mathrm{L}$ no mesmo período. Os desvios padrão calculados mostram isso, com $0,1 \mathrm{~mL} / \mathrm{L}$ nos efluentes e $1,6 \mathrm{~mL} / \mathrm{L}$ no afluente. As eficiências de remoção foram bastante elevadas, em torno de $97 \%$ nos dois reatores estudados.

A Figura 5.17 mostra os gráficos da análise estatística. Ali se vê que a grande variação dos dados de entrada não é percebida nas saídas. 


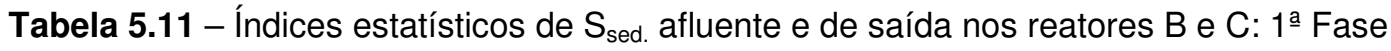

\begin{tabular}{lccc}
\hline \multicolumn{1}{c}{$\begin{array}{c}\text { PONTO DE } \\
\text { COLETA }\end{array}$} & ESGOTO BRUTO & $\begin{array}{c}\text { EFLUENTE } \\
\text { REATOR B }\end{array}$ & $\begin{array}{c}\text { EFLUENTE } \\
\text { REATOR C }\end{array}$ \\
\hline $\begin{array}{l}\text { VALOR MÉDIO } \\
\text { [mL/L] }\end{array}$ & 2,8 & 0,1 & 0,1 \\
\hline MíNIMO [mL/L] & 0,5 & 0,0 & 0,0 \\
\hline MÁXIMO [mL/L] & 7,4 & 0,2 & 0,3 \\
\hline $\begin{array}{l}\text { DESVIO } \\
\text { PADRÃO }\end{array}$ & 1,6 & 0,1 & 0,1 \\
\hline VARIANÇA & 0,56 & 1,26 & 1,10 \\
\hline $\begin{array}{l}\text { EFICIÊNCIA DE } \\
\text { REMOÇÃOO [\%] }\end{array}$ & - & 97,9 & 97,0 \\
\hline
\end{tabular}

Identifica-se também que o esgoto afluente é muito diluído, em algumas oportunidades quase atingindo o parâmetro legal de lançamento, 1,0 mL/L.

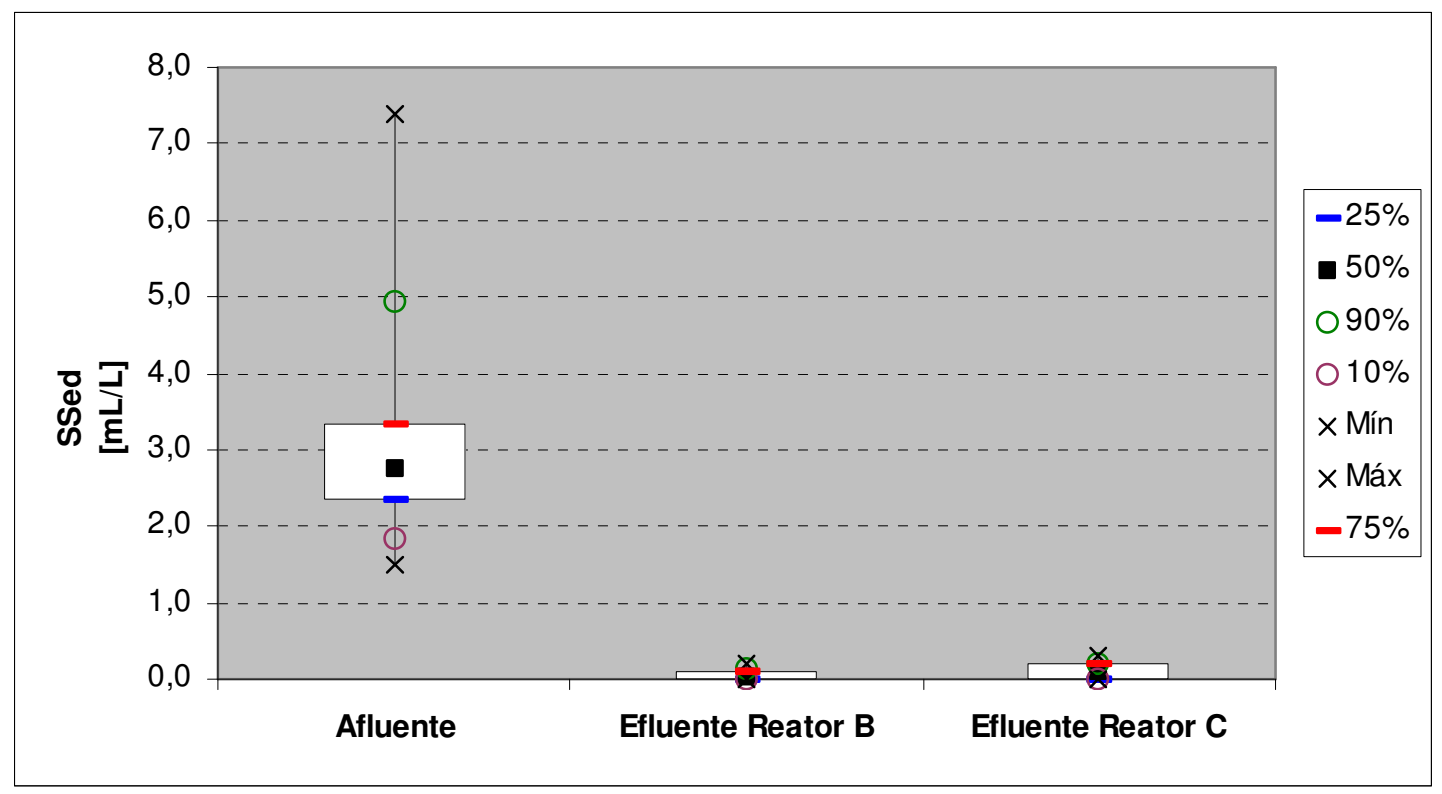

Figura 5.17 - Sólidos sedimentáveis da 1ª Fase: análise estatística

\subsection{Resultados da $2^{a}$ Fase - Com Adição de $25 \mathrm{mg} / \mathrm{L}$ de Cloreto Férrico}

Neste período, entre setembro de 2005 e fevereiro de 2006, deu-se início à dosagem de coagulante $\left(\mathrm{FeCl}_{3}\right)$, na concentração de $25 \mathrm{mg} / \mathrm{L}$ de esgoto afluente ao reator $B$, continuando o reator $C$ sem qualquer aplicação. Os parâmetros acompanhados durante a $1^{\underline{a}}$ Fase foram ampliados em quantidade e acrescidos do monitoramento de $\mathrm{pH}$ e alcalinidade. 
Nesta ocasião, o reator com aplicação de coagulante tinha uma aparência levemente escura, com a presença de pequenas partículas negras saindo junto com o clarificado. Por problemas no sistema de dosagem de cloreto férrico, não houve aplicação entre os dias 2 e 3 de outubro (24 horas), em 10/10, 24/10, 16/01 por um período de algumas horas e entre 2 e $3 / 11$.

O efluente do reator B passou a formar um tipo de espuma na canaleta de saída, 0 que não se notou nas outras 3 unidades da ETE.

Com o início da operação com o cloreto férrico, surgiram algumas dificuldades devidas ao caráter fortemente corrosivo desse produto. As mangueiras mais indicadas foram as de PVC "cristal", com espessura de 1,5 mm, pois essa mesma mangueira, com espessura $1,0 \mathrm{~mm}$ não resistiu por muito tempo. A válvula borboleta, com corpo em aço carbono, instalada para drenagem do reservatório de cloreto também teve uma curta duração ( 24 horas). Essa peça foi substituída por outra, em PVC, mas com um ajunta de borracha que também se deteriorou, permitindo um pequeno vazamento. O reservatório, inicialmente em fibra de vidro, teve vida útil de 4 meses, quando apresentou trincas e também vazamentos. Foi trocado por outra unidade em polipropileno.

Em 23/11/05, foi feita a desobstrução dos tubos de distribuição dos reatores B e C. Estes tubos, dos quais cerca de 1/3 estavam entupidos, se fecham com a areia presente no fundo das unidades, próxima às descargas de esgoto. Com a limpeza, o fluxo pelos vertedores de efluente clarificado de saída tornou-se mais homogêneo.

Por volta de 18/11/05, uma grande quantidade de sólidos grosseiros afluiu à ETE, causando uma aparência ruim nas superfícies líquidas dos reatores e nas calhas vertedoras. 


\subsubsection{DQO Total}

Nesta fase foram realizadas 21 análises, mostradas no Capítulo 7. ANEXOS, na Tabela A.15. Na Figura 5.18 observa-se a variação da concentração de matéria orgânica afluente e nas saídas dos reatores. O reator $B$, já nessa condição de pequena adição de coagulante, pareceu ter um desempenho melhor na maior parte do tempo.

Na última semana do mês de novembro de 2005, houve a incidência de fortes chuvas, contrariando o que se poderia esperar, com o aumento de carga orgânica visto no gráfico da Figura 5.18.

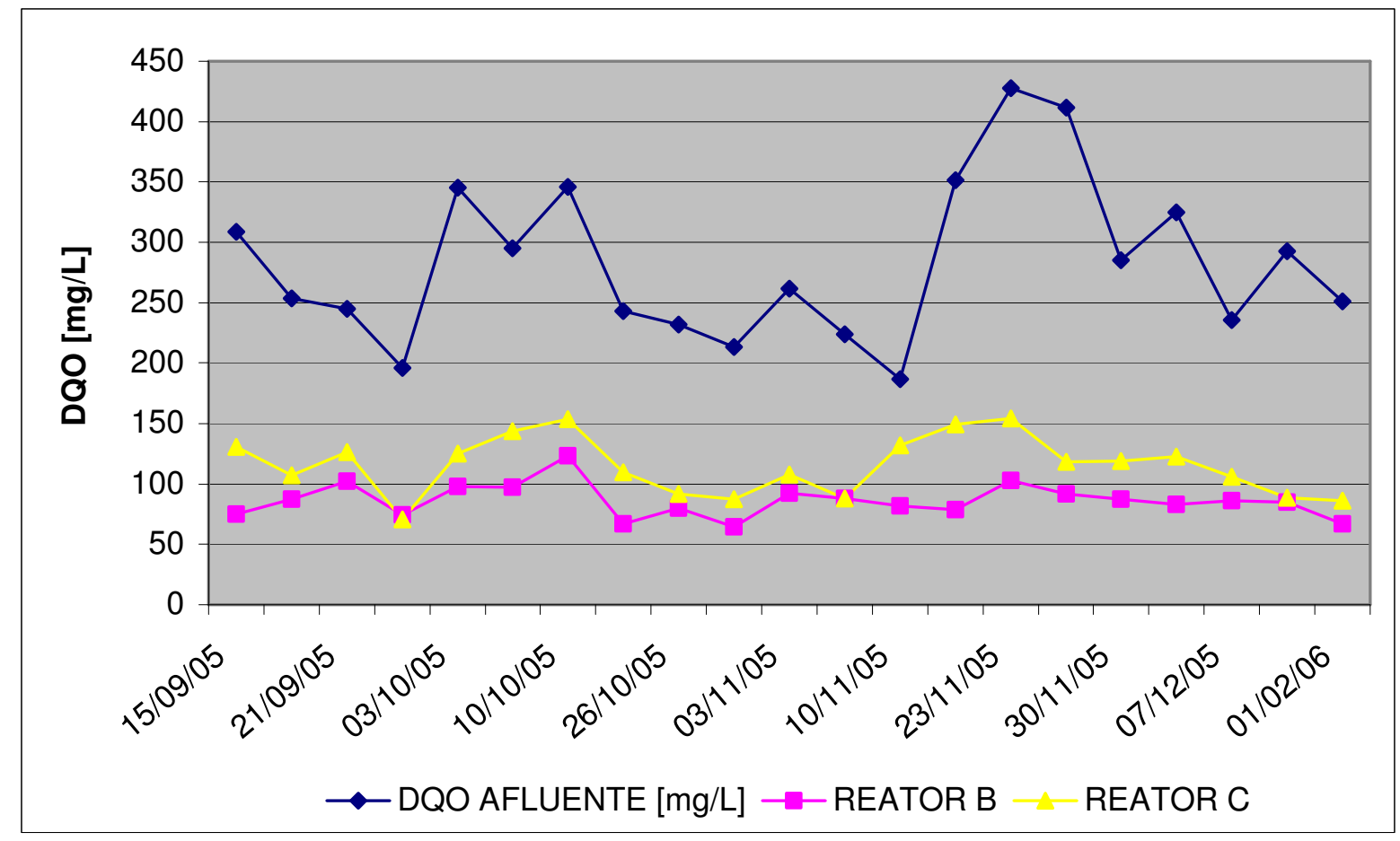

Figura 5.18 - Valores de DQO total afluente e nas saídas dos reatores B e C: 2ª Fase

Os valores médios obtidos estão apresentados na Tabela 5.12, com os respectivos dados estatísticos. Estes indicam uma diferença percentual alta (o reator B produziu efluente com $50 \mathrm{mg} \mathrm{DQO} / \mathrm{L}$, enquanto o reator $\mathrm{C}$ tinha $107 \mathrm{mg} / \mathrm{L})$. O desvio padrão também foi menor no reator $B(18 \mathrm{mg} / \mathrm{L})$, indicando uma regularidade maior dessa unidade de tratamento. 
Na Figura 5.19 estão as representações gráficas dessa análise estatística.

Tabela 5.12 - Índices estatísticos da DQO total afluente e da saída dos reatores B e C: $2^{\underline{a}}$ Fase

\begin{tabular}{lccc}
\hline \multicolumn{1}{c}{$\begin{array}{c}\text { PONTO DE } \\
\text { COLETA }\end{array}$} & ESGOTO BRUTO & $\begin{array}{c}\text { EFLUENTE } \\
\text { REATOR B }\end{array}$ & $\begin{array}{c}\text { EFLUENTE } \\
\text { REATOR C }\end{array}$ \\
\hline $\begin{array}{l}\text { VALOR MÉDIO } \\
\text { [mg/L] }\end{array}$ & 126 & 50 & 107 \\
\hline MíNIMO [mg/L] & 54 & 4 & 28 \\
\hline MÁXIMO [mg/L] & 194 & 77 & 154 \\
\hline $\begin{array}{l}\text { DESVIO } \\
\text { PADRÃO }\end{array}$ & 31 & 18 & 32 \\
\hline VARIANÇA & 0,24 & 0,36 & 0,30 \\
\hline $\begin{array}{l}\text { EFICIÊNCIA DE } \\
\text { REMOÇÃO [\%] }\end{array}$ & - & 60,3 & 14,8 \\
\hline
\end{tabular}

Como se pode concluir, os valores de remoção mostrados dão a clara idéia de melhor desempenho no reator $\mathrm{B}$.

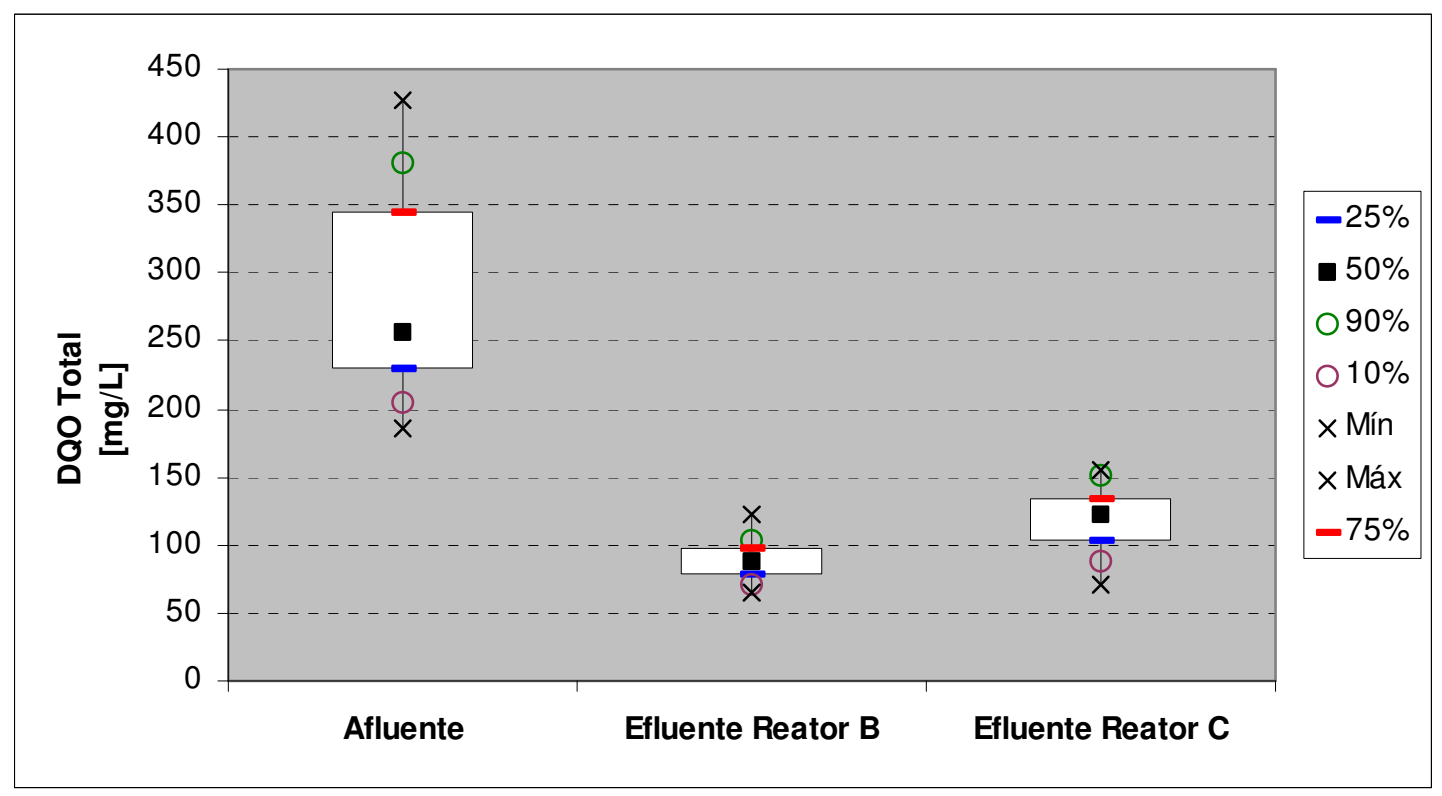

Figura 5.19 - DQO total da $2^{2}$ Fase: análise estatística

\subsubsection{DQO Filtrada}

Neste ponto foram realizadas 21 análises, como mostrado no Capítulo 7. ANEXOS, na Tabela A.16. Da Figura 5.20 percebe-se uma pequena melhora na eficiência do 
reator $\mathrm{B}$ em relação ao $\mathrm{C}$, que em algumas oportunidades teve valores bem maiores na carga orgânica do efluente tratado.

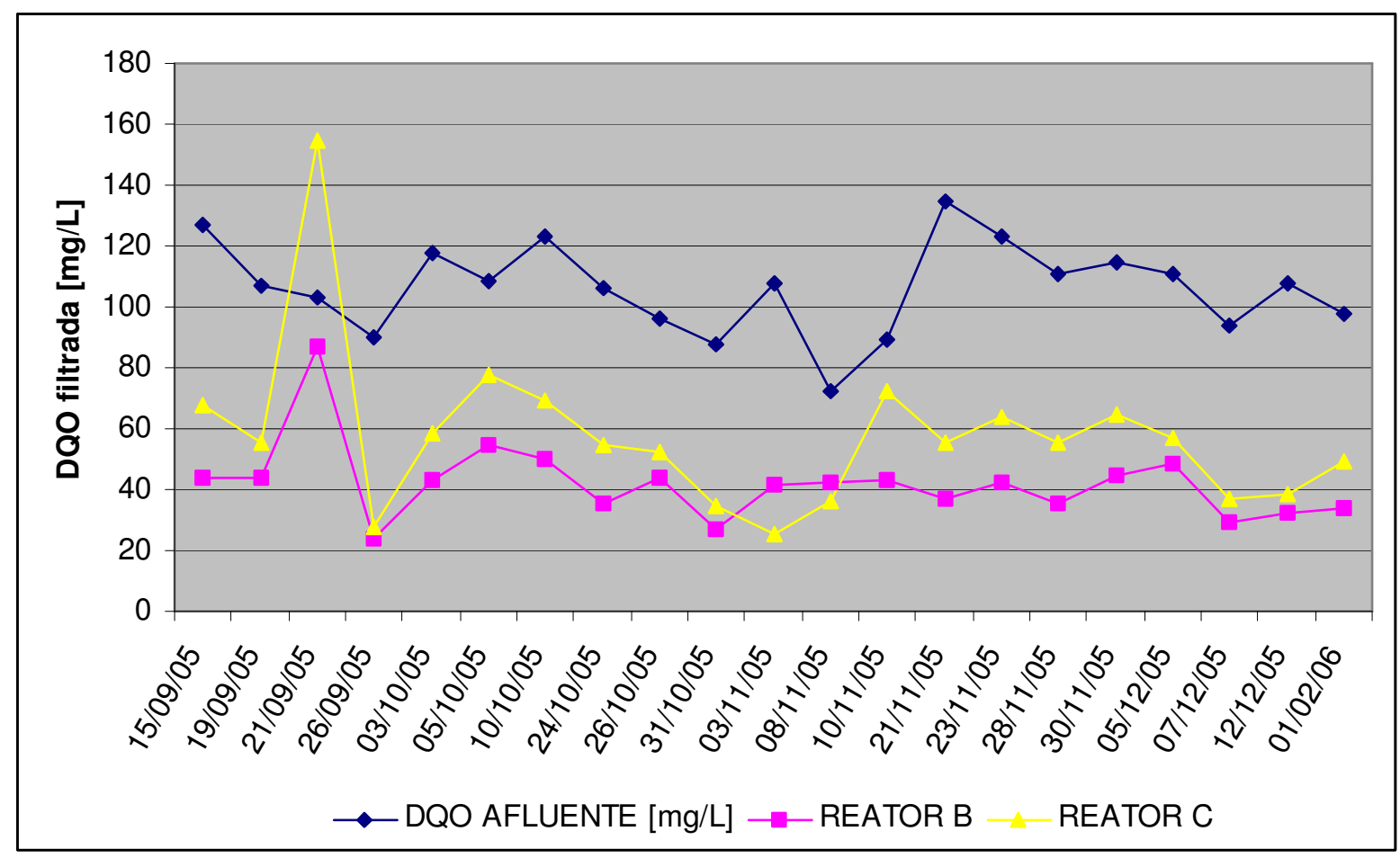

Figura 5.20 - Valores de DQO filtrada afluente e na saída dos reatores B e C: 2aㅡ Fase

Os valores médios obtidos estão apresentados na Tabela 5.13, com os respectivos dados estatísticos dessa amostragem. Na Figura 5.21 estão as representações gráficas da análise estatística.

Tabela 5.13 - Índices estatísticos da DQO filtrada afluente e de saída nos reatores B e C: $2^{2}$ Fase

\begin{tabular}{lccc}
\hline \multicolumn{1}{c}{$\begin{array}{c}\text { PONTO DE } \\
\text { COLETA }\end{array}$} & ESGOTO BRUTO & $\begin{array}{c}\text { EFLUENTE } \\
\text { REATOR B }\end{array}$ & $\begin{array}{c}\text { EFLUENTE } \\
\text { REATOR C }\end{array}$ \\
\hline $\begin{array}{l}\text { VALOR MÉDIO } \\
\text { [mg/L] }\end{array}$ & 106 & 42 & 57 \\
\hline MÍNIMO [mg/L] & 72 & 24 & 26 \\
\hline MÁXIMO [mg/L] & 135 & 87 & 154 \\
\hline $\begin{array}{l}\text { DESVIO } \\
\text { PADRÃO }\end{array}$ & 15 & 13 & 27 \\
\hline VARIANÇA & 0,14 & 0,31 & 0,46 \\
\hline $\begin{array}{l}\text { EFICIÊNCIA DE } \\
\text { REMOÇÃO [\%] }\end{array}$ & - & 60,4 & 45,8 \\
\hline
\end{tabular}


Para este parâmetro, as diferenças não são tão expressivas, com as eficiências de remoção bem mais próximas, $60,4 \%$ e $45,8 \%$ respectivamente para os reatores $\mathrm{B}$ e C.

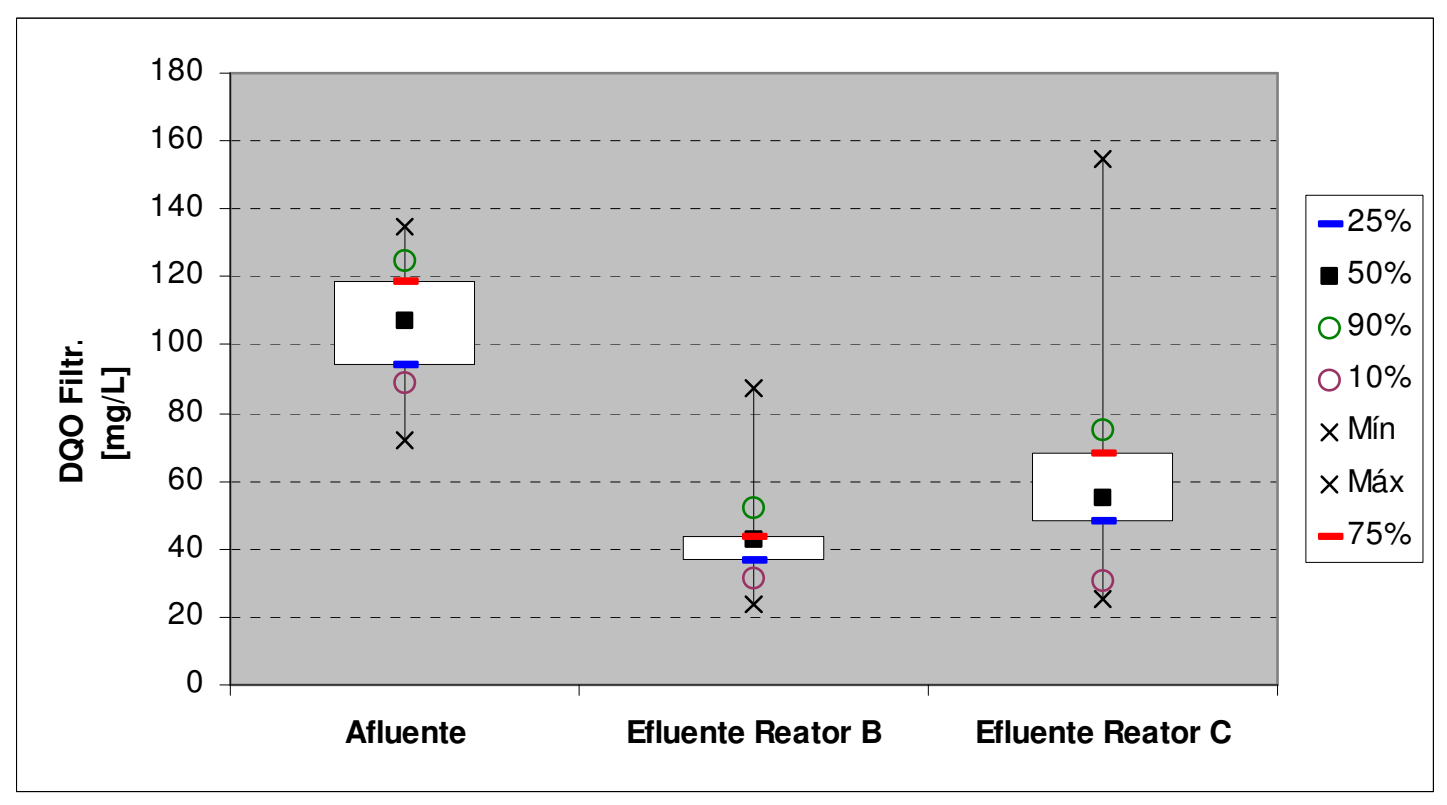

Figura 5.21 - DQO filtrada da 2ª Fase: análise estatística

\subsection{3. $\mathrm{DBO}_{5,20^{\circ} \mathrm{C}}$ Total}

Foram realizadas 10 análises, mostradas no Capítulo 7. ANEXOS, na Tabela A.17.

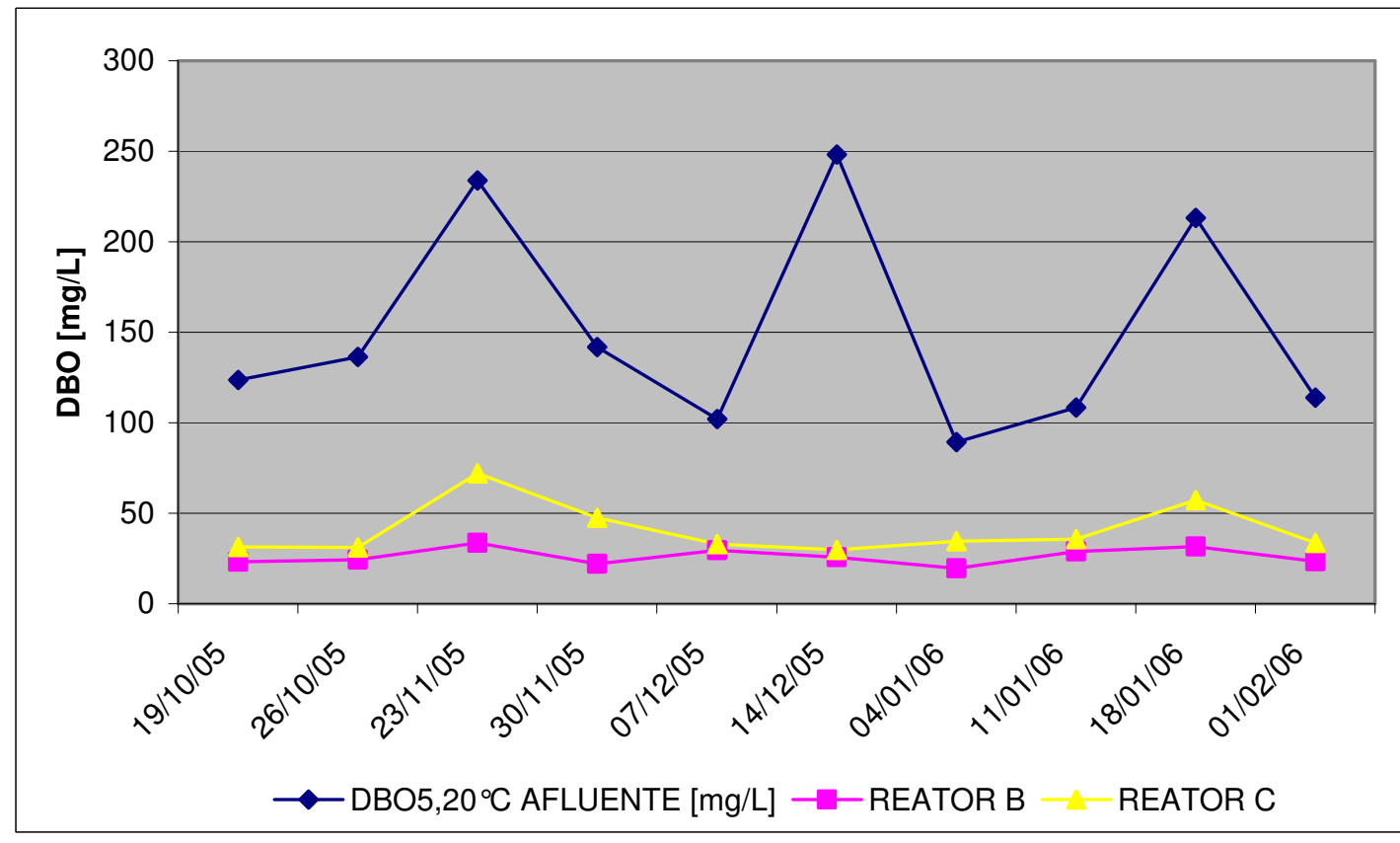

Figura 5.22 - Valores de $\mathrm{DBO}_{5,20^{\circ} \mathrm{C}}$ total afluente e na saída dos reatores $\mathrm{B}$ e C: $2^{\mathrm{a}}$ Fase 
Observando a Figura 5.22, vê-se a mesma (ligeira) vantagem pró o reator $B$, que em todo o período coberto por amostragens concentrações abaixo de $40 \mathrm{mg} / \mathrm{L}$. As remoções foram de aproximadamente $120 \mathrm{mg} / \mathrm{L}$ no reator $B$ e de $\sim 100 \mathrm{mg} / \mathrm{L}$. As médias obtidas para a entrada e os reatores B e C foram $151 \mathrm{mg} / \mathrm{L}, 26 \mathrm{mg} / \mathrm{L}$ e 41 $\mathrm{mg} / \mathrm{L}$, expondo a pequena diferença dos desempenhos.

Tabela 5.14 - Índices estatísticos da $\mathrm{DBO}_{5,20^{\circ} \mathrm{C}}$ total afluente e de saída nos reatores B e C: $2^{\mathrm{a}}$ Fase

\begin{tabular}{lccc}
\hline \multicolumn{1}{c}{$\begin{array}{c}\text { PONTO DE } \\
\text { COLETA }\end{array}$} & ESGOTO BRUTO & $\begin{array}{c}\text { EFLUENTE } \\
\text { REATOR B }\end{array}$ & $\begin{array}{c}\text { EFLUENTE } \\
\text { REATOR C }\end{array}$ \\
\hline $\begin{array}{l}\text { VALOR MÉDIO } \\
\text { [mg/L] }\end{array}$ & 151 & 26 & 41 \\
\hline MÍNIMO [mg/L] & 89 & 19 & 30 \\
\hline MÁXIMO [mg/L] & 248 & 34 & 72 \\
\hline $\begin{array}{l}\text { DESVIO } \\
\text { PADRÃO }\end{array}$ & 58 & 5 & 14 \\
\hline VARIANÇA & 0,39 & 0,17 & 0,35 \\
\hline $\begin{array}{l}\text { EFICIÊNCIA DE } \\
\text { REMOÇÃO [\%] }\end{array}$ & - & 82,7 & 73,1 \\
\hline
\end{tabular}

As médias obtidas estão apresentadas na Tabela 5.14, com os respectivos dados estatísticos dessa amostragem. Na Figura 5.23 estão as representações gráficas da amostragem.

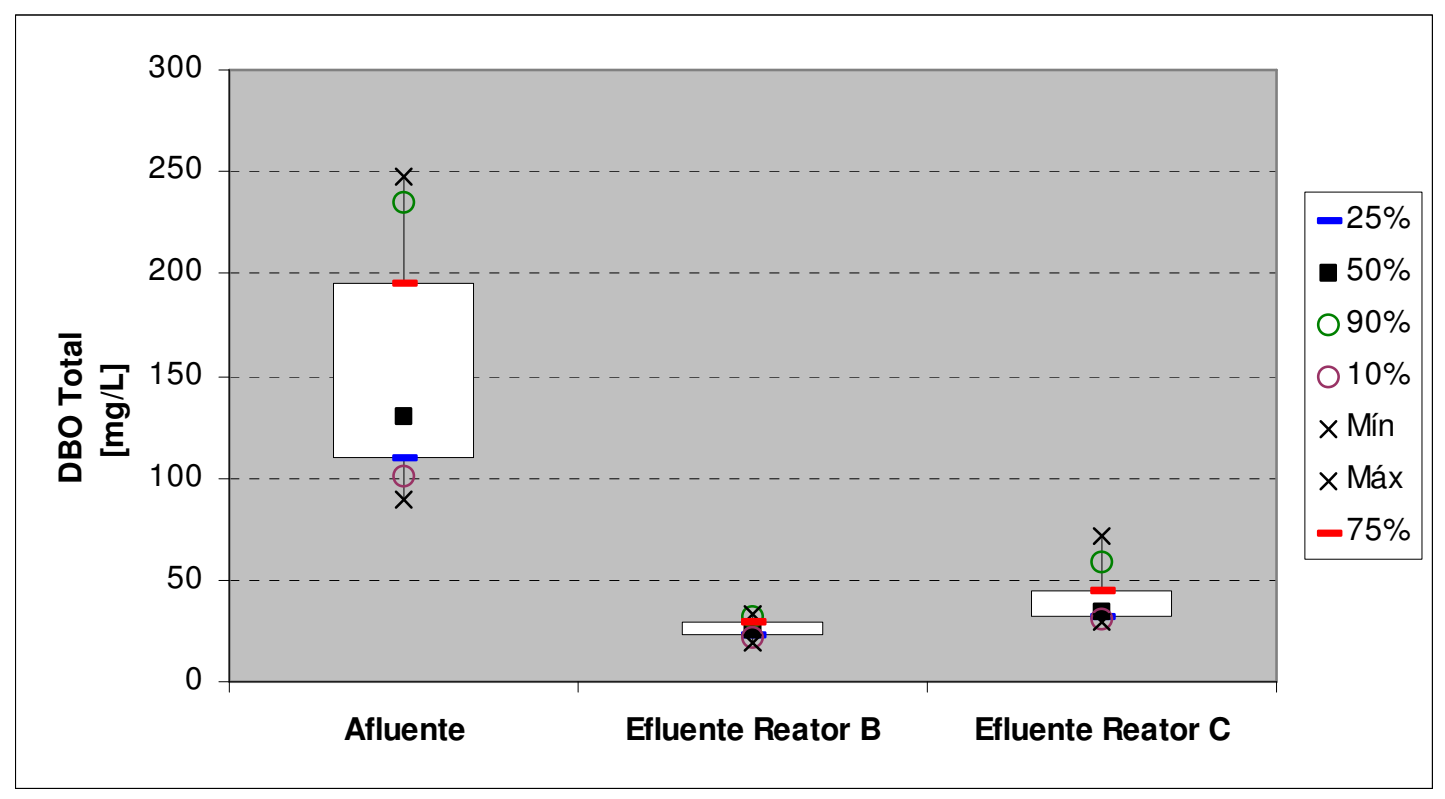

Figura $5.23-\mathrm{DBO}_{5,20^{\circ} \mathrm{C}}$ total da $2^{\mathrm{a}}$ Fase: análise estatística 


\subsection{4. $D B O_{5,20^{\circ} \mathrm{C}}$ Filtrada}

Foram realizadas 10 análises, listadas no Capítulo 7. ANEXOS, na Tabela A.18. Na Figura 5.24 estão apresentados os valores de carga orgânica afluentes e das saídas dos 2 reatores, aonde se vê o efluente do reator $C$ acompanhar as variações do esgoto bruto, enquanto o reator $B$ teve melhores condições de amortecimento dos aumentos de DBO, com ocasiões em que apresentou concentrações menores que $10 \mathrm{mg} / \mathrm{L}$.

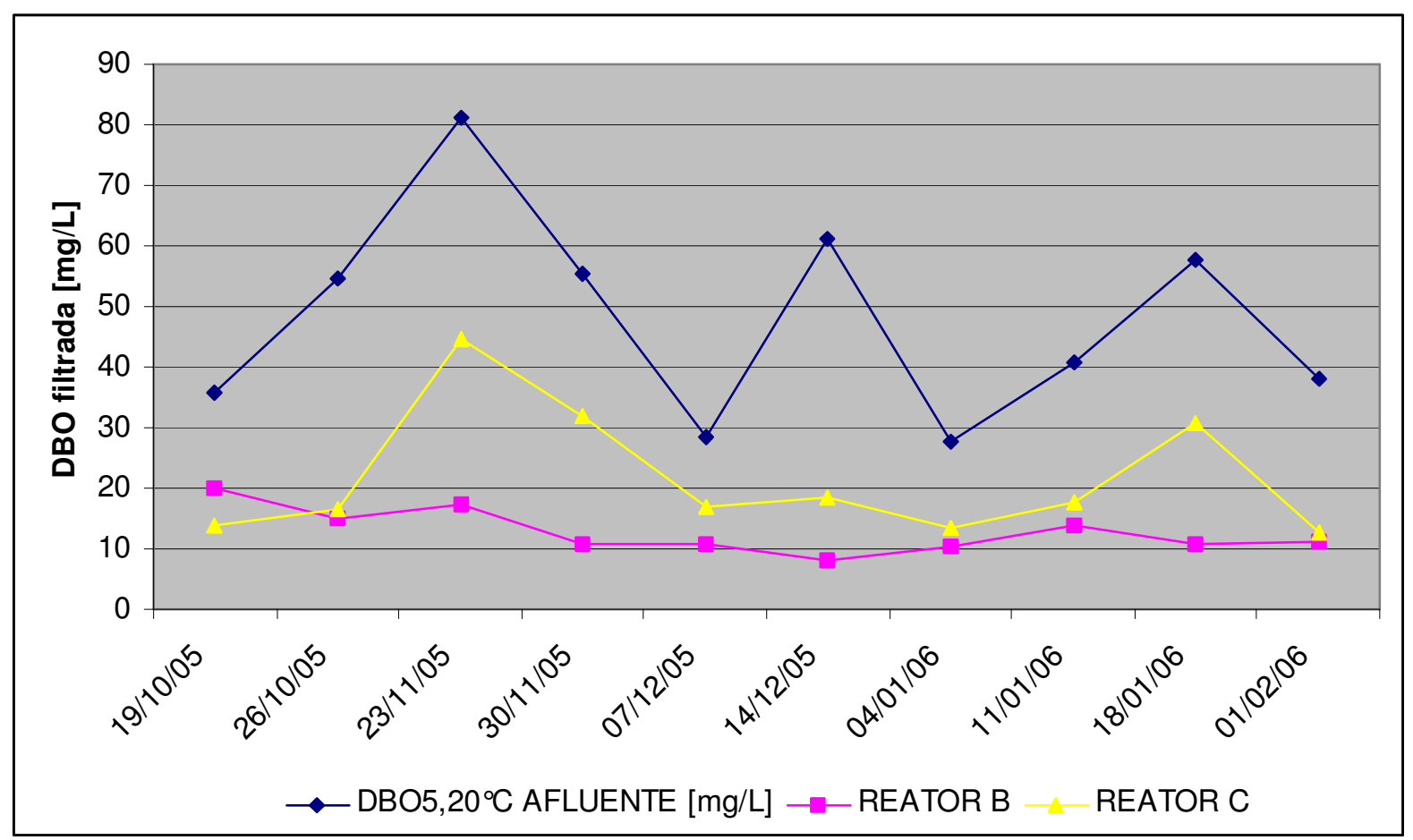

Figura 5.24 - Valores de $\mathrm{DBO}_{5,20^{\circ} \mathrm{C}}$ filtrada afluente e na saída dos reatores $\mathrm{B}$ e C: $2^{\underline{a}}$ Fase

As médias estão mostradas na Tabela 5.15 , com os respectivos dados estatísticos da amostragem. Na Figura 5.25 estão as representações gráficas dessa análise estatística.

Há uma performance melhor, mas com uma diferença muito reduzida, do reator $B$, que teve eficiência de $73,3 \%$, comparada a $55,1 \%$ do outro UASB. Por outro lado, os valores de desvio padrão foram elevados em relação às médias, podendo-se depreender uma igualdade estatística dos dois. 
Tabela 5.15 - Índices estatísticos da $\mathrm{DBO}_{5,20^{\circ} \mathrm{C}}$ filtrada : $2^{\mathrm{a}}$ Fase

\begin{tabular}{lccc}
\hline $\begin{array}{c}\text { PONTO DE } \\
\text { COLETA }\end{array}$ & ESGOTO BRUTO & $\begin{array}{c}\text { EFLUENTE } \\
\text { REATOR B }\end{array}$ & $\begin{array}{c}\text { EFLUENTE } \\
\text { REATOR C }\end{array}$ \\
\hline $\begin{array}{l}\text { VALOR MÉDIO } \\
\text { [mg/L] }\end{array}$ & 48 & 13 & 22 \\
\hline MíNIMO [mg/L] & 28 & 8 & 13 \\
\hline MÁXIMO [mg/L] & 81 & 20 & 44 \\
\hline $\begin{array}{l}\text { DESVIO } \\
\text { PADRÃO }\end{array}$ & 17 & 4 & 11 \\
\hline VARIANÇA & 0,35 & 0,29 & 0,49 \\
\hline $\begin{array}{l}\text { EFICIÊNCIA DE } \\
\text { REMOÇÃO [\%] }\end{array}$ & - & 73,3 & 55,1 \\
\hline
\end{tabular}

Ainda sobre a Figura 5.25, identifica-se uma pequena zona de sobreposição dos valores dos 2 reatores.

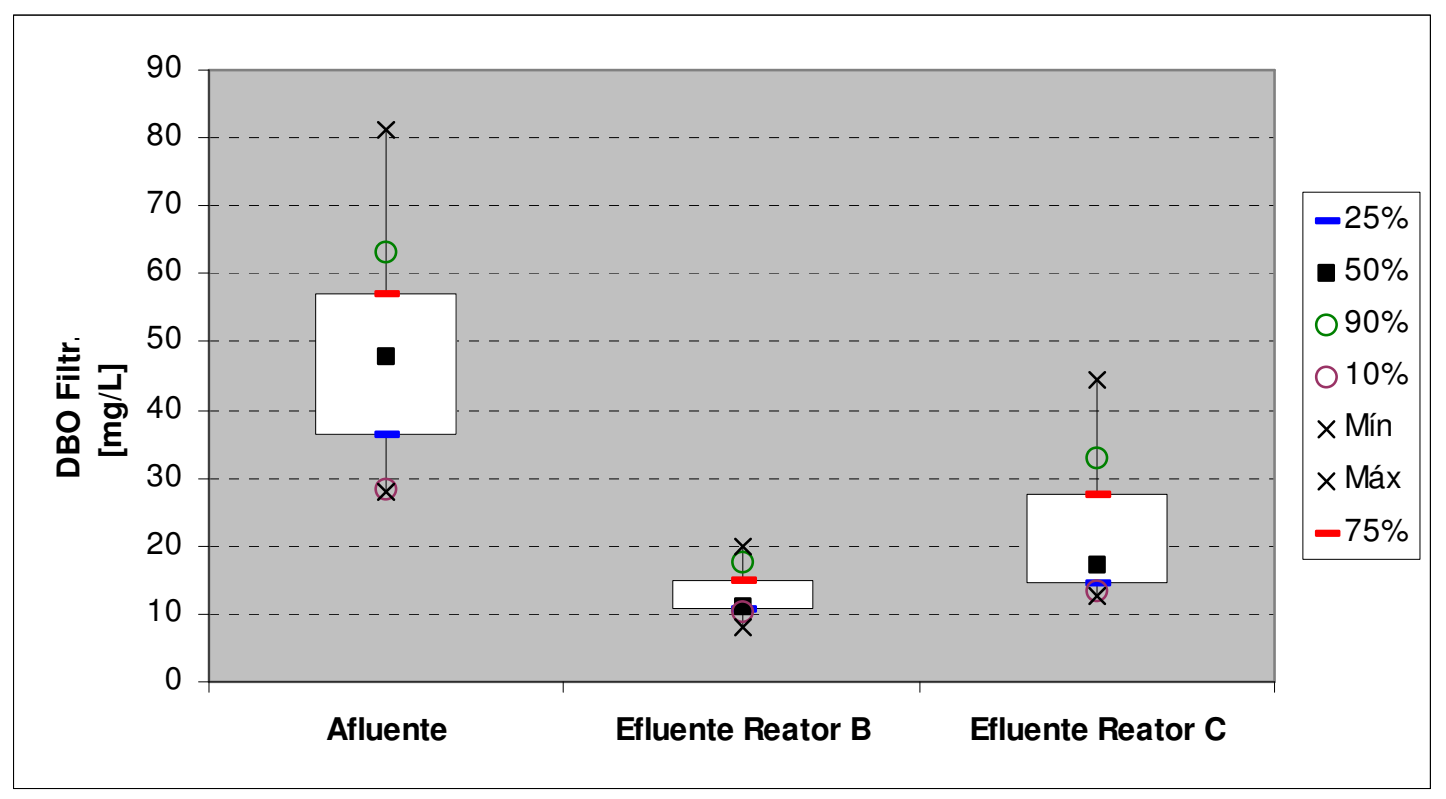

Figura $5.25-\mathrm{DBO}_{5,20^{\circ} \mathrm{C}}$ filtrada da $2^{\mathrm{a}}$ Fase: análise estatística

\subsubsection{Fósforo Total}

Foram realizadas 26 análises, listadas no Capítulo 7. ANEXOS, na Tabela A.19. Na Figura 5.26 estão os valores de fósforo total afluentes e das saídas dos 2 reatores. 
Pode-se ver claramente que não há uma melhora na remoção de fósforo com esse nível de dosagem.

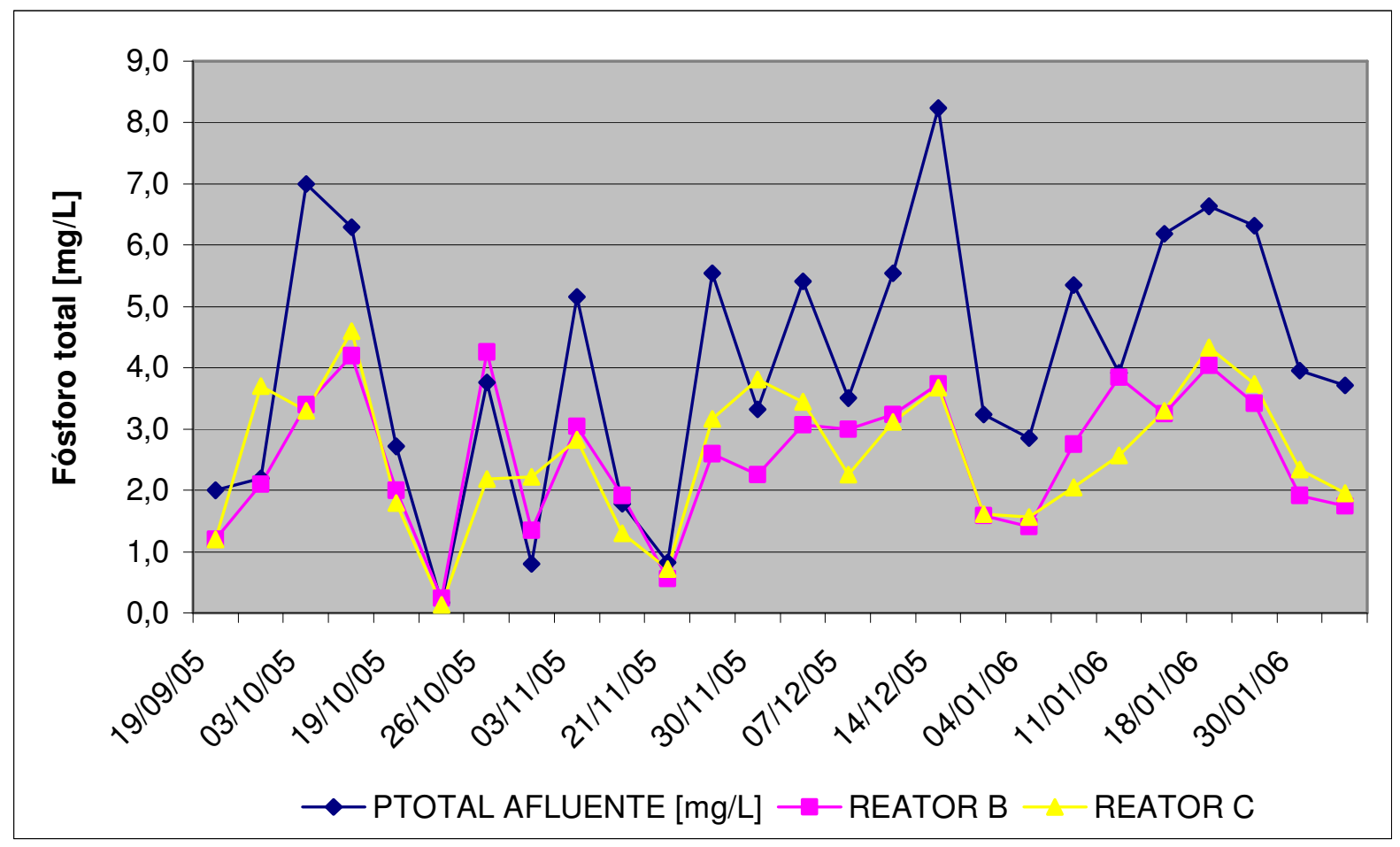

Figura 5.26 - Valores de fósforo total afluente e na saída dos reatores B e C: 2ª Fase

As médias estão mostradas na Tabela 5.16, com os respectivos dados estatísticos da amostragem. Na Figura 5.27 estão as representações gráficas dessa análise estatística.

Tabela 5.16 - Índices estatísticos do Fósforo total afluente e de saída nos reatores B e C: $2^{2}$ Fase

\begin{tabular}{lccc}
\hline $\begin{array}{c}\text { PONTO DE } \\
\text { COLETA }\end{array}$ & ESGOTO BRUTO & $\begin{array}{c}\text { EFLUENTE } \\
\text { REATOR B }\end{array}$ & $\begin{array}{c}\text { EFLUENTE } \\
\text { REATOR C }\end{array}$ \\
\hline $\begin{array}{l}\text { VALOR MÉDIO } \\
\text { [mg/L] }\end{array}$ & 4,1 & 2,5 & 2,6 \\
\hline MíNIMO [mg/L] & 0,2 & 0,2 & 0,1 \\
\hline MÁXIMO [mg/L] & 8,2 & 4,3 & 4,6 \\
\hline $\begin{array}{l}\text { DESVIO } \\
\text { PADRÃO }\end{array}$ & 2,1 & 1,1 & 1,1 \\
\hline VARIANÇA & 0,51 & 0,44 & 0,44 \\
\hline $\begin{array}{l}\text { EFICIÊNCIA DE } \\
\text { REMOÇÃO [\%] }\end{array}$ & - & 37,9 & 37,1 \\
\hline
\end{tabular}


Pode-se perceber a igualdade das eficiências de remoção dos 2 reatores, 37,9\% do B e $37,1 \%$ do $C$.

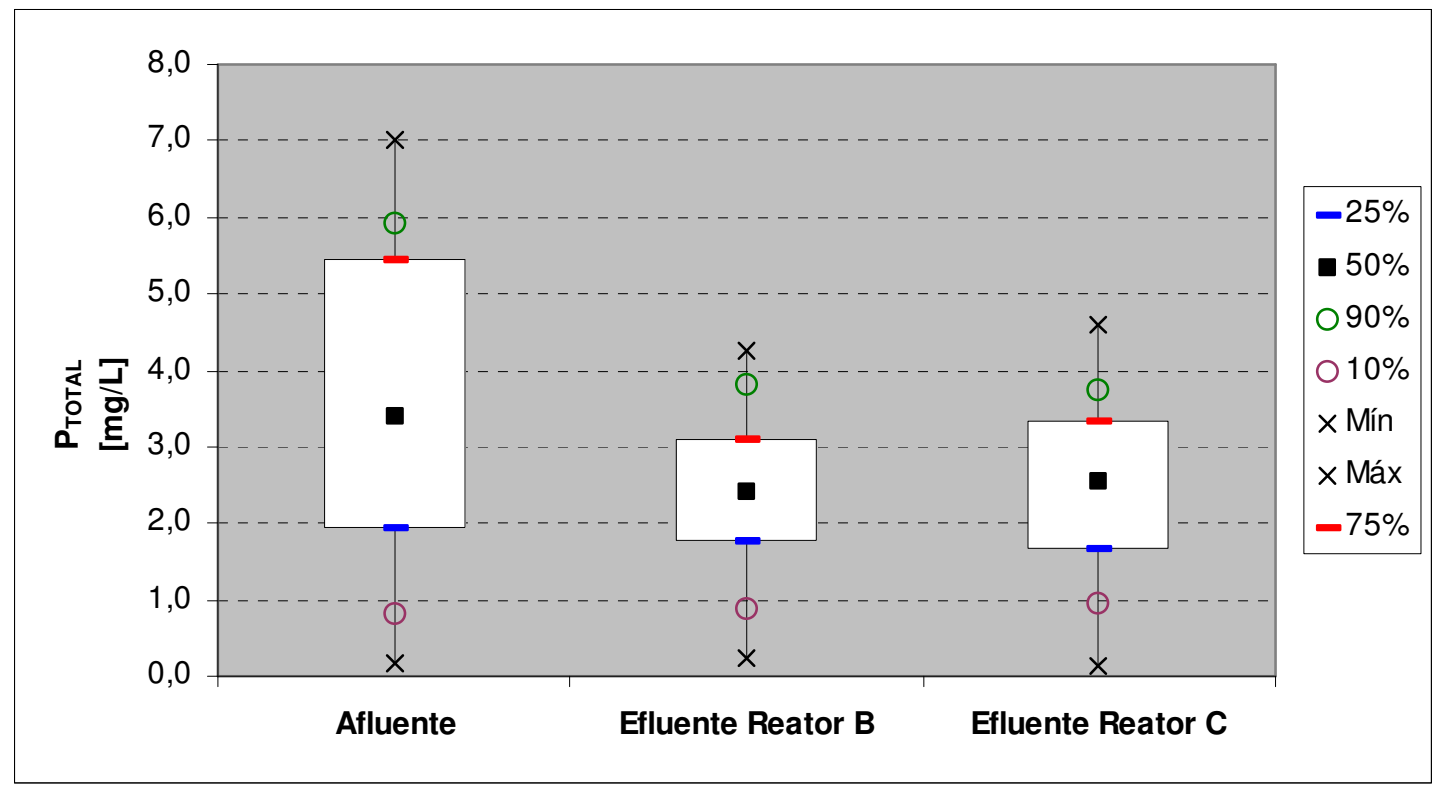

Figura 5.27 - Fósforo total da $2^{2}{ }^{\mathrm{a}}$ Fase: análise estatística

\subsubsection{Ortofosfatos}

Nesta etapa foram feitas 29 análises, indicadas no Capítulo 7. ANEXOS, na Tabela A.20.

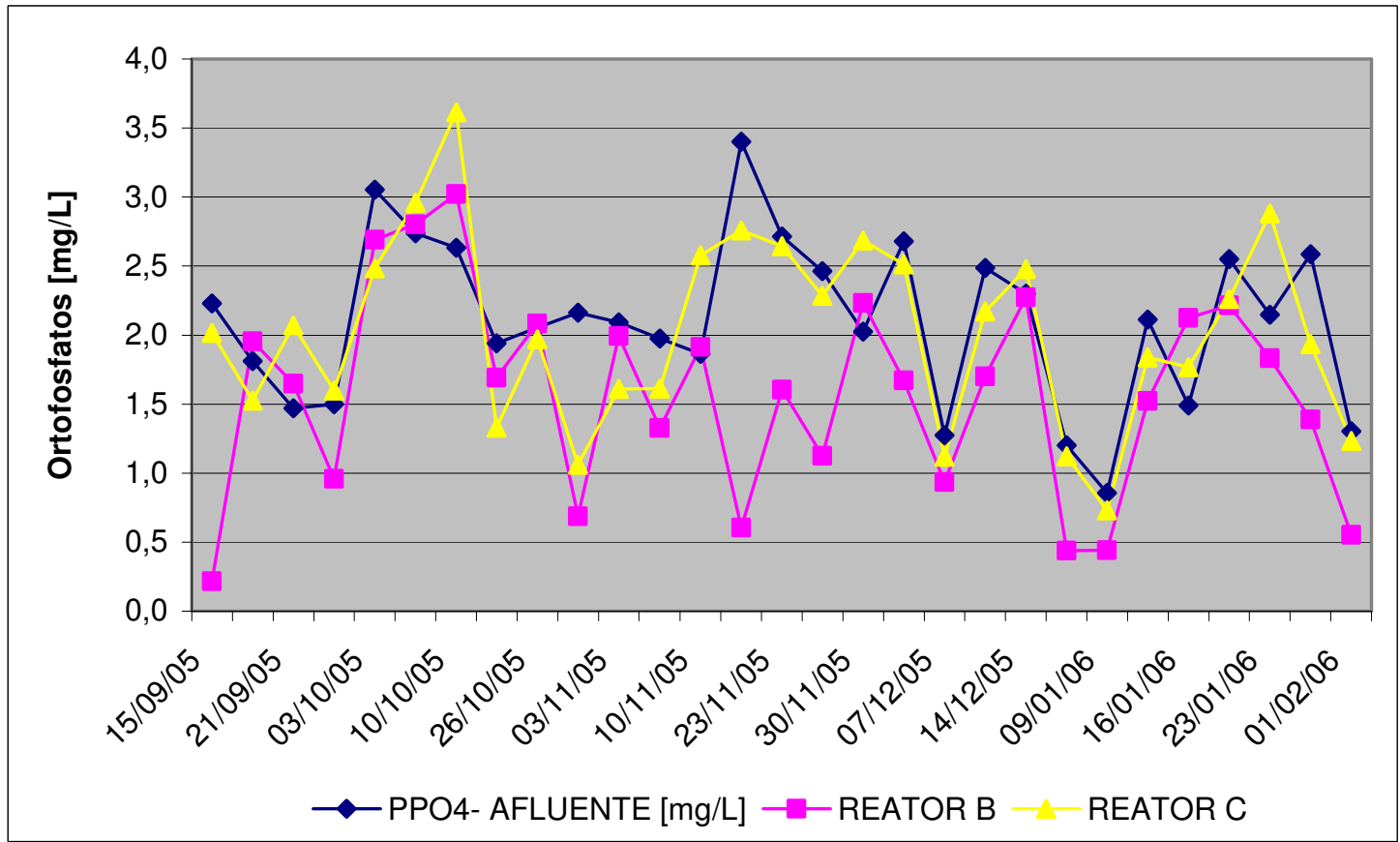

Figura 5.28 - Concentração de ortofosfatos afluente e nas saídas dos reatores B e C: $2^{\text {a }}$ Fase 
$\mathrm{Na}$ Figura 5.28 vê-se a vantagem discreta do reator com adição de cloreto férrico (B), quanto à remoção de ortofosfatos.

Os valores médios estão apresentados na Tabela 5.17 , com os dados estatísticos dessa amostragem. Na Figura 5.29 estão os gráficos da análise estatística.

Tabela 5.17 - Índices estatísticos de ortofosfatos afluente e de saída nos reatores B e C: $2^{2}$ Fase

\begin{tabular}{lccc}
\hline \multicolumn{1}{c}{$\begin{array}{c}\text { PONTO DE } \\
\text { COLETA }\end{array}$} & ESGOTO BRUTO & $\begin{array}{c}\text { EFLUENTE } \\
\text { REATOR B }\end{array}$ & $\begin{array}{c}\text { EFLUENTE } \\
\text { REATOR C }\end{array}$ \\
\hline $\begin{array}{l}\text { VALOR MÉDIO } \\
\text { [mg/L] }\end{array}$ & 2,1 & 1,6 & 2,0 \\
\hline MíNIMO [mg/L] & 0,9 & 0,2 & 0,7 \\
\hline MÁXIMO [mg/L] & 3,4 & 3,0 & 3,6 \\
\hline $\begin{array}{l}\text { DESVIO } \\
\text { PADRÃO }\end{array}$ & 0,6 & 0,7 & 0,7 \\
\hline VARIANÇA & 0,28 & 0,47 & 0,33 \\
\hline EFICIÊNCIA DE & - & 25,3 & 3,7 \\
REMOÇÃO [\%] & & &
\end{tabular}

As eficiências indicadas na Tabela 5.17 indicam a remoção maior no reator B $(25,3 \%$ contra $3,7 \%$ do reator $\mathrm{C}$ ).

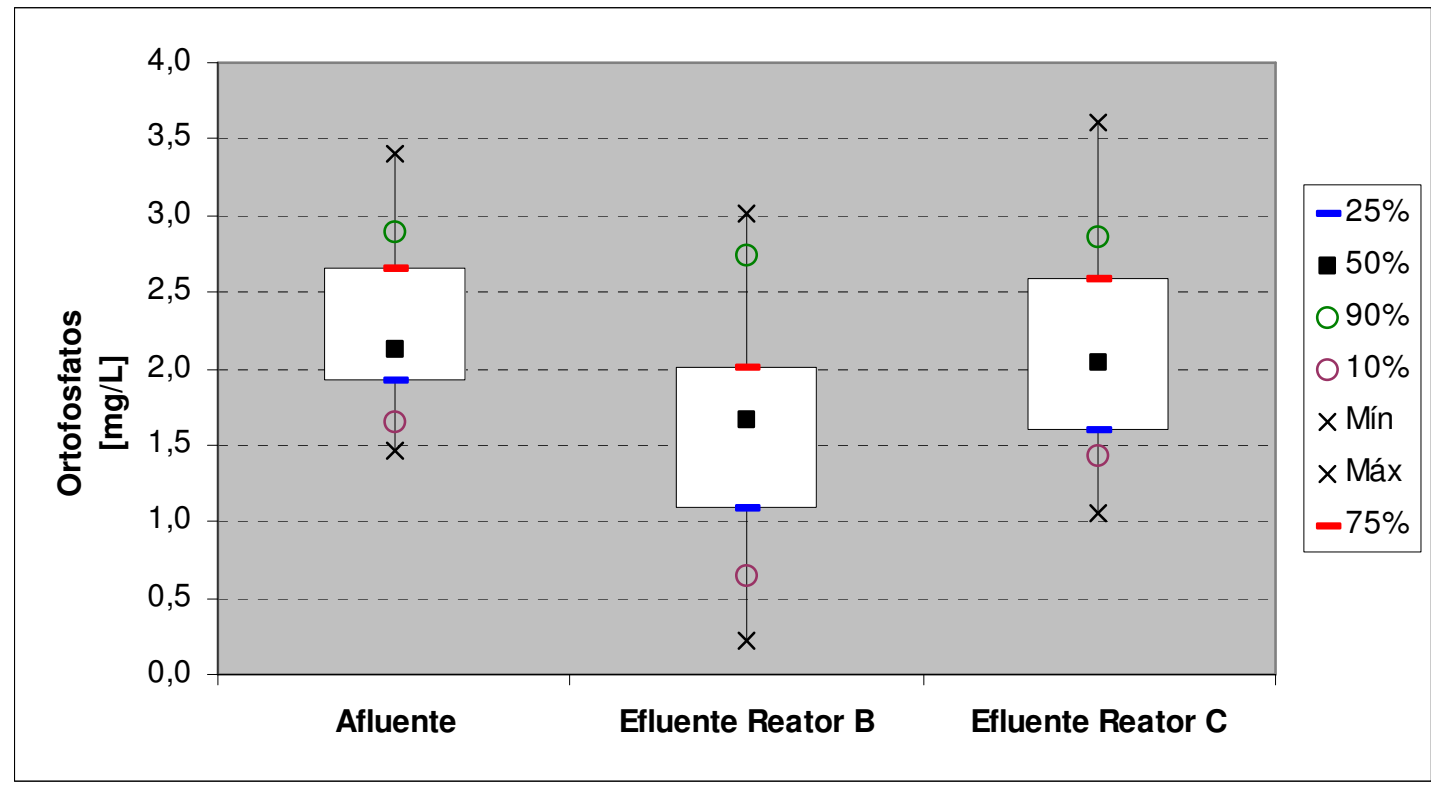

Figura 5.29 - Ortofosfatos da $2^{2}$ Fase: análise estatística 


\subsubsection{Sulfetos}

Foram realizadas 14 análises, indicadas no Capítulo 7. ANEXOS, na Tabela A.21. Os valores obtidos estão médios estão apresentados na Figura 5.30.

$\mathrm{Na}$ comparação dos 2 reatores conclui-se que a adição de cloreto férrico (em 25 $\mathrm{mg} / \mathrm{L})$ não tem nenhum efeito sobre a remoção de sulfetos.

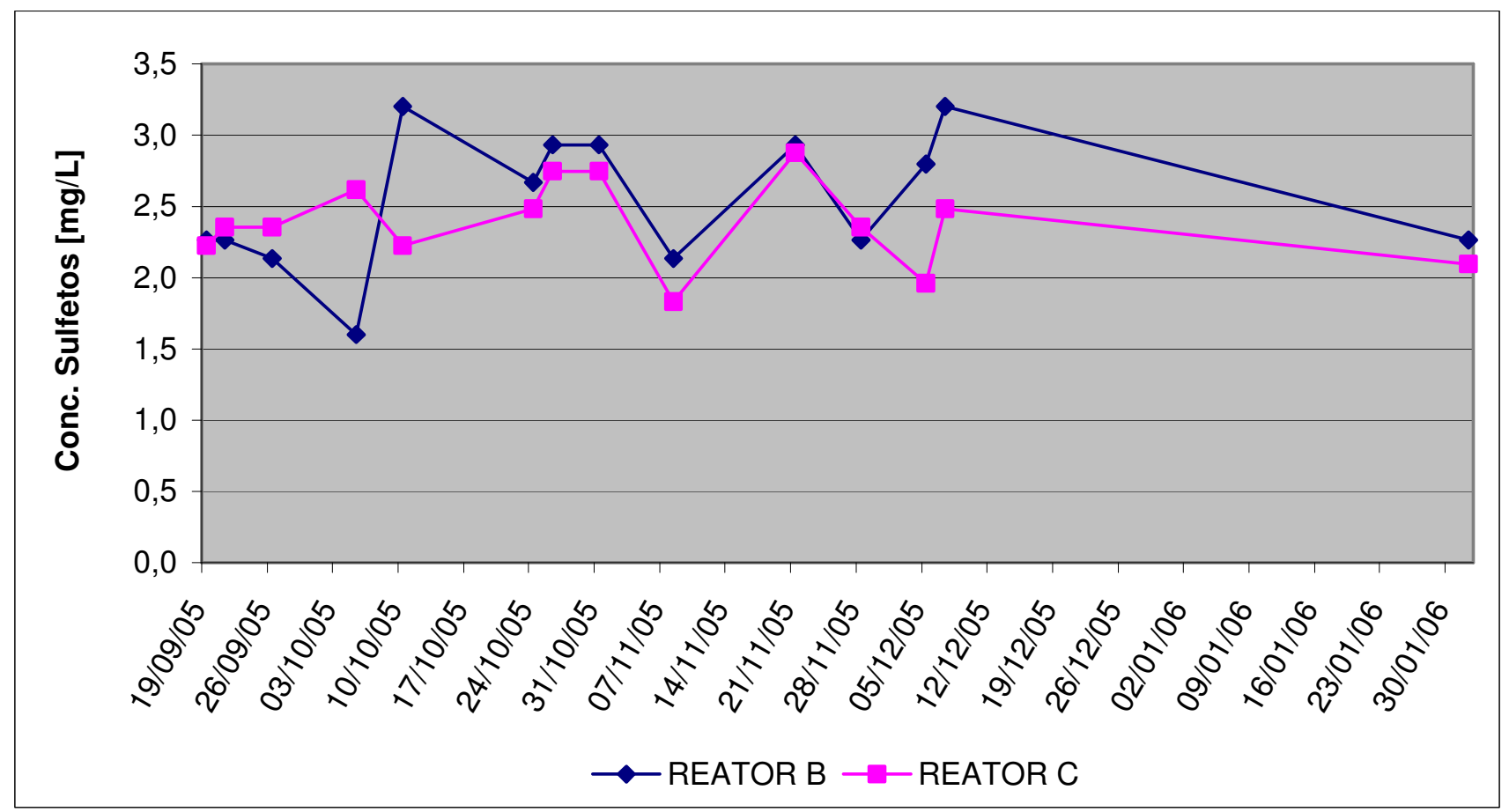

Figura 5.30 - Concentração de sulfetos nas saídas dos reatores B e C: $2^{\underline{a}}$ Fase

Os valores médios estão apresentados na Tabela 5.18, com os dados estatísticos dessa amostragem. Na Figura 5.31 estão os gráficos dessa análise estatística.

As concentrações médias de 2,5 e 2,4 mg/L exibem a ausência de diferença entre a condição com cloreto férrico e sem cloreto férrico no esgoto afluente. Os desvios padrão também são muito próximos. 
Tabela 5.18 - Índices estatísticos de sulfetos nas saídas dos reatores B e C: $2^{\text {a }}$ Fase

\begin{tabular}{lccc}
\hline \multicolumn{1}{c}{$\begin{array}{c}\text { PONTO DE } \\
\text { COLETA }\end{array}$} & ESGOTO BRUTO & $\begin{array}{c}\text { EFLUENTE } \\
\text { REATOR B }\end{array}$ & $\begin{array}{c}\text { EFLUENTE } \\
\text { REATOR C }\end{array}$ \\
\hline $\begin{array}{l}\text { VALOR MÉDIO } \\
\text { [mg/L] }\end{array}$ & - & 2,5 & 2,4 \\
\hline MÍNIMO [mg/L] & - & 1,6 & 1,8 \\
\hline MÁXIMO [mg/L] & - & 3,2 & 2,9 \\
\hline $\begin{array}{l}\text { DESVIO } \\
\text { PADRÃO }\end{array}$ & - & 0,5 & 0,3 \\
\hline VARIANÇA & - & 0,19 & 0,13 \\
\hline $\begin{array}{l}\text { EFICIÊNCIA DE } \\
\text { REMOÇÃO [\%] }\end{array}$ & - & - & - \\
\hline
\end{tabular}

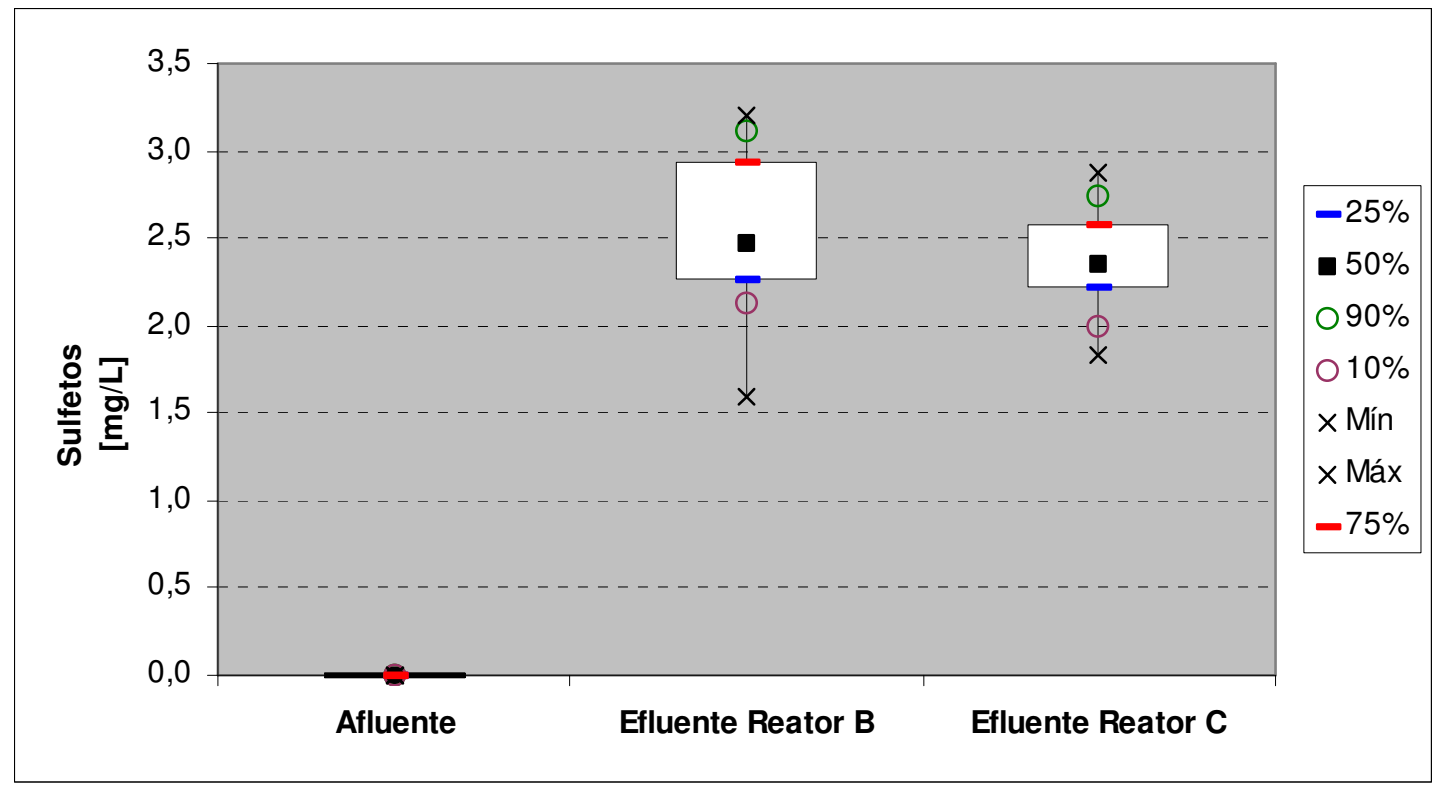

Figura 5.31 - Sulfetos da $2^{\text {a }}$ Fase: análise estatística

\subsubsection{Sólidos Totais}

Para este parâmetro foram feitas 12 análises, mostradas no Capítulo 7. ANEXOS, na Tabela A.22. 


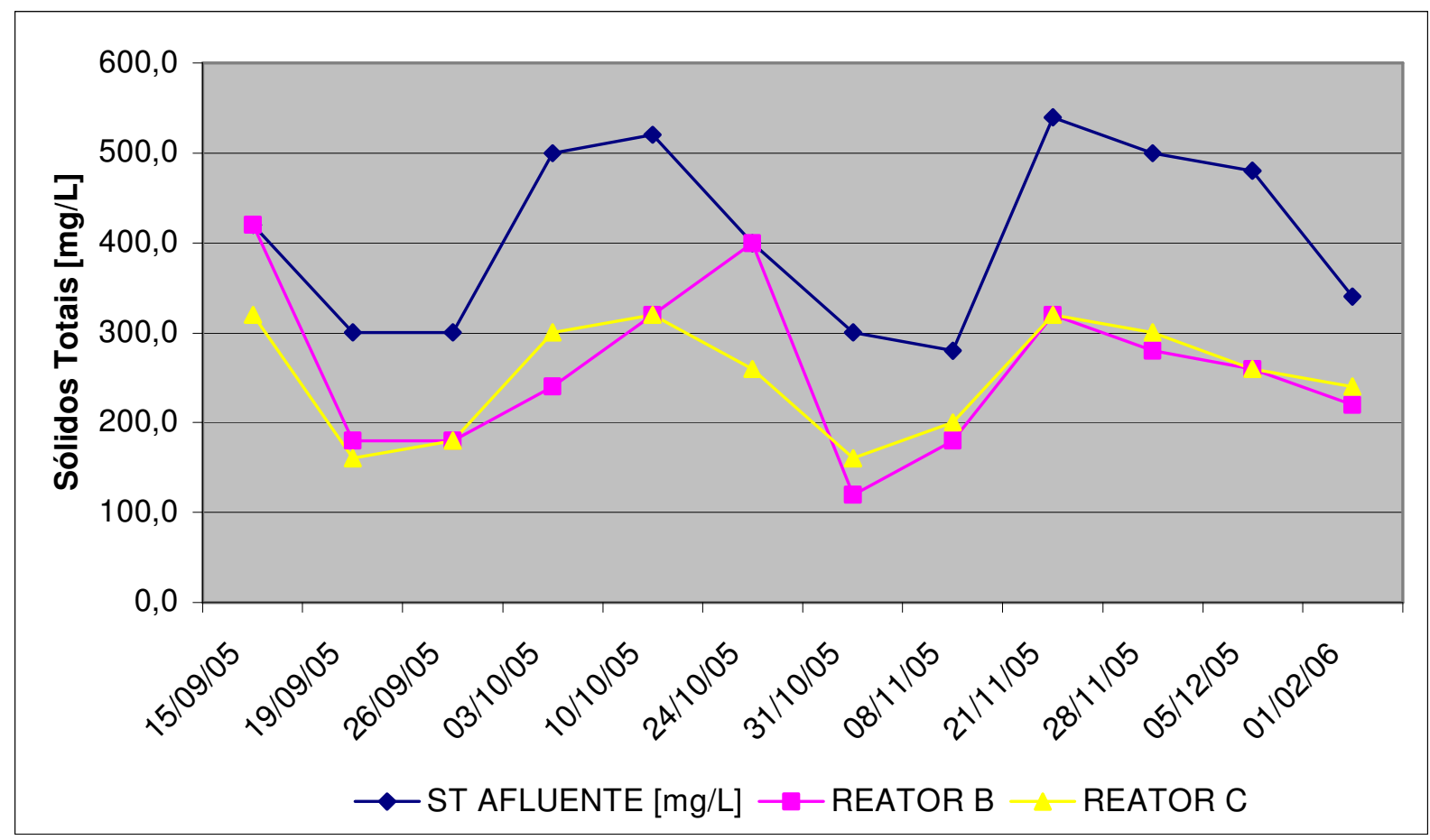

Figura 5.32 - Valores de sólidos totais afluentes e na saída dos reatores B e C: $2^{2}$ - Fase

Na Figura 5.32 observa-se que os reatores mantiveram-se com comportamento equivalente, com uma diferença de $150 \mathrm{mg} / \mathrm{L}$ a $200 \mathrm{mg} / \mathrm{L}$ entre entrada e saída.

Os valores médios estão apresentados na Tabela 5.19, com os dados estatísticos. Na Figura 5.33 mostram-se os gráficos dessa análise estatística.

Tabela 5.19 - Índices estatísticos de ortofosfatos afluente e de saída nos reatores B e C: $2^{2}$ Fase

\begin{tabular}{lccc}
\hline \multicolumn{1}{c}{$\begin{array}{c}\text { PONTO DE } \\
\text { COLETA }\end{array}$} & ESGOTO BRUTO & $\begin{array}{c}\text { EFLUENTE } \\
\text { REATOR B }\end{array}$ & $\begin{array}{c}\text { EFLUENTE } \\
\text { REATOR C }\end{array}$ \\
\hline $\begin{array}{l}\text { VALOR MÉDIO } \\
\text { [mg/L] }\end{array}$ & 406,7 & 260,0 & 251,7 \\
\hline MÍNIMO [mg/L] & 280,0 & 120,0 & 160,0 \\
\hline MÁXIMO [mg/L] & 540,0 & 420,0 & 320,0 \\
\hline $\begin{array}{l}\text { DESVIO } \\
\text { PADRÃO }\end{array}$ & 99,2 & 92,2 & 62,9 \\
\hline VARIANÇA & 0,24 & 0,35 & 0,25 \\
\hline $\begin{array}{l}\text { EFICIÊNCIA DE } \\
\text { REMOÇÃO [\%] }\end{array}$ & - & 36,1 & 38,1 \\
\hline
\end{tabular}


Desses comparativos, percebe-se uma igualdade dos dois reatores, com as eficiências de 36,1\% (reator B) e 38,1\% (reator C).

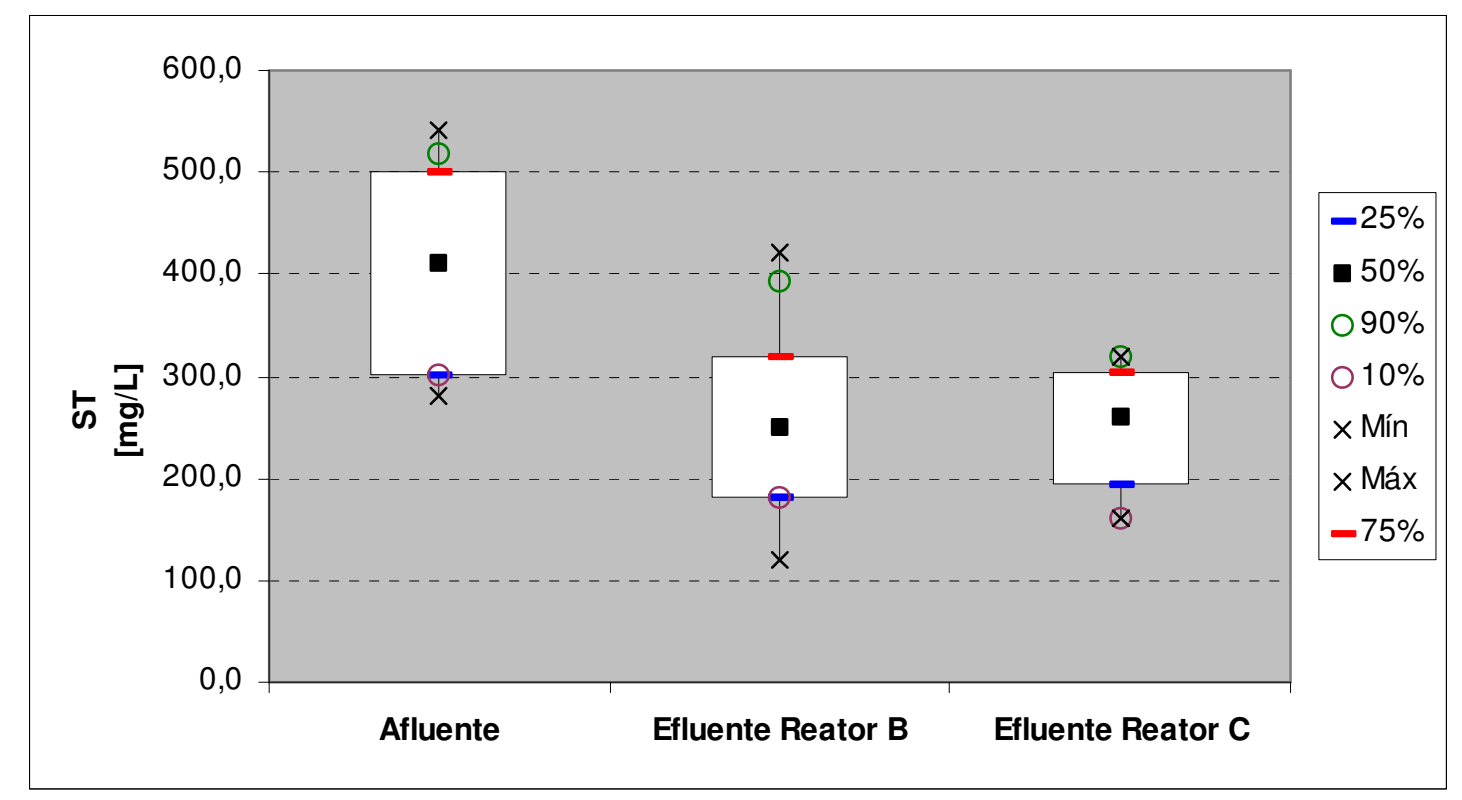

Figura 5.33 - Sólidos totais da 2ª Fase: análise estatística

\subsubsection{Sólidos Suspensos Totais}

Nesta etapa foram executadas 21 análises, mostradas no Capítulo 7. ANEXOS, na Tabela A.25.

Na Figura 5.34 observa-se que não diferença entre os 2 reatores, que mostraram valores bastante estáveis, ainda que o esgoto afluente tivesse concentrações maiores.

As saídas dos 2 reatores se mantiveram próximas a $50 \mathrm{mg} / \mathrm{L}$, quase não variando, mesmo com as alterações do esgoto bruto. 


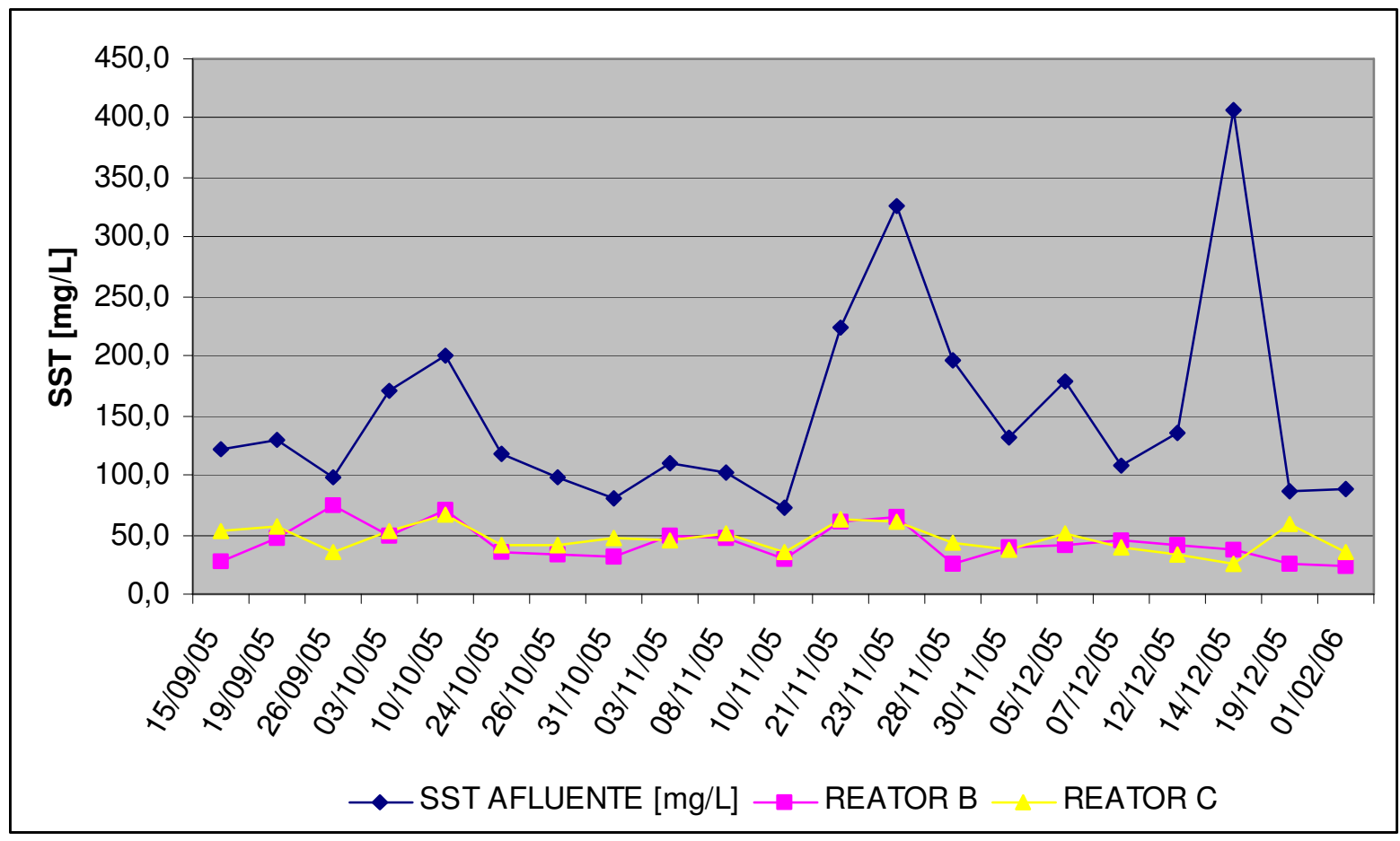

Figura 5.34 - Valores de sólidos suspensos totais afluentes e na saída dos reatores B e C: $2^{\text {a }}$ Fase

Os valores médios estão apresentados na Tabela 5.20, com os dados estatísticos dessa amostragem. Na Figura 5.35 mostram-se os gráficos dessa análise estatística.

Tabela 5.20 - Índices estatísticos de SST afluente e de saída nos reatores B e C: $2^{\underline{a}}$ Fase

\begin{tabular}{lccc}
\hline \multicolumn{1}{c}{$\begin{array}{c}\text { PONTO DE } \\
\text { COLETA }\end{array}$} & ESGOTO BRUTO & $\begin{array}{c}\text { EFLUENTE } \\
\text { REATOR B }\end{array}$ & $\begin{array}{c}\text { EFLUENTE } \\
\text { REATOR C }\end{array}$ \\
\hline $\begin{array}{l}\text { VALOR MÉDIO } \\
\text { [mg/L] }\end{array}$ & 151,4 & 43,2 & 46,8 \\
\hline MíNIMO [mg/L] & 72,0 & 24,0 & 26,0 \\
\hline MÁXIMO [mg/L] & 406,0 & 74,0 & 66,0 \\
\hline $\begin{array}{l}\text { DESVIO } \\
\text { PADRÃO }\end{array}$ & 83,8 & 14,5 & 10,7 \\
\hline VARIANÇA & 0,55 & 0,34 & 0,23 \\
\hline $\begin{array}{l}\text { EFICIÊNCIA DE } \\
\text { REMOÇÃO [\%] }\end{array}$ & - & 71,5 & 69,1 \\
\hline
\end{tabular}

As remoções médias também foram muito parecidas, sendo $71,5 \%$ para o reator $B$ e $69,1 \%$ para o reator $C$. 


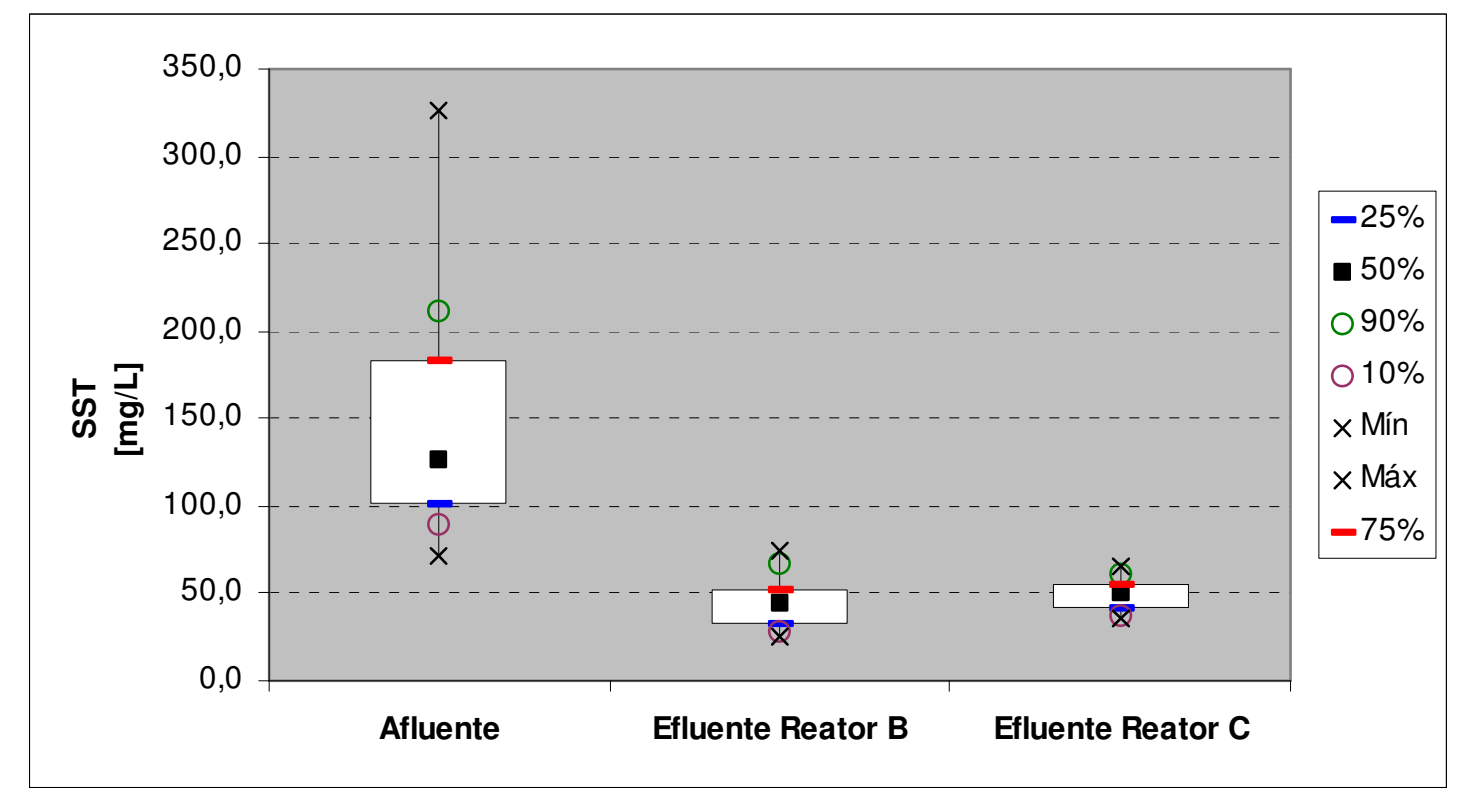

Figura 5.35 - Sólidos suspensos totais da $2^{\underline{a}}$ Fase: análise estatística

\subsubsection{Sólidos Suspensos Voláteis}

Nesta etapa foram executadas 21 análises, mostradas no Capítulo 7. ANEXOS, na Tabela A.27. Na Figura 5.36 observa-se que as respostas dos reatores acompanharam o desempenho apresentado quanto aos sólidos suspensos totais.

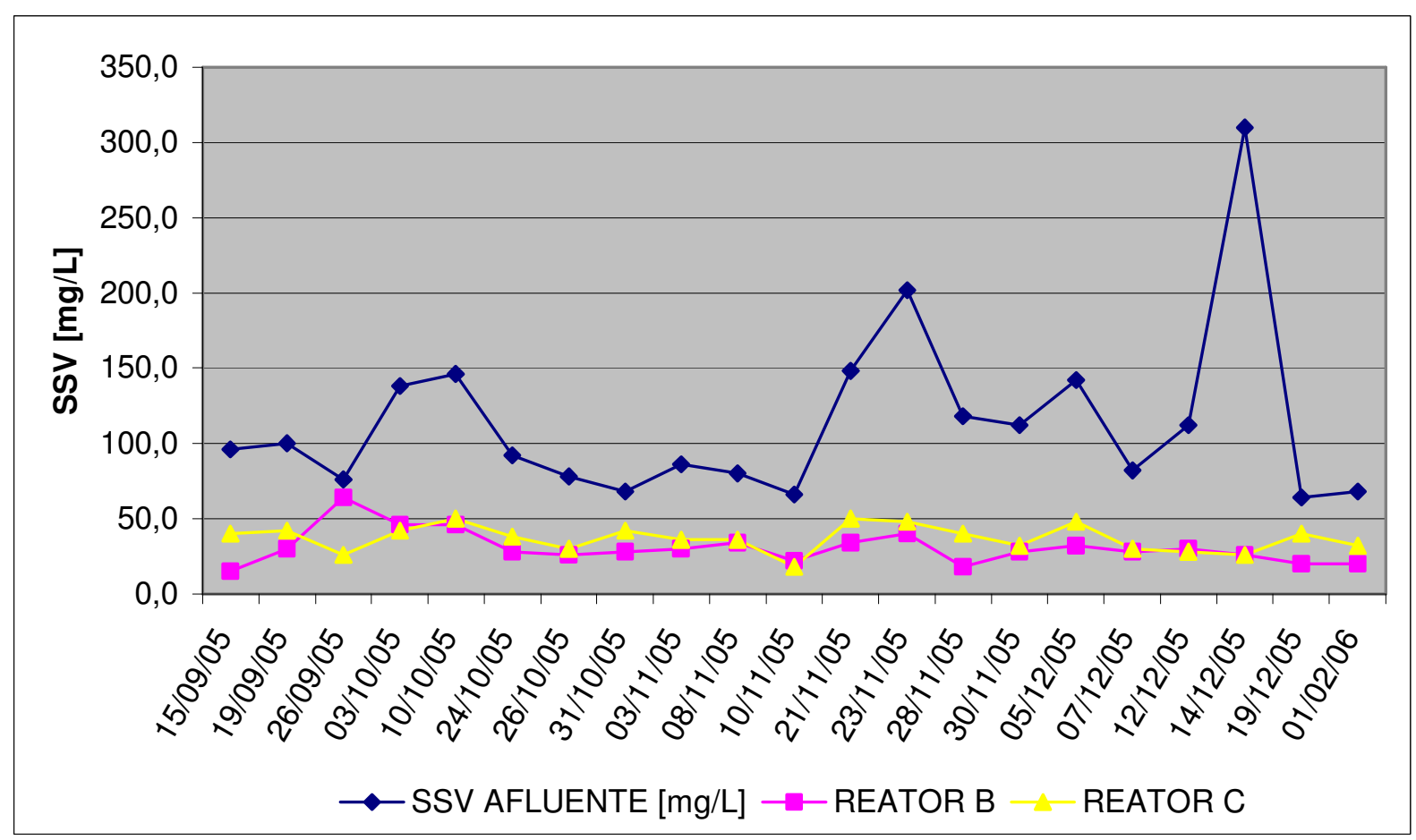

Figura 5.36 - Valores de sólidos suspensos voláteis afluentes e na saída dos reatores B e C: $2^{\underline{a}}$ Fase 
Os valores médios estão apresentados na Tabela 5.21, com os dados estatísticos da amostragem. A Figura 5.37 mostra os gráficos dessa análise estatística.

Tabela 5.21 - Índices estatísticos de SSV afluente e de saída nos reatores B e C: 2ª Fase

\begin{tabular}{lccc}
\hline $\begin{array}{c}\text { PONTO DE } \\
\text { COLETA }\end{array}$ & ESGOTO BRUTO & $\begin{array}{c}\text { EFLUENTE } \\
\text { REATOR B }\end{array}$ & $\begin{array}{c}\text { EFLUENTE } \\
\text { REATOR C }\end{array}$ \\
\hline $\begin{array}{l}\text { VALOR MÉDIO } \\
\text { [mg/L] }\end{array}$ & 113,5 & 30,7 & 36,9 \\
\hline MíNIMO [mg/L] & 64,0 & 15,0 & 18,0 \\
\hline MÁXIMO [mg/L] & 310,0 & 64,0 & 50,0 \\
\hline $\begin{array}{l}\text { DESVIO } \\
\text { PADRÃO }\end{array}$ & 57,2 & 11,1 & 8,7 \\
\hline VARIANÇA & 0,50 & 0,36 & 0,24 \\
\hline $\begin{array}{l}\text { EFICIÊNCIA DE } \\
\text { REMOÇÃO [\%] }\end{array}$ & - & 72,9 & 67,5 \\
\hline
\end{tabular}

Nota-se uma discreta vantagem para o reator B, com eficiência de $72,9 \%$, contra $67,5 \%$ do reator $\mathrm{C}$.

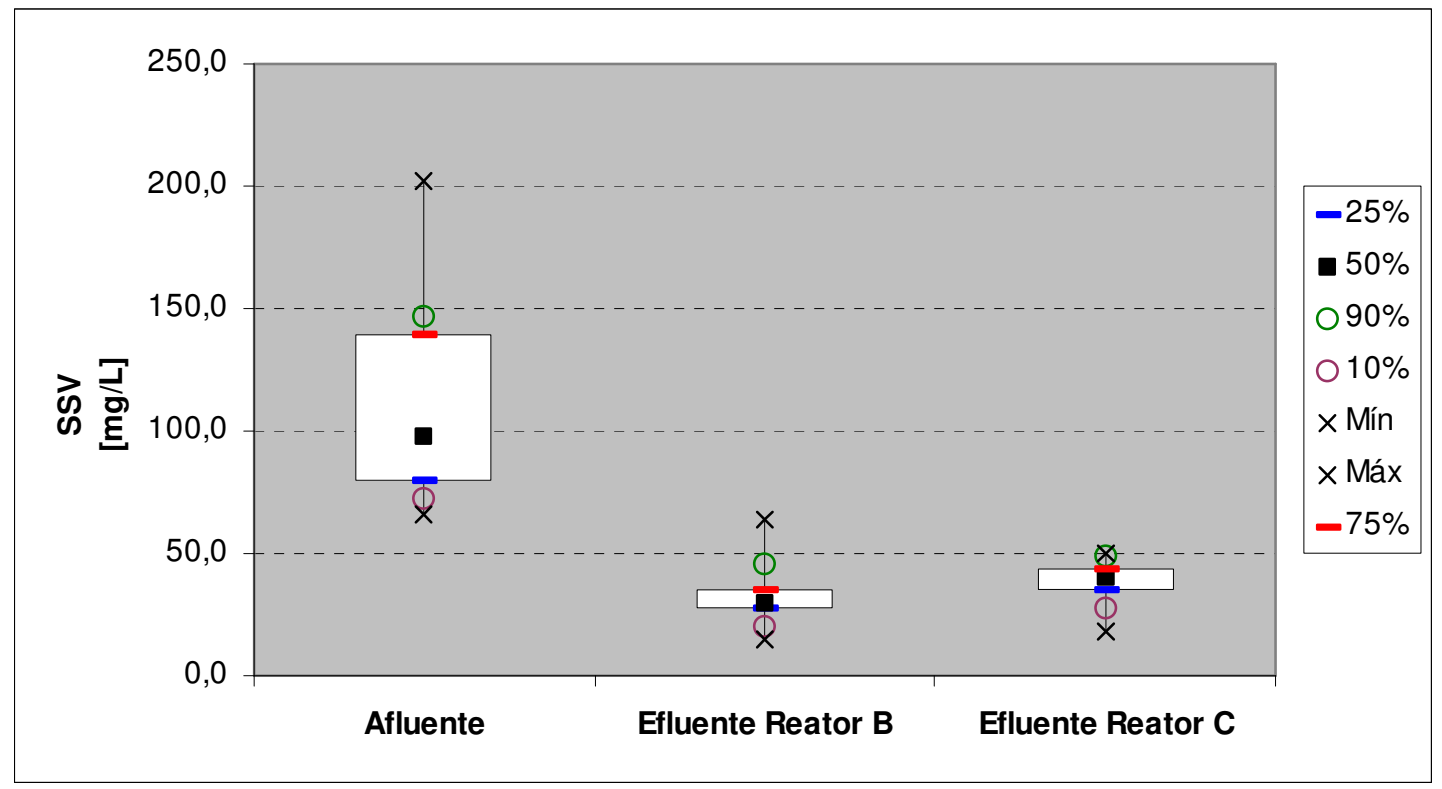

Figura 5.37 - Sólidos suspensos voláteis da $2^{2}$ - Fase: análise estatística 


\subsubsection{Sólidos Sedimentáveis}

Para este parâmetro foram realizadas análises semanais, num total de 11, mostradas no Capítulo 7. ANEXOS, na Tabela A.28. Na Figura 5.38 tem-se os resultados da avaliação, sendo que os valores nos efluentes dos 2 reatores continuaram próximos a $0 \mathrm{~mL} / \mathrm{L}$ (zero).

A exemplo da $1^{\text {a }}$ fase, aqui também os efluentes se mantiveram constantes e próximos a zero nos dois reatores. Com isto, delineia-se uma eficiência alta de remoção desse parâmetro independente da dosagem ou não de coagulante na entrada do tratamento. $O$ que foi observado é que há um aumento nos valores de sólidos sedimentáveis quando da ocorrência de chuvas.

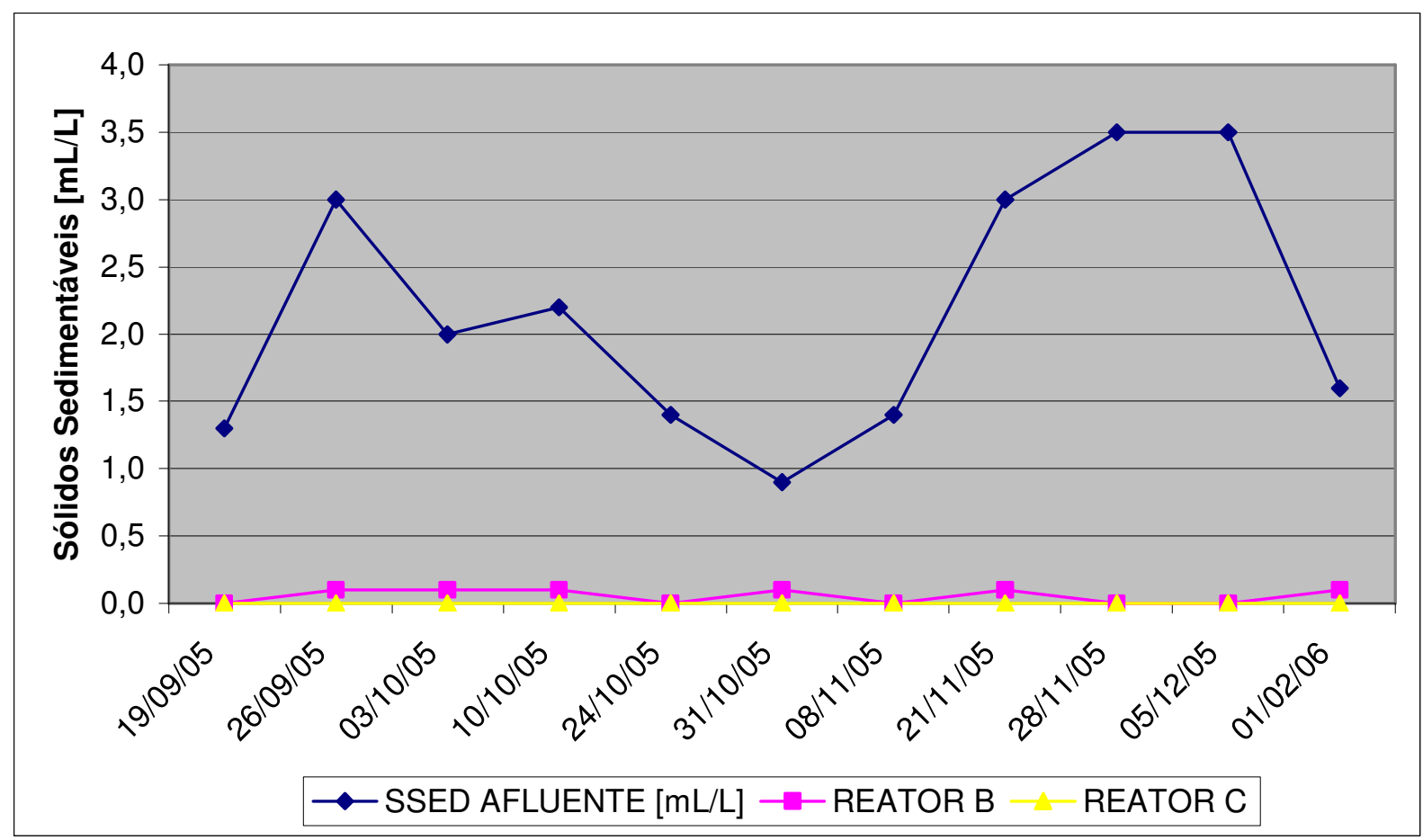

Figura 5.38 - Valores de sólidos sedimentáveis afluentes e na saída dos reatores B e C: 2ª Fase

Os valores médios estão apresentados na Tabela 5.22, aonde se tem ainda os dados estatísticos dessa amostragem. A Figura 5.39 mostra os gráficos da análise estatística. $O$ reator $C$ produziu, em todo o período da $1^{\underline{a}}$ fase, $0,0 \mathrm{~mL} / \mathrm{L}$, enquanto 0 reator $B$ variou entre 0,0 e $0,1 \mathrm{~mL} / \mathrm{L}$. 
Tabela 5.22 - Índices estatísticos de $\mathrm{S}_{\text {sed. }}$ afluente e de saída nos reatores B e C: $2^{2}{ }^{\mathrm{a}}$ Fase

\begin{tabular}{lccc}
\hline $\begin{array}{c}\text { PONTO DE } \\
\text { COLETA }\end{array}$ & ESGOTO BRUTO & $\begin{array}{c}\text { EFLUENTE } \\
\text { REATOR B }\end{array}$ & $\begin{array}{c}\text { EFLUENTE } \\
\text { REATOR C }\end{array}$ \\
\hline $\begin{array}{l}\text { VALOR MÉDIO } \\
\text { [mL/L] }\end{array}$ & 2,2 & 0,1 & 0,0 \\
\hline MíNIMO [mL/L] & 0,9 & 0,0 & 0,0 \\
\hline MÁXIMO [mL/L] & 3,5 & 0,1 & 0,0 \\
\hline $\begin{array}{l}\text { DESVIO } \\
\text { PADRÃO }\end{array}$ & 0,9 & 0,1 & 0,0 \\
\hline VARIANÇA & 0,43 & 0,96 & - \\
\hline $\begin{array}{l}\text { EFICIÊNCIA DE } \\
\text { REMOÇÃO [\%] }\end{array}$ & - & 97,5 & 100,0 \\
\hline
\end{tabular}

$\mathrm{Na}$ entrada, a variação foi mais pronunciada, como dito anteriormente, devido às chuvas, que, pela grande contribuição de infiltrações na rede coletora.

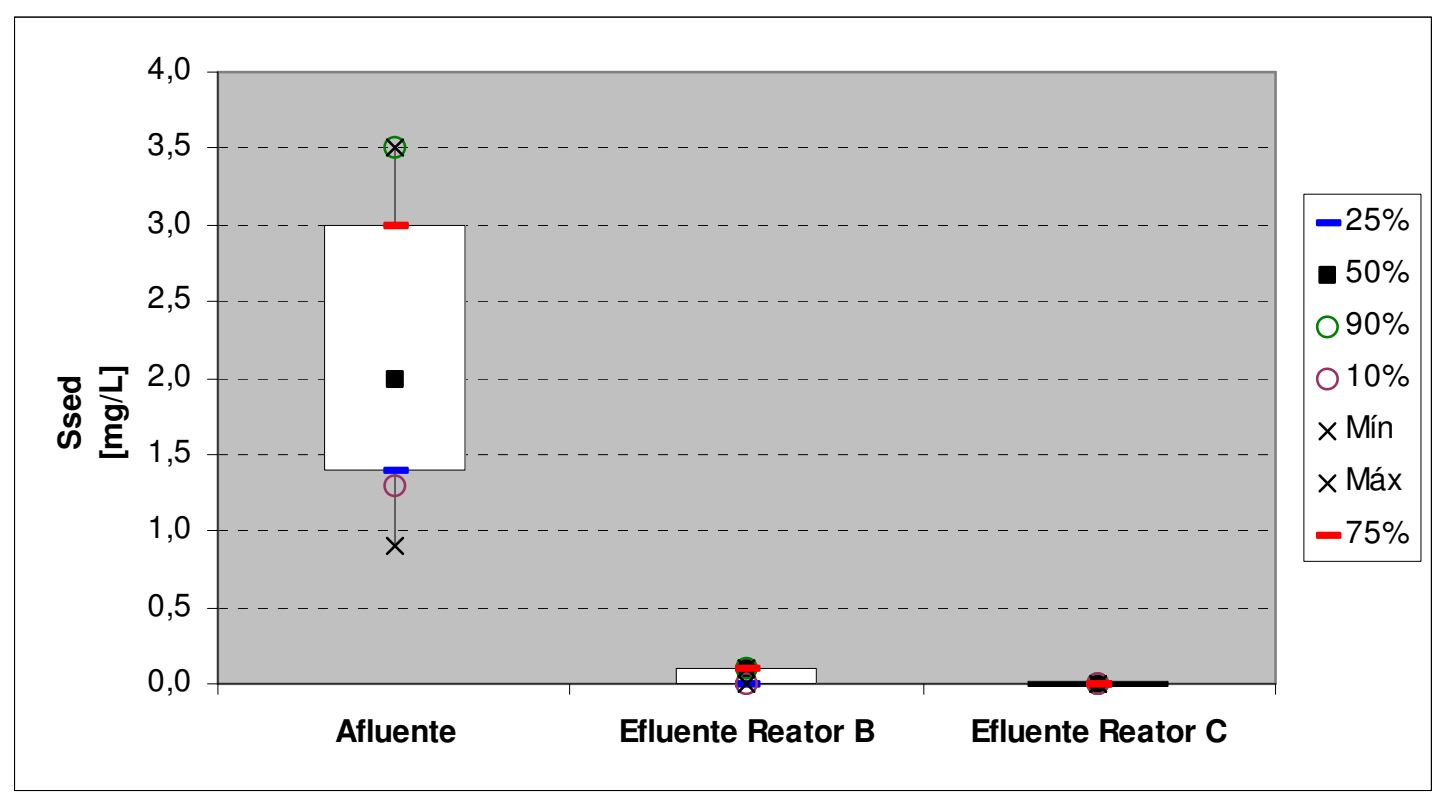

Figura 5.39 - Sólidos sedimentáveis da 2ª Fase: análise estatística

\subsubsection{2. $p H$}

$\mathrm{O} \mathrm{pH}$ do esgoto afluente bem como dos 2 reatores foram acompanhados com a finalidade de antever qualquer desequilíbrio operacional nos mesmos. Foram realizadas 19 análises, mostradas no Capítulo 7. ANEXOS, na Tabela A.29. Na 
Figura 5.40 notamos que ao longo de 4 meses de dosagem não houve mudança significativa em nenhum dos 2 reatores.

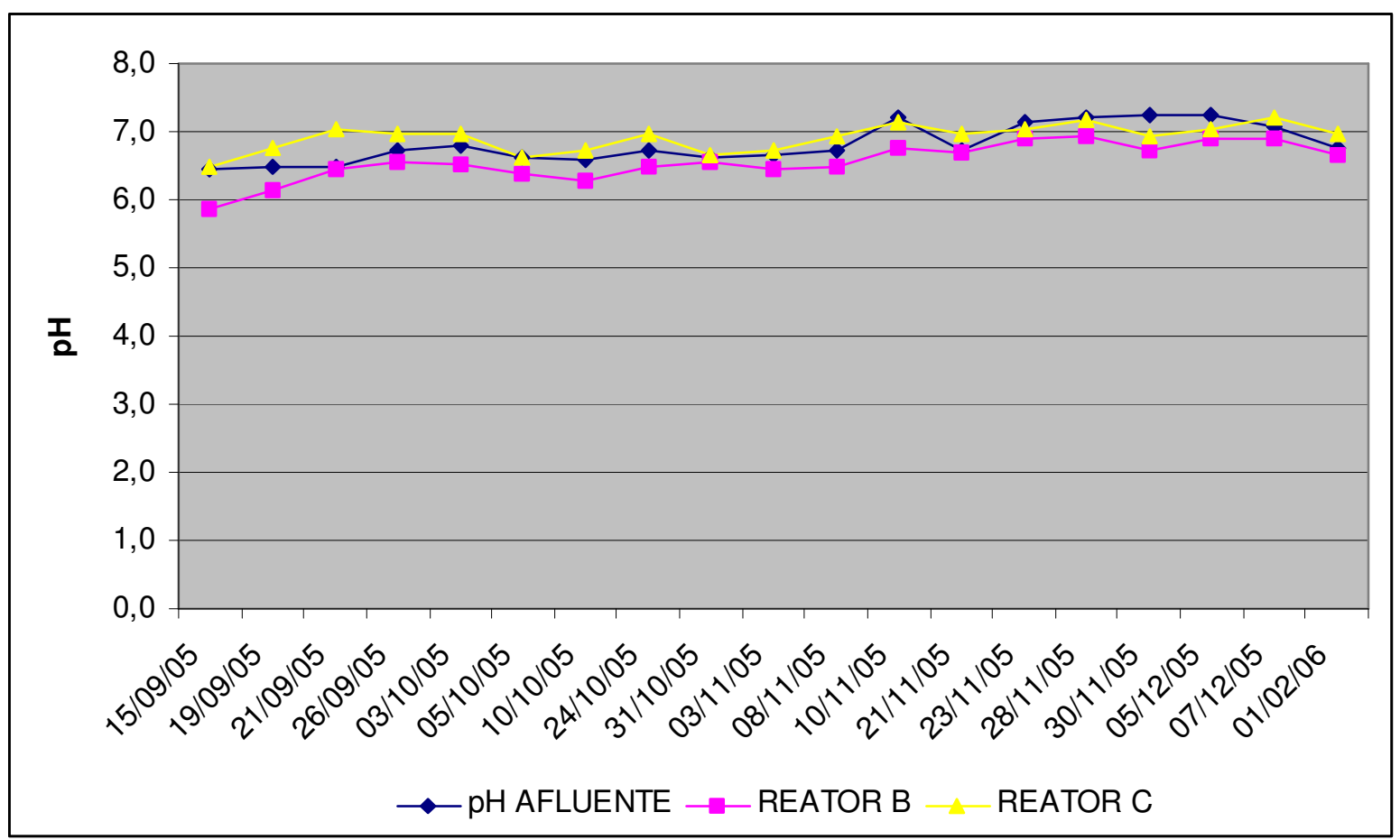

Figura 5.40 - Valores de $\mathrm{pH}$ no esgoto afluente e nos reatores $\mathrm{B}$ e C: $2^{\mathrm{a}}$ Fase

Os valores médios estão apresentados na Tabela 5.23 , aonde se tem ainda os dados estatísticos da amostragem. A Figura 5.41 mostra os gráficos dessa análise estatística.

Tabela 5.23 - Índices estatísticos de pH no esgoto afluente e dos reatores B e C: $2^{2}$ Fase

\begin{tabular}{lccc}
\hline $\begin{array}{c}\text { PONTO DE } \\
\text { COLETA }\end{array}$ & ESGOTO BRUTO & $\begin{array}{c}\text { EFLUENTE } \\
\text { REATOR B }\end{array}$ & $\begin{array}{c}\text { EFLUENTE } \\
\text { REATOR C }\end{array}$ \\
\hline VALOR MÉDIO & 6,8 & 6,6 & 6,9 \\
\hline MÍNIMO & 6,5 & 5,9 & 6,5 \\
\hline MÁXIMO & 7,3 & 6,9 & 7,2 \\
\hline DESVIO & 0,3 & 0,3 & 0,2 \\
\hline PADRÃO & 0,04 & 0,04 & 0,03 \\
\hline VARIANÇA & & &
\end{tabular}

Percebe-se uma muito reduzida diminuição desse parâmetro, provavelmente pela adição do cloreto férrico. 


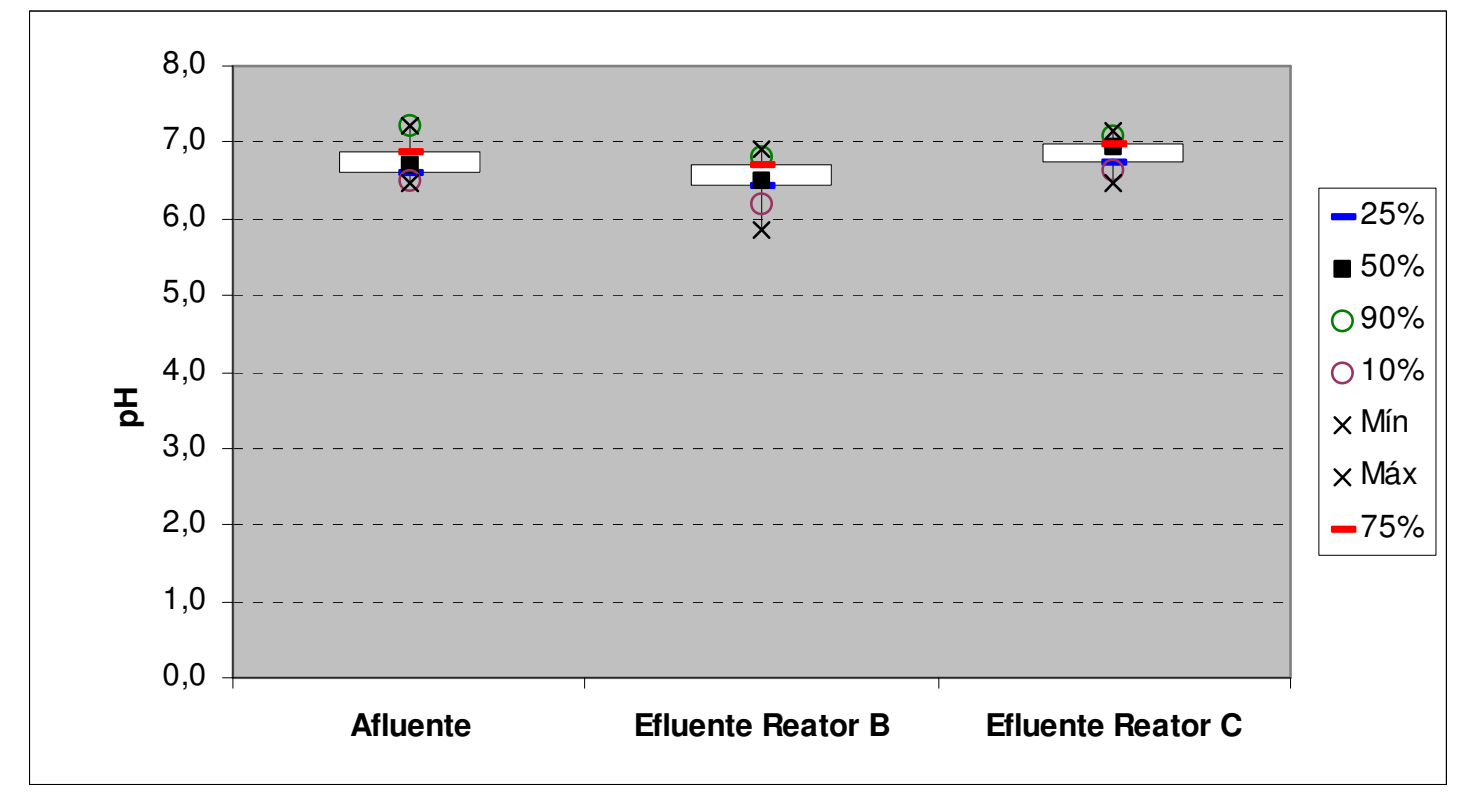

Figura 5.41 - pH durante a 2 ${ }^{\mathrm{a}}$ Fase: análise estatística

\subsubsection{Alcalinidade}

Outro parâmetro de controle foi a alcalinidade dos 2 reatores, os quais foram acompanhados a fim de se precaver contra seu eventual desequilíbrio. Foram realizadas 19 análises, mostradas no Capítulo 7. ANEXOS, na Tabela A.30.

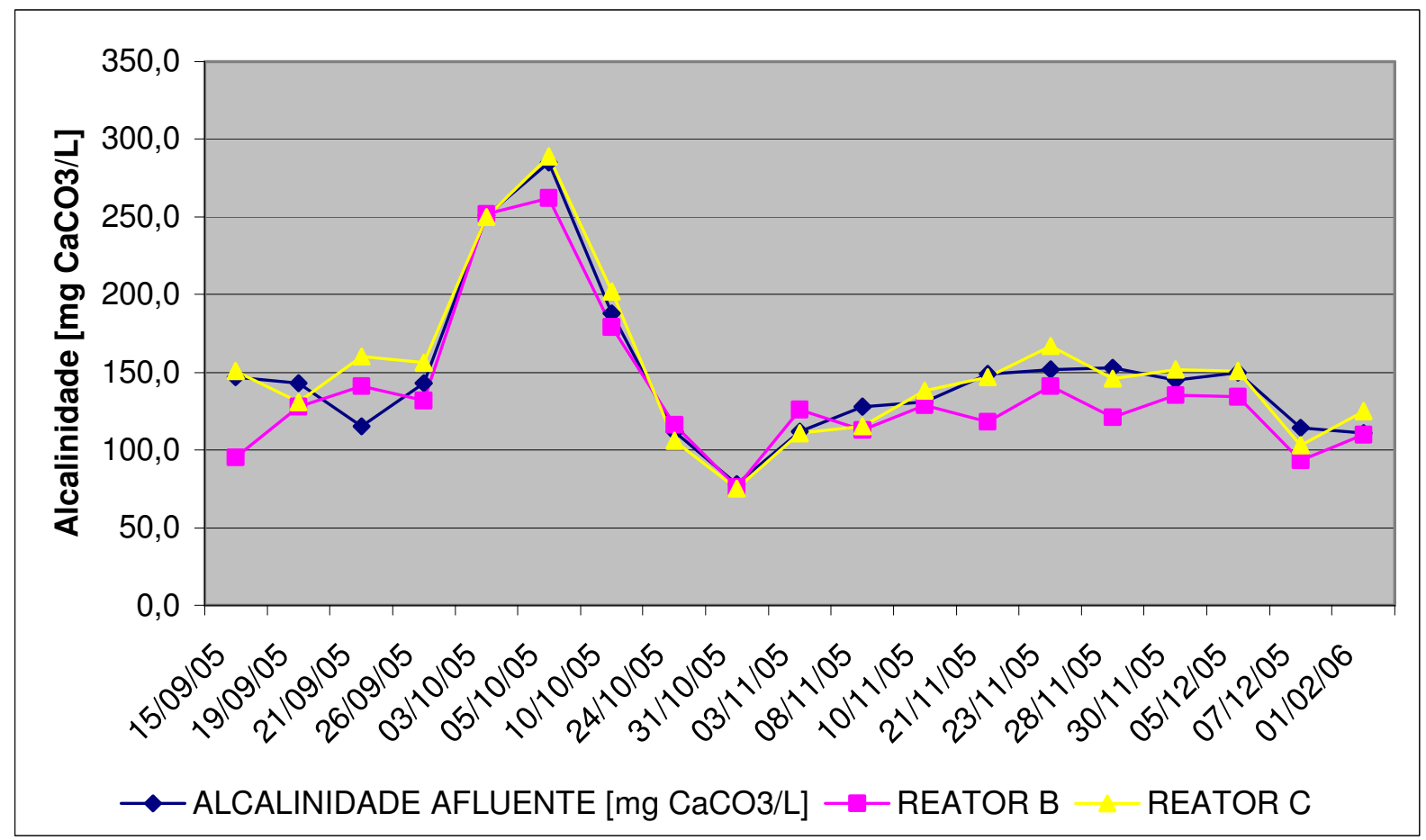

Figura 5.42 - Valores de alcalinidade do esgoto afluente e dos reatores B e C: $2^{a}$ Fase 
Na Figura 5.42 tem-se claramente que esse parâmetro variou de forma idêntica em função da entrada, sem cair a valores problemáticos.

Os valores médios estão apresentados na Tabela 5.24 , aonde se tem ainda os dados estatísticos dessa amostragem. A Figura 5.43 mostra os gráficos da análise estatística.

Tabela 5.24 - Índices estatísticos de alcalinidade do esgoto afluente e dos reatores B e C: $2^{\mathrm{a}}$ Fase

\begin{tabular}{|c|c|c|c|}
\hline $\begin{array}{c}\text { PONTO DE } \\
\text { COLETA }\end{array}$ & ESGOTO BRUTO & $\begin{array}{l}\text { EFLUENTE } \\
\text { REATOR B }\end{array}$ & $\begin{array}{l}\text { EFLUENTE } \\
\text { REATOR C }\end{array}$ \\
\hline $\begin{array}{l}\text { VALOR MÉDIO } \\
\left.\text { [mg CaCO }_{3} / \mathrm{L}\right]\end{array}$ & 148 & 137 & 151 \\
\hline $\begin{array}{l}\text { MíNIMO [mg } \\
\mathrm{CaCO}_{3} / \mathrm{L} \text { ] }\end{array}$ & 78 & 76 & 75 \\
\hline $\begin{array}{l}\text { MÁXIMO [mg } \\
\left.\mathrm{CaCO}_{3} / \mathrm{L}\right]\end{array}$ & 285 & 262 & 289 \\
\hline $\begin{array}{l}\text { DESVIO } \\
\text { PADRÃO }\end{array}$ & 48,8 & 47,6 & 50,6 \\
\hline VARIANÇA & 0,33 & 0,35 & 0,33 \\
\hline
\end{tabular}

Há, como se pode ver na Figura 5.43, uma pequena diminuição da alcalinidade, conseqüência da adição dos $25 \mathrm{mg} / \mathrm{L}$ de cloreto férrico.

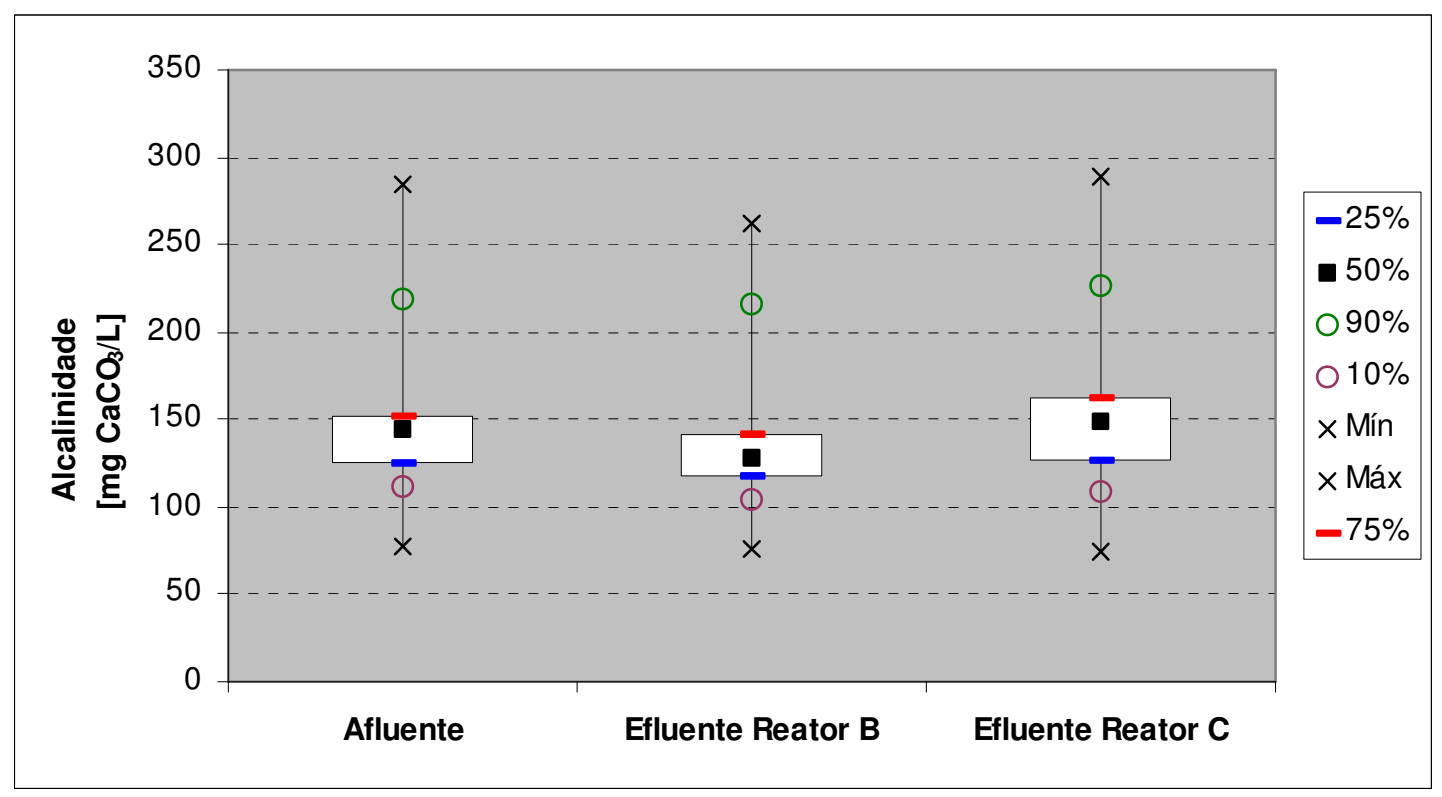

Figura 5.43 - Alcalinidade durante a $2^{\underline{a}}$ Fase: análise estatística 


\subsection{Resultados da 3a Fase - Com Adição de $50 \mathrm{mg} / \mathrm{L}$ de Cloreto Férrico}

A $3^{\text {a }}$ fase do trabalho se deu entre março e maio de 2006, quando foi realizada a dosagem de coagulante $\left(\mathrm{FeCl}_{3}\right)$, na concentração de $50 \mathrm{mg}$ por litro de esgoto afluente ao reator $B$, mantendo-se $o$ reator $C$ sem qualquer aplicação. Os parâmetros acompanhados foram os mesmos da $2^{\underline{a}}$ Fase.

Neste período notou-se uma vazão maior no esgoto afluente, devido a, além das contribuições de infiltração já existentes, um ponto concentrado, num rompimento da rede coletora junto ao Ribeirão Pires, nas proximidades da elevatória EE-5. Uma comprovação desse fato foi a presença constante nessa fase de peixes no gradeamento e nos reatores da ETE.

Após a substituição dos materiais, só houve uma interrupção na dosagem de cloreto férrico, ocorrida entre os dias 7 e 10/4/06.

No final desta fase, a ETE teve uma interrupção em seu funcionamento, devida ao rompimento da linha de recalque da elevatória final EE-5.

Com isto, as fases de dosagem de $50 \mathrm{mg} / \mathrm{L}$ contou com somente 18 amostras de fósforo e ortofosfato e a seguinte, de $100 \mathrm{mg} / \mathrm{L}$, inicialmente prevista, não pode ser concretizada.

\subsubsection{DQO Total}

Nesta fase foram realizadas 18 análises, mostradas no Capítulo 7. ANEXOS, na Tabela A.31. Na Figura 5.44 é possível verificar as melhores respostas do reator B, que na maior parte do tempo exibiu concentrações abaixo de $100 \mathrm{mg} / \mathrm{L}$.

Em 17/5/06, quando a DQO afluente subiu para $646 \mathrm{mg} / \mathrm{L}$, a carga do efluente manteve-se abaixo dos $150 \mathrm{mg} / \mathrm{L}$, enquanto que no reator $\mathrm{C}$ foi de $262 \mathrm{mg} / \mathrm{L}$. 


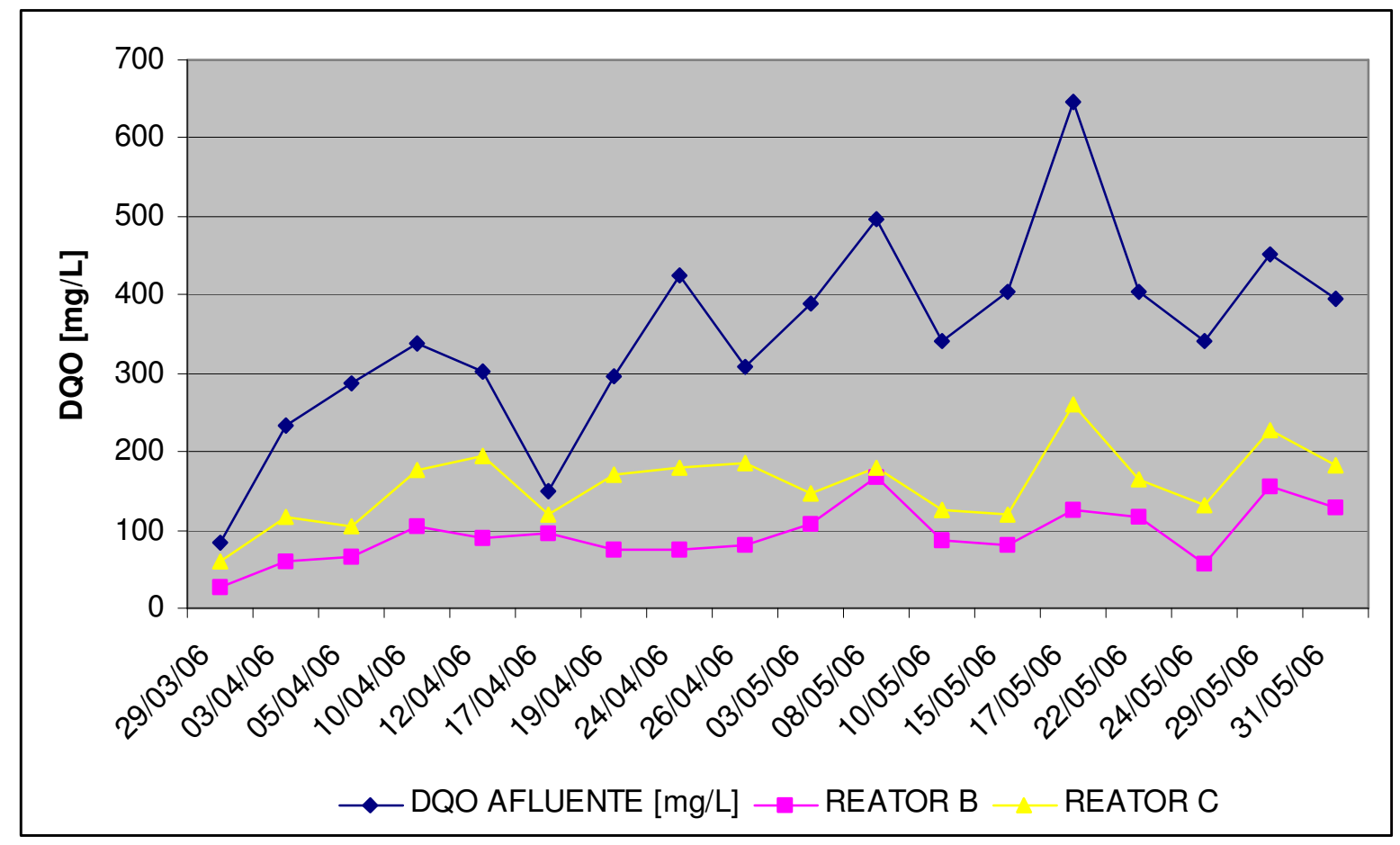

Figura 5.44 - Valores de DQO total afluente e nas saídas dos reatores B e C: $3^{\text {a }}$ Fase

Os valores médios obtidos estão apresentados na Tabela 5.25, com os respectivos dados estatísticos dessa amostragem. Na Figura 5.45 estão as representações gráficas da análise estatística.

Tabela 5.25 - Índices estatísticos da DQO total afluente e da saída dos reatores B e C: $3^{\underline{a}}$ Fase

\begin{tabular}{lccc}
\hline \multicolumn{1}{c}{$\begin{array}{c}\text { PONTO DE } \\
\text { COLETA }\end{array}$} & ESGOTO BRUTO & $\begin{array}{c}\text { EFLUENTE } \\
\text { REATOR B }\end{array}$ & $\begin{array}{c}\text { EFLUENTE } \\
\text { REATOR C }\end{array}$ \\
\hline $\begin{array}{l}\text { VALOR MÉDIO } \\
\text { [mg/L] }\end{array}$ & 350 & 95 & 158 \\
\hline MÍNIMO [mg/L] & 84 & 28 & 60 \\
\hline MÁXIMO [mg/L] & 646 & 167 & 262 \\
\hline $\begin{array}{l}\text { DESVIO } \\
\text { PADRÃO }\end{array}$ & 126 & 35 & 48 \\
\hline VARIANÇA & 0,36 & 0,37 & 0,30 \\
\hline $\begin{array}{l}\text { EFICIÊNCIA DE } \\
\text { REMOÇÃO [\%] }\end{array}$ & - & 73,0 & 54,8 \\
\hline
\end{tabular}

A eficiência de remoção foi de $73 \%$ do reator $B$, contra os $54,8 \%$ do reator $C$. 


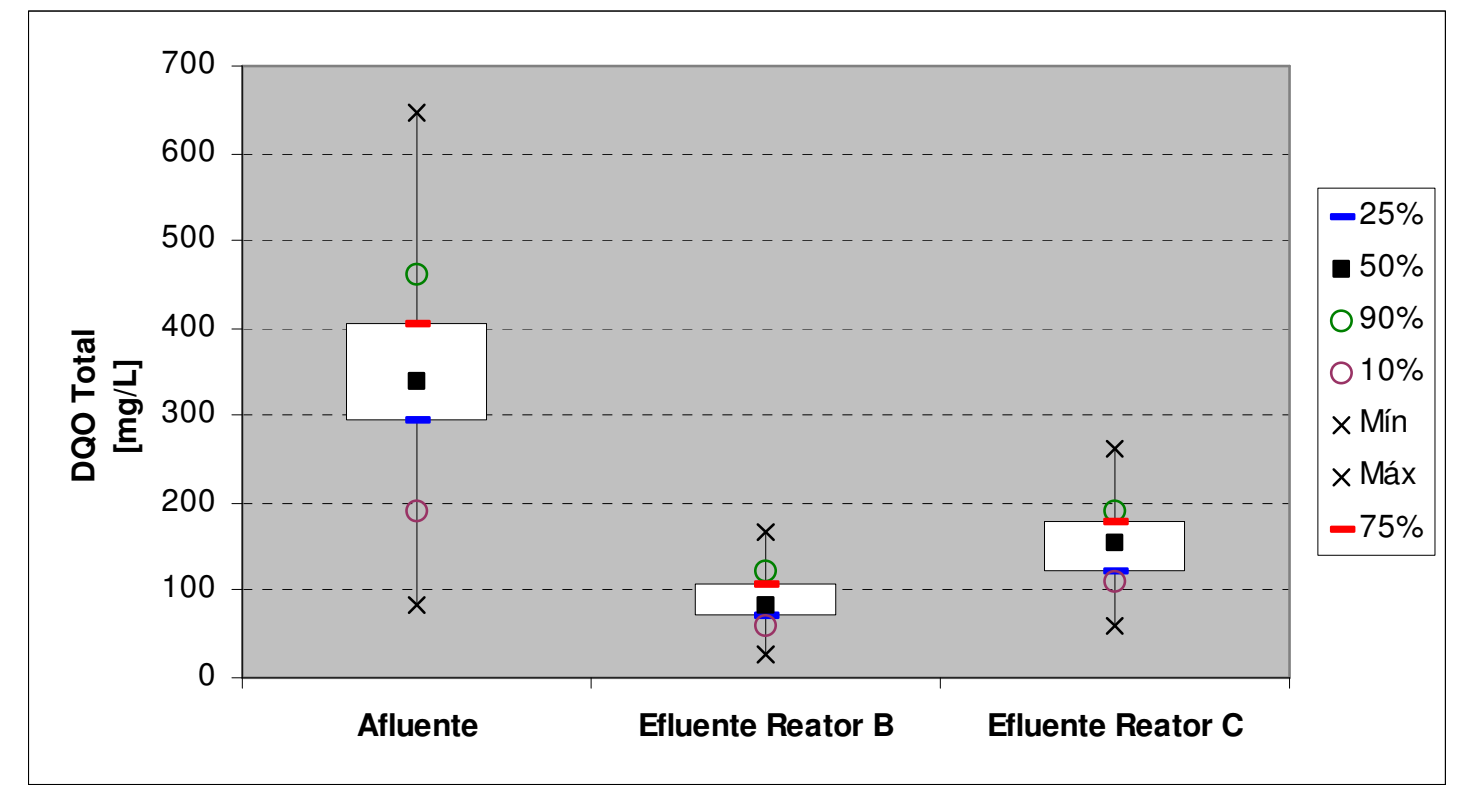

Figura 5.45 - DQO total da $3^{a}$ Fase: análise estatística

\subsubsection{DQO Filtrada}

Para este parâmetro foram realizadas 18 análises, como mostrado no Capítulo 7 . ANEXOS, na Tabela A.32. Na Figura 5.46 os dados estão representados.

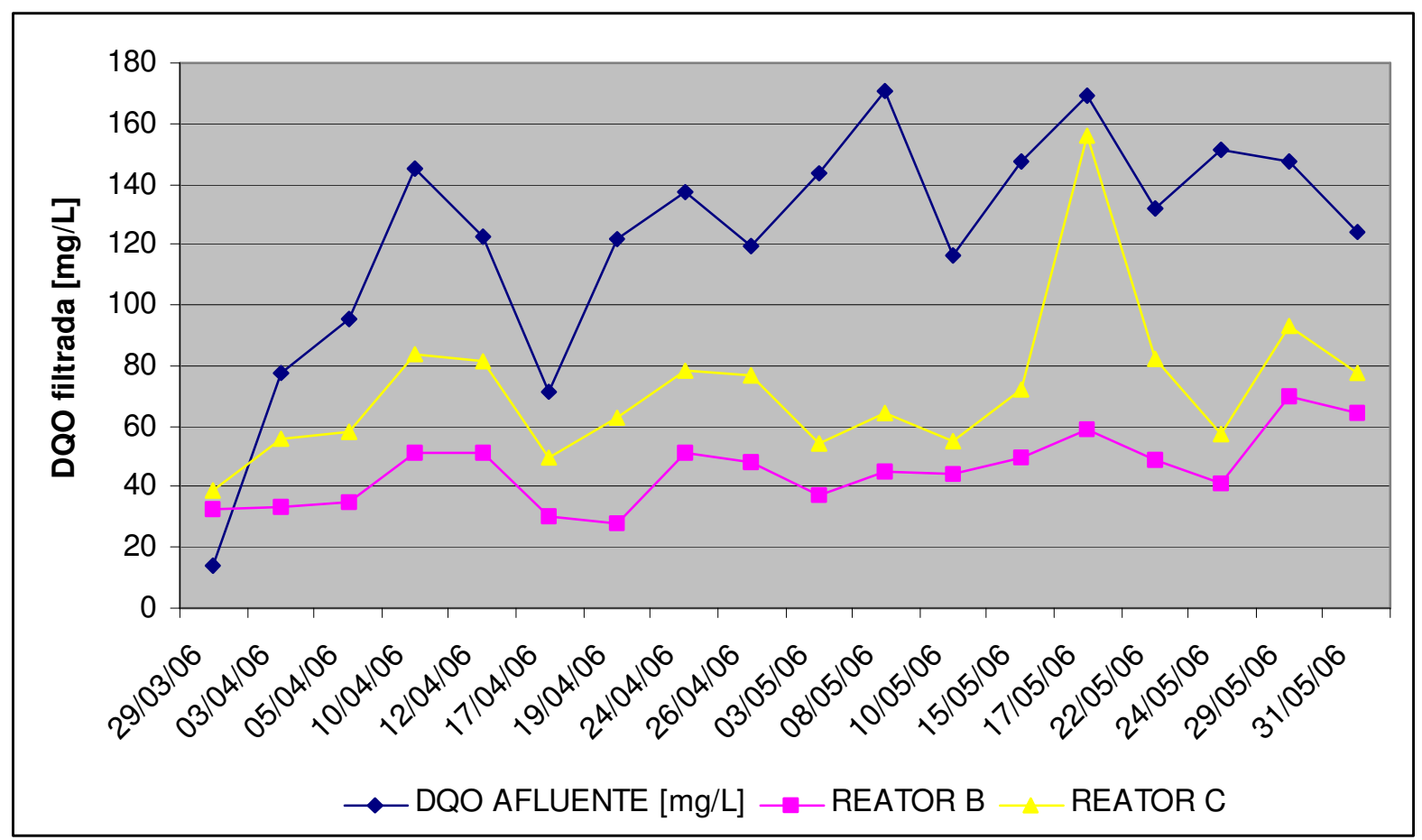

Figura 5.46 - Valores de DQO filtrada afluente e na saída dos reatores B e C: $3^{\text {a }}$ Fase 
Os valores médios obtidos estão apresentados na Tabela 5.26, com os dados estatísticos $\mathrm{Na}$ Figura 5.47 estão as representações gráficas dessa análise estatística.

Tabela 5.26 - Índices estatísticos da DQO filtrada afluente e de saída nos reatores B e C: $3^{\text {a }}$ Fase

\begin{tabular}{lccc}
\hline $\begin{array}{c}\text { PONTO DE } \\
\text { COLETA }\end{array}$ & ESGOTO BRUTO & $\begin{array}{c}\text { EFLUENTE } \\
\text { REATOR B }\end{array}$ & $\begin{array}{c}\text { EFLUENTE } \\
\text { REATOR C }\end{array}$ \\
\hline $\begin{array}{l}\text { VALOR MÉDIO } \\
\text { [mg/L] }\end{array}$ & 123 & 46 & 72 \\
\hline MÍNIMO [mg/L] & 14 & 28 & 38 \\
\hline MÁXIMO [mg/L] & 171 & 70 & 156 \\
\hline $\begin{array}{l}\text { DESVIO } \\
\text { PADRÃO }\end{array}$ & 38 & 12 & 25 \\
\hline VARIANÇA & 0,31 & 0,26 & 0,35 \\
\hline $\begin{array}{l}\text { EFICIÊNCIA DE } \\
\text { REMOÇÃO [\%] }\end{array}$ & - & 62,9 & 41,2 \\
\hline
\end{tabular}

As eficiências indicaram um melhor desempenho do reator B $(62,9 \%)$, porém menos pronunciada que na DQO total.

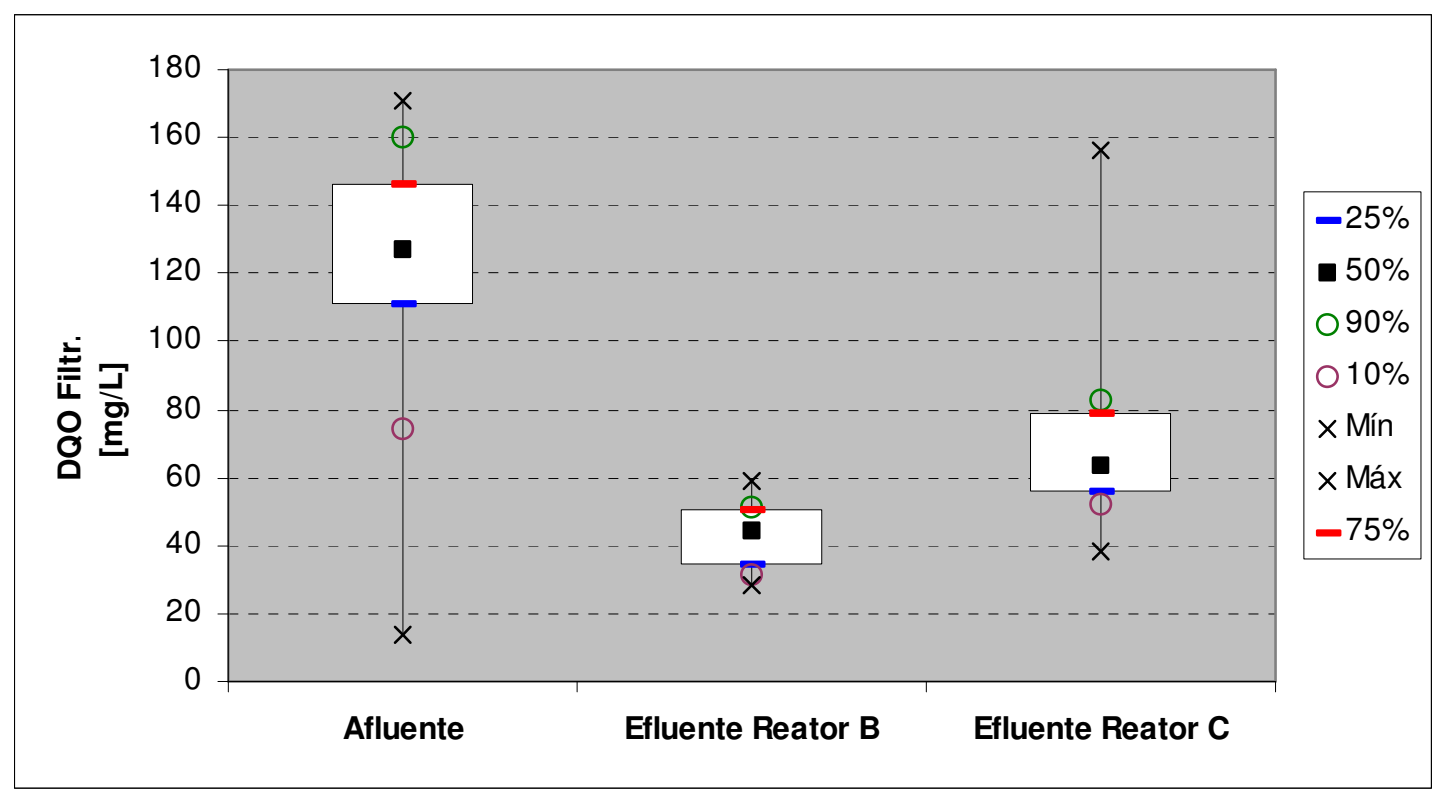

Figura 5.47 - DQO filtrada da 3ª Fase: análise estatística 


\subsection{3. $\mathrm{DBO}_{5,20^{\circ} \mathrm{C}}$ Total}

Foram realizadas 9 análises, mostradas no Capítulo 7. ANEXOS, na Tabela A.33. É digno de nota que, observando a Figura 5.48, o reator B sempre teve a DBO abaixo dos $50 \mathrm{mg} / \mathrm{L}$.

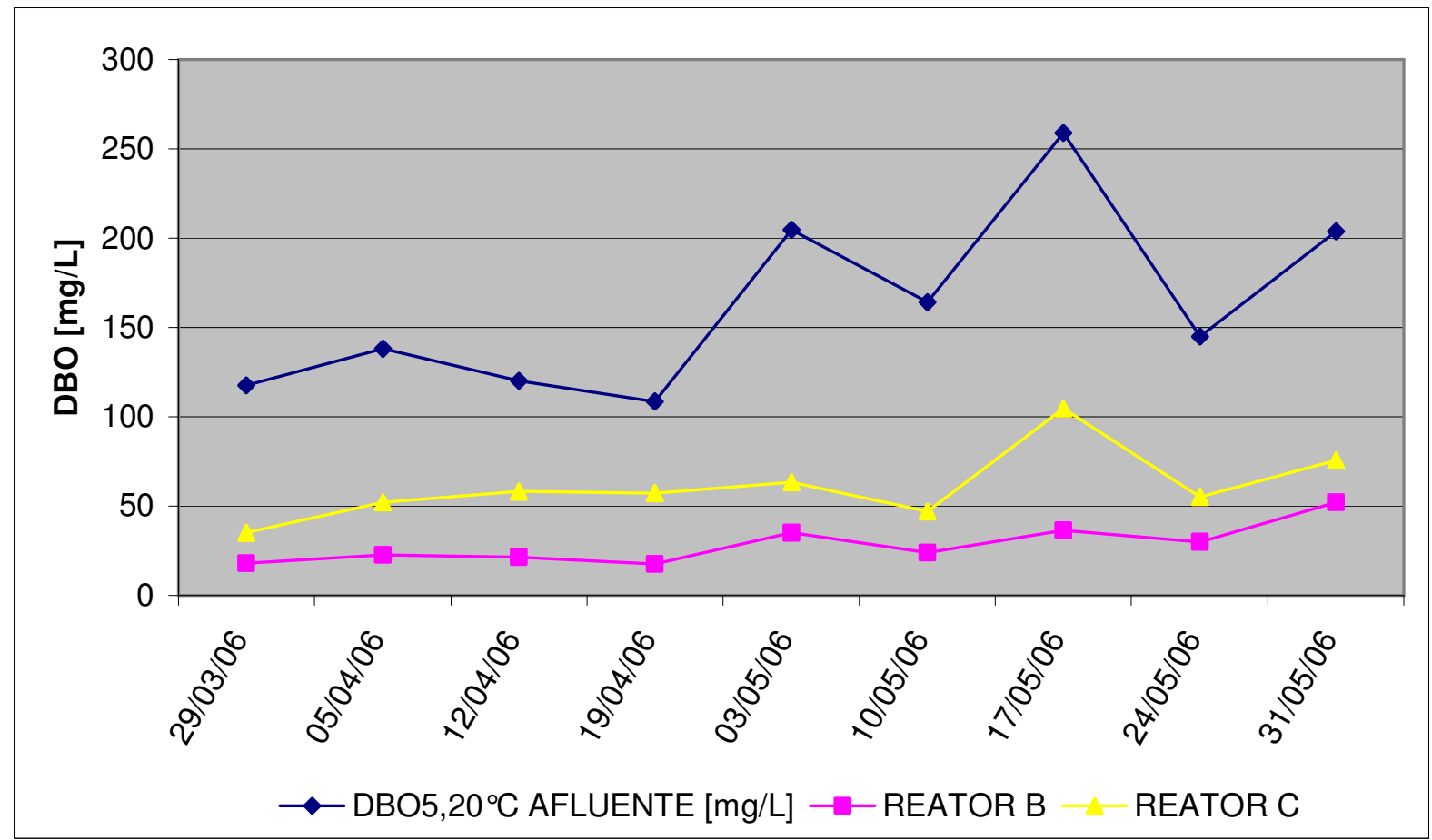

Figura 5.48 - Valores de $\mathrm{DBO}_{5,20^{\circ} \mathrm{C}}$ total afluente e na saída dos reatores $\mathrm{B}$ e C: $3^{\underline{a}}$ Fase

As médias obtidas estão apresentadas na Tabela 5.27, com o resumo do levantamento estatístico. Na Figura 5.49 estão as representações gráficas dessa análise estatística.

Tabela 5.27 - Índices estatísticos da $\mathrm{DBO}_{5,20^{\circ} \mathrm{C}}$ total afluente e de saída nos reatores $\mathrm{B}$ e C: $3^{\mathrm{a}}$ Fase

\begin{tabular}{lccc}
\hline \multicolumn{1}{c}{$\begin{array}{c}\text { PONTO DE } \\
\text { COLETA }\end{array}$} & ESGOTO BRUTO & $\begin{array}{c}\text { EFLUENTE } \\
\text { REATOR B }\end{array}$ & $\begin{array}{c}\text { EFLUENTE } \\
\text { REATOR C }\end{array}$ \\
\hline $\begin{array}{l}\text { VALOR MÉDIO } \\
\text { [mg/L] }\end{array}$ & 162 & 29 & 61 \\
\hline MíNIMO [mg/L] & 109 & 18 & 35 \\
\hline MÁXIMO [mg/L] & 259 & 52 & 105 \\
\hline $\begin{array}{l}\text { DESVIO } \\
\text { PADRÃO }\end{array}$ & 51 & 11 & 20 \\
\hline VARIANÇA & 0,31 & 0,39 & 0,32 \\
\hline $\begin{array}{l}\text { EFICIÊNCIA DE } \\
\text { REMOÇÃO [\%] }\end{array}$ & - & 82,4 & 62,5 \\
\hline
\end{tabular}




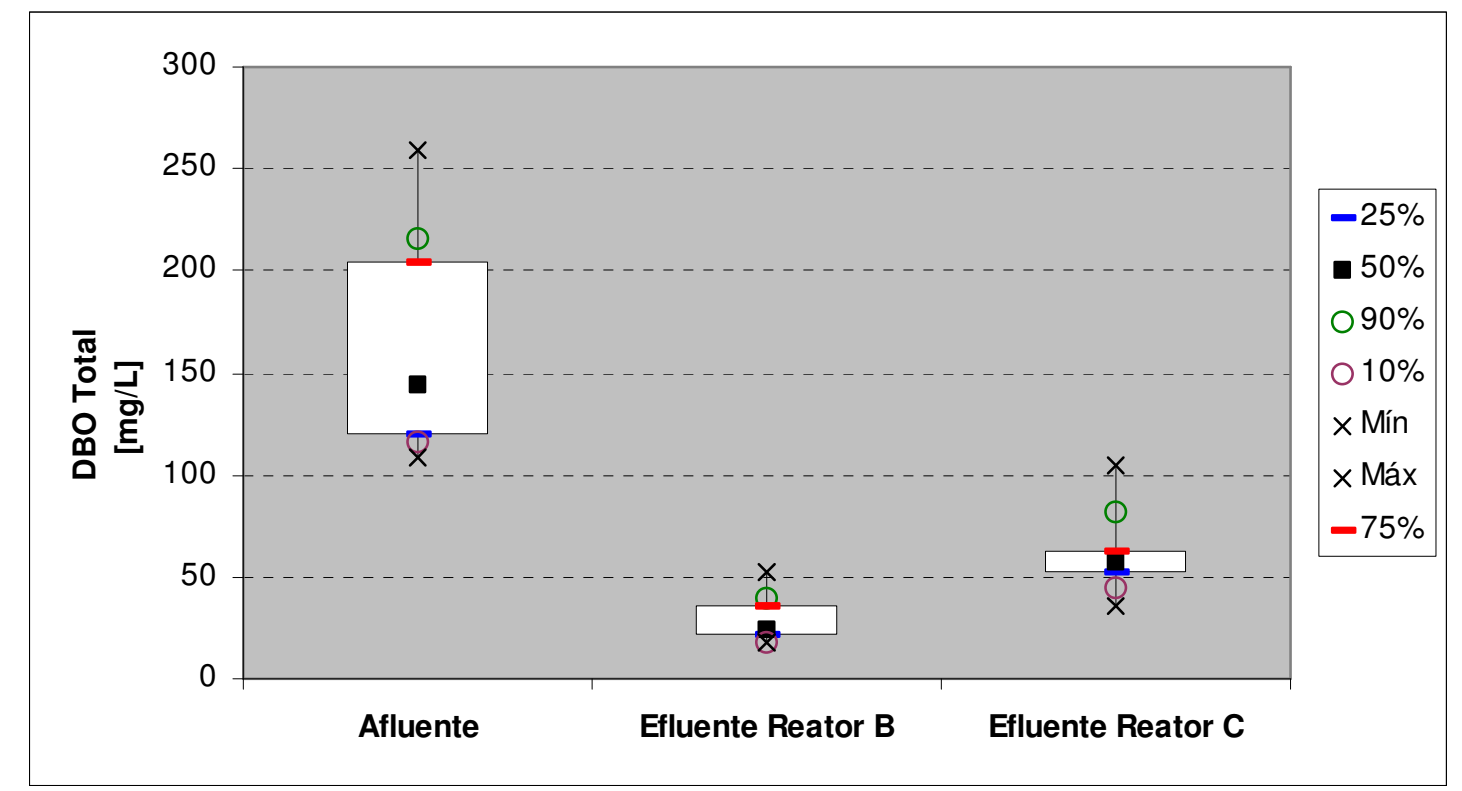

Figura $5.49-\mathrm{DBO}_{5,20^{\circ} \mathrm{C}}$ total da $3^{\text {a }}$ Fase: análise estatística

\subsection{4. $\mathrm{DBO}_{5,20^{\circ} \mathrm{C}}$ Filtrada}

Foram realizadas 9 análises, listadas no Capítulo 7. ANEXOS, na Tabela A.34. $\mathrm{Na}$ Figura 5.50 estão apresentados os valores de carga orgânica afluentes e das saídas dos 2 reatores. Mais uma vez observa-se a estabilidade do reator $B$, que ao longo do período de estudo, esteve abaixo de $20 \mathrm{mg} / \mathrm{L}$.

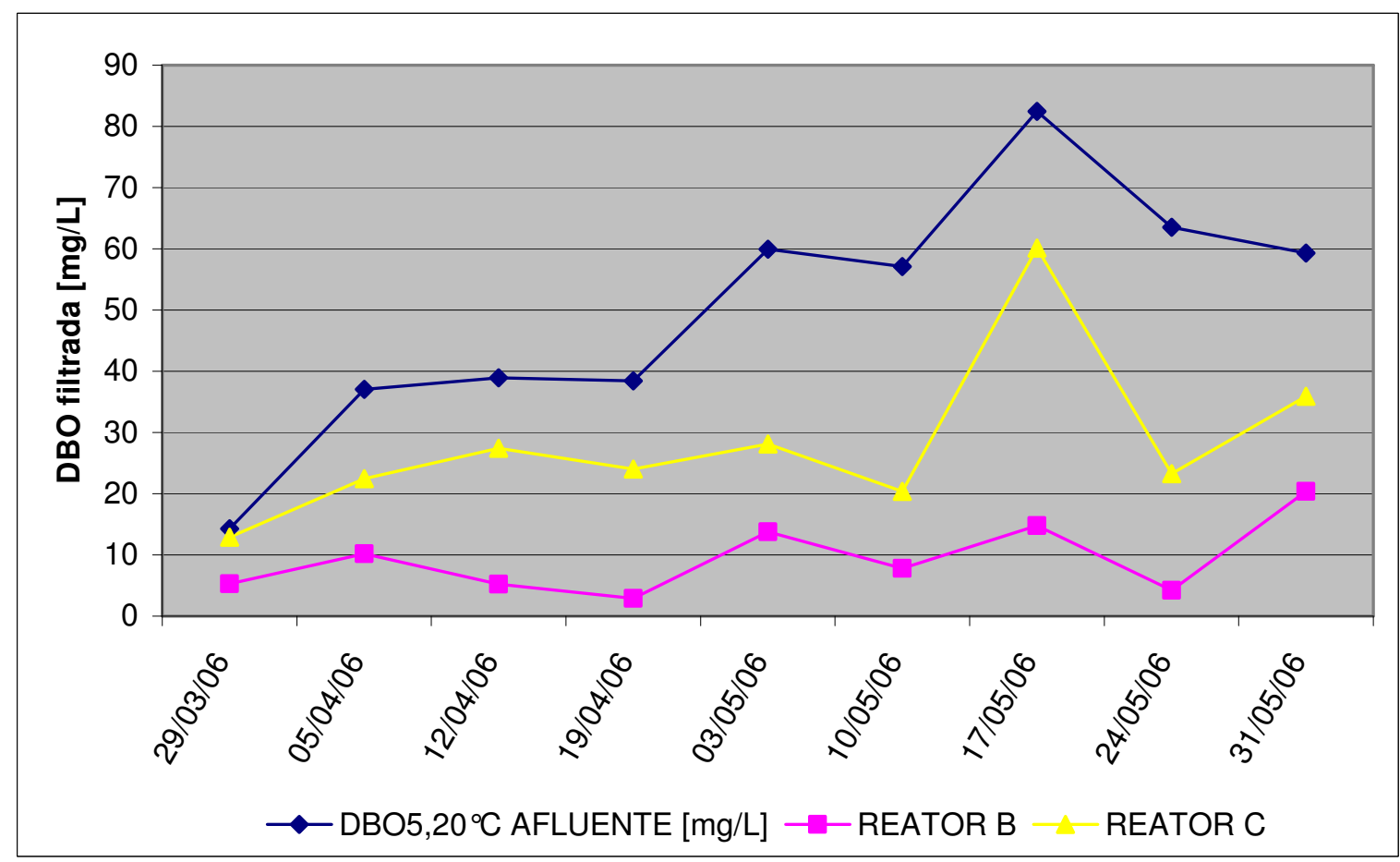

Figura 5.50 - Valores de $\mathrm{DBO}_{5,20^{\circ} \mathrm{C}}$ filtrada afluente e na saída dos reatores $\mathrm{B}$ e C: $3^{\underline{a}}$ Fase 
As médias estão mostradas na Tabela 5.28, com seus dados estatísticos da amostragem. Na Figura 5.51 estão as representações gráficas dessa análise estatística.

Tabela 5.28 - Índices estatísticos da $\mathrm{DBO}_{5,20^{\circ} \mathrm{C}}$ filtrada : $3^{\mathrm{a}}$ Fase

\begin{tabular}{lccc}
\hline $\begin{array}{c}\text { PONTO DE } \\
\text { COLETA }\end{array}$ & ESGOTO BRUTO & $\begin{array}{c}\text { EFLUENTE } \\
\text { REATOR B }\end{array}$ & $\begin{array}{c}\text { EFLUENTE } \\
\text { REATOR C }\end{array}$ \\
\hline $\begin{array}{l}\text { VALOR MÉDIO } \\
\text { [mg/L] }\end{array}$ & 50 & 9 & 28 \\
\hline MíNIMO [mg/L] & 14 & 3 & 13 \\
\hline MÁXIMO [mg/L] & 82 & 20 & 60 \\
\hline $\begin{array}{l}\text { DESVIO } \\
\text { PADRÃO }\end{array}$ & 20 & 6 & 13 \\
\hline VARIANÇA & 0,40 & 0,62 & 0,48 \\
\hline $\begin{array}{l}\text { EFICIÊNCIA DE } \\
\text { REMOÇÃO [\%] }\end{array}$ & - & 81,3 & 43,6 \\
\hline
\end{tabular}

Nota-se a eficiência mais alta $(81,3 \%)$ do reator $B$, ao se comparar com o reator $\mathrm{C}$ (43,6\%).

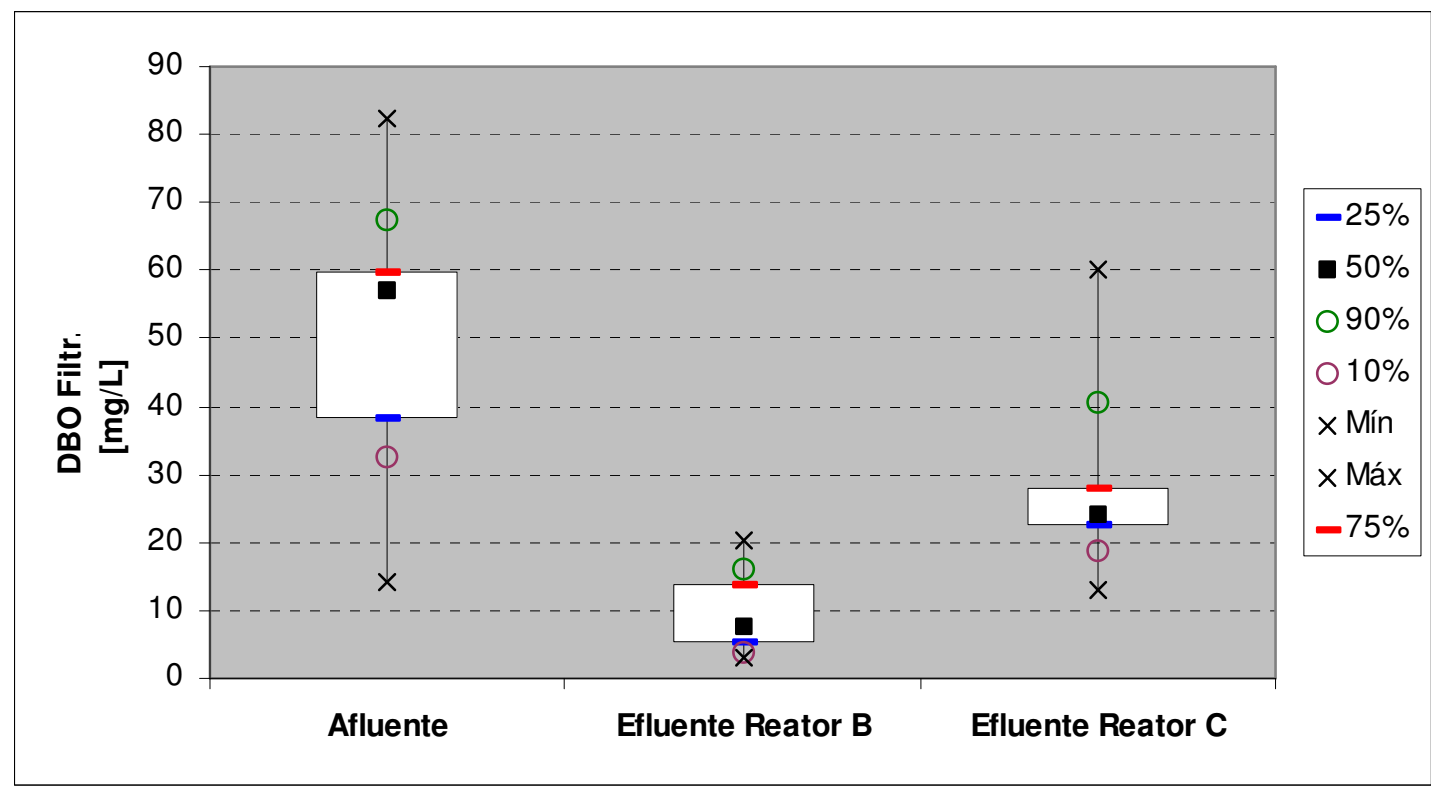

Figura $5.51-\mathrm{DBO}_{5,20^{\circ} \mathrm{C}}$ filtrada da $3^{\mathrm{a}}$ Fase: análise estatística 


\subsubsection{Fósforo Total}

Foram realizadas 18 análises, listadas no Capítulo 7. ANEXOS, na Tabela A.35. Na Figura 5.52 estão os valores de fósforo total afluentes e das saídas dos 2 reatores.

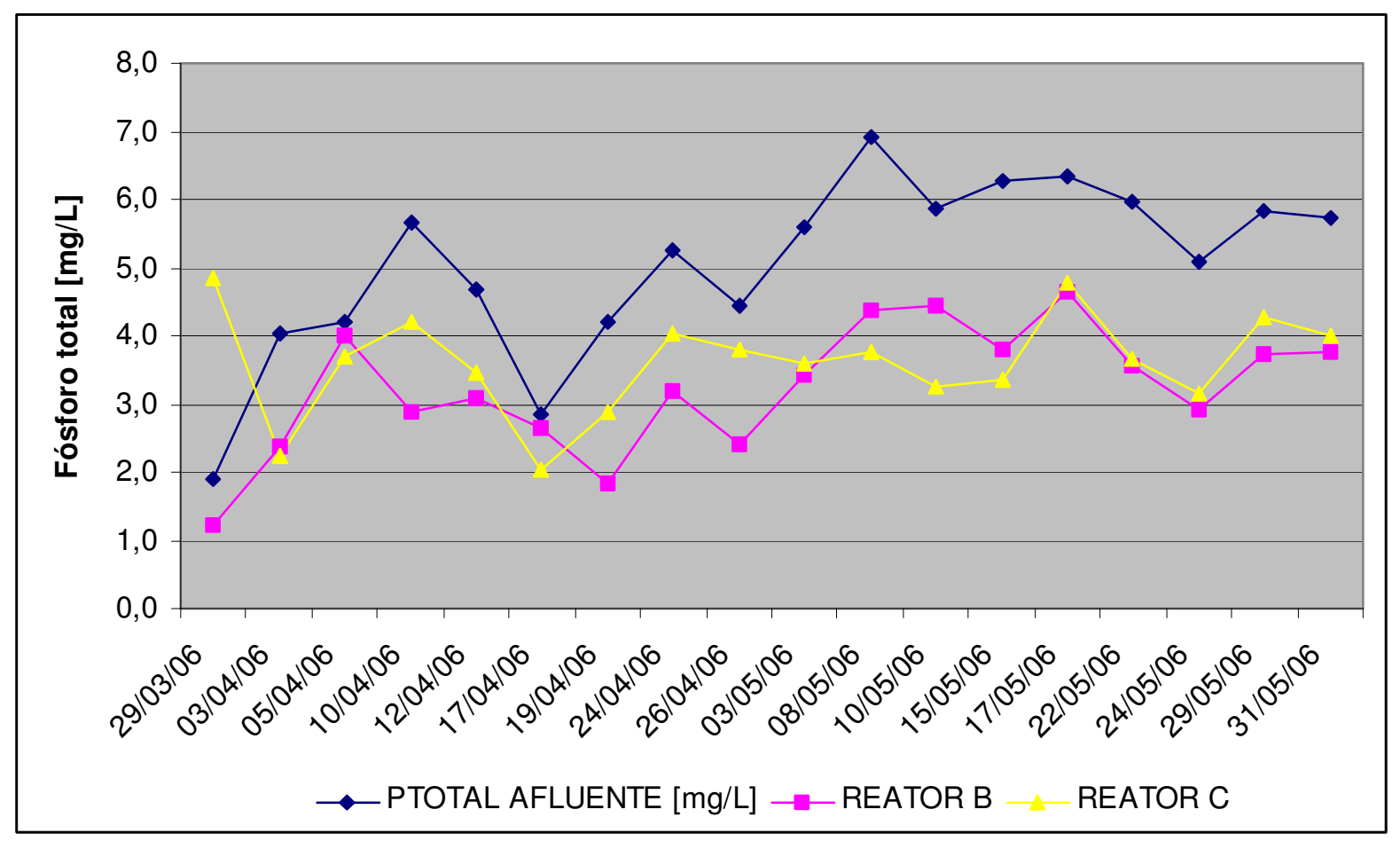

Figura 5.52 - Valores de fósforo total afluente e na saída dos reatores B e C: $3^{\text {a }}$ Fase

As médias estão mostradas na Tabela 5.29 , com os respectivos dados estatísticos da amostragem. Na Figura 5.53 estão as representações gráficas dessa análise estatística.

Apesar do aumento da dosagem para $50 \mathrm{mg} / \mathrm{L}$, os 2 reatores mantiveram-se semelhantes no que se refere à remoção de fósforo total. 
Tabela 5.29 - Índices estatísticos do Fósforo total afluente e de saída nos reatores B e C: $3^{\text {a }}$ Fase

\begin{tabular}{cccc}
\hline $\begin{array}{c}\text { PONTO DE } \\
\text { COLETA }\end{array}$ & ESGOTO BRUTO & $\begin{array}{c}\text { EFLUENTE } \\
\text { REATOR B }\end{array}$ & $\begin{array}{c}\text { EFLUENTE } \\
\text { REATOR C }\end{array}$ \\
\hline $\begin{array}{c}\text { VALOR MÉDIO } \\
\text { [mg/L] }\end{array}$ & 5,0 & 3,2 & 3,6 \\
\hline $\begin{array}{c}\text { MÍNIMO [mg/L] } \\
\text { MÁXIMO [mg/L] }\end{array}$ & 1,9 & 1,2 & 2,0 \\
\hline $\begin{array}{c}\text { DESVIO } \\
\text { PADRÃO }\end{array}$ & 1,3 & 4,7 & 4,8 \\
\hline VARIANÇA & 0,25 & 0,9 & 0,7 \\
\hline $\begin{array}{c}\text { EFICIÊNCIA DE } \\
\text { REMOÇÃO [\%] }\end{array}$ & - & 0,28 & 0,21 \\
\hline
\end{tabular}

Percebe-se uma maior remoção de fósforo total no reator B $(35,8 \%)$, apesar de irrisória diante da necessidade para se atingir o valor exigido pela legislação.

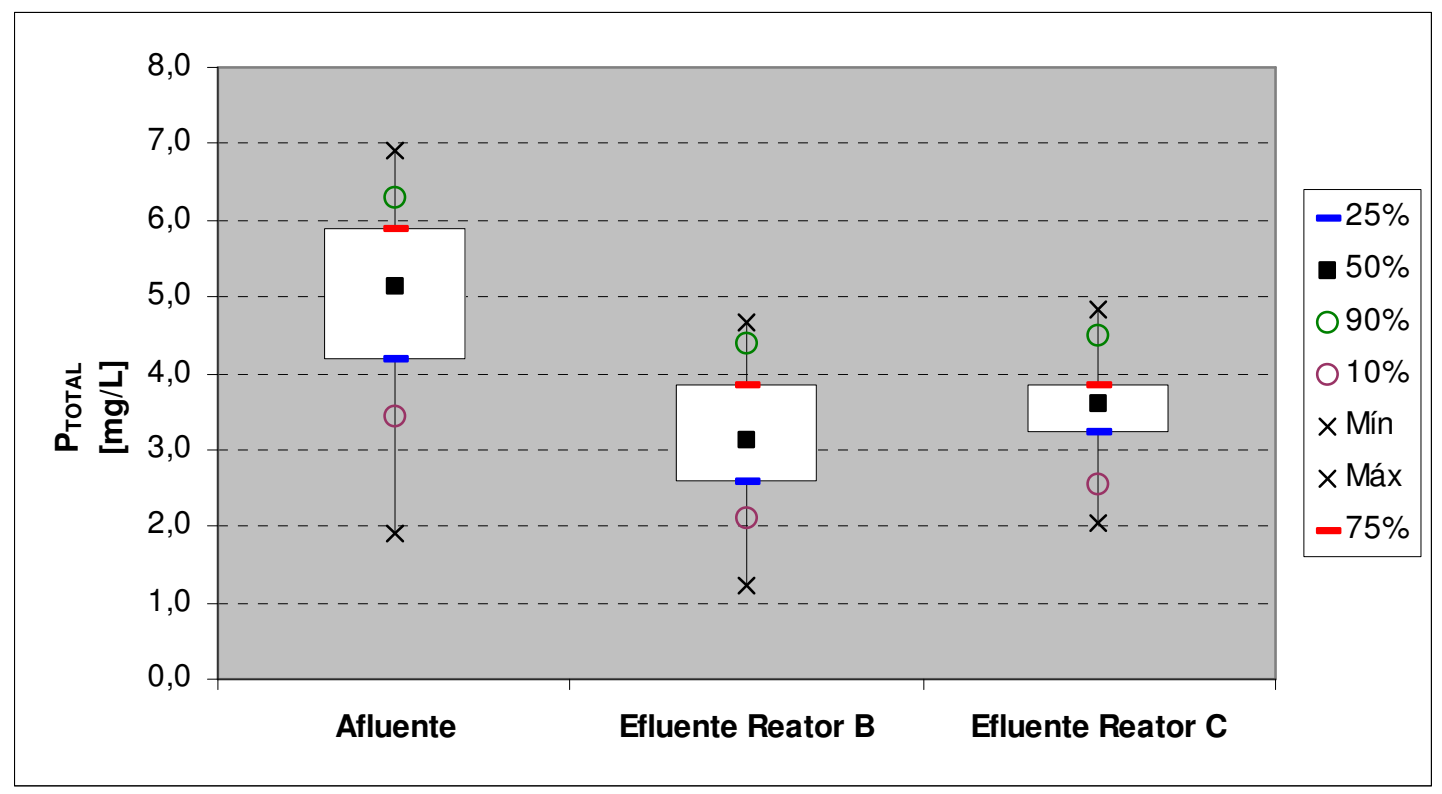

Figura 5.53 - Fósforo total da 3ª Fase: análise estatística

\subsubsection{Ortofosfatos}

Nesta etapa foram feitas 19 análises, indicadas no Capítulo 7. ANEXOS, na Tabela A.36. Com a Figura 5.54 vê-se a remoção de 1,0 a $1,5 \mathrm{mg} / \mathrm{L}$ de ortofosfatos no reator $\mathrm{B}$ em relação ao reator $\mathrm{C}$. Este último praticamente não apresentou remoção. 


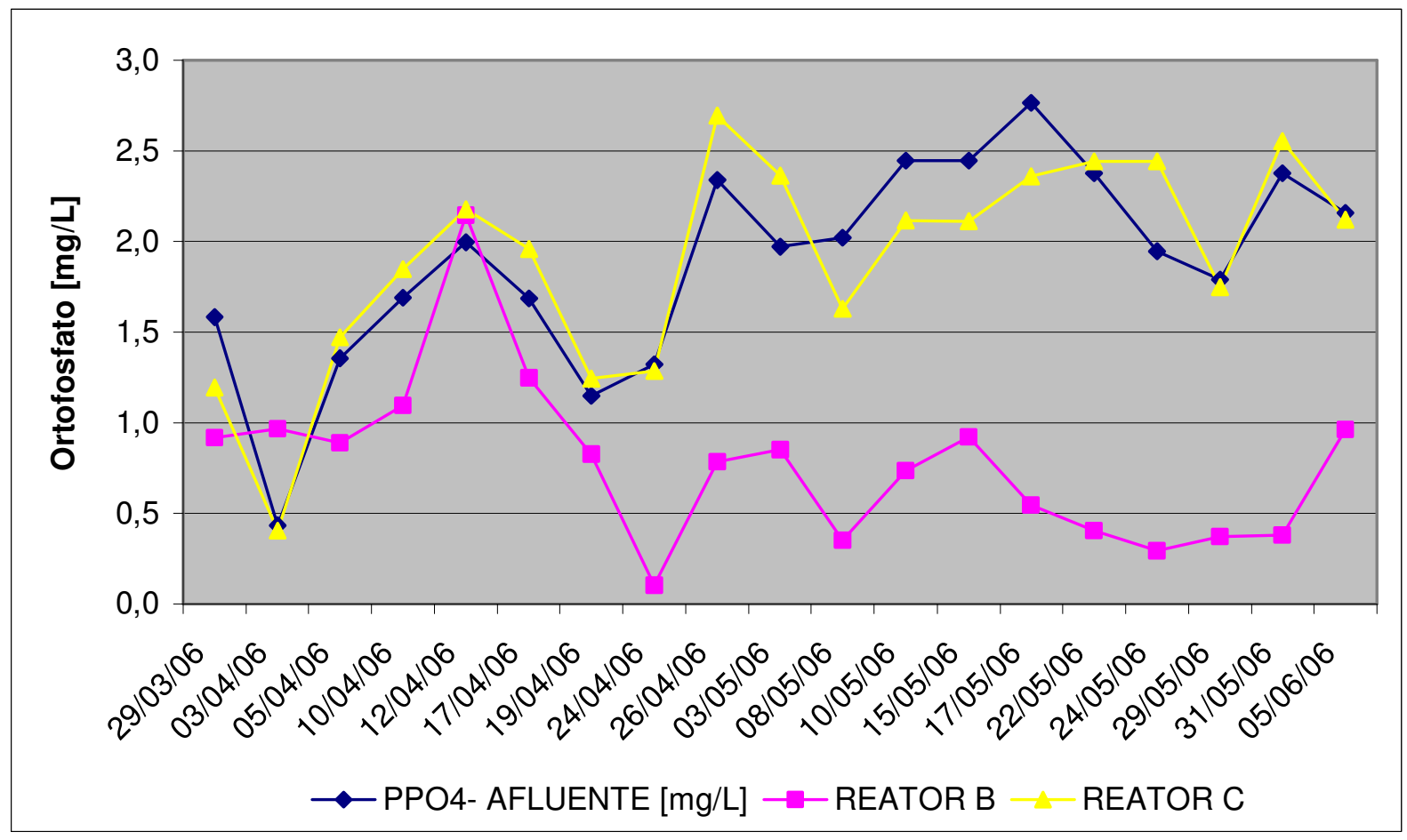

Figura 5.54 - Concentração de ortofosfatos afluente e nas saídas dos reatores B e C: $3^{\text {a }}$ Fase

Os valores médios estão apresentados na Tabela 5.30. Na Figura 5.30 estão os gráficos dessa análise estatística.

Tabela 5.30 - Índices estatísticos de ortofosfatos afluente e de saída nos reatores B e C: $3^{\text {a }}$ Fase

\begin{tabular}{lccc}
\hline $\begin{array}{c}\text { PONTO DE } \\
\text { COLETA }\end{array}$ & ESGOTO BRUTO & $\begin{array}{c}\text { EFLUENTE } \\
\text { REATOR B }\end{array}$ & $\begin{array}{c}\text { EFLUENTE } \\
\text { REATOR C }\end{array}$ \\
\hline $\begin{array}{l}\text { VALOR MÉDIO } \\
\text { [mg/L] }\end{array}$ & 1,9 & 0,8 & 1,9 \\
\hline MíNIMO [mg/L] & 0,4 & 0,1 & 0,4 \\
\hline MÁXIMO [mg/L] & 2,8 & 2,1 & 2,7 \\
\hline $\begin{array}{l}\text { DESVIO } \\
\text { PADRÃO }\end{array}$ & 0,6 & 0,5 & 0,6 \\
\hline VARIANÇA & 0,30 & 0,58 & 0,31 \\
\hline EFICIÊNCIA DE & - & 58,7 & - \\
REMOÇÃO [\%] & & &
\end{tabular}

Há uma remoção considerável no reator $\mathrm{B}$, de 58,7\%, sem qualquer remoção do outro reator. 


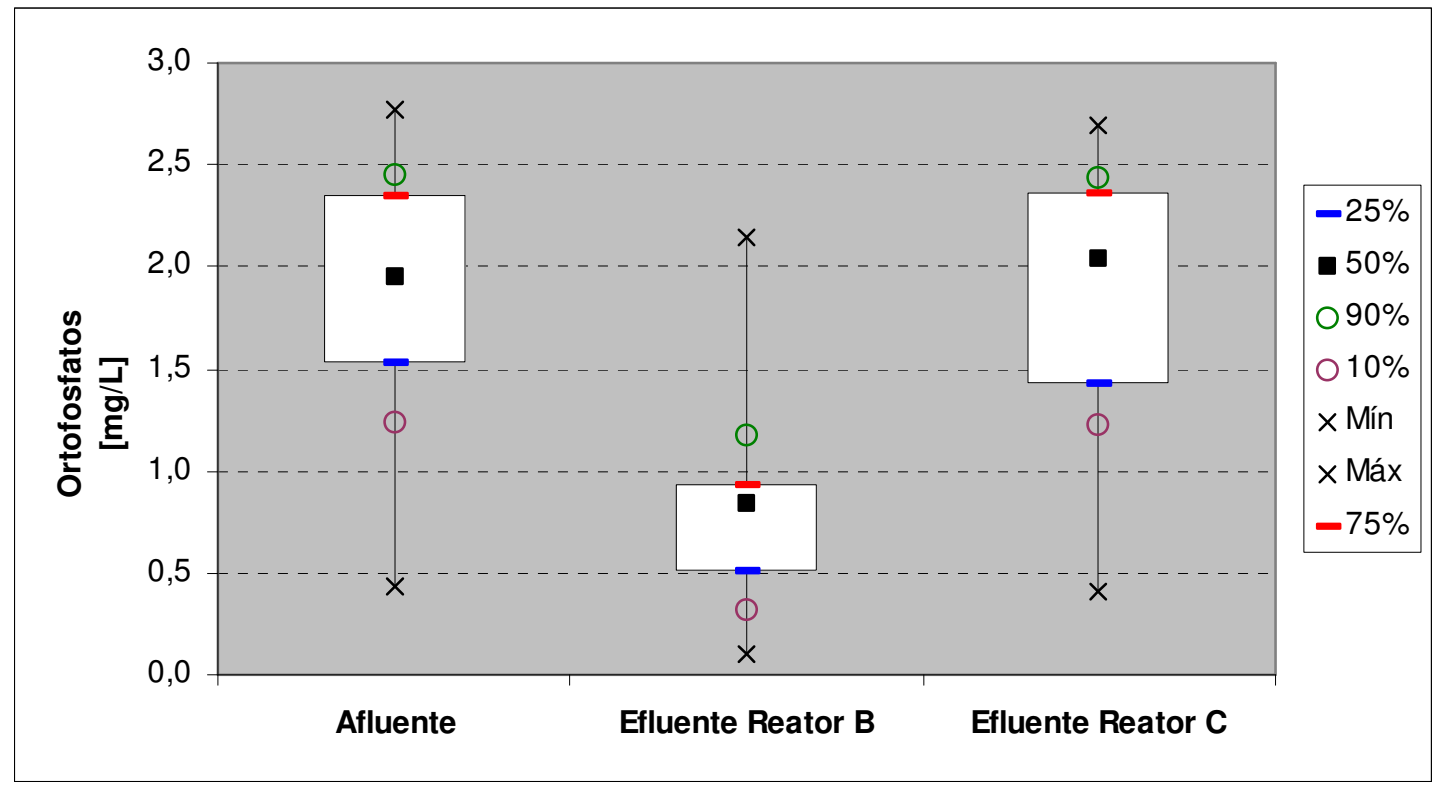

Figura 5.55 - Ortofosfatos da $3^{a}$ Fase: análise estatística

\subsubsection{Sulfetos}

Foram realizadas 10 análises, indicadas no Capítulo 7. ANEXOS, na Tabela A.37. Os valores obtidos estão médios estão apresentados na Figura 5.56 e indicam que não há qualquer influência da dosagem de cloreto férrico na remoção dessa substância.

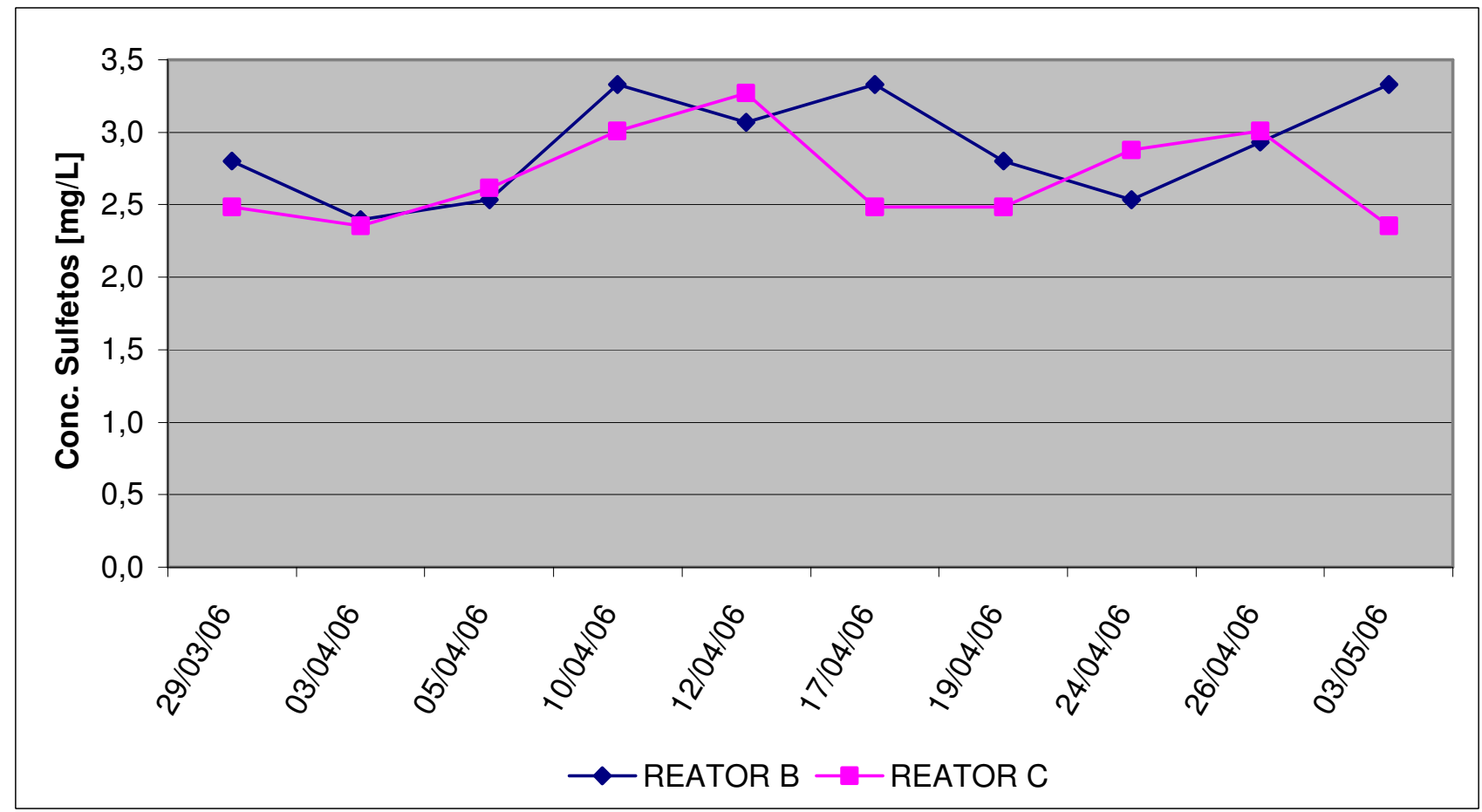

Figura 5.56 - Concentração de sulfetos nas saídas dos reatores B e C: $3^{a}$ Fase 
Os valores médios estão apresentados na Tabela 5.31, com os dados estatísticos da amostragem. Na Figura 5.57 estão os gráficos dessa análise estatística.

Tabela 5.31 - Índices estatísticos de sulfetos nas saídas dos reatores B e C: $3^{\text {a }}$ Fase

\begin{tabular}{lccc}
\hline $\begin{array}{c}\text { PONTO DE } \\
\text { COLETA }\end{array}$ & ESGOTO BRUTO & $\begin{array}{c}\text { EFLUENTE } \\
\text { REATOR B }\end{array}$ & $\begin{array}{c}\text { EFLUENTE } \\
\text { REATOR C }\end{array}$ \\
\hline $\begin{array}{l}\text { VALOR MÉDIO } \\
\text { [mg/L] }\end{array}$ & - & 2,9 & 2,7 \\
\hline MíNIMO [mg/L] & - & 2,4 & 2,4 \\
\hline MÁXIMO [mg/L] & - & 3,3 & 3,3 \\
\hline DESVIO & - & 0,4 & 0,3 \\
PADRÃO & - & 0,12 & 0,12 \\
\hline VARIANÇA & - & - & - \\
\hline $\begin{array}{l}\text { EFICIÊNCIA DE } \\
\text { REMOÇÃO [\%] }\end{array}$ & - & & \\
\hline
\end{tabular}

A conclusão é que não há qualquer efeito da adição de cloreto férrico na remoção de sulfetos.

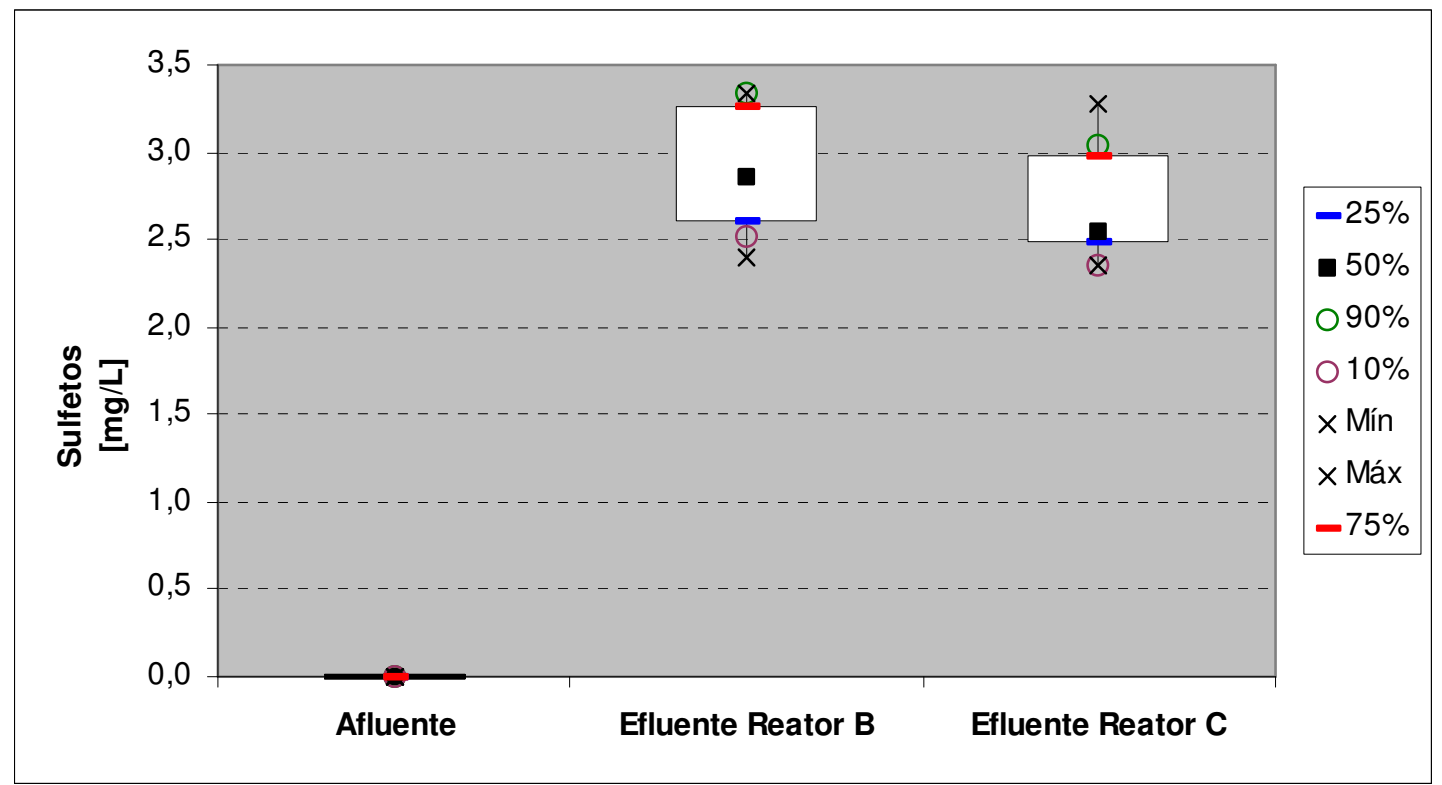

Figura 5.57 - Sulfetos da $3^{a}$ Fase: análise estatística 


\subsubsection{Sólidos Totais}

Para este parâmetro foram feitas 11 análises, mostradas no Capítulo 7. ANEXOS, na Tabela A.38. Na Figura 5.58 observa-seque os 2 reatores removem em torno de $150 \mathrm{mg} / \mathrm{L}$, havendo pouca diferença em suas performances.

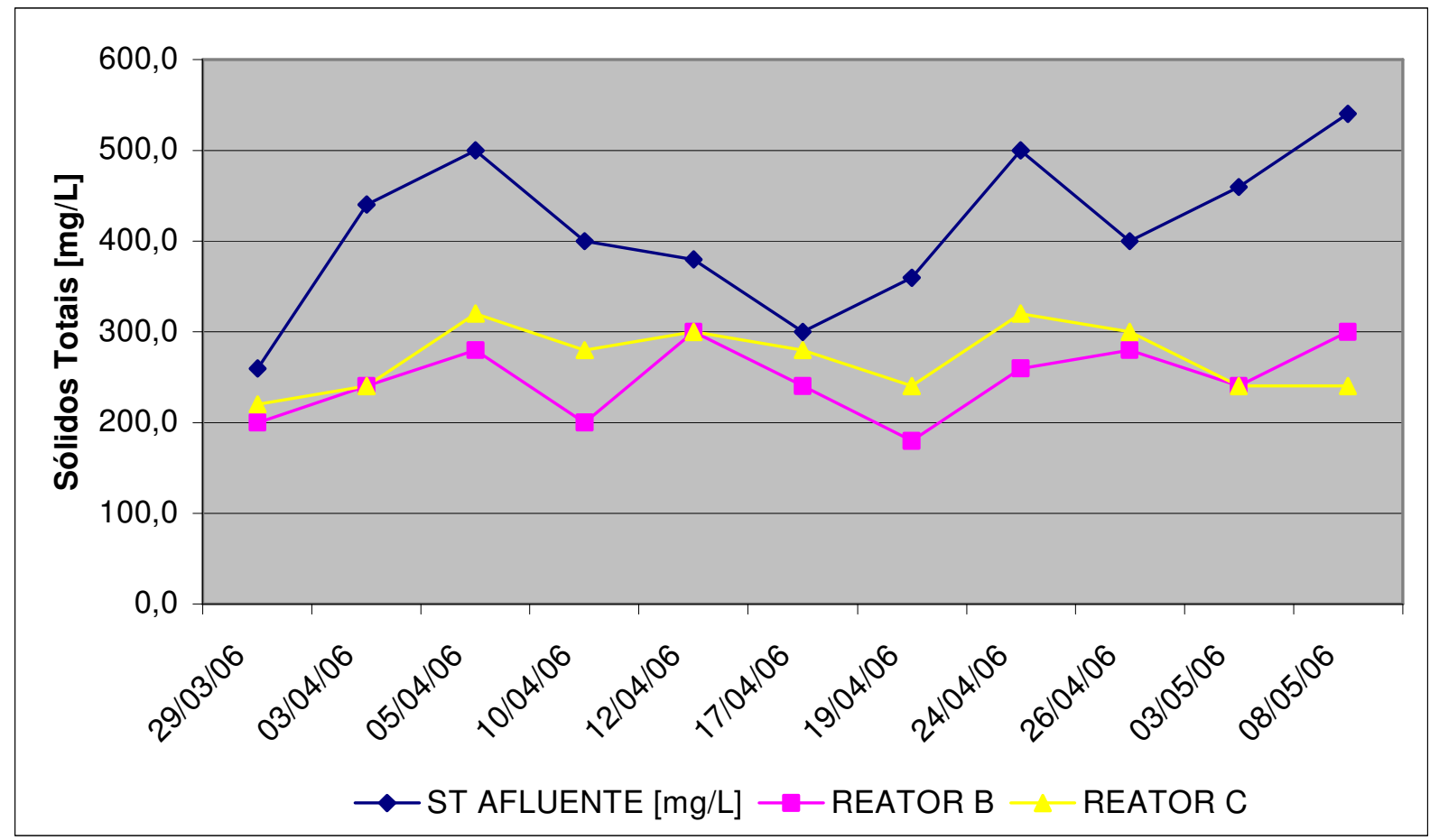

Figura 5.58 - Valores de sólidos totais afluentes e na saída dos reatores B e C: 3ª Fase

Os valores médios estão apresentados na Tabela 5.32, também com os dados estatísticos. Na Figura 5.59 mostram-se os gráficos dessa análise estatística.

Tabela 5.32 - Índices estatísticos de ortofosfatos afluente e de saída nos reatores B e C: $3^{\underline{a}}$ Fase

\begin{tabular}{lccc}
\hline $\begin{array}{c}\text { PONTO DE } \\
\text { COLETA }\end{array}$ & ESGOTO BRUTO & $\begin{array}{c}\text { EFLUENTE } \\
\text { REATOR B }\end{array}$ & $\begin{array}{c}\text { EFLUENTE } \\
\text { REATOR C }\end{array}$ \\
\hline $\begin{array}{l}\text { VALOR MÉDIO } \\
\text { [mg/L] }\end{array}$ & 412,7 & 247,3 & 270,9 \\
\hline MíNIMO [mg/L] & 260,0 & 180,0 & 220,0 \\
\hline MÁXIMO [mg/L] & 540,0 & 300,0 & 320,0 \\
\hline $\begin{array}{l}\text { DESVIO } \\
\text { PADRÃO }\end{array}$ & 86,4 & 41,3 & 36,2 \\
\hline VARIANÇA & 0,21 & 0,17 & 0,13 \\
\hline $\begin{array}{l}\text { EFICIÊNCIA DE } \\
\text { REMOÇÃO [\%] }\end{array}$ & - & 40,1 & 34,4 \\
\hline
\end{tabular}




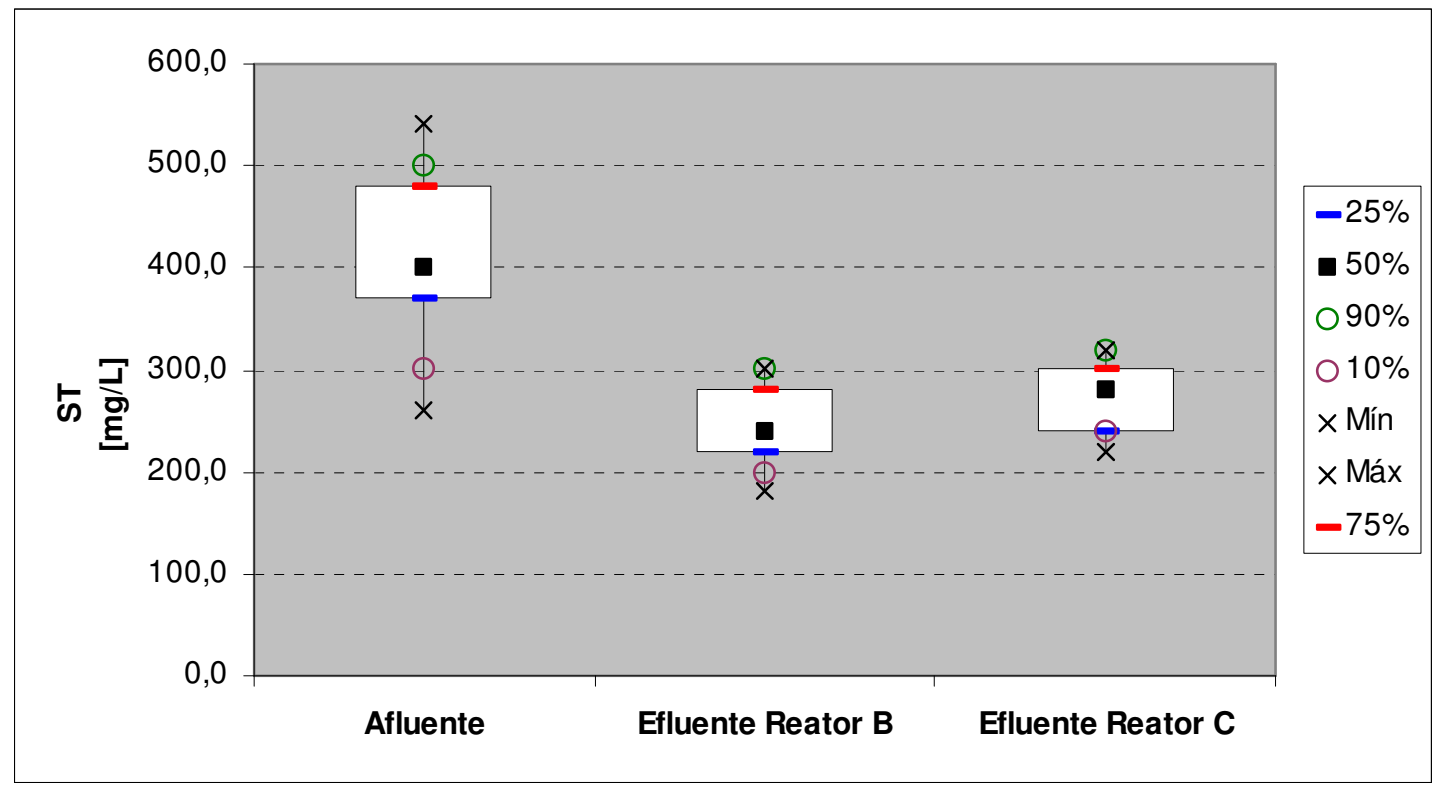

Figura 5.59 - Sólidos totais da $3^{\text {a }}$ Fase: análise estatística

\subsubsection{Sólidos Suspensos Totais}

Nesta etapa foram executadas 18 análises, mostradas no Capítulo 7. ANEXOS, na Tabela A.41. Pode-se ver na Figura 5.60 que não há diferenças entre os 2 reatores.

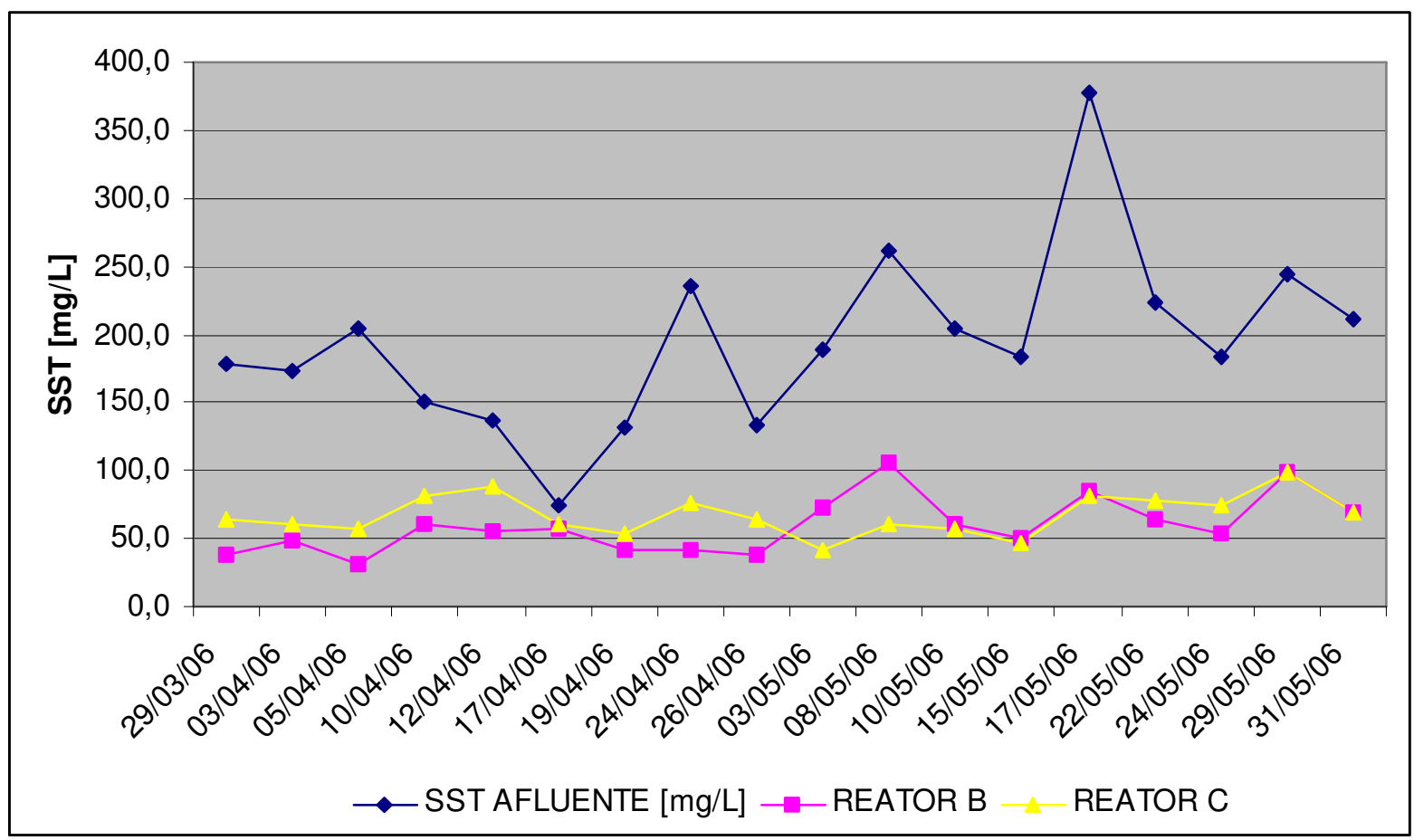

Figura 5.60 - Valores de sólidos suspensos totais afluentes e na saída dos reatores B e C: $3^{\underline{a}}$ Fase 
Os valores médios estão apresentados na Tabela 5.33, com os dados estatísticos dessa amostragem. Na Figura 5.61 mostram-se os gráficos da análise estatística.

Tabela 5.33 - Índices estatísticos de SST afluente e de saída nos reatores B e C: $3^{a}$ Fase

\begin{tabular}{lccc}
\hline $\begin{array}{c}\text { PONTO DE } \\
\text { COLETA }\end{array}$ & ESGOTO BRUTO & $\begin{array}{c}\text { EFLUENTE } \\
\text { REATOR B }\end{array}$ & $\begin{array}{c}\text { EFLUENTE } \\
\text { REATOR C }\end{array}$ \\
\hline $\begin{array}{l}\text { VALOR MÉDIO } \\
\text { [mg/L] }\end{array}$ & 194,3 & 59,6 & 67,4 \\
\hline MíNIMO [mg/L] & 74,0 & 32,0 & 42,0 \\
\hline MÁXIMO [mg/L] & 378,0 & 106,0 & 98,0 \\
\hline $\begin{array}{l}\text { DESVIO } \\
\text { PADRÃO }\end{array}$ & 65,2 & 20,4 & 14,7 \\
\hline VARIANÇA & 0,34 & 0,34 & 0,22 \\
\hline $\begin{array}{l}\text { EFICIÊNCIA DE } \\
\text { REMOÇÃO [\%] }\end{array}$ & - & 69,4 & 65,3 \\
\hline
\end{tabular}

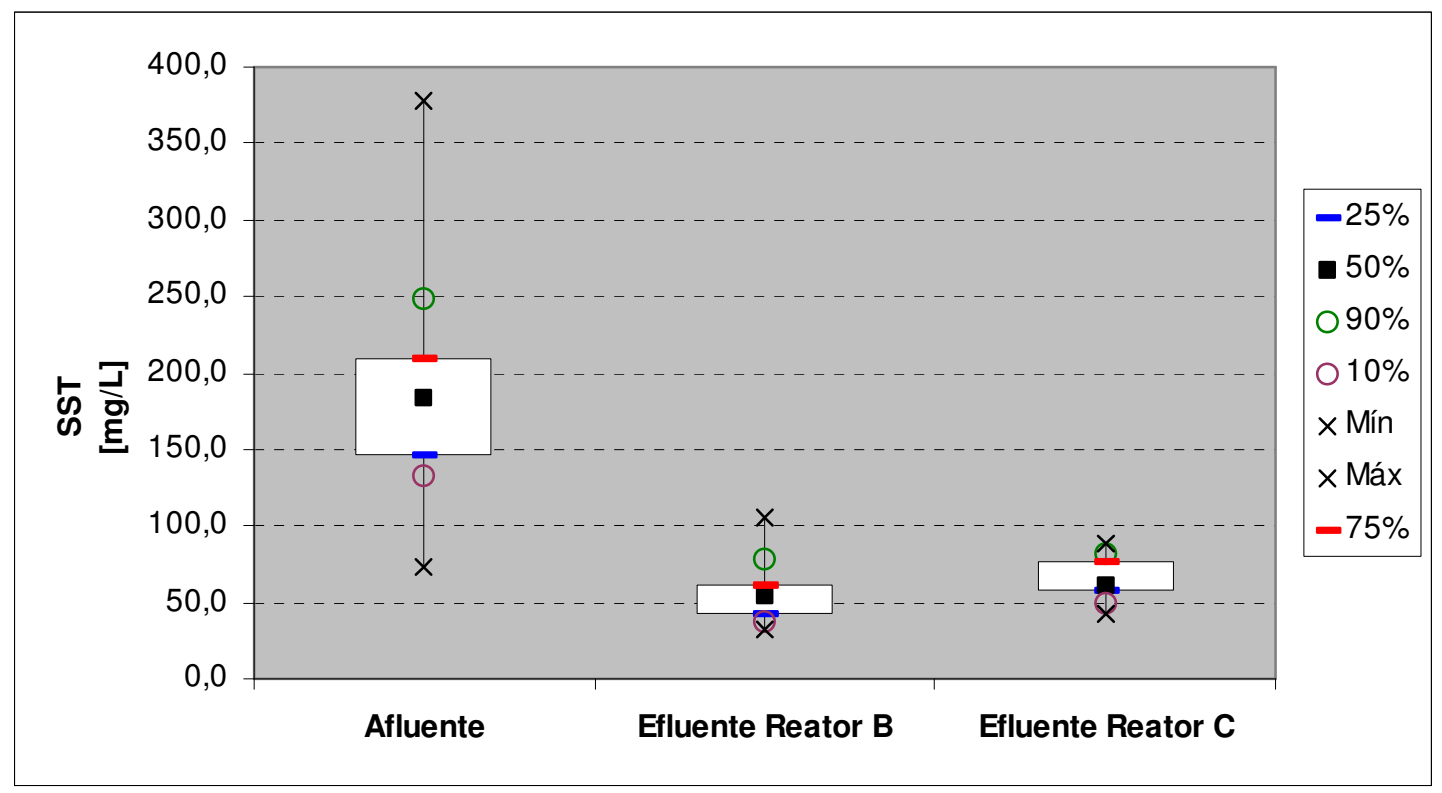

Figura 5.61 - Sólidos suspensos totais da 3ª Fase: análise estatística

\subsubsection{Sólidos Suspensos Voláteis}

Nesta etapa foram executadas 18 análises, mostradas no Capítulo 7. ANEXOS, na Tabela A.43. Na Figura 5.62 observa-se que o comportamento relativo aos sólidos suspensos totais se repetiu na sua fração volátil, sem o reator B se sobressair. 


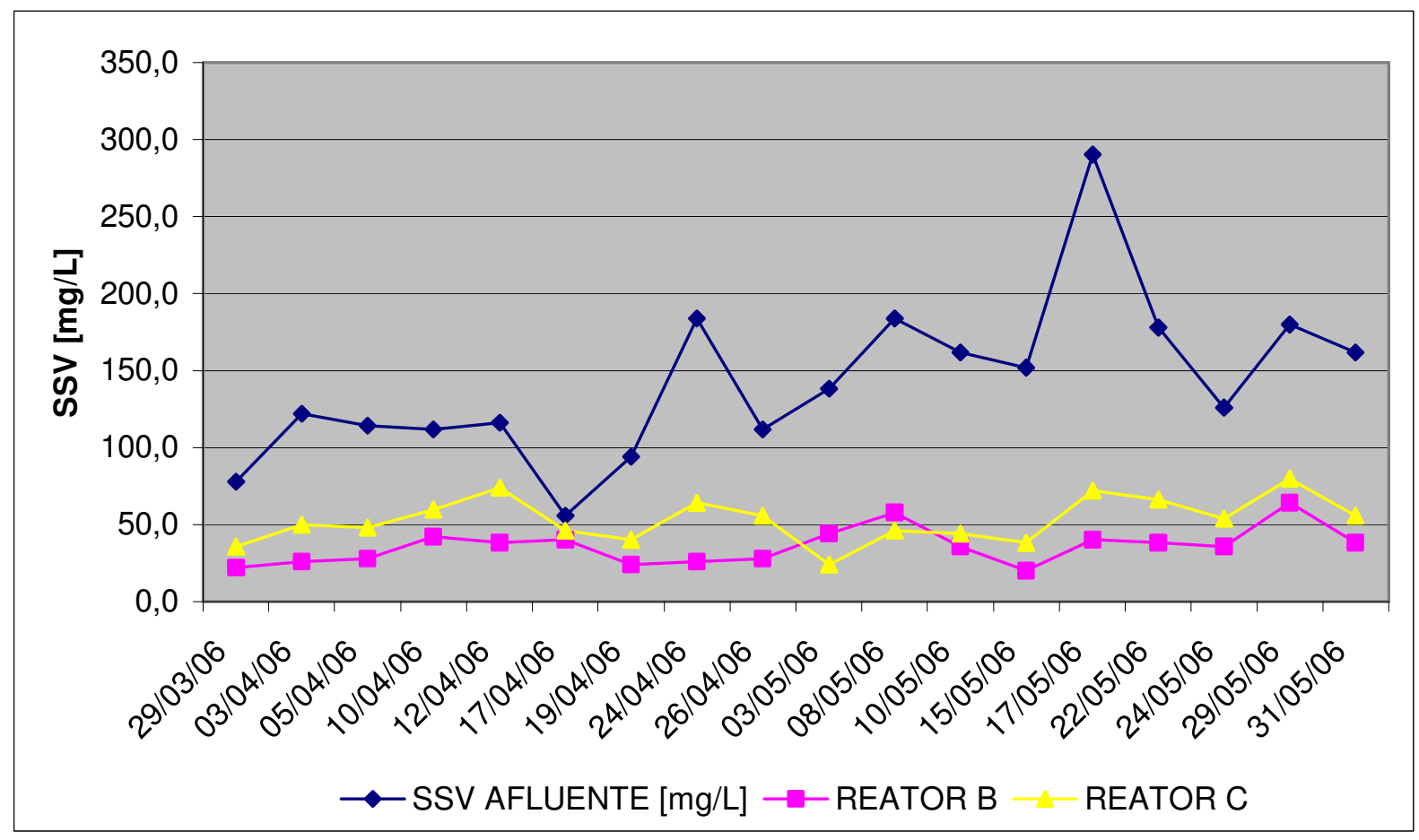

Figura 5.62 - Valores de sólidos suspensos voláteis afluentes e na saída dos reatores B e C: $3^{\text {a }}$ Fase

Os valores médios estão apresentados na Tabela 5.34, com os dados estatísticos da amostragem. A Figura 5.63 mostra os gráficos dessa análise estatística.

Tabela 5.34 - Índices estatísticos de SSV afluente e de saída nos reatores B e C: 3aㅗ Fase

\begin{tabular}{lccc}
\hline $\begin{array}{c}\text { PONTO DE } \\
\text { COLETA }\end{array}$ & ESGOTO BRUTO & $\begin{array}{c}\text { EFLUENTE } \\
\text { REATOR B }\end{array}$ & $\begin{array}{c}\text { EFLUENTE } \\
\text { REATOR C }\end{array}$ \\
\hline $\begin{array}{l}\text { VALOR MÉDIO } \\
\text { [mg/L] }\end{array}$ & 142,2 & 36,0 & 53,0 \\
\hline MÍNIMO [mg/L] & 56,0 & 20,0 & 24,0 \\
\hline MÁXIMO [mg/L] & 290,0 & 64,0 & 80,0 \\
\hline $\begin{array}{l}\text { DESVIO } \\
\text { PADRÃO }\end{array}$ & 52,5 & 11,7 & 14,6 \\
\hline VARIANÇA & 0,37 & 0,33 & 0,28 \\
\hline $\begin{array}{l}\text { EFICIÊNCIA DE } \\
\text { REMOÇÃO [\%] }\end{array}$ & - & 74,7 & 62,7 \\
\hline
\end{tabular}




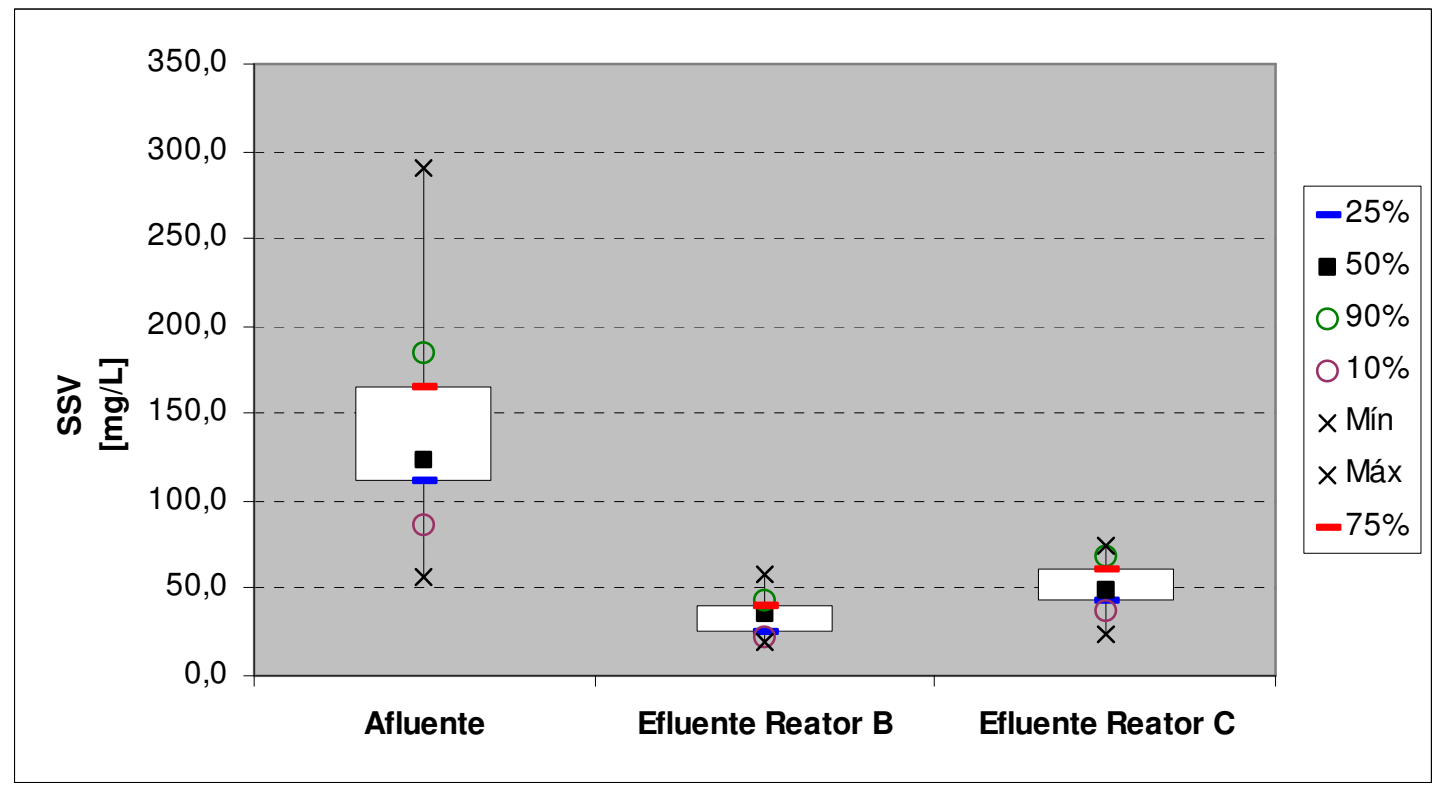

Figura 5.63 - Sólidos suspensos voláteis da 3ª Fase: análise estatística

\subsubsection{Sólidos Sedimentáveis}

Para este parâmetro foram realizadas análises semanais, num total de 9 , mostradas no Capítulo 7. ANEXOS, na Tabela A.44. Na Figura 5.64 observamos a queda da eficiência do reator $B$, mesmo quando a condição de entrada foi bastante favorável.

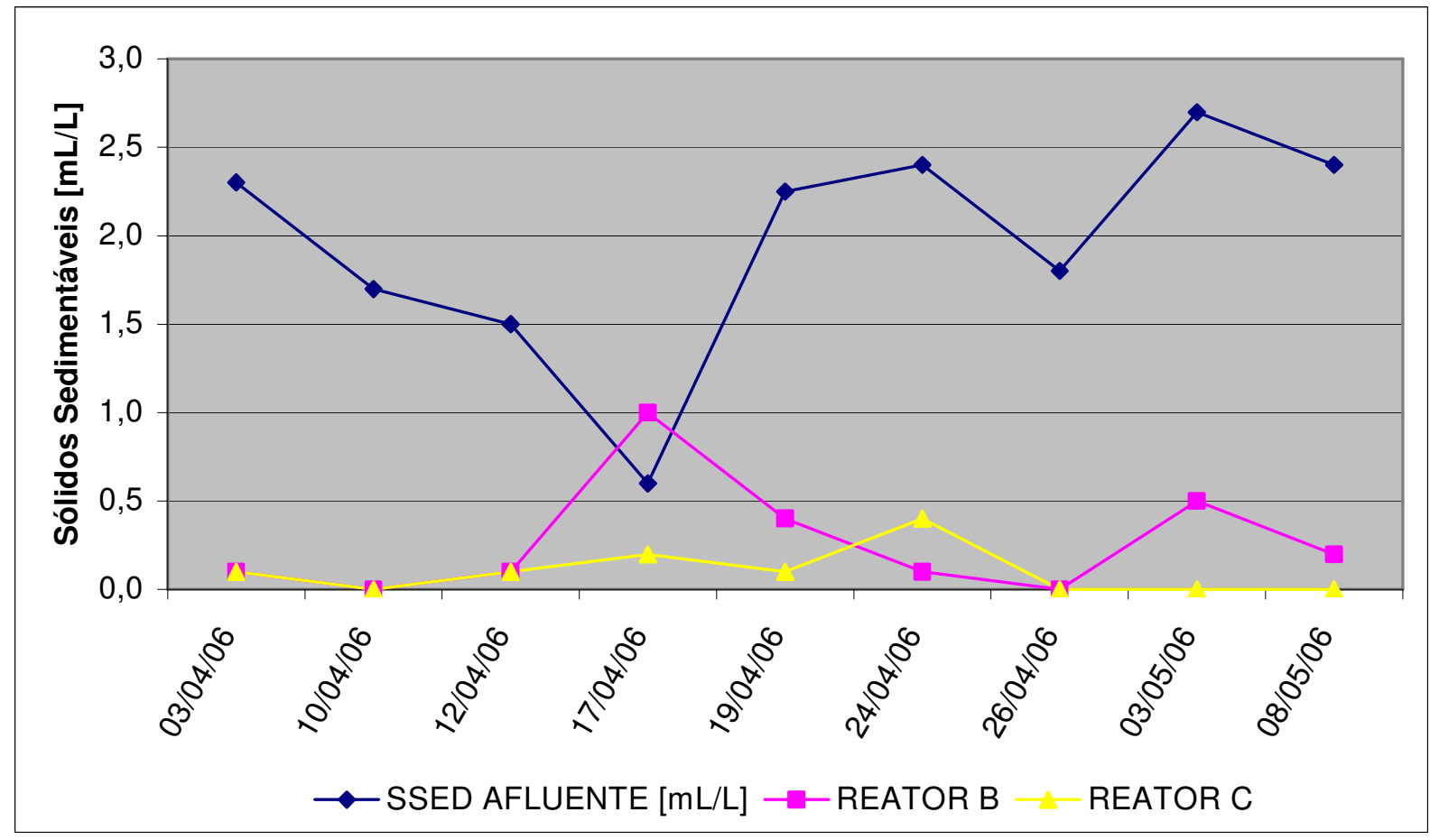

Figura 5.64 - Valores de sólidos sedimentáveis afluentes e na saída dos reatores B e C: $3^{\underline{a}}$ Fase 
Os valores médios estão apresentados na Tabela 5.35, aonde se tem ainda os dados estatísticos dessa amostragem. A Figura 5.65 mostra os gráficos da análise estatística.

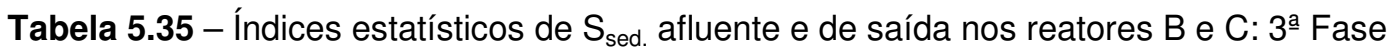

\begin{tabular}{lccc}
\hline $\begin{array}{c}\text { PONTO DE } \\
\text { COLETA }\end{array}$ & ESGOTO BRUTO & $\begin{array}{c}\text { EFLUENTE } \\
\text { REATOR B }\end{array}$ & $\begin{array}{c}\text { EFLUENTE } \\
\text { REATOR C }\end{array}$ \\
\hline $\begin{array}{l}\text { VALOR MÉDIO } \\
\text { [mL/L] }\end{array}$ & 2,0 & 0,3 & 0,1 \\
\hline MíNIMO [mL/L] & 0,6 & 0,0 & 0,0 \\
\hline MÁXIMO [mL/L] & 2,7 & 1,0 & 0,4 \\
\hline $\begin{array}{l}\text { DESVIO } \\
\text { PADRÃO }\end{array}$ & 0,6 & 0,3 & 0,1 \\
\hline VARIANÇA & 0,33 & 1,22 & 1,32 \\
\hline $\begin{array}{l}\text { EFICIÊNCIA DE } \\
\text { REMOÇÃO [\%] }\end{array}$ & - & 86,4 & 94,9 \\
\hline
\end{tabular}

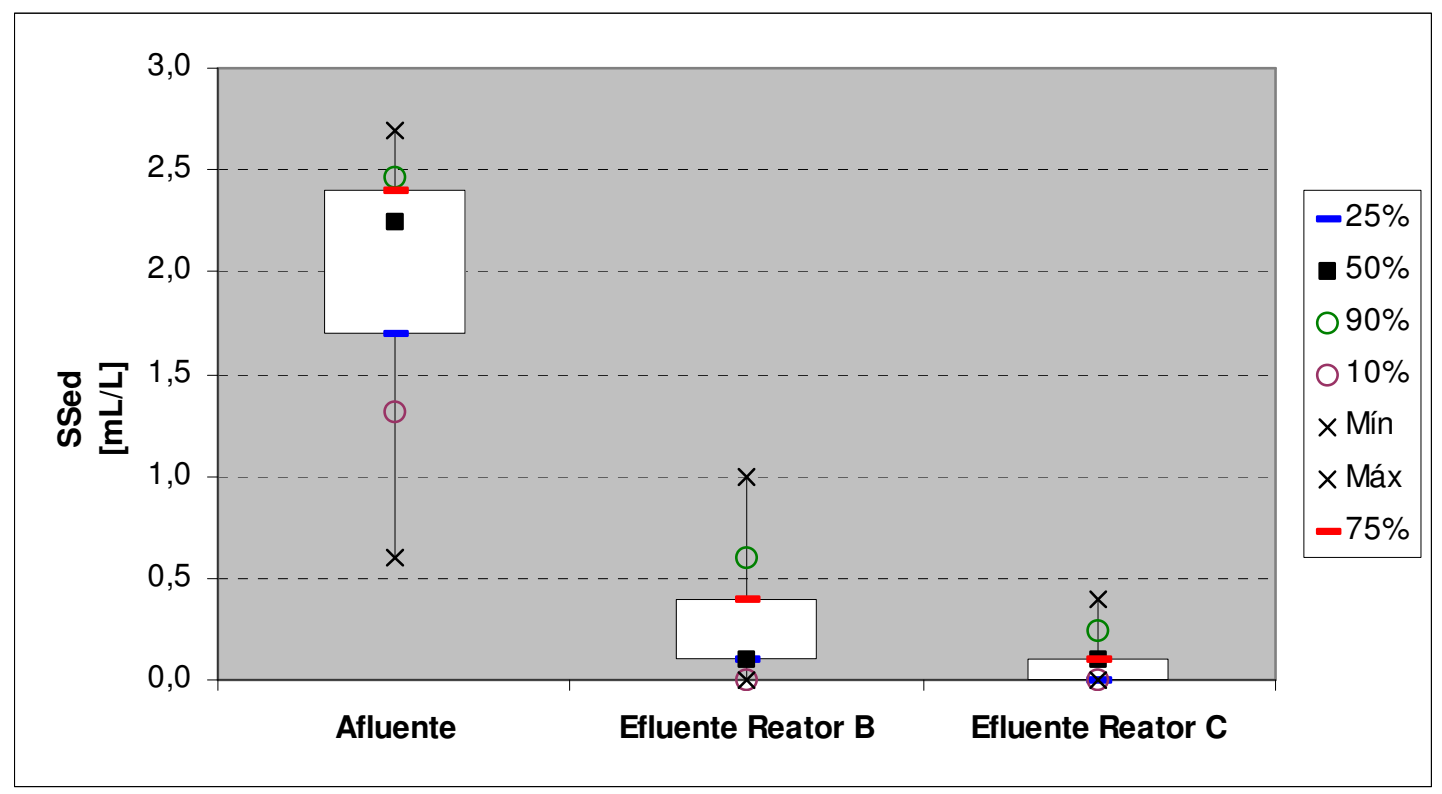

Figura 5.65 - Sólidos sedimentáveis da 3ª Fase: análise estatística

\subsubsection{2. $\mathrm{pH}$}

$\mathrm{O} \mathrm{pH}$ do esgoto afluente bem como dos 2 reatores foram acompanhados com a finalidade de antever qualquer desequilíbrio operacional nos mesmos. Foram realizadas 18 análises, mostradas no Capítulo 7. ANEXOS, na Tabela A.45. Na 
Figura 5.66 tem-se a evolução dos resultados nos 2 reatores, sendo que o reator B teve o menor valor de $\mathrm{pH}, 6,0$.

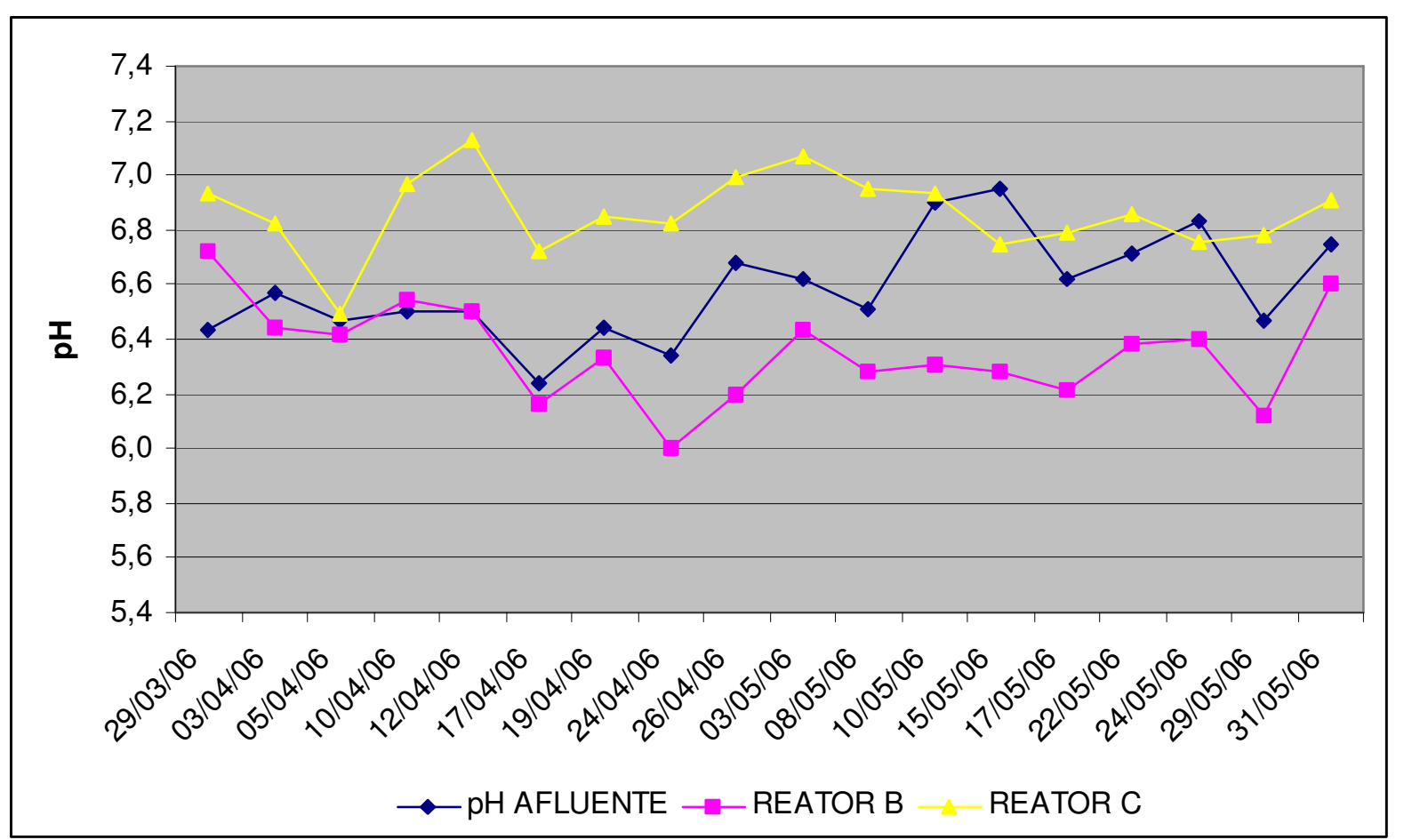

Figura 5.66 - Valores de pH no esgoto afluente e nos reatores B e C: 3a Fase

Os valores médios estão apresentados na Tabela 5.36. A Figura 5.67 mostra os gráficos dessa análise estatística.

Tabela 5.36 - Índices estatísticos de $\mathrm{pH}$ no esgoto afluente e dos reatores B e C: 3ª Fase

\begin{tabular}{lccc}
\hline $\begin{array}{c}\text { PONTO DE } \\
\text { COLETA }\end{array}$ & ESGOTO BRUTO & $\begin{array}{c}\text { EFLUENTE } \\
\text { REATOR B }\end{array}$ & $\begin{array}{c}\text { EFLUENTE } \\
\text { REATOR C }\end{array}$ \\
\hline VALOR MÉDIO & 6,6 & 6,4 & 6,9 \\
\hline MÍNIMO & 6,2 & 6,0 & 6,5 \\
\hline MÁXIMO & 7,0 & 6,7 & 7,1 \\
\hline $\begin{array}{l}\text { DESVIO } \\
\text { PADRÃO }\end{array}$ & 0,2 & 0,2 & 0,1 \\
\hline VARIANÇA & 0,03 & 0,03 & 0,02 \\
\hline
\end{tabular}




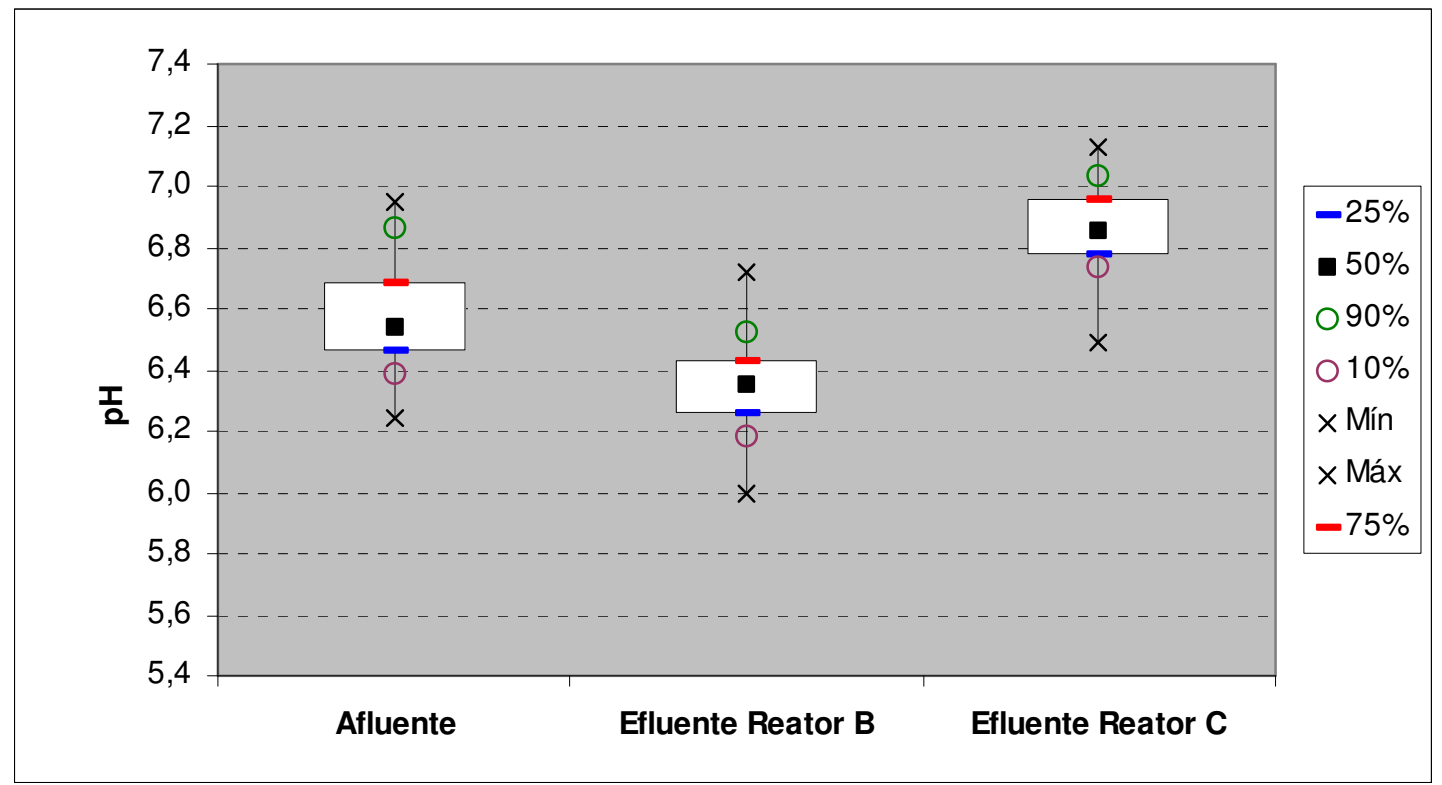

Figura 5.67 - pH durante a 3ª̣ Fase: análise estatística

\subsubsection{Alcalinidade}

Outro parâmetro de controle, a alcalinidade, foi acompanhada a fim de se precaver contra seu eventual desequilíbrio. Foram realizadas 18 análises, mostradas no Capítulo 7. ANEXOS, na Tabela A.46. Na Figura 5.68 tem-se a evolução dos resultados.

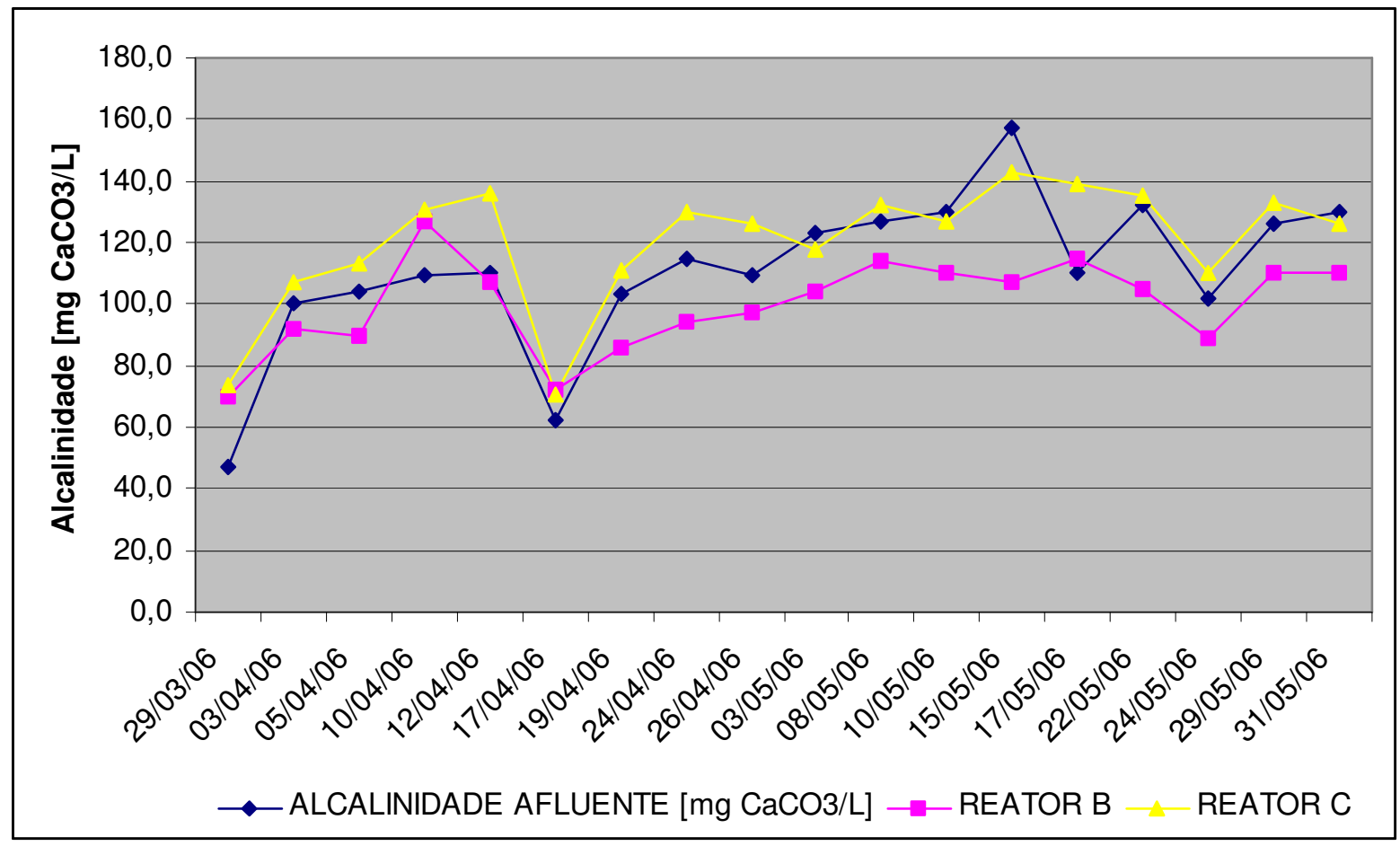

Figura 5.68 - Valores de alcalinidade do esgoto afluente e dos reatores B e C: $3^{\text {a }}$ Fase 
Os valores médios estão apresentados na Tabela 5.37, com os parâmetros estatísticos. A Figura 5.69 mostra os gráficos dessa análise estatística.

Tabela 5.37 - Índices estatísticos de alcalinidade do esgoto afluente e dos reatores B e C: $3^{\underline{a}}$ Fase

\begin{tabular}{lccc}
\hline $\begin{array}{c}\text { PONTO DE } \\
\text { COLETA }\end{array}$ & ESGOTO BRUTO & $\begin{array}{c}\text { EFLUENTE } \\
\text { REATOR B }\end{array}$ & $\begin{array}{c}\text { EFLUENTE } \\
\text { REATOR C }\end{array}$ \\
\hline $\begin{array}{l}\text { VALOR MÉDIO } \\
\text { [mg CaCO }\end{array}$ /L] & 110,9 & 99,9 & 120,1 \\
\hline $\begin{array}{l}\text { MíNIMO [mg } \\
\text { CaCO }_{3} / \text { L] }\end{array}$ & 47,0 & 70,0 & 71,0 \\
\hline $\begin{array}{l}\text { MÁXIMO [mg } \\
\text { CaCO }_{3} / \text { L] }\end{array}$ & 157,0 & 127,0 & 143,0 \\
\hline $\begin{array}{l}\text { DESVIO } \\
\text { PADRÃO }\end{array}$ & 25,1 & 14,9 & 20,2 \\
\hline VARIANÇA & 0,23 & 0,15 & 0,17 \\
\hline
\end{tabular}

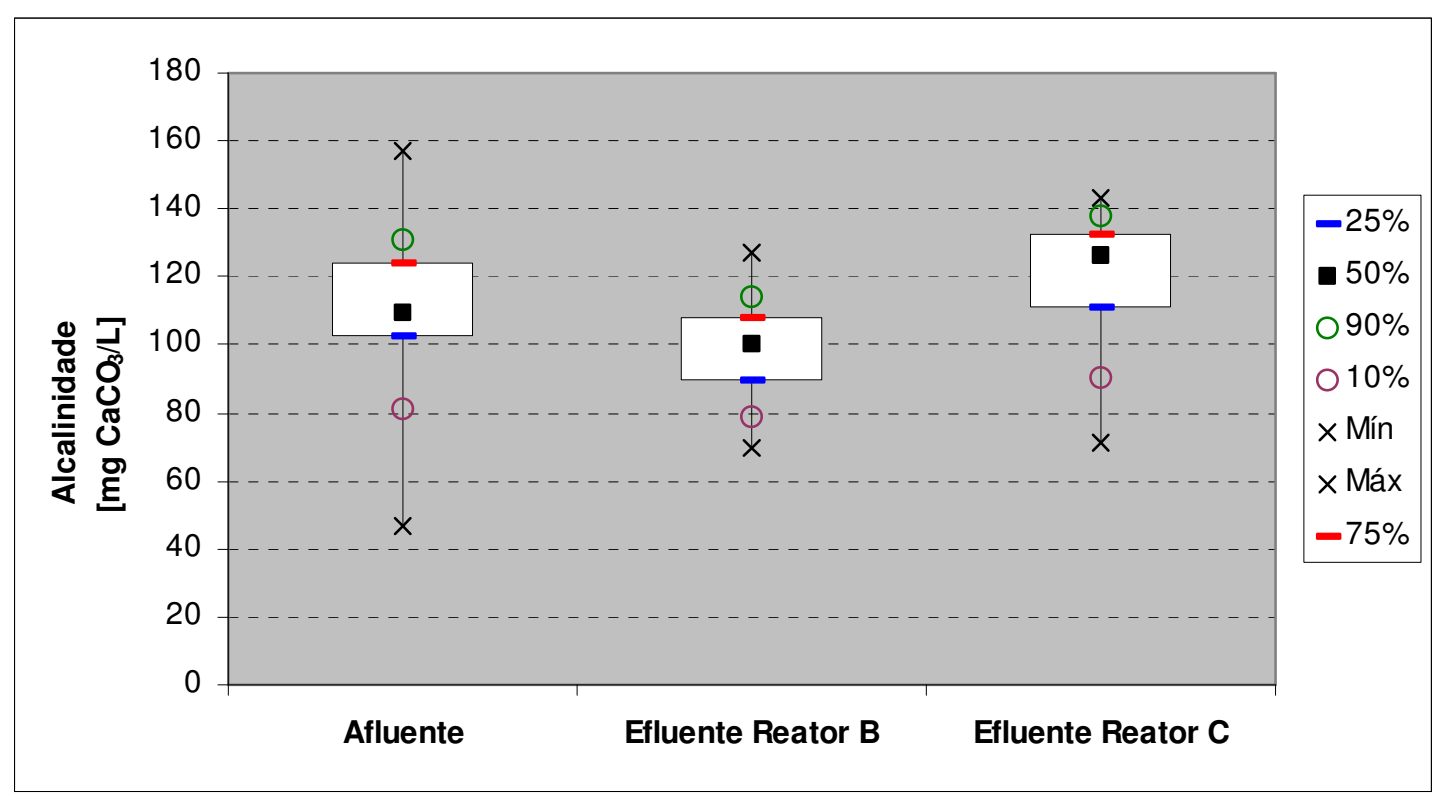

Figura 5.69 - Alcalinidade durante a 3aㅗ Fase: análise estatística

\subsection{Estudo Comparativo}

Com os dados levantados e expostos acima, pôde-se traçar um comparativo das 3 fases do experimento para os 2 fatores mais importantes abordados neste trabalho: o fósforo e a matéria orgânica. Na Figura 5.70 é apresentado uma seqüência de 
dados referentes às concentrações de ortofosfato afluentes e na saída do reator $B$, no qual houve a adição de cloreto férrico como coagulante.

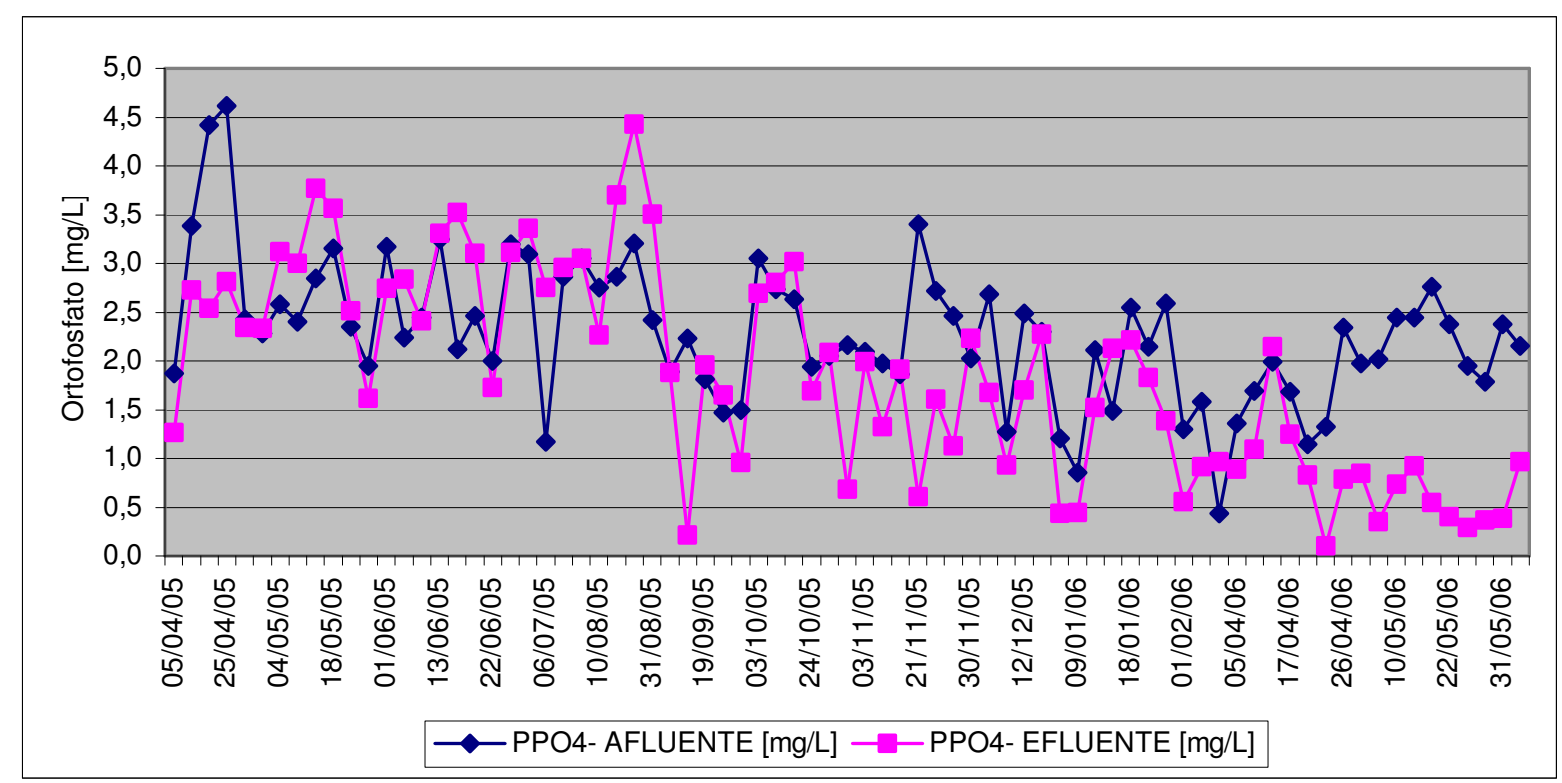

Figura 5.70 - Acompanhamento do reator B quanto às concentrações de ortofosfato

Pode-se concluir que há uma remoção maior do ortofosfato na medida em que se aumenta a dosagem de coagulante (parte final do experimento). No tocante ao fósforo total, tem-se a Figura 5.71, com o mesmo acompanhamento.

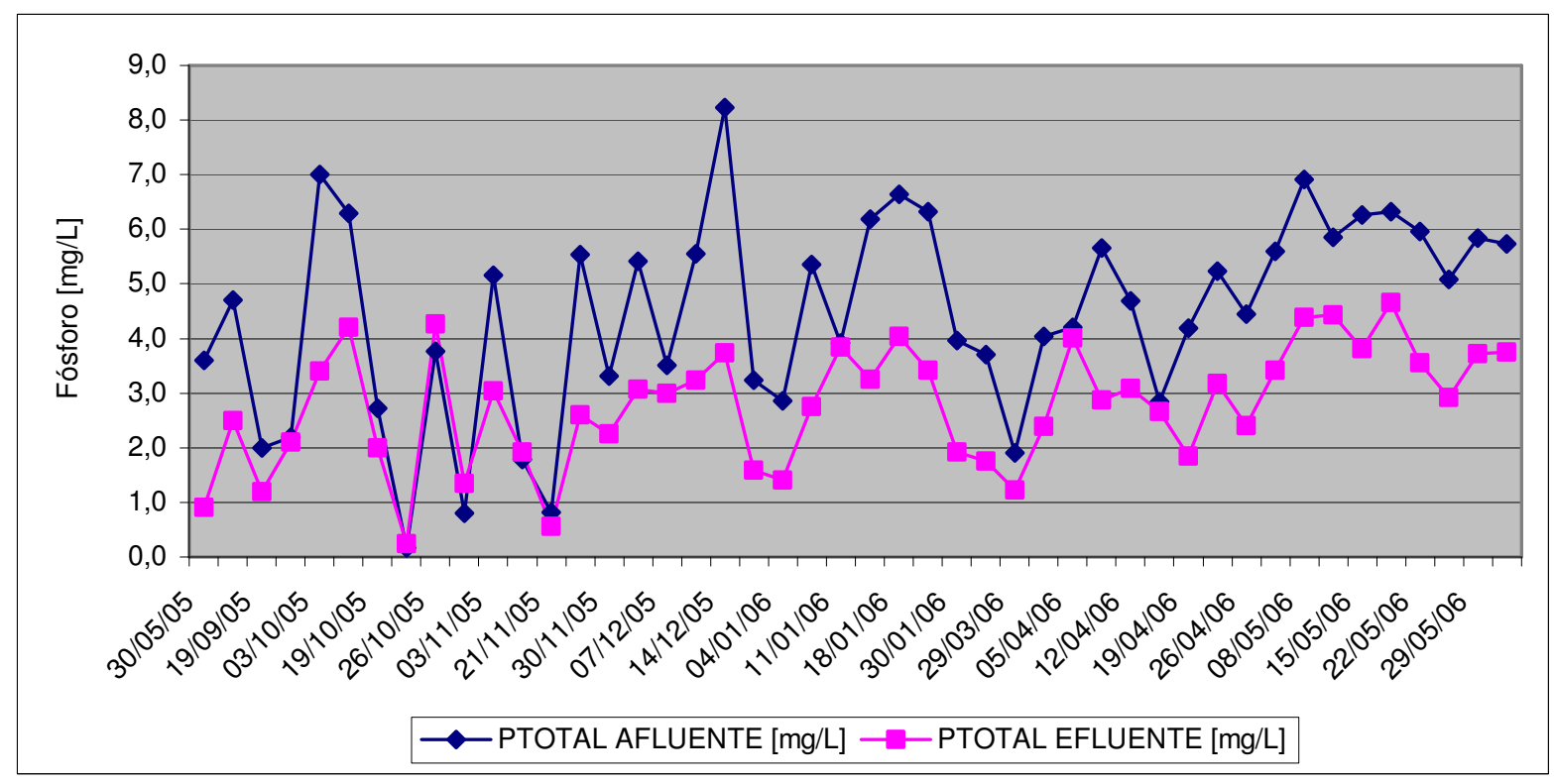

Figura 5.71 - Acompanhamento do reator B quanto às concentrações de fósforo 
Deste comparativo, percebe-se que as diferenças entre as concentrações de entrada e saída se mantiveram praticamente as mesmas desde o início do estudo, em todas as dosagens aplicadas.

Quanto às cargas orgânicas, tem-se a Figura 5.72 e 5.73, com o mesmo comparativo para $\mathrm{DQO}$ e $\mathrm{DBO}_{5,20^{\circ} \mathrm{C}}$ totais, afluentes e na saída do reator $\mathrm{B}$ :

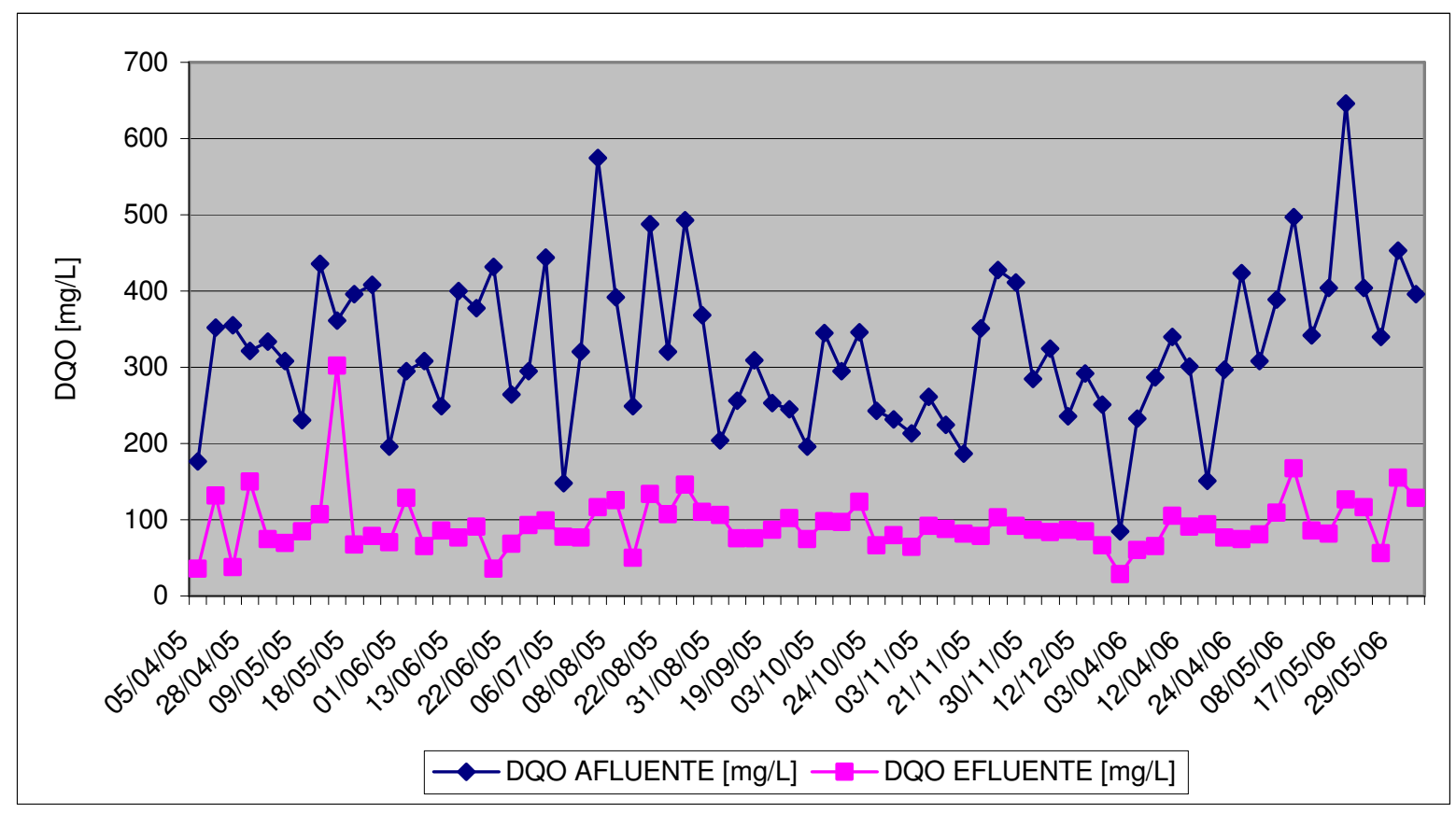

Figura 5.72 - Acompanhamento do reator B quanto às concentrações de DQO total

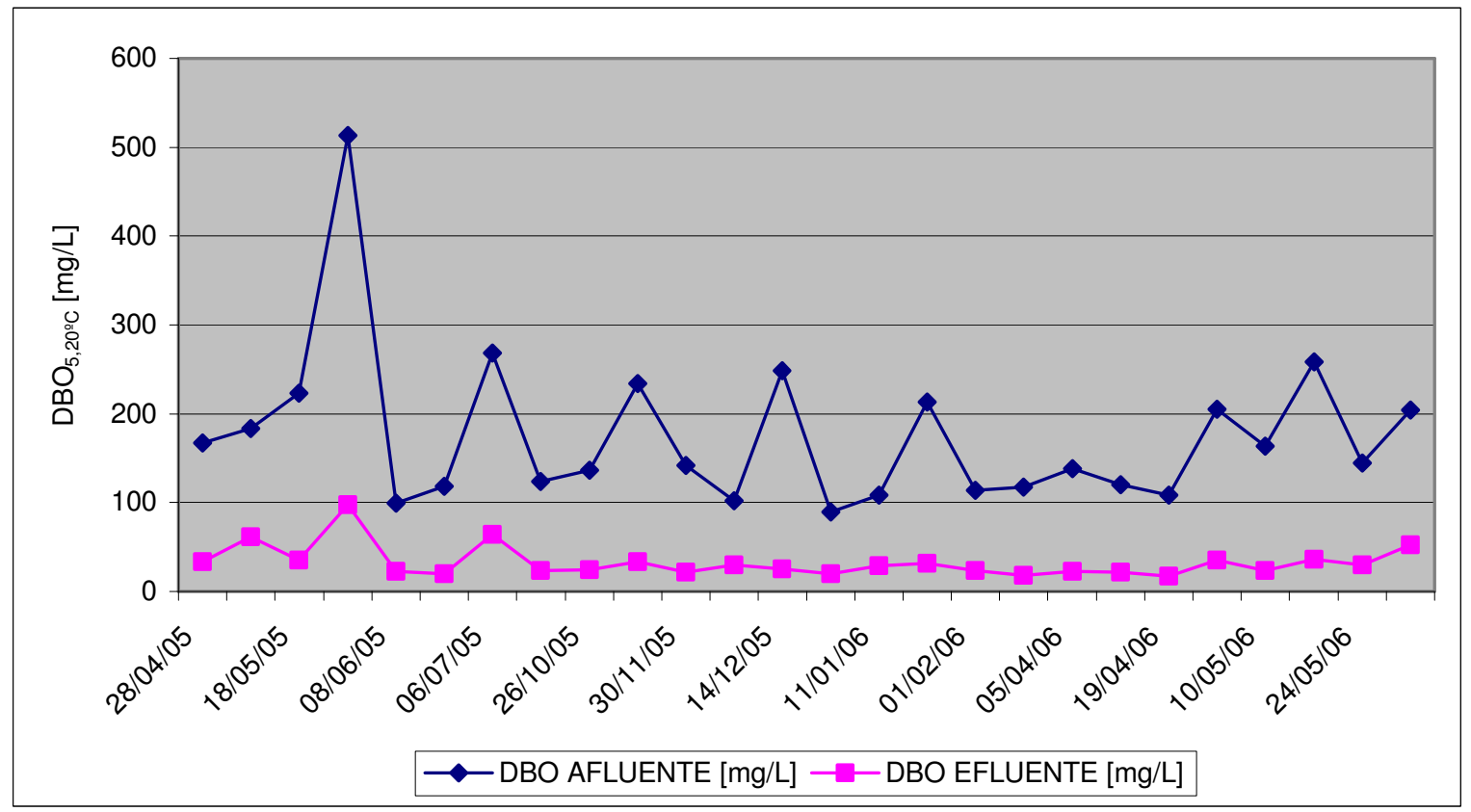

Figura 5.73 - Acompanhamento do reator $\mathrm{B}$ quanto às concentrações de $\mathrm{DBO}_{5,20^{\circ} \mathrm{C}}$ 
Com o estudo dessa comparação pode-se afirmar que, nas dosagens praticadas, houve um significativo aumento na remoção de carga orgânica, principalmente na fase final do experimento, quando se empregou $50 \mathrm{mg} / \mathrm{L}$ de coagulante.

De forma sintética, os resultados podem ser expressos nas Tabelas 5.38, e 5.39, respectivamente para a $2^{\underline{a}}$ e $3^{\text {a }}$ Fases.

Tabela 5.38 - Resumo dos Dados Obtidos com a Dosagem $25 \mathrm{mg} \mathrm{FeCl}_{3} / \mathrm{L}$

\begin{tabular}{|l|c|c|c|c|c|}
\hline \multirow{2}{*}{ Ponto de Amostragem } & \multicolumn{2}{|c|}{$\begin{array}{c}\text { DQO } \\
(\mathrm{mg} / \mathrm{L})\end{array}$} & $\begin{array}{c}\mathrm{DBO}_{5,20} \\
(\mathrm{mg} / \mathrm{L})\end{array}$ & \multicolumn{2}{c|}{$\begin{array}{c}\text { Fósforo } \\
(\mathrm{mg} \mathrm{P} / \mathrm{L})\end{array}$} \\
\cline { 2 - 6 } & Total & Filtrada & Total & Total & $\mathrm{PO}_{4}{ }^{-}$ \\
\hline Esgoto Bruto & 282 & 106 & 151 & 4,1 & 2,1 \\
& \pm 66 & \pm 15 & \pm 58 & $\pm 2,1$ & $\pm 0,6$ \\
\hline Efluente do UASB com adição de $\mathrm{FeCl}_{3}$ & 86 & 42 & 26 & 2,5 & 1,6 \\
& \pm 14 & \pm 13 & \pm 5 & $\pm 1,1$ & $\pm 0,7$ \\
\hline Efluente do UASB sem adição de $\mathrm{FeCl}_{3}$ & 115 & 57 & 41 & 2,6 & 2,0 \\
& \pm 24 & \pm 27 & \pm 14 & $\pm 1,1$ & $\pm 0,7$ \\
\hline
\end{tabular}

Tabela 5.39 - Resumo dos Dados Obtidos com a Dosagem $50 \mathrm{mg} \mathrm{FeCl} / \mathrm{L}$

\begin{tabular}{|l|c|c|c|c|c|}
\hline \multirow{2}{*}{ Ponto de Amostragem } & \multicolumn{2}{|c|}{$\begin{array}{c}\text { DQO } \\
(\mathrm{mg} / \mathrm{L})\end{array}$} & $\begin{array}{c}\mathrm{DBO}_{5,20} \\
(\mathrm{mg} / \mathrm{L})\end{array}$ & \multicolumn{2}{c|}{$\begin{array}{c}\text { Fósforo } \\
(\mathrm{mg} \mathrm{P} / \mathrm{L})\end{array}$} \\
\cline { 2 - 6 } & Total & Filtrada & Total & Total & $\mathrm{PO}_{4}{ }^{-}$ \\
\hline Esgoto Bruto & 350 & 123 & 162 & 4,5 & 1,8 \\
& \pm 126 & \pm 38 & \pm 51 & $\pm 2,0$ & $\pm 0,7$ \\
\hline Efluente do UASB com adição de $\mathrm{FeCl}_{3}$ & 58 & 46 & 29 & 2,9 & 0,7 \\
& \pm 45 & \pm 12 & \pm 11 & $\pm 1,3$ & $\pm 0,5$ \\
\hline Efluente do UASB sem adição de $\mathrm{FeCl}_{3}$ & 95 & 72 & 61 & 3,3 & 1,8 \\
& \pm 37 & \pm 25 & \pm 20 & $\pm 1,3$ & $\pm 0,7$ \\
\hline
\end{tabular}




\subsection{Acompanhamento do Manto de Lodo}

O lodo integrante dos mantos dos 2 reatores foram acompanhados com coletas e análises da série de sólidos de amostras coletadas em 3 alturas a partir da laje de fundo das unidades: 1,0 m, 2,0 m e 3,0 m. Como há um grande acúmulo de areia no fundo dos mesmos, houve alguma dificuldade em coletar essas porções de lodo, sendo que as amostras relativas a 1,0 m, por vezes foi obtida na altura de 1,20 m, o que, para efeitos deste trabalho, não implicou em um grande fator de erro.

As Tabelas 5.40 e 5.41 mostram os valores médios das frações de sólidos totais e em suspensão dos 2 reatores das 6 coletas realizadas ao longo deste estudo, que podem ser avaliadas isoladamente nas Tabelas D.1 a D.12, no Capítulo 7 ANEXOS.

Tabela 5.40 - Reator B - Série de Sólidos do Manto de Lodo: Valores Médios

Reator B - Série de Sólidos do Manto de Lodo: Valores Médios

\begin{tabular}{ccccccc}
\hline $\begin{array}{c}\text { Altura a } \\
\text { partir do } \\
\text { fundo do } \\
\text { reator [m]: }\end{array}$ & ST [mg/L] & STF [mg/L] & STV [mg/L] & SST [mg/L] & SSF [mg/L] & SSV [mg/L] \\
\hline $\mathbf{3 , 0}$ & 24446 & 13254 & 11192 & 14526 & 7852 & 6673 \\
\hline $\mathbf{2 , 0}$ & 42757 & 23690 & 19067 & 52736 & 29873 & 22863 \\
\hline $\mathbf{1 , 0}$ & 78777 & 45157 & 33620 & 86913 & 36051 & 50863 \\
\hline
\end{tabular}

Tabela 5.41 - Reator C - Série de Sólidos do Manto de Lodo: Valores Médios

Reator C - Série de Sólidos do Manto de Lodo: Valores Médios

\begin{tabular}{ccccccc}
\hline $\begin{array}{c}\text { Altura a } \\
\text { partir do } \\
\text { fundo do } \\
\text { reator [m]: }\end{array}$ & ST [mg/L] & STF [mg/L] & STV [mg/L] & SST [mg/L] & SSF [mg/L] SSV [mg/L] & ST \\
\hline $\mathbf{3 , 0}$ & 14080 & 7960 & 6120 & 13568 & 7473 & 6122 \\
\hline $\mathbf{2 , 0}$ & 76963 & 44600 & 32363 & 78635 & 41972 & 43220 \\
\hline $\mathbf{1 , 0}$ & 82163 & 49680 & 32483 & 96041 & 51149 & 49963 \\
\hline
\end{tabular}


Do exame desses valores médios, pode-se ver que há uma tendência do reator que teve aplicação de cloreto férrico formar uma camada (manto) de lodo mais espesso, com concentrações altas de sólidos até na altura de 3,0 m. Por outro lado, esse manto apresenta uma concentração mais baixa do que as obtidas nas mesmas alturas no reator $\mathrm{C}$, de 1,0 e 2,0 m.

A altura de 3,0 $\mathrm{m}$ acima do fundo coincide exatamente com o começo da zona de decantação dos reatores (como mostra a Figura C.3). Com isto, um número alto de concentração de sólidos nessa altura implica em perdas de sólidos no efluente clarificado, indicando a necessidade de descarte de lodo. Nas amostras de 15/08/05, 05/10/05 e 17/05/06 (Tabelas D.5, D.7 e D.11, do reator B e D.6, do reator C), os valores para a altura 3,0 m estiveram acima do desejável (ST $\sim 500 \mathrm{mg} / \mathrm{L}$ ), como se deu nas demais coletas. Os descartes de lodo ocorreram nas seguintes datas:

- Reator B: 04/11/05, 06/02/06, 07/04/06 e 17/05/06;

- Reator C: 06/02/06, 07/04/06 e 17/05/06.

Com isto, vê-se que após o descarte no reator B em 04/11/05, as concentrações de sólidos caíram para condições melhores.

- ST do reator B em 05/10/05: $56.320 \mathrm{mg} / \mathrm{L}$ (nos 3,0 m);

- ST do reator B em 06/02/06: 776 mg/L (também na altura de 3,0 m).

Já o reator $C$ teve um menor acúmulo de sólidos, com valores mais baixos de sólidos no ponto de passagem para a zona de decantação.

\subsection{Comportamento dos Reatores}

Como exposto anteriormente, a aplicação de cloreto férrico como coagulante no reator implicou em algumas alterações do aspecto do mesmo. Houve a formação de espuma, como a Figura 5.74 mostra, junto à saída da calha coletora do reator B. 


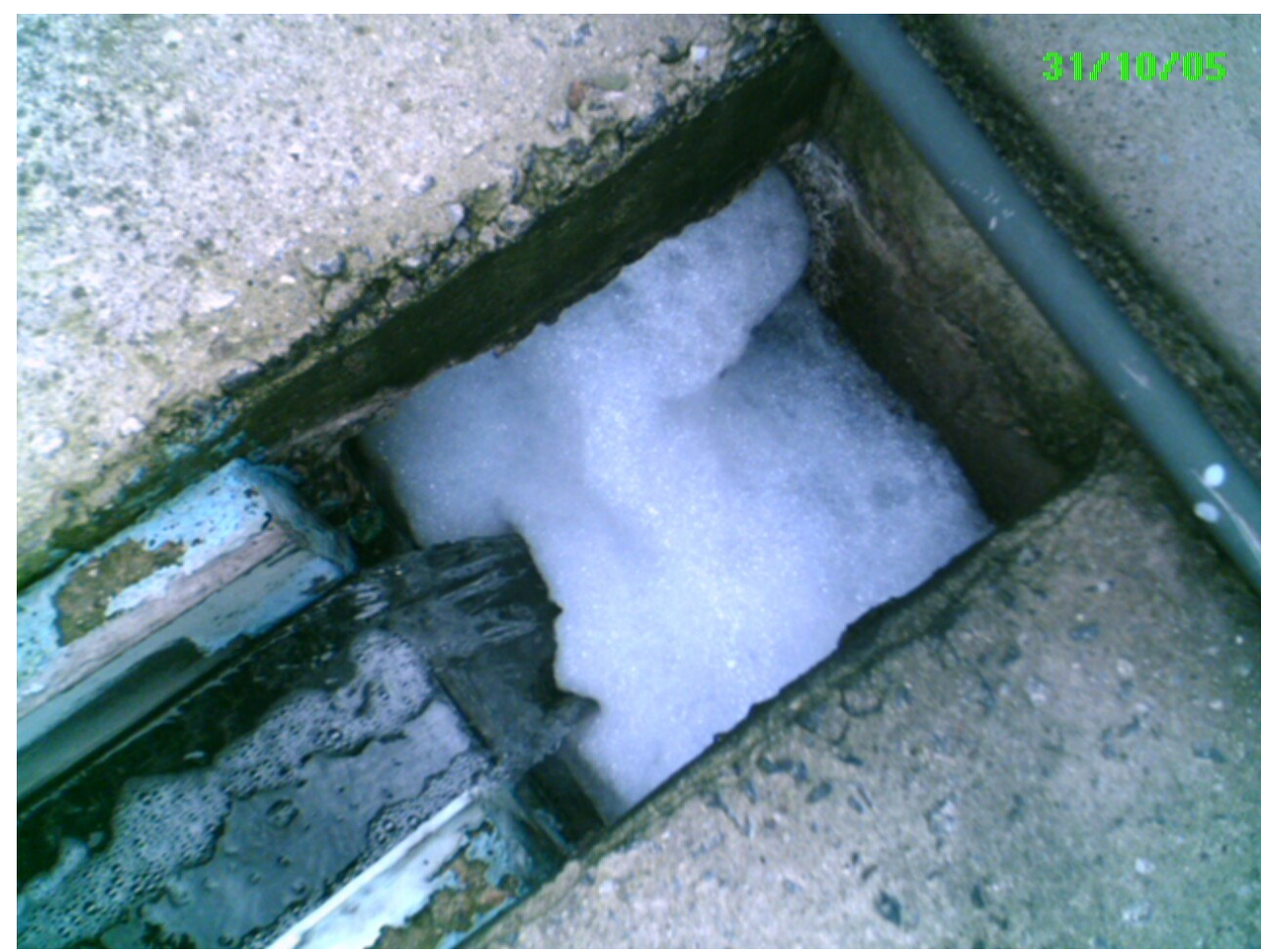

Figura $\mathbf{5 . 7 4}$ - Formação de espuma na saída de clarificado do reator B

Outra alteração foi a aparência da superfície do reato com dosagem de coagulante, que se apresentou em algumas vezes com coloração avermelhada e com algum material flutuante, com pode-se observar na Figura 5.75.

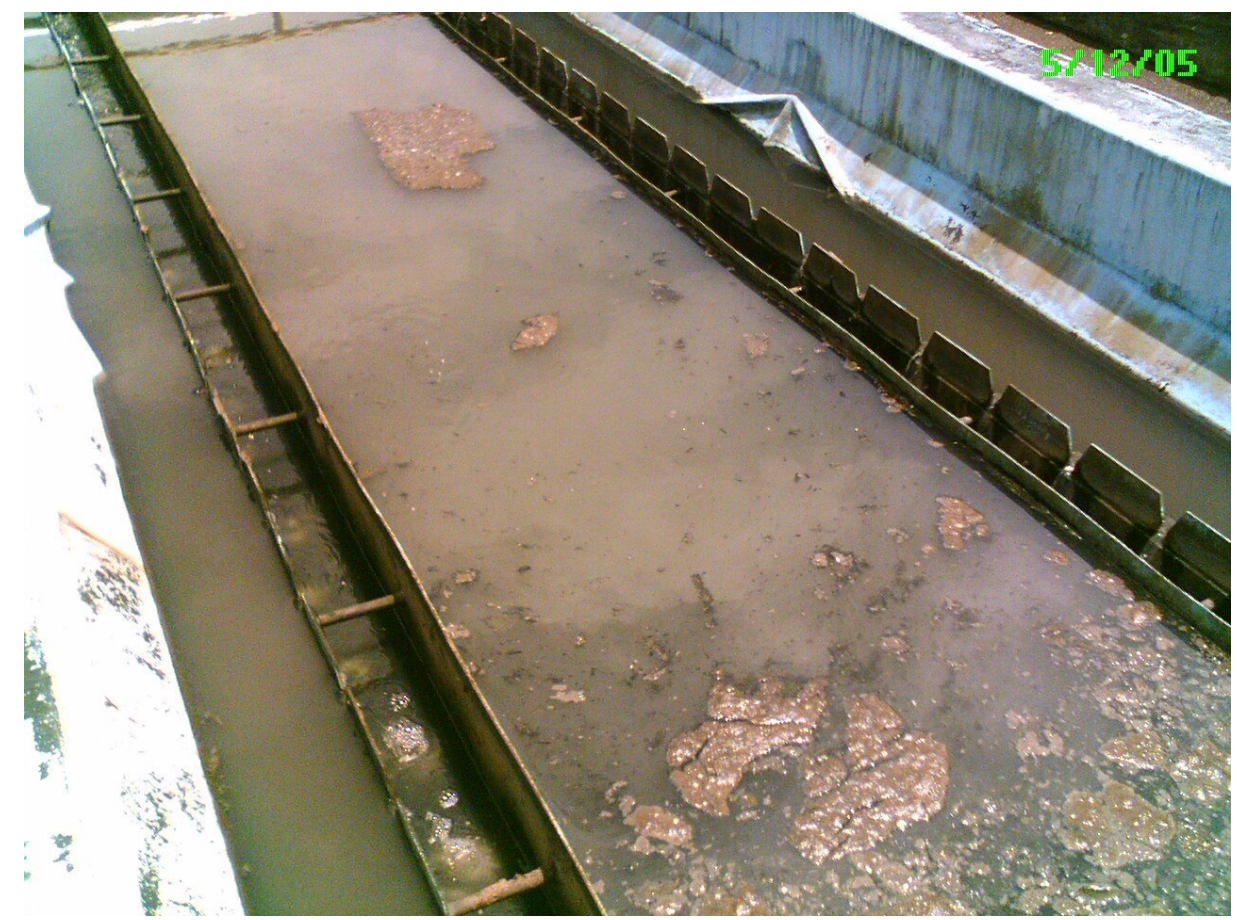

Figura 5.75 - Aspecto da superfície do reator B 


\subsection{Características de Desaguamento do Lodo Descartado}

O lodo descartado pelos 2 reatores estudados (com e sem aplicação de cloreto férrico na alimentação de esgoto bruto) foi acompanhado durante 2 ciclos de secagem nos leitos de areia da ETE. A Tabela 5.42 mostra as espessuras da camada de lodo sobre o leito de secagem ao longo do Ciclo 1.

Tabela 5.42 - Ciclo de desaguamento nos leitos de secagem - Ciclo 1

\begin{tabular}{ccc}
\hline \multirow{2}{*}{ Data: } & \multicolumn{2}{c}{ Altura da camada de lodo sobre o leito [cm] } \\
\cline { 2 - 3 } & Reator B: & Reator C: \\
\hline $07 / 04 / 06$ & 25 & 25 \\
\hline $10 / 04 / 06$ & 10 & 15 \\
\hline $12 / 04 / 06$ & 8 & 12 \\
\hline $17 / 04 / 06$ & 6,5 & 11,5 \\
\hline $19 / 04 / 06$ & 4,5 & 9,5 \\
\hline $26 / 04 / 06$ & - & 7 \\
\hline
\end{tabular}

É clara a vantagem da secagem do lodo proveniente do reator B, que teve aplicação de $50 \mathrm{mg} / \mathrm{L}$ de cloreto férrico no esgoto bruto.

Comparativamente, o lodo do reator $B$ encerrou seu ciclo de desaguamento 10 dias após seu descarte, enquanto que o lodo do reator $\mathrm{C}$ precisou de 20 dias para chegar à mesma espessura. A Figura 5.76 mostra graficamente essa evolução.

Os sólidos totais dos 2 "lodos" foram analisados, e os resultados foram os seguintes:

- Lodo do reator B: ST = 649,0 g/L (teor de sólidos $~ 65,9 \%$ );

- Lodo do reator C: ST = 513,0 g/L (teor de sólidos $~ 51,3 \%$ ). 


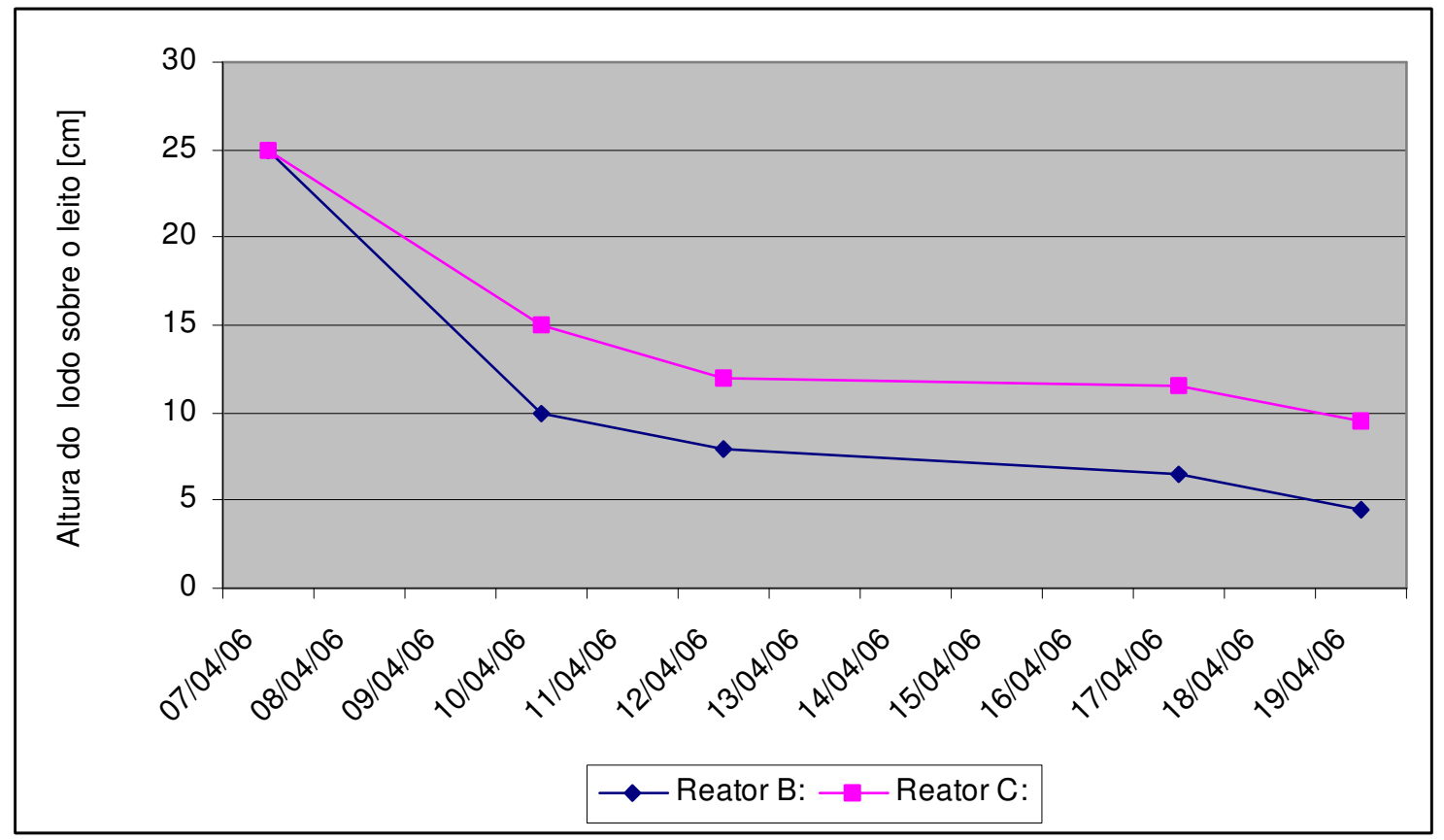

Figura 5.76 - Ciclo de desaguamento nos leitos de secagem - Ciclo 1

A Figura 5.77 mostra as tortas secas retiradas dos leitos em 19/04/06, aonde se vê a significativa redução do volume do lodo gerado no reator B (a direita no foto).

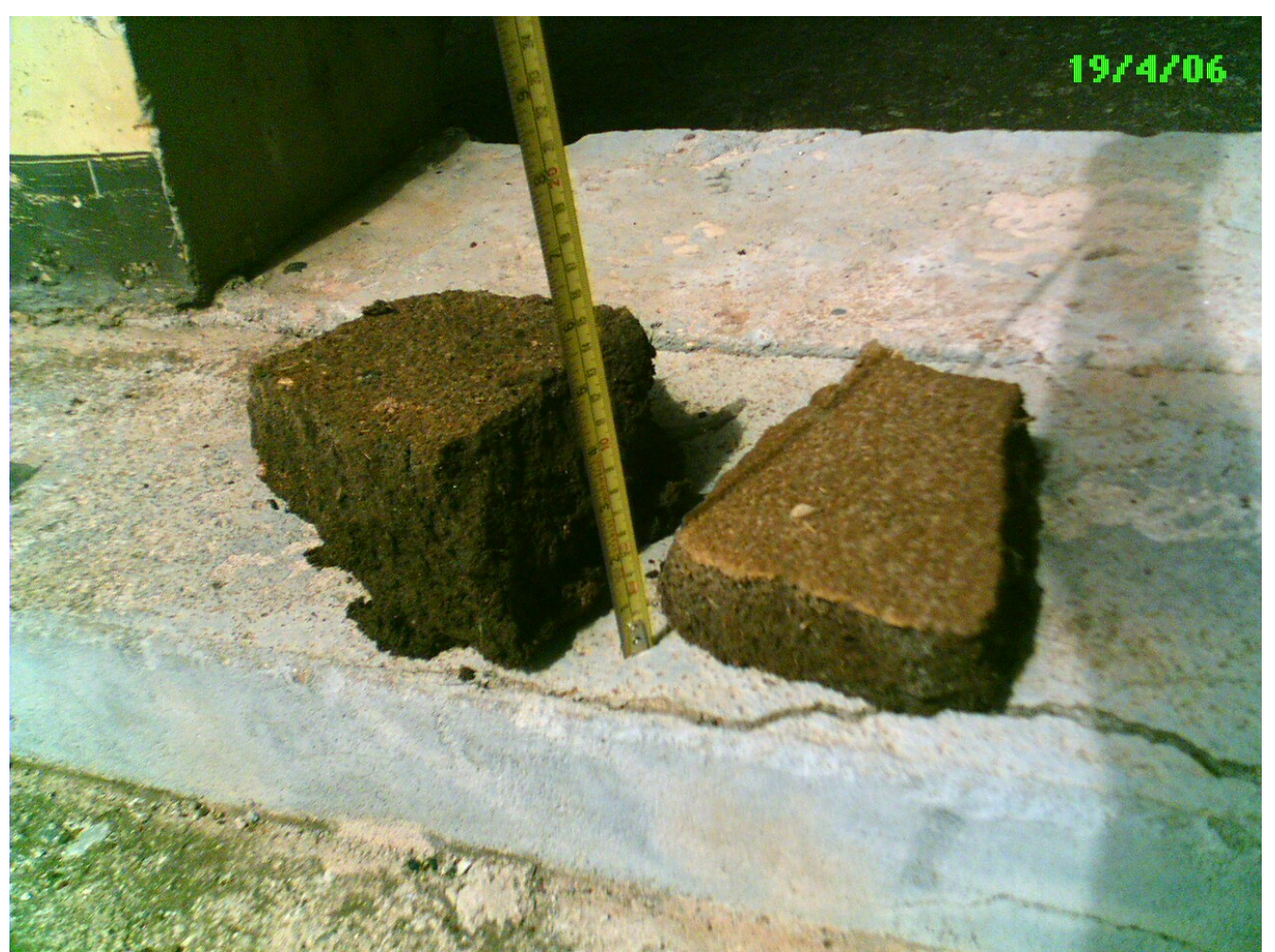

Figura 5.77 - Lodos dos leitos de secagem (reator C a esquerda e reator B a direita) - Ciclo 1 
No segundo ciclo de secagem acompanhado, obteve-se os resultados indicados na Tabela 5.43 .

Tabela 5.43 - Ciclo de desaguamento nos leitos de secagem - Ciclo 2

\begin{tabular}{ccc}
\hline \multirow{2}{*}{ Data: } & \multicolumn{2}{c}{ Altura da camada de lodo sobre o leito [cm] } \\
\cline { 2 - 3 } & Reator B: & Reator C: \\
\hline $17 / 05 / 06$ & 25 & 20 \\
\hline $22 / 05 / 06$ & 14 & 15 \\
\hline $24 / 05 / 06$ & 13,5 & 14 \\
\hline $29 / 05 / 06$ & 10 & 13 \\
\hline
\end{tabular}

Na data de 24/05/06 choveu, o que, ao se observar a tabela do Ciclo 2, mostra que a influência das precipitações não é tão grande. Mais uma vez a vantagem do desaguamento do lodo proveniente do reator B ficou evidenciada, como se pode ver na Figura 5.78.

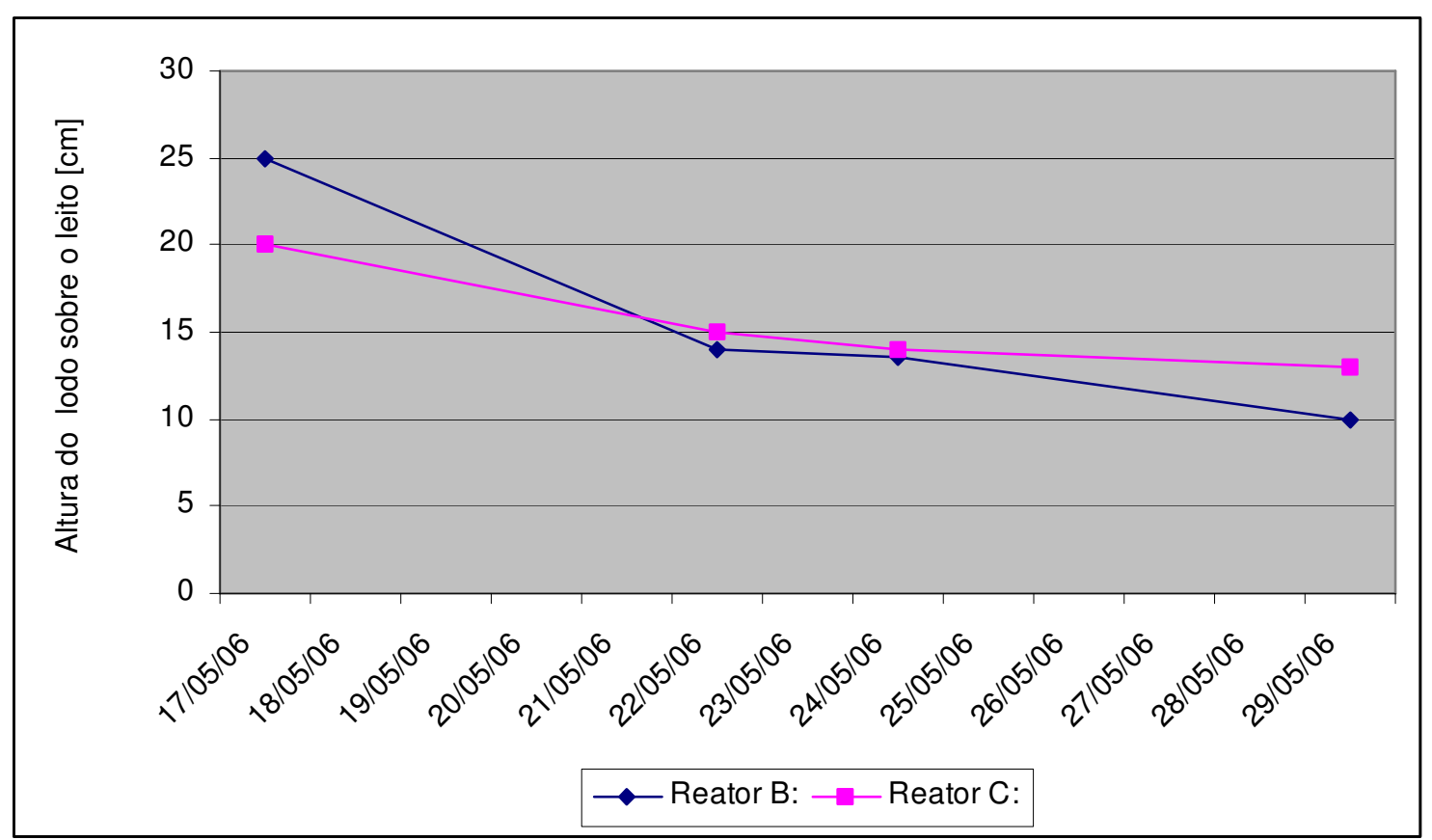

Figura 5.78 - Ciclo de desaguamento nos leitos de secagem - Ciclo 2 


\subsection{Informações Adicionais}

Da operação dos reatores UASB com e sem a aplicação de cloreto férrico foi possível tirar algumas lições válidas para outras situações aonde se tenha processo anaeróbio e/ou aplicação de cloreto férrico. $O$ ataque às tubulações de ferro fundido devido à formação de compostos de enxofre consumiu quase integralmente algumas de suas paredes, principalmente da linha de efluente tratado. Como mostra a foto da Figura 5.78, o referido tubo de $\varnothing 400 \mathrm{~mm}$ e espessura inicial de $3 / 8 "(9,5 \mathrm{~mm})$ praticamente desapareceu (na parte superior do conduto livre) em pouco mais de 11 anos de operação.

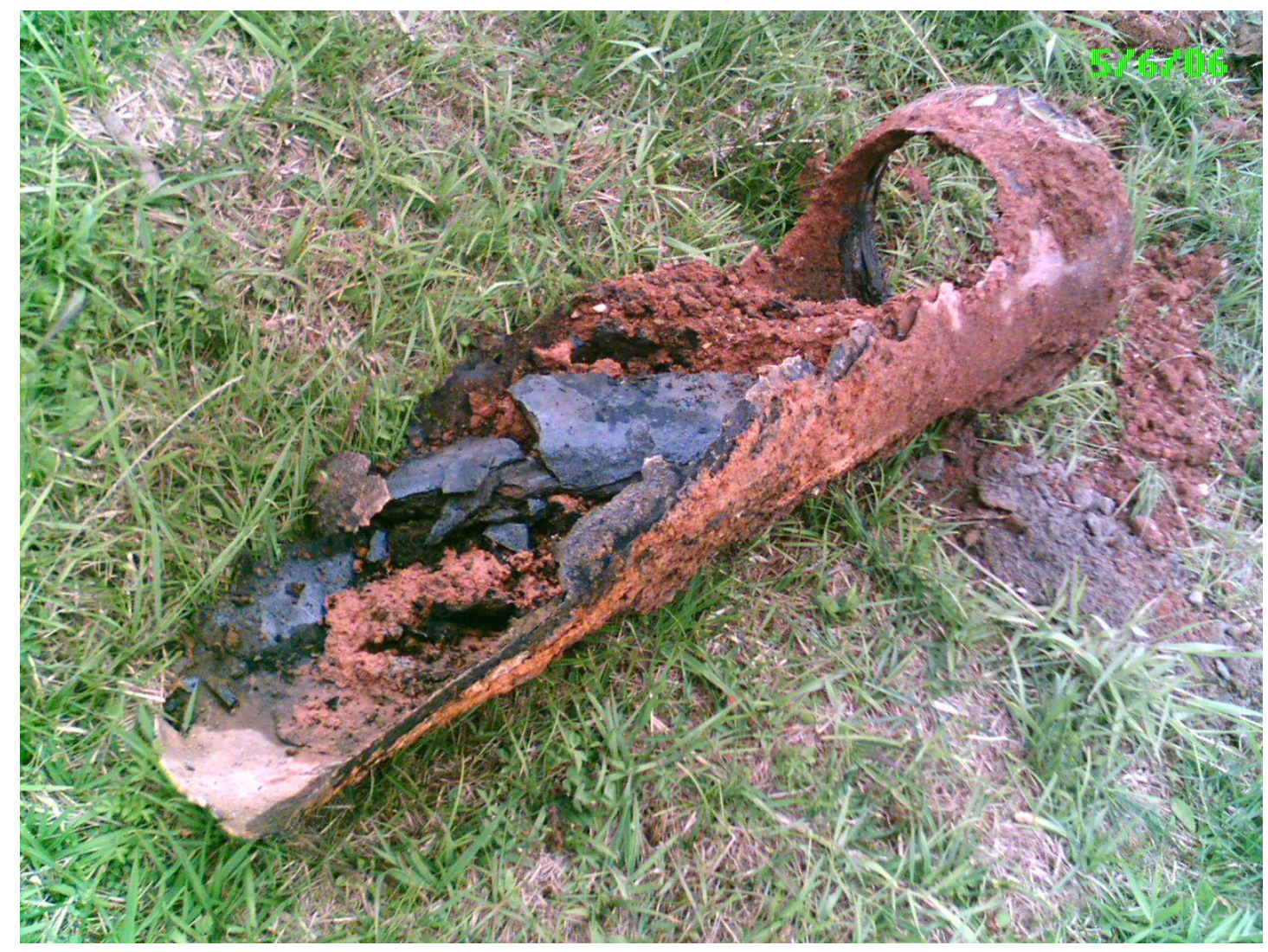

Figura 5.78 - Tubulação de efluente tratado: efeito da corrosão em sistemas anaeróbios

Outro ponto onde a corrosão causou problemas foi no sistema de coleta de gás das campânulas. A Figura 5.79 mostra uma das mangueiras que se deteriorou com a ação corrosiva do $\mathrm{H}_{2} \mathrm{~S}$, causando problemas de mau cheiro na ETE e vizinhança. 
Com isto, recomenda-se o emprego de materiais que resistam ao ambiente anaeróbio, como por exemplo o aço inoxidável (para o gás) e o PEAD e o polipropileno para tubulações de efluente. Também o concreto das paredes internas deve receber tratamento contra o ataque químico.

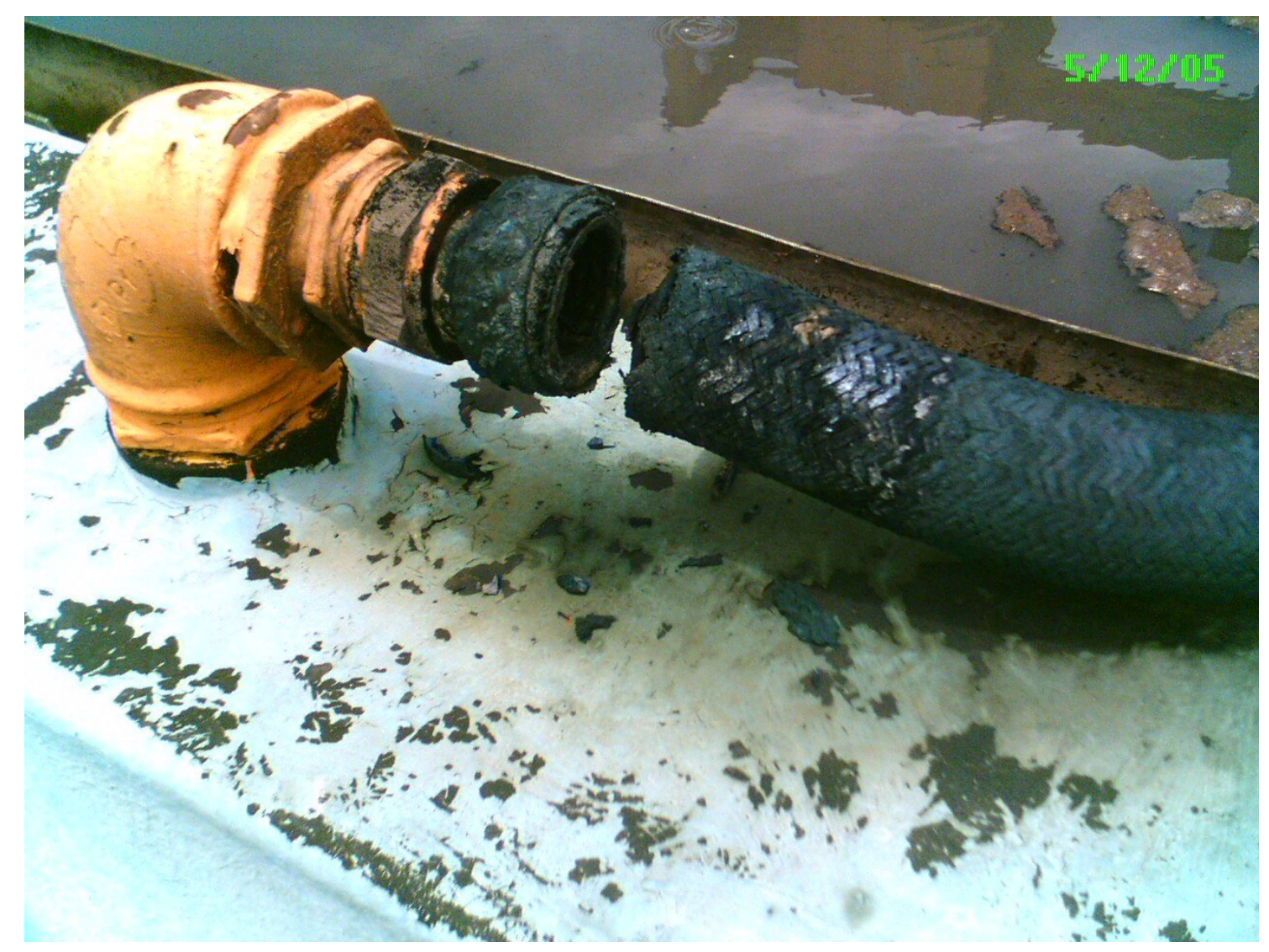

Figura 5.79 - Tubulação de coleta de gás

Para a reservação do cloreto férrico, os materiais mais indicados são reservatórios em polipropileno ou fibra de vidro, esta última com resina interna de proteção. Um dos reservatórios utilizados não resistiu, precisando ser substituído após somente 4 meses. Na Figura 5.80 é mostrada a trinca, através da qual se iniciou um vazamento do produto.

As mangueiras para a condução de cloreto férrico devem ser em PVC "cristal" com espessura de $1,5 \mathrm{~mm}$. 
$\mathrm{Na}$ fase final do experimento foram verificados os parâmetro de cor e turbidez dos esgotos bruto e efluentes dos reatores. Os resultados, mostrados abaixo na Tabela 5.44 , indicaram uma melhor qualidade do efluente do reator B.

Tabela 5.44 - Cor e turbidez do esgoto afluente e efluentes dos reatores B e C

\begin{tabular}{ccc} 
Ponto de Coleta & Cor [UC] & Turbidez [NTU] \\
\hline Esgoto afluente & 250 & 16,7 \\
\hline Saída do reator B & 150 & 6,0 \\
\hline Saída do reator C & 190 & 11,4 \\
\hline
\end{tabular}

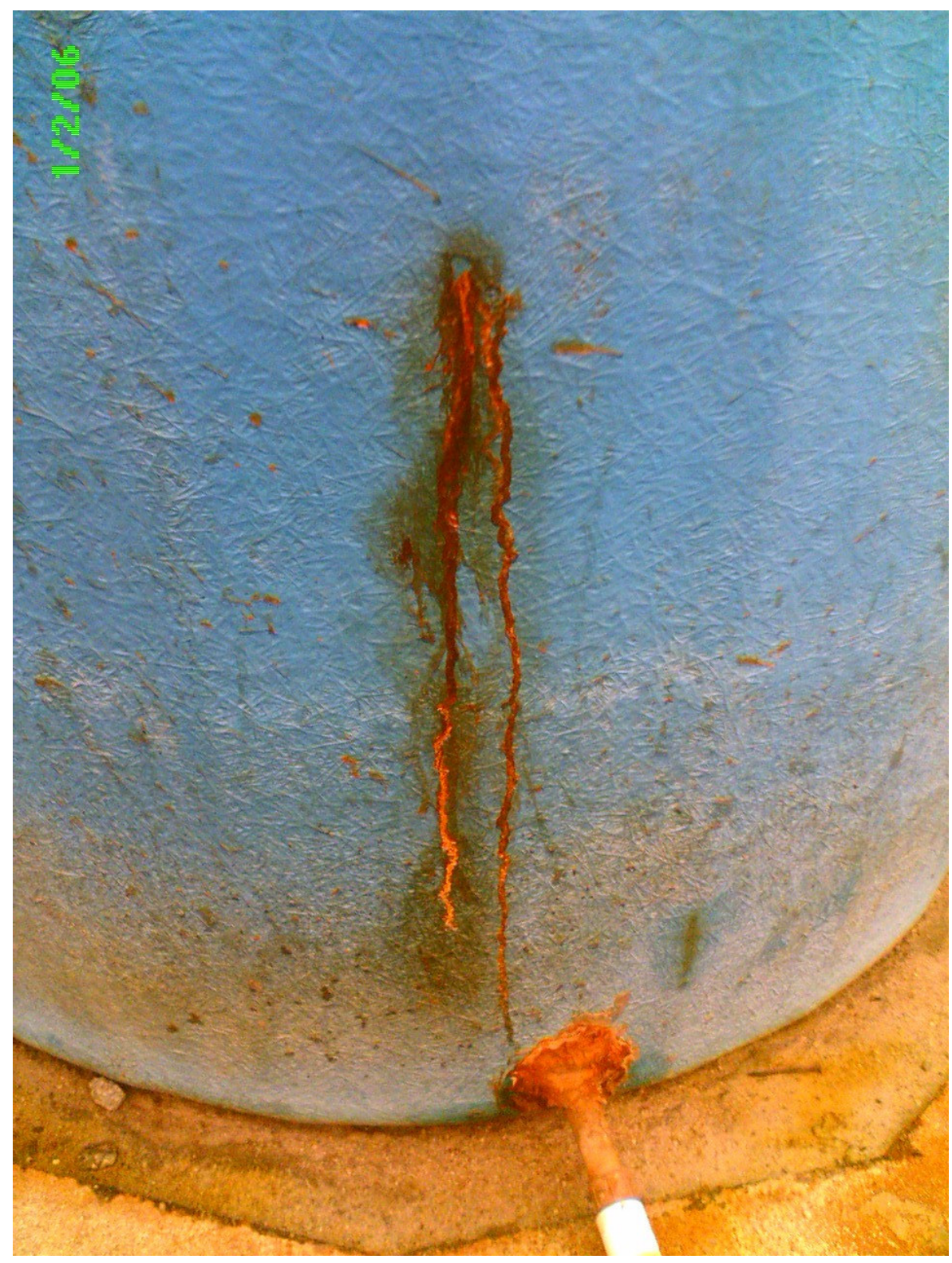

Figura 5.80 - Reservatório de fibra de vidro atacado pelo cloreto férrico 


\section{CONCLUSÕES}

Da avaliação, podemos concluir que a adição de cloreto férrico à entrada de um reator UASB gera aumento significativo de eficiência de remoção de carga orgânica. No caso da dosagem de $50 \mathrm{mg} \mathrm{FeCl} / / \mathrm{L}$, a eficiência de remoção de DQO total passou de $55 \%$ (sem coagulante, o que já pode ser considerada alta) para $73 \%$ (com coagulante). A eficiência de remoção de $\mathrm{DBO}_{5,20^{\circ} \mathrm{C}}$ subiu de $63 \%$ para $82 \%$. Este fato pode, independente da remoção de fósforo, justificar o uso desse sistema em aplicações reais, desde que sua viabilidade técnico-econômica seja verificada. $O$ custo do cloreto férrico era de $R \$ 0,46 / \mathrm{kg}$. A massa específica do produto é $1,4 \mathrm{~kg} / \mathrm{L}$, na concentração de $38 \%$. O litro do cloreto custa portanto $R \$ 0,644$. Para a dosagem de $50 \mathrm{mg} / \mathrm{L}$ numa vazão de esgoto bruto de $10 \mathrm{~L} / \mathrm{s}$ (vazão tratada durante o experimento), são requeridos $3,26 \mathrm{~L} / \mathrm{h}$, ou $2.426 \mathrm{~L} / \mathrm{mês}$. Com isto, o custo de produtos químicos é de $\mathrm{R} \$ 1.562,00 /$ mês. Para vazões e dosagens maiores, o custo é proporcional. Já o custo da instalação pode ser considerado irrisório diante do custo de uma estação de tratamento, abaixo dos $R \$ 5.000,00$, envolvendo 2 reservatórios, bases de concreto e baias de contenção para produtos químicos, bomba dosadora e respectiva instalação elétrica e mangueiras.

No que se refere aos compostos de fósforo, o que se percebe é uma alta remoção de ortofosfatos, mas uma quase imperceptível remoção de fósforo total. Possivelmente, os ortofosfatos "removidos" são transformados em outros compostos de fósforo, sendo detectados na análise de fósforo total.

Com relação ao lodo gerado, o que se percebeu foi uma melhora na capacidade de desaguamento (o ciclo de secagem do lodo com adição de cloreto era de 2 semanas enquanto que o lodo sem adição consome cerca de 3 a 4 semanas) e a obtenção de torta (do lodo do reator com adição de cloreto) com aproximadamente $60 \%$ do volume do lodo sem cloreto. Na caracterização do perfil do manto de lodo, o que se observou foram as seguintes diferenças: 
- reator com aplicação de cloreto férrico: o manto de lodo é mais espesso (atinge uma altura maior dentro do reator) e com menor concentração de sólidos em seu interior;

- reator sem aplicação de produto: tem-se o manto com menor altura e com maiores concentrações.

Dessa constatação, uma conseqüência negativa da adição de coagulante pode ser a tendência a maior perda de sólidos junto com o efluente clarificado, por termos 0 lodo depositado numa altura próxima ao separador trifásico e suas partículas de certa forma mais leves e mais propícias a serem arrastadas com o esgoto tratado.

Quanto à estabilidade da massa anaeróbia do reator, não se notou variações expressivas nos valores de alcalinidade e $\mathrm{pH}$ da unidade que trabalhou com cloreto férrico. Eventualmente, numa dosagem mais alta, pode ser requerida a adição de barrilha para este controle operacional.

No tocante à remoção de sulfetos, pode-se afirmar que, com as dosagens praticadas durante o estudo, não houve qualquer redução de suas concentrações, o que descarta este procedimento para fins de eliminação de maus odores, típicos em processos anaeróbios.

A lâmina líquida, bem como o clarificado coletado nas canaletas se mostraram com uma aparência "escura", com uma quase imperceptível dispersão de sólidos finos, o que não re repetiu nos demais reatores da estação.

Cabe, por fim, lembrar que as "respostas" dadas pelo sistema utilizando esse coagulante foram sempre muito rápidas, obviamente naqueles parâmetros nos quais a sua utilização produzia algum efeito. Em termos práticos, pode-se dizer que os resultados de uma aplicação eram identificados em cerca de 2 dias (período entre coletas praticado no experimento), ao passo que o tempo de detenção hidráulico médio foi de 11 horas. Fica ainda a recomendação para a dosagem de $100 \mathrm{mg}$ $\mathrm{FeCl}_{3} / \mathrm{L}$ e seu acompanhamento quanto às remoções de $\mathrm{DBO}_{5,20^{\circ} \mathrm{C}}$, DQO, surfactantes e fósforo, com o controle da alcalinidade e do $\mathrm{pH}$. 


\section{ANEXOS}
A. Planilhas dos dados levantados para o experimento
B. Planilhas de dados anteriores ao experimento
C. Desenhos da ETE Ribeirão Pires
D. Planilhas de dados de sólidos nas alturas do manto de lodo

E. Hidrograma de vazões de esgoto sanitário afluente à ETE Ribeirão Pires 
Tabela A.1 - DQO Total - Sem dosagem

REATOR B

REATOR C

DATA DQO AFLUENTE DQO EFLUENTE DQO AFLUENTE DQO EFLUENTE [mg/L] [mg/L] [mg/L]

\begin{tabular}{|c|c|c|c|c|}
\hline & & & & \\
\hline 05/04/05 & 177 & 35 & 177 & 39 \\
\hline $12 / 04 / 05$ & 352 & 131 & 352 & 162 \\
\hline $25 / 04 / 05$ & 355 & 38 & 355 & 53 \\
\hline 28/04/05 & 321 & 150 & 321 & 101 \\
\hline 02/05/05 & 333 & 74 & 333 & 89 \\
\hline 04/05/05 & 308 & 70 & 308 & 81 \\
\hline 09/05/05 & 231 & 85 & 231 & 100 \\
\hline $11 / 05 / 05$ & 436 & 107 & 436 & 174 \\
\hline $16 / 05 / 05$ & 361 & 302 & 361 & 212 \\
\hline $18 / 05 / 05$ & 396 & 67 & 396 & 107 \\
\hline 23/05/05 & 408 & 78 & 408 & 118 \\
\hline $30 / 05 / 05$ & 196 & 71 & 196 & 114 \\
\hline 01/06/05 & 295 & 128 & 295 & 117 \\
\hline 06/06/05 & 308 & 65 & 308 & 115 \\
\hline 08/06/05 & 249 & 85 & 249 & 144 \\
\hline $13 / 06 / 05$ & 400 & 77 & 400 & 131 \\
\hline $15 / 06 / 05$ & 377 & 91 & 377 & 132 \\
\hline 20/06/05 & 432 & 36 & 432 & 64 \\
\hline 22/06/05 & 264 & 68 & 264 & 102 \\
\hline 27/06/05 & 295 & 93 & 295 & 117 \\
\hline 04/07/05 & 444 & 99 & 444 & 150 \\
\hline 06/07/05 & 148 & 78 & 148 & 85 \\
\hline $11 / 07 / 05$ & 320 & 76 & 320 & 107 \\
\hline 01/08/05 & 575 & 117 & 575 & 167 \\
\hline 08/08/05 & 392 & 125 & 392 & 157 \\
\hline $10 / 08 / 05$ & 249 & 50 & 249 & 54 \\
\hline $17 / 08 / 05$ & 488 & 133 & 488 & 217 \\
\hline 22/08/05 & 320 & 107 & 320 & 175 \\
\hline 24/08/05 & 493 & 145 & 493 & 238 \\
\hline 29/08/05 & 369 & 110 & 369 & 157 \\
\hline $31 / 08 / 05$ & 204 & 106 & 204 & 200 \\
\hline 05/09/05 & 256 & 76 & 256 & 108 \\
\hline
\end{tabular}


Tabela A.2 - DQO Filtrada - Sem dosagem

REATOR B

REATOR C

DATA DQO AFLUENTE DQO EFLUENTE DQO AFLUENTE DQO EFLUENTE [mg/L] [mg/L] [mg/L]

\begin{tabular}{|c|c|c|c|c|}
\hline $11 / 05 / 05$ & 158 & 63 & 158 & 95 \\
\hline $16 / 05 / 05$ & 110 & 27 & 110 & 35 \\
\hline $18 / 05 / 05$ & 127 & 63 & 127 & 44 \\
\hline $23 / 05 / 05$ & 133 & 47 & 133 & 59 \\
\hline $30 / 05 / 05$ & 82 & 43 & 82 & 43 \\
\hline 01/06/05 & 132 & 66 & 132 & 66 \\
\hline 06/06/05 & 119 & 23 & 119 & 23 \\
\hline 08/06/05 & 78 & 50 & 78 & 66 \\
\hline $13 / 06 / 05$ & 115 & 35 & 115 & 50 \\
\hline $15 / 06 / 05$ & 121 & 60 & 121 & 72 \\
\hline 22/06/05 & 117 & 38 & 117 & 49 \\
\hline $27 / 06 / 05$ & 140 & 62 & 140 & 66 \\
\hline 04/07/05 & 147 & 51 & 147 & 67 \\
\hline 06/07/05 & 54 & 39 & 54 & 39 \\
\hline $11 / 07 / 05$ & 122 & 38 & 122 & 53 \\
\hline 01/08/05 & 194 & 70 & 194 & 97 \\
\hline 08/08/05 & 149 & 55 & 149 & 75 \\
\hline $10 / 08 / 05$ & 124 & 4 & 124 & 8 \\
\hline $17 / 08 / 05$ & 171 & 65 & 171 & 95 \\
\hline 22/08/05 & 122 & 69 & 122 & 95 \\
\hline 24/08/05 & 170 & 77 & 170 & 125 \\
\hline 29/08/05 & 114 & 67 & 114 & 102 \\
\hline $31 / 08 / 05$ & 118 & 59 & 118 & 71 \\
\hline 05/09/05 & 104 & 28 & 104 & 44 \\
\hline
\end{tabular}


Tabela A.3 - $\mathrm{DBO}_{5,20^{\circ} \mathrm{C}}$ Total - Sem dosagem

\begin{tabular}{|c|c|c|c|c|}
\hline \multirow[b]{2}{*}{ DATA } & \multicolumn{2}{|c|}{ REATOR B } & \multicolumn{2}{|c|}{ REATOR C } \\
\hline & $\begin{array}{c}\text { DBO }_{5,20^{\circ} \mathrm{C}} \\
\text { AFLUENTE } \\
\text { [mg/L] }\end{array}$ & $\begin{array}{l}\text { DBO }_{5,200^{\circ}} \\
\text { EFLUENTE } \\
\text { [mg/L] }\end{array}$ & $\begin{array}{c}\text { DBO }_{5,20^{\circ} \mathrm{C}} \\
\text { AFLUENTE } \\
\text { [mg/L] }\end{array}$ & $\begin{array}{c}\text { DBO }_{5,20^{\circ} \mathrm{C}} \\
\text { EFLUENTE } \\
\text { [mg/L] }\end{array}$ \\
\hline 28/04/05 & 167 & 34 & 167 & 34 \\
\hline 04/05/05 & 183 & 61 & 183 & 38 \\
\hline $11 / 05 / 05$ & - & 59 & - & - \\
\hline $18 / 05 / 05$ & 223 & 35 & 223 & 41 \\
\hline 01/06/05 & 514 & 98 & 514 & 85 \\
\hline 08/06/05 & 100 & 23 & 100 & 44 \\
\hline $15 / 06 / 05$ & 118 & 20 & 118 & 28 \\
\hline 06/07/05 & 268 & 64 & 268 & 65 \\
\hline
\end{tabular}

Tabela A.4 - $\mathrm{DBO}_{5,20^{\circ} \mathrm{C}}$ Filtrada - Sem dosagem

\begin{tabular}{|c|c|c|c|c|}
\hline \multirow[b]{2}{*}{ DATA } & \multicolumn{2}{|c|}{ REATOR B } & \multicolumn{2}{|c|}{ REATOR C } \\
\hline & $\begin{array}{l}\text { DBO }_{5,20^{\circ} \mathrm{C}} \\
\text { AFLUENTE } \\
\text { [mg/L] }\end{array}$ & $\begin{array}{c}\text { DBO }_{5,20^{\circ} \mathrm{C}} \\
\text { EFLUENTTE } \\
\text { [mg/L] }\end{array}$ & $\begin{array}{c}\text { DBO }_{5,20^{\circ} \mathrm{C}} \\
\text { AFLUENTE } \\
\text { [mg/L] }\end{array}$ & $\begin{array}{c}\text { DBO }_{5,20^{\circ} \mathrm{C}} \\
\text { EFLUENTE } \\
\text { [mg/L] }\end{array}$ \\
\hline $18 / 05 / 05$ & 99 & 44 & 99 & 35 \\
\hline 01/06/05 & 242 & 76 & 242 & 58 \\
\hline 08/06/05 & 39 & 15 & 39 & 18 \\
\hline $15 / 06 / 05$ & 36 & 12 & 36 & 17 \\
\hline 06/07/05 & 78 & 34 & 78 & 38 \\
\hline
\end{tabular}

Tabela A.5 - Fósforo Total - Sem dosagem

\begin{tabular}{|c|c|c|c|c|}
\hline \multirow[b]{2}{*}{ DATA } & \multicolumn{2}{|c|}{ REATOR B } & \multicolumn{2}{|c|}{ REATOR C } \\
\hline & $\begin{array}{c}P_{\text {TOTAL }} \\
\text { AFLUENTE } \\
\text { [mg/L] }\end{array}$ & $\begin{array}{c}P_{\text {TOTAL }} \\
\text { EFLUENTE } \\
{[\mathrm{mg} / \mathrm{L}]}\end{array}$ & $\begin{array}{c}P_{\text {TOTAL }} \\
\text { AFLUENTE } \\
\text { [mg/L] }\end{array}$ & $\begin{array}{c}\mathbf{P}_{\text {TOTAL }} \\
\text { EFLUENTE } \\
{[\mathrm{mg} / \mathrm{L}]}\end{array}$ \\
\hline $30 / 05 / 05$ & 3,6 & 0,9 & 3,6 & 1,7 \\
\hline 06/06/05 & 4,7 & 2,5 & 4,7 & 2,6 \\
\hline
\end{tabular}


Tabela A.6 - Ortofosfato - Sem dosagem

REATOR B

REATOR C

\begin{tabular}{|c|c|c|c|c|}
\hline DATA & 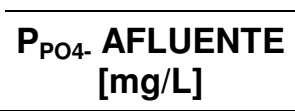 & $\begin{array}{l}P_{\text {PO4- }} \text { EFLUENTE } \\
{[\mathrm{mg} / \mathrm{L}]}\end{array}$ & $\begin{array}{l}\text { P }_{\text {PO4- AFLUENTE }} \\
{[\mathrm{mg} / \mathrm{L}]}\end{array}$ & $\begin{array}{l}P_{\text {PO4- }} \text { EFLUENTE } \\
{[\mathrm{mg} / \mathrm{L}]}\end{array}$ \\
\hline 05/04/05 & 1,9 & 1,3 & 1,9 & 1,7 \\
\hline $12 / 04 / 05$ & 3,4 & 2,7 & 3,4 & 2,5 \\
\hline $18 / 04 / 05$ & 4,4 & 2,5 & 4,4 & 2,7 \\
\hline $25 / 04 / 05$ & 4,6 & 2,8 & 4,6 & 2,6 \\
\hline $28 / 04 / 05$ & 2,4 & 2,3 & 2,4 & 2,1 \\
\hline 02/05/05 & 2,3 & 2,3 & 2,3 & 2,2 \\
\hline $04 / 05 / 05$ & 2,6 & 3,1 & 2,6 & 2,7 \\
\hline 09/05/05 & 2,4 & 3,0 & 2,4 & 2,6 \\
\hline $16 / 05 / 05$ & 2,8 & 3,8 & 2,8 & 2,9 \\
\hline $18 / 05 / 05$ & 3,2 & 3,6 & 3,2 & 3,1 \\
\hline $23 / 05 / 05$ & 2,3 & 2,5 & 2,3 & 2,4 \\
\hline $30 / 05 / 05$ & 2,0 & 1,6 & 2,0 & 1,7 \\
\hline 01/06/05 & 3,2 & 2,7 & 3,2 & 2,2 \\
\hline 06/06/05 & 2,2 & 2,8 & 2,2 & 2,5 \\
\hline 08/06/05 & 2,4 & 2,4 & 2,4 & 2,8 \\
\hline $13 / 06 / 05$ & 3,2 & 3,3 & 3,2 & 3,3 \\
\hline $15 / 06 / 05$ & 2,1 & 3,5 & 2,1 & 3,3 \\
\hline $20 / 06 / 05$ & 2,5 & 3,1 & 2,5 & 2,9 \\
\hline $22 / 06 / 05$ & 2,0 & 1,7 & 2,0 & 1,8 \\
\hline $27 / 06 / 05$ & 3,2 & 3,1 & 3,2 & 2,6 \\
\hline 04/07/05 & 3,1 & 3,4 & 3,1 & 2,8 \\
\hline 06/07/05 & 1,2 & 2,8 & 1,2 & 1,9 \\
\hline $11 / 07 / 05$ & 2,9 & 3,0 & 2,9 & 2,9 \\
\hline 08/08/05 & 3,1 & 3,1 & 3,1 & 3,2 \\
\hline $10 / 08 / 05$ & 2,8 & 2,3 & 2,8 & 2,1 \\
\hline $17 / 08 / 05$ & 2,9 & 3,7 & 2,9 & 3,3 \\
\hline 29/08/05 & 3,2 & 4,4 & 3,2 & 4,6 \\
\hline $31 / 08 / 05$ & 2,4 & 3,5 & 2,4 & 2,7 \\
\hline 05/09/05 & 1,9 & 1,9 & 1,9 & 1,5 \\
\hline
\end{tabular}


Tabela A.7 - Sulfetos - Sem dosagem

REATOR B

REATOR C

DATA CONCENTRAÇÃO DE SULFETOS CONCENTRAÇÃO DE SULFETOS EFLUENTE [mg/L] EFLUENTE [mg/L]

\begin{tabular}{lll}
\hline $18 / 05 / 05$ & 4,7 & 3,8 \\
\hline $06 / 06 / 05$ & 2,9 & 2,6 \\
\hline $05 / 09 / 05$ & 1,6 & 1,7 \\
\hline
\end{tabular}

Tabela A.8 - Sólidos Totais - Sem dosagem

REATOR B

REATOR C

\begin{tabular}{|c|c|c|c|c|}
\hline DATA & $\begin{array}{l}\text { ST AFLUENTE } \\
{[\mathrm{mg} / \mathrm{L}]}\end{array}$ & $\begin{array}{c}\text { ST EFLUENTE } \\
{[\mathrm{mg} / \mathrm{L}]}\end{array}$ & $\begin{array}{l}\text { ST AFLUENTE } \\
{[\mathrm{mg} / \mathrm{L}]}\end{array}$ & $\begin{array}{l}\text { ST EFLUENTE } \\
\text { [mg/L] }\end{array}$ \\
\hline $12 / 04 / 05$ & 360,0 & 200,0 & 360,0 & 200,0 \\
\hline $18 / 04 / 05$ & 520,0 & 200,0 & 520,0 & 260,0 \\
\hline $25 / 04 / 05$ & 540,0 & 220,0 & 540,0 & 220,0 \\
\hline 02/05/05 & 400,0 & 160,0 & 400,0 & 200,0 \\
\hline 09/05/05 & 320,0 & 140,0 & 320,0 & 160,0 \\
\hline $16 / 05 / 05$ & 460,0 & 420,0 & 460,0 & 360,0 \\
\hline $23 / 05 / 05$ & 500,0 & 240,0 & 500,0 & 240,0 \\
\hline $30 / 05 / 05$ & 380,0 & 220,0 & 380,0 & 220,0 \\
\hline 06/06/05 & 320,0 & 160,0 & 320,0 & 200,0 \\
\hline $13 / 06 / 05$ & 560,0 & 260,0 & 560,0 & 300,0 \\
\hline $20 / 06 / 05$ & 520,0 & 220,0 & 520,0 & 220,0 \\
\hline $27 / 06 / 05$ & 380,0 & 200,0 & 380,0 & 200,0 \\
\hline 04/07/05 & 520,0 & 220,0 & 520,0 & 260,0 \\
\hline $11 / 07 / 05$ & 400,0 & 160,0 & 400,0 & 200,0 \\
\hline 01/08/05 & 580,0 & 220,0 & 580,0 & 260,0 \\
\hline 08/08/05 & 560,0 & 360,0 & 560,0 & 360,0 \\
\hline $17 / 08 / 05$ & 620,0 & 360,0 & 620,0 & 380,0 \\
\hline 22/08/05 & 440,0 & 340,0 & 440,0 & 360,0 \\
\hline 29/08/05 & 380,0 & 260,0 & 380,0 & 300,0 \\
\hline 05/09/05 & 360,0 & 180,0 & 360,0 & 220,0 \\
\hline
\end{tabular}


Tabela A.9 - Sólidos Totais Fixos - Sem dosagem

REATOR B

REATOR C

\begin{tabular}{|c|c|c|c|c|}
\hline DATA & $\begin{array}{c}\text { STF AFLUENTE } \\
{[\mathrm{mg} / \mathrm{L}]}\end{array}$ & $\begin{array}{c}\text { STF EFLUENTE } \\
{[\mathrm{mg} / \mathrm{L}]}\end{array}$ & $\begin{array}{c}\text { STF AFLUENTE } \\
{[\mathrm{mg} / \mathrm{L}]}\end{array}$ & $\begin{array}{c}\text { STF EFLUENTE } \\
\text { [mg/L] }\end{array}$ \\
\hline $12 / 04 / 05$ & 30,0 & - & 30,0 & 50,0 \\
\hline $18 / 04 / 05$ & 80,0 & 80,0 & 80,0 & 120,0 \\
\hline $25 / 04 / 05$ & 140,0 & 80,0 & 140,0 & 40,0 \\
\hline $02 / 05 / 05$ & 240,0 & 140,0 & 240,0 & 160,0 \\
\hline 09/05/05 & 120,0 & 80,0 & 120,0 & 100,0 \\
\hline $16 / 05 / 05$ & 220,0 & 260,0 & 220,0 & 220,0 \\
\hline $23 / 05 / 05$ & 180,0 & 120,0 & 180,0 & 120,0 \\
\hline $30 / 05 / 05$ & 180,0 & 120,0 & 180,0 & 120,0 \\
\hline 06/06/05 & 160,0 & 120,0 & 160,0 & 140,0 \\
\hline $13 / 06 / 05$ & 280,0 & 180,0 & 280,0 & 220,0 \\
\hline 20/06/05 & 180,0 & 120,0 & 180,0 & 120,0 \\
\hline 27/06/05 & 160,0 & 100,0 & 160,0 & 100,0 \\
\hline 04/07/05 & 200,0 & 100,0 & 200,0 & 140,0 \\
\hline $11 / 07 / 05$ & 140,0 & 100,0 & 140,0 & 100,0 \\
\hline 01/08/05 & 220,0 & 100,0 & 220,0 & 100,0 \\
\hline 08/08/05 & 320,0 & 200,0 & 320,0 & 200,0 \\
\hline $17 / 08 / 05$ & 300,0 & 240,0 & 300,0 & 240,0 \\
\hline 22/08/05 & 260,0 & 280,0 & 260,0 & 260,0 \\
\hline 29/08/05 & 80,0 & 100,0 & 80,0 & 160,0 \\
\hline 05/09/05 & 160,0 & 100,0 & 160,0 & 80,0 \\
\hline
\end{tabular}


Tabela A.10 - Sólidos Totais Voláteis - Sem dosagem

REATOR B

REATOR C

\begin{tabular}{|c|c|c|c|c|}
\hline DATA & $\begin{array}{l}\text { STV AFLUENTE } \\
{[\mathrm{mg} / \mathrm{L}]}\end{array}$ & $\begin{array}{c}\text { STV EFLUENTE } \\
{[\mathrm{mg} / \mathrm{L}]}\end{array}$ & $\begin{array}{l}\text { STV AFLUENTE } \\
{[\mathrm{mg} / \mathrm{L}]}\end{array}$ & $\begin{array}{c}\text { STV EFLUENTE } \\
{[\mathrm{mg} / \mathrm{L}]}\end{array}$ \\
\hline $12 / 04 / 05$ & 330,0 & 210,0 & 330,0 & 150,0 \\
\hline $18 / 04 / 05$ & 440,0 & 120,0 & 440,0 & 140,0 \\
\hline $25 / 04 / 05$ & 400,0 & 140,0 & 400,0 & 180,0 \\
\hline 02/05/05 & 160,0 & 20,0 & 160,0 & 40,0 \\
\hline 09/05/05 & 200,0 & 60,0 & 200,0 & 60,0 \\
\hline $16 / 05 / 05$ & 240,0 & 160,0 & 240,0 & 140,0 \\
\hline $23 / 05 / 05$ & 320,0 & 120,0 & 320,0 & 120,0 \\
\hline $30 / 05 / 05$ & 200,0 & 100,0 & 200,0 & 100,0 \\
\hline 06/06/05 & 160,0 & 40,0 & 160,0 & 60,0 \\
\hline $13 / 06 / 05$ & 280,0 & 80,0 & 280,0 & 80,0 \\
\hline $20 / 06 / 05$ & 340,0 & 100,0 & 340,0 & 100,0 \\
\hline $27 / 06 / 05$ & 220,0 & 100,0 & 220,0 & 100,0 \\
\hline 04/07/05 & 320,0 & 120,0 & 320,0 & 120,0 \\
\hline $11 / 07 / 05$ & 260,0 & 60,0 & 260,0 & 100,0 \\
\hline 01/08/05 & 360,0 & 120,0 & 360,0 & 160,0 \\
\hline 08/08/05 & 240,0 & 160,0 & 240,0 & 160,0 \\
\hline $17 / 08 / 05$ & 320,0 & 120,0 & 320,0 & 140,0 \\
\hline $22 / 08 / 05$ & 180,0 & 60,0 & 180,0 & 100,0 \\
\hline 29/08/05 & 300,0 & 160,0 & 300,0 & 140,0 \\
\hline 05/09/05 & 200,0 & 80,0 & 200,0 & 140,0 \\
\hline
\end{tabular}


Tabela A.11 - Sólidos Suspensos Totais - Sem dosagem

REATOR B

REATOR C

\begin{tabular}{ccccc} 
DATA & $\begin{array}{c}\text { SST AFLUENTE } \\
\text { [mg/L] }\end{array}$ & $\begin{array}{c}\text { EFLUENTE } \\
\text { [mg/L] }\end{array}$ & $\begin{array}{c}\text { SST AFLUENTE } \\
\text { [mg/L] }\end{array}$ & $\begin{array}{c}\text { SST EFLUENTE } \\
\text { [mg/L] }\end{array}$ \\
\hline $12 / 04 / 05$ & 258,0 & 28,0 & 258,0 & 22,0 \\
\hline $18 / 04 / 05$ & 212,0 & 22,0 & 212,0 & 52,0 \\
\hline $25 / 04 / 05$ & 210,0 & 8,0 & 210,0 & 132,0 \\
\hline $02 / 05 / 05$ & 128,0 & 24,0 & 128,0 & 54,0 \\
\hline $09 / 05 / 05$ & 178,0 & 28,0 & 178,0 & 48,0 \\
\hline $16 / 05 / 05$ & 218,0 & 292,0 & 218,0 & 202,0 \\
\hline $23 / 05 / 05$ & 196,0 & 16,0 & 196,0 & 52,0 \\
\hline $30 / 05 / 05$ & 124,0 & 28,0 & 124,0 & 48,0 \\
\hline $06 / 06 / 05$ & 156,0 & 30,0 & 156,0 & 74,0 \\
\hline $08 / 06 / 05$ & 152,0 & 73,0 & 152,0 & 70,0 \\
\hline $13 / 06 / 05$ & 104,0 & 14,0 & 104,0 & 37,0 \\
\hline $15 / 06 / 05$ & 111,0 & 108,0 & 111,0 & 42,0 \\
\hline $20 / 06 / 05$ & 286,0 & 48,0 & 286,0 & 70,0 \\
\hline $22 / 06 / 05$ & 111,0 & 108,0 & 111,0 & 42,0 \\
\hline $27 / 06 / 05$ & 100,0 & 12,0 & 100,0 & 40,0 \\
\hline $04 / 07 / 05$ & 226,0 & 36,0 & 226,0 & 68,0 \\
\hline $11 / 07 / 05$ & 156,0 & 28,0 & 156,0 & 50,0 \\
\hline $01 / 08 / 05$ & 236,0 & 33,0 & 236,0 & 57,0 \\
\hline $08 / 08 / 05$ & 178,0 & 48,0 & 178,0 & 60,0 \\
\hline $17 / 08 / 05$ & 212,0 & 44,0 & 212,0 & 80,0 \\
\hline $22 / 08 / 05$ & 144,0 & 26,0 & 144,0 & 64,0 \\
\hline $05 / 09 / 05$ & 112,0 & 25,0 & 112,0 & 52,0 \\
\hline & & & & \\
\hline
\end{tabular}


Tabela A.12 - Sólidos Suspensos Fixos - Sem dosagem

REATOR B

REATOR C

\begin{tabular}{ccccc} 
DATA & $\begin{array}{c}\text { SSF AFLUENTE SSF EFLUENTE } \\
{[\mathrm{mg} / \mathrm{L}]}\end{array}$ & $\begin{array}{c}\text { SSF AFLUENTE } \\
{[\mathrm{mg} / \mathbf{L}]}\end{array}$ & $\begin{array}{c}\text { SSF EFLUENTE } \\
{[\mathrm{mg} / \mathbf{L}]}\end{array}$ \\
\hline $02 / 05 / 05$ & 20,0 & 0,0 & 20,0 & 12,0 \\
\hline $09 / 05 / 05$ & 36,0 & 0,0 & 36,0 & 12,0 \\
\hline $16 / 05 / 05$ & 46,0 & 120,0 & 46,0 & 82,0 \\
\hline $30 / 05 / 05$ & 21,0 & 6,0 & 21,0 & 14,0 \\
\hline $06 / 06 / 05$ & 29,0 & 6,0 & 29,0 & 23,0 \\
\hline $13 / 06 / 05$ & 18,0 & 2,0 & 18,0 & 13,0 \\
\hline $15 / 06 / 05$ & 28,0 & 63,0 & 28,0 & 18,0 \\
\hline $20 / 06 / 05$ & 64,0 & 8,0 & 64,0 & 12,0 \\
\hline $22 / 06 / 05$ & 28,0 & 63,0 & 28,0 & 18,0 \\
\hline $27 / 06 / 05$ & 12,0 & 0,0 & 12,0 & 2,0 \\
\hline $04 / 07 / 05$ & 46,0 & 10,0 & 46,0 & 20,0 \\
\hline $11 / 07 / 05$ & 24,0 & 2,0 & 24,0 & 10,0 \\
\hline $01 / 08 / 05$ & 46,0 & 2,0 & 46,0 & 9,0 \\
\hline $08 / 08 / 05$ & 32,0 & 8,0 & 32,0 & 14,0 \\
\hline $17 / 08 / 05$ & 48,0 & 12,0 & 48,0 & 22,0 \\
\hline $22 / 08 / 05$ & 20,0 & 0,0 & 20,0 & 10,0 \\
\hline $29 / 08 / 05$ & 34,0 & 4,0 & 34,0 & 6,0 \\
\hline $05 / 09 / 05$ & 25,3 & 4,0 & 25,3 & 14,0 \\
\hline
\end{tabular}


Tabela A.13 - Sólidos Suspensos Voláteis - Sem dosagem

REATOR B

REATOR C

\begin{tabular}{lcccc} 
DATA & $\begin{array}{c}\text { SSV AFLUENTE SSV EFLUENTE } \\
\text { [mg/L] }\end{array}$ & $\begin{array}{c}\text { SSV AFLUENTE } \\
\text { [mg/L] }\end{array}$ & $\begin{array}{c}\text { SSV EFLUENTE } \\
\text { [mg/L] }\end{array}$ \\
\hline $12 / 04 / 05$ & 254,0 & 40,0 & 254,0 & 44,0 \\
\hline $18 / 04 / 05$ & 174,0 & 34,0 & 174,0 & 52,0 \\
\hline $25 / 04 / 05$ & 184,0 & 22,0 & 184,0 & 212,0 \\
\hline $02 / 05 / 05$ & 108,0 & 24,0 & 108,0 & 42,0 \\
\hline $09 / 05 / 05$ & 142,0 & 28,0 & 142,0 & 36,0 \\
\hline $16 / 05 / 05$ & 172,0 & 172,0 & 172,0 & 120,0 \\
\hline $23 / 05 / 05$ & 156,0 & 18,0 & 156,0 & 42,0 \\
\hline $30 / 05 / 05$ & 103,0 & 22,0 & 103,0 & 34,0 \\
\hline $06 / 06 / 05$ & 127,0 & 24,0 & 127,0 & 51,0 \\
\hline $08 / 06 / 05$ & 128,0 & 133,0 & 128,0 & 56,0 \\
\hline $13 / 06 / 05$ & 86,0 & 12,0 & 86,0 & 24,0 \\
\hline $15 / 06 / 05$ & 83,0 & 45,0 & 83,0 & 24,0 \\
\hline $20 / 06 / 05$ & 222,0 & 40,0 & 222,0 & 58,0 \\
\hline $22 / 06 / 05$ & 83,0 & 45,0 & 83,0 & 24,0 \\
\hline $27 / 06 / 05$ & 88,0 & 12,0 & 88,0 & 38,0 \\
\hline $04 / 07 / 05$ & 180,0 & 26,0 & 180,0 & 48,0 \\
\hline $11 / 07 / 05$ & 132,0 & 26,0 & 132,0 & 40,0 \\
\hline $01 / 08 / 05$ & 190,0 & 31,0 & 190,0 & 48,0 \\
\hline $08 / 08 / 05$ & 146,0 & 40,0 & 146,0 & 46,0 \\
\hline $17 / 08 / 05$ & 164,0 & 32,0 & 164,0 & 58,0 \\
\hline $22 / 08 / 05$ & 124,0 & 26,0 & 124,0 & 54,0 \\
\hline $29 / 08 / 05$ & 130,0 & 24,0 & 130,0 & 36,0 \\
\hline $05 / 09 / 05$ & 86,7 & 21,0 & 86,7 & 38,0 \\
\hline & & & & \\
\hline
\end{tabular}


Tabela A.14 - Sólidos Sedimentáveis - Sem dosagem

REATOR B

REATOR C

\begin{tabular}{|c|c|c|c|c|}
\hline DATA & $\begin{array}{c}\text { S }_{\text {SED }} \text { AFLUENTE } \\
{[\mathrm{mL} / \mathrm{L}]}\end{array}$ & $\begin{array}{c}\mathrm{S}_{\mathrm{SED}} \text { EFLUENTE } \\
{[\mathrm{mL} / \mathrm{L}]}\end{array}$ & $\begin{array}{c}\text { S }_{\text {SED }} \text { AFLUENTE } \\
{[\mathrm{mL} / \mathrm{L}]}\end{array}$ & $\begin{array}{c}\mathrm{S}_{\mathrm{SED}} \text { EFLUENTE } \\
{[\mathrm{mL} / \mathrm{L}]}\end{array}$ \\
\hline $12 / 04 / 05$ & 2,8 & 0,1 & 2,8 & 0,0 \\
\hline $18 / 04 / 05$ & 7,4 & 0,1 & 7,4 & 0,1 \\
\hline $25 / 04 / 05$ & 4,9 & 0,0 & 4,9 & 0,0 \\
\hline $28 / 04 / 05$ & 2,7 & 0,0 & 2,7 & 0,0 \\
\hline 02/05/05 & 2,2 & 0,0 & 2,2 & 0,0 \\
\hline 09/05/05 & 3,3 & 0,1 & 3,3 & 0,1 \\
\hline $16 / 05 / 05$ & 3,5 & 0,1 & 3,5 & 0,2 \\
\hline 23/05/05 & 2,7 & 0,0 & 2,7 & 0,2 \\
\hline $30 / 05 / 05$ & 1,7 & 0,0 & 1,7 & 0,1 \\
\hline 06/06/05 & 1,5 & 0,2 & 1,5 & 0,1 \\
\hline $13 / 06 / 05$ & 2,4 & 0,1 & 2,4 & 0,2 \\
\hline $20 / 06 / 05$ & 5,0 & 0,2 & 5,0 & 0,3 \\
\hline 27/06/05 & 2,0 & 0,0 & 2,0 & 0,0 \\
\hline 04/07/05 & 2,5 & 0,1 & 2,5 & 0,2 \\
\hline $11 / 07 / 05$ & 3,2 & 0,0 & 3,2 & 0,1 \\
\hline 01/08/05 & 3,1 & 0,0 & 3,1 & 0,0 \\
\hline 08/08/05 & 2,8 & 0,2 & 2,8 & 0,1 \\
\hline 22/08/05 & 1,0 & 0,0 & 1,0 & 0,0 \\
\hline 29/08/05 & 0,5 & 0,0 & 0,5 & 0,0 \\
\hline 05/09/05 & 1,2 & 0,0 & 1,2 & 0,0 \\
\hline
\end{tabular}


Tabela A.15 - DQO Total - Dosagem de $25 \mathrm{mg} \mathrm{FeCl}_{3} / \mathrm{L}$ no Reator B REATOR B

REATOR C

DATA DQO AFLUENTE DQO EFLUENTE DQO AFLUENTE DQO EFLUENTE [mg/L] [mg/L] [mg/L]

\begin{tabular}{|c|c|c|c|c|}
\hline $15 / 09 / 05$ & 309 & 75 & 309 & 131 \\
\hline $19 / 09 / 05$ & 253 & 87 & 253 & 107 \\
\hline 21/09/05 & 245 & 102 & 245 & 127 \\
\hline 26/09/05 & 196 & 75 & 196 & 71 \\
\hline 03/10/05 & 345 & 98 & 345 & 125 \\
\hline 05/10/05 & 295 & 97 & 295 & 144 \\
\hline $10 / 10 / 05$ & 346 & 123 & 346 & 154 \\
\hline 24/10/05 & 243 & 67 & 243 & 110 \\
\hline $26 / 10 / 05$ & 232 & 80 & 232 & 92 \\
\hline 31/10/05 & 213 & 65 & 213 & 88 \\
\hline 03/11/05 & 262 & 92 & 262 & 108 \\
\hline 08/11/05 & 224 & 88 & 224 & 88 \\
\hline $10 / 11 / 05$ & 186 & 82 & 186 & 132 \\
\hline $21 / 11 / 05$ & 351 & 79 & 351 & 150 \\
\hline 23/11/05 & 428 & 103 & 428 & 154 \\
\hline $28 / 11 / 05$ & 411 & 91 & 411 & 118 \\
\hline $30 / 11 / 05$ & 285 & 87 & 285 & 119 \\
\hline 05/12/05 & 325 & 83 & 325 & 123 \\
\hline 07/12/05 & 235 & 86 & 235 & 106 \\
\hline $12 / 12 / 05$ & 292 & 85 & 292 & 88 \\
\hline 01/02/06 & 251 & 67 & 251 & 86 \\
\hline
\end{tabular}


Tabela A.16 - DQO Filtrada - Dosagem de $25 \mathrm{mg} \mathrm{FeCl}_{3} / \mathrm{L}$ no Reator B

REATOR B

REATOR C

DATA DQO AFLUENTE DQO EFLUENTE DQO AFLUENTE DQO EFLUENTE $[\mathrm{mg} / \mathrm{L}]$

\begin{tabular}{|c|c|c|c|c|}
\hline & & & & \\
\hline $15 / 09 / 05$ & 127 & 44 & 127 & 67 \\
\hline 19/09/05 & 107 & 44 & 107 & 55 \\
\hline 21/09/05 & 103 & 87 & 103 & 154 \\
\hline 26/09/05 & 90 & 24 & 90 & 27 \\
\hline 03/10/05 & 118 & 43 & 118 & 59 \\
\hline 05/10/05 & 109 & 54 & 109 & 78 \\
\hline 10/10/05 & 123 & 50 & 123 & 69 \\
\hline 24/10/05 & 106 & 35 & 106 & 55 \\
\hline $26 / 10 / 05$ & 96 & 44 & 96 & 52 \\
\hline $31 / 10 / 05$ & 88 & 27 & 88 & 35 \\
\hline 03/11/05 & 108 & 42 & 108 & 26 \\
\hline 08/11/05 & 72 & 42 & 72 & 36 \\
\hline $10 / 11 / 05$ & 89 & 43 & 89 & 72 \\
\hline $21 / 11 / 05$ & 135 & 37 & 135 & 56 \\
\hline 23/11/05 & 123 & 42 & 123 & 64 \\
\hline 28/11/05 & 110 & 35 & 110 & 55 \\
\hline $30 / 11 / 05$ & 115 & 45 & 115 & 65 \\
\hline 05/12/05 & 111 & 49 & 111 & 57 \\
\hline 07/12/05 & 94 & 30 & 94 & 37 \\
\hline $12 / 12 / 05$ & 108 & 32 & 108 & 38 \\
\hline 01/02/06 & 98 & 34 & 98 & 49 \\
\hline
\end{tabular}


Tabela A.17 - $\mathrm{DBO}_{5,20^{\circ} \mathrm{C}}$ Total - Dosagem de $25 \mathrm{mg} \mathrm{FeCl} / \mathrm{L}$ no Reator B

REATOR B

REATOR C

\begin{tabular}{ccccc}
\cline { 2 - 5 } DATA & $\begin{array}{c}\text { DBO }_{5,20}{ }^{\circ} \mathrm{C} \\
\text { AFLUENTE } \\
\text { [mg/L] }\end{array}$ & $\begin{array}{c}\text { DBO }_{5,20}{ }^{\circ} \mathrm{C} \\
\text { EFLUENTE } \\
\text { [mg/L] }\end{array}$ & $\begin{array}{c}\text { DBO }_{5,20}{ }^{\circ} \mathrm{C} \\
\text { AFLUENTE } \\
\text { [mg/L] }\end{array}$ & $\begin{array}{c}\text { DBO }_{5,20}{ }^{\circ} \mathrm{C} \\
\text { EFLUENTE } \\
\text { [mg/L] }\end{array}$ \\
\hline $19 / 10 / 05$ & 124 & 23 & 124 & 31 \\
\hline $26 / 10 / 05$ & 136 & 24 & 136 & 31 \\
\hline $23 / 11 / 05$ & 234 & 34 & 234 & 72 \\
\hline $30 / 11 / 05$ & 142 & 22 & 142 & 48 \\
\hline $07 / 12 / 05$ & 102 & 30 & 102 & 33 \\
\hline $14 / 12 / 05$ & 248 & 26 & 248 & 30 \\
\hline $04 / 01 / 06$ & 89 & 19 & 89 & 35 \\
\hline $11 / 01 / 06$ & 108 & 29 & 108 & 36 \\
\hline $18 / 01 / 06$ & 213 & 32 & 213 & 57 \\
\hline $01 / 02 / 06$ & 114 & 23 & 114 & 34 \\
\hline
\end{tabular}

Tabela A.18 - $\mathrm{DBO}_{5,20^{\circ} \mathrm{C}}$ Filtrada - Dosagem de $25 \mathrm{mg} \mathrm{FeCl} / 3 / \mathrm{L}$ no Reator B

REATOR B

REATOR C

\begin{tabular}{lcccc}
\hline DATA & $\begin{array}{c}\text { DBO }_{5,20^{\circ} \mathrm{C}} \\
\text { AFLUENTE } \\
\text { [mg/L] }\end{array}$ & $\begin{array}{c}\text { DBO }_{5,20^{\circ} \mathrm{C}} \\
\text { EFLUENTE } \\
{[\mathrm{mg} / \mathrm{L}]}\end{array}$ & $\begin{array}{c}\text { DBO }_{5,20} \mathrm{C} \\
\text { AFLUENTE } \\
\text { [mg/L] }\end{array}$ & $\begin{array}{c}\text { DBO }_{5,20^{\circ} \mathrm{C}} \\
\text { EFLUENTE } \\
\text { [mg/L] }\end{array}$ \\
\hline $19 / 10 / 05$ & 36 & 20 & 36 & 14 \\
\hline $26 / 10 / 05$ & 55 & 15 & 55 & 16 \\
\hline $23 / 11 / 05$ & 81 & 17 & 81 & 44 \\
\hline $30 / 11 / 05$ & 55 & 11 & 55 & 32 \\
\hline $07 / 12 / 05$ & 29 & 11 & 29 & 17 \\
\hline $14 / 12 / 05$ & 61 & 8 & 61 & 18 \\
\hline $04 / 01 / 06$ & 28 & 10 & 28 & 18 \\
\hline $11 / 01 / 06$ & 41 & 14 & 41 & 31 \\
\hline $18 / 01 / 06$ & 58 & 11 & 58 & 13 \\
\hline $01 / 02 / 06$ & 38 & 11 & 38 & 14 \\
\hline
\end{tabular}


Tabela A.19 - Fósforo Total - Dosagem de 25 mg FeCl $/ 2$ no Reator B

REATOR B

REATOR C

\begin{tabular}{|c|c|c|c|c|}
\hline DATA & $\begin{array}{c}\text { P }_{\text {TOTAL }} \\
\text { AFLUENTE } \\
\text { [mg/L] }\end{array}$ & $\begin{array}{c}P_{\text {TOTAL }} \\
\text { EFLUENTE } \\
{[\mathrm{mg} / \mathrm{L}]}\end{array}$ & $\begin{array}{c}P_{\text {TOTAL }} \\
\text { AFLUENTE } \\
{[\mathrm{mg} / \mathrm{L}]}\end{array}$ & $\begin{array}{c}\mathbf{P}_{\text {TOTAL }} \\
\text { EFLUENTE } \\
\text { [mg/L] }\end{array}$ \\
\hline $19 / 09 / 05$ & 2,0 & 1,2 & 2,0 & 1,2 \\
\hline 26/09/05 & 2,2 & 2,1 & 2,2 & 3,7 \\
\hline 03/10/05 & 7,0 & 3,4 & 7,0 & 3,3 \\
\hline $10 / 10 / 05$ & 6,3 & 4,2 & 6,3 & 4,6 \\
\hline $19 / 10 / 05$ & 2,7 & 2,0 & 2,7 & 1,8 \\
\hline $24 / 10 / 05$ & 0,2 & 0,2 & 0,2 & 0,1 \\
\hline 26/10/05 & 3,8 & 4,3 & 3,8 & 2,2 \\
\hline $31 / 10 / 05$ & 0,8 & 1,3 & 0,8 & 2,2 \\
\hline 03/11/05 & 5,2 & 3,0 & 5,2 & 2,8 \\
\hline $10 / 11 / 05$ & 1,8 & 1,9 & 1,8 & 1,3 \\
\hline $21 / 11 / 05$ & 0,8 & 0,6 & 0,8 & 0,7 \\
\hline $28 / 11 / 05$ & 5,5 & 2,6 & 5,5 & 3,2 \\
\hline $30 / 11 / 05$ & 3,3 & 2,3 & 3,3 & 3,8 \\
\hline 05/12/05 & 5,4 & 3,1 & 5,4 & 3,4 \\
\hline 07/12/05 & 3,5 & 3,0 & 3,5 & 2,3 \\
\hline $12 / 12 / 05$ & 5,5 & 3,2 & 5,5 & 3,1 \\
\hline $14 / 12 / 05$ & 8,2 & 3,7 & 8,2 & 3,7 \\
\hline $19 / 12 / 05$ & 3,2 & 1,6 & 3,2 & 1,6 \\
\hline 04/01/06 & 2,9 & 1,4 & 2,9 & 1,6 \\
\hline 09/01/06 & 5,3 & 2,8 & 5,3 & 2,0 \\
\hline $11 / 01 / 06$ & 3,9 & 3,8 & 3,9 & 2,6 \\
\hline $16 / 01 / 06$ & 6,2 & 3,3 & 6,2 & 3,3 \\
\hline 18/01/06 & 6,6 & 4,0 & 6,6 & 4,3 \\
\hline 23/01/06 & 6,3 & 3,4 & 6,3 & 3,7 \\
\hline $30 / 01 / 06$ & 4,0 & 1,9 & 4,0 & 2,3 \\
\hline 01/02/06 & 3,7 & 1,7 & 3,7 & 1,9 \\
\hline
\end{tabular}


Tabela A.20 - Ortofosfato - Dosagem de $25 \mathrm{mg} \mathrm{FeCl}_{3} / \mathrm{L}$ no Reator B REATOR B

REATOR C

\begin{tabular}{|c|c|c|c|c|}
\hline DATA & $\begin{array}{l}\text { P }_{\text {PO4- AFLUENTE }} \text { Amg/L] } \\
{[\mathrm{mg}}\end{array}$ & $\begin{array}{c}P_{\text {PO4- }} \text { EFLUENTE } \\
{[\mathrm{mg} / \mathrm{L}]}\end{array}$ & $\begin{array}{c}\text { Pro4- }_{\text {POLLUENTE }} \\
{[\mathrm{mg} / \mathrm{L}]}\end{array}$ & $\begin{array}{l}\text { P }_{\text {PO4- }} \text { EFLUENTE } \\
{[\mathrm{mg} / \mathrm{L}]}\end{array}$ \\
\hline $15 / 09 / 05$ & 2,2 & 0,2 & 2,2 & 2,0 \\
\hline 19/09/05 & 1,8 & 2,0 & 1,8 & 1,5 \\
\hline $21 / 09 / 05$ & 1,5 & 1,6 & 1,5 & 2,1 \\
\hline $26 / 09 / 05$ & 1,5 & 1,0 & 1,5 & 1,6 \\
\hline 03/10/05 & 3,1 & 2,7 & 3,1 & 2,5 \\
\hline 05/10/05 & 2,7 & 2,8 & 2,7 & 3,0 \\
\hline $10 / 10 / 05$ & 2,6 & 3,0 & 2,6 & 3,6 \\
\hline $24 / 10 / 05$ & 1,9 & 1,7 & 1,9 & 1,3 \\
\hline $26 / 10 / 05$ & 2,1 & 2,1 & 2,1 & 2,0 \\
\hline $31 / 10 / 05$ & 2,2 & 0,7 & 2,2 & 1,1 \\
\hline 03/11/05 & 2,1 & 2,0 & 2,1 & 1,6 \\
\hline 08/11/05 & 2,0 & 1,3 & 2,0 & 1,6 \\
\hline $10 / 11 / 05$ & 1,9 & 1,9 & 1,9 & 2,6 \\
\hline $21 / 11 / 05$ & 3,4 & 0,6 & 3,4 & 2,8 \\
\hline $23 / 11 / 05$ & 2,7 & 1,6 & 2,7 & 2,6 \\
\hline $28 / 11 / 05$ & 2,5 & 1,1 & 2,5 & 2,3 \\
\hline $30 / 11 / 05$ & 2,0 & 2,2 & 2,0 & 2,7 \\
\hline 05/12/05 & 2,7 & 1,7 & 2,7 & 2,5 \\
\hline 07/12/05 & 1,3 & 0,9 & 1,3 & 1,1 \\
\hline $12 / 12 / 05$ & 2,5 & 1,7 & 2,5 & 2,2 \\
\hline $14 / 12 / 05$ & 2,3 & 2,3 & 2,3 & 2,5 \\
\hline 19/12/05 & 1,2 & 0,4 & 1,2 & 1,1 \\
\hline 09/01/06 & 0,9 & 0,4 & 0,9 & 0,7 \\
\hline $11 / 01 / 06$ & 2,1 & 1,5 & 2,1 & 1,8 \\
\hline $16 / 01 / 06$ & 1,5 & 2,1 & 1,5 & 1,8 \\
\hline $18 / 01 / 06$ & 2,6 & 2,2 & 2,6 & 2,3 \\
\hline 23/01/06 & 2,1 & 1,8 & 2,1 & 2,9 \\
\hline $30 / 01 / 06$ & 2,6 & 1,4 & 2,6 & 1,9 \\
\hline 01/02/06 & 1,3 & 0,6 & 1,3 & 1,2 \\
\hline
\end{tabular}


Tabela A.21 - Sulfetos - Dosagem de $25 \mathrm{mg} \mathrm{FeCl} / / \mathrm{L}$ no Reator B

REATOR B

REATOR C

DATA CONCENTRAÇÃO DE SULFETOS CONCENTRAÇÃO DE SULFETOS EFLUENTE [mg/L]

\begin{tabular}{lll}
\hline $19 / 09 / 05$ & 2,3 & 2,2 \\
\hline $21 / 09 / 05$ & 2,3 & 2,4 \\
\hline $26 / 09 / 05$ & 2,1 & 2,4 \\
\hline $05 / 10 / 05$ & 1,6 & 2,6 \\
\hline $10 / 10 / 05$ & 3,2 & 2,2 \\
\hline $24 / 10 / 05$ & 2,7 & 2,5 \\
\hline $26 / 10 / 05$ & 2,9 & 2,7 \\
\hline $31 / 10 / 05$ & 2,9 & 2,7 \\
\hline $08 / 11 / 05$ & 2,1 & 1,8 \\
\hline $21 / 11 / 05$ & 2,9 & 2,9 \\
\hline $28 / 11 / 05$ & 2,3 & 2,4 \\
\hline $05 / 12 / 05$ & 2,8 & 2,0 \\
\hline $07 / 12 / 05$ & 3,2 & 2,5 \\
\hline $01 / 02 / 06$ & 2,3 & 2,1 \\
\hline
\end{tabular}

Tabela A.22 - Sólidos Totais - Dosagem de $25 \mathrm{mg} \mathrm{FeCl} / / \mathrm{L}$ no Reator B

REATOR B

REATOR C

\begin{tabular}{ccccc} 
DATA & $\begin{array}{c}\text { ST AFLUENTE } \\
{[\mathrm{mg} / \mathrm{L}]}\end{array}$ & $\begin{array}{c}\text { ST EFLUENTE } \\
\text { [mg/L] }\end{array}$ & $\begin{array}{c}\text { ST AFLUENTE } \\
{[\mathrm{mg} / \mathrm{L}]}\end{array}$ & $\begin{array}{c}\text { ST EFLUENTE } \\
{[\mathrm{mg} / \mathbf{L}]}\end{array}$ \\
\hline $15 / 09 / 05$ & 420,0 & 420,0 & 420,0 & 320,0 \\
\hline $26 / 09 / 05$ & 300,0 & 180,0 & 300,0 & 180,0 \\
\hline $03 / 10 / 05$ & 500,0 & 240,0 & 500,0 & 300,0 \\
\hline $10 / 10 / 05$ & 520,0 & 320,0 & 520,0 & 320,0 \\
\hline $24 / 10 / 05$ & 400,0 & 400,0 & 400,0 & 260,0 \\
\hline $31 / 10 / 05$ & 300,0 & 120,0 & 300,0 & 160,0 \\
\hline $21 / 11 / 05$ & 540,0 & 320,0 & 540,0 & 320,0 \\
\hline $28 / 11 / 05$ & 500,0 & 280,0 & 500,0 & 300,0 \\
\hline $05 / 12 / 05$ & 480,0 & 260,0 & 480,0 & 260,0 \\
\hline $01 / 02 / 06$ & 340,0 & 220,0 & 340,0 & 240,0 \\
\hline
\end{tabular}


Tabela A.23 - Sólidos Totais Fixos - Dosagem de $25 \mathrm{mg} \mathrm{FeCl}_{3} / \mathrm{L}$ no Reator B

REATOR B

REATOR C

\begin{tabular}{ccccc} 
DATA & $\begin{array}{c}\text { STF AFLUENTE } \\
{[\mathbf{m g} / \mathbf{L}]}\end{array}$ & $\begin{array}{c}\text { STF EFLUENTE } \\
{[\mathrm{mg} / \mathbf{L}]}\end{array}$ & $\begin{array}{c}\text { STF AFLUENTE } \\
{[\mathbf{m g} / \mathbf{L}]}\end{array}$ & $\begin{array}{c}\text { STF EFLUENTE } \\
{[\mathbf{m g} / \mathbf{L}]}\end{array}$ \\
\hline $15 / 09 / 05$ & 200,0 & 180,0 & 200,0 & 180,0 \\
\hline $19 / 09 / 05$ & 160,0 & 120,0 & 160,0 & 100,0 \\
\hline $26 / 09 / 05$ & 140,0 & 80,0 & 140,0 & 100,0 \\
\hline $03 / 10 / 05$ & 240,0 & 140,0 & 240,0 & 160,0 \\
\hline $10 / 10 / 05$ & 260,0 & 200,0 & 260,0 & 180,0 \\
\hline $24 / 10 / 05$ & 200,0 & 200,0 & 200,0 & 120,0 \\
\hline $31 / 10 / 05$ & 160,0 & 80,0 & 160,0 & 100,0 \\
\hline $08 / 11 / 05$ & 100,0 & 100,0 & 100,0 & 80,0 \\
\hline $21 / 11 / 05$ & 280,0 & 180,0 & 280,0 & 180,0 \\
\hline $28 / 11 / 05$ & 340,0 & 220,0 & 340,0 & 220,0 \\
\hline $05 / 12 / 05$ & 240,0 & 140,0 & 240,0 & 160,0 \\
\hline $01 / 02 / 06$ & 180,0 & 60,0 & 180,0 & 160,0 \\
\hline
\end{tabular}

Tabela A.24 - Sólidos Totais Voláteis - Dosagem de 25 mg FeCl $/ 2$ no Reator B

REATOR B

REATOR C

DATA STV AFLUENTE STV EFLUENTE STV AFLUENTE STV EFLUENTE

\begin{tabular}{ccccc} 
& {$[\mathrm{mg} / \mathrm{L}]$} & {$[\mathrm{mg} / \mathbf{L}]$} & {$[\mathbf{m g} / \mathbf{L}]$} & {$[\mathrm{mg} / \mathbf{L}]$} \\
\hline $15 / 09 / 05$ & 220,0 & 240,0 & 220,0 & 140,0 \\
\hline $19 / 09 / 05$ & 140,0 & 60,0 & 140,0 & 60,0 \\
\hline $26 / 09 / 05$ & 160,0 & 100,0 & 160,0 & 80,0 \\
\hline $03 / 10 / 05$ & 260,0 & 100,0 & 260,0 & 140,0 \\
\hline $10 / 10 / 05$ & 260,0 & 120,0 & 260,0 & 140,0 \\
\hline $24 / 10 / 05$ & 200,0 & 200,0 & 200,0 & 140,0 \\
\hline $31 / 10 / 05$ & 140,0 & 40,0 & 140,0 & 60,0 \\
\hline $08 / 11 / 05$ & 180,0 & 80,0 & 180,0 & 120,0 \\
\hline $21 / 11 / 05$ & 260,0 & 140,0 & 260,0 & 140,0 \\
\hline $28 / 11 / 05$ & 160,0 & 60,0 & 160,0 & 80,0 \\
\hline $05 / 12 / 05$ & 240,0 & 120,0 & 240,0 & 100,0 \\
\hline $01 / 02 / 06$ & 160,0 & 160,0 & 160,0 & 80,0 \\
\hline
\end{tabular}


Tabela A.25 - Sólidos Suspensos Totais - Dosagem de 25 mg FeCl 3 /L no Reator B

REATOR B

REATOR C

DATA SST AFLUENTE SST EFLUENTE SST AFLUENTE SST EFLUENTE [mg/L] [mg/L]

\begin{tabular}{|c|c|c|c|c|}
\hline & & & & \\
\hline $15 / 09 / 05$ & 122,0 & 27,0 & 122,0 & 53,0 \\
\hline $19 / 09 / 05$ & 130,0 & 48,0 & 130,0 & 57,0 \\
\hline 26/09/05 & 98,0 & 74,0 & 98,0 & 36,0 \\
\hline 03/10/05 & 170,0 & 50,0 & 170,0 & 54,0 \\
\hline $10 / 10 / 05$ & 200,0 & 70,0 & 200,0 & 66,0 \\
\hline 24/10/05 & 118,0 & 36,0 & 118,0 & 42,0 \\
\hline 26/10/05 & 98,0 & 34,0 & 98,0 & 42,0 \\
\hline $31 / 10 / 05$ & 80,0 & 32,0 & 80,0 & 48,0 \\
\hline 03/11/05 & 110,0 & 50,0 & 110,0 & 46,0 \\
\hline 08/11/05 & 102,0 & 48,0 & 102,0 & 52,0 \\
\hline $10 / 11 / 05$ & 72,0 & 30,0 & 72,0 & 36,0 \\
\hline $21 / 11 / 05$ & 224,0 & 60,0 & 224,0 & 62,0 \\
\hline 23/11/05 & 326,0 & 64,0 & 326,0 & 60,0 \\
\hline $28 / 11 / 05$ & 196,0 & 26,0 & 196,0 & 44,0 \\
\hline $30 / 11 / 05$ & 132,0 & 40,0 & 132,0 & 38,0 \\
\hline 05/12/05 & 178,0 & 42,0 & 178,0 & 52,0 \\
\hline 07/12/05 & 108,0 & 46,0 & 108,0 & 40,0 \\
\hline $12 / 12 / 05$ & 136,0 & 42,0 & 136,0 & 34,0 \\
\hline $14 / 12 / 05$ & 406,0 & 38,0 & 406,0 & 26,0 \\
\hline $19 / 12 / 05$ & 86,0 & 26,0 & 86,0 & 58,0 \\
\hline 01/02/06 & 88,0 & 24,0 & 88,0 & 36,0 \\
\hline
\end{tabular}


Tabela A.26 - Sólidos Suspensos Fixos - Dosagem de 25 mg FeCl $/ 2$ no Reator B

REATOR B

REATOR C

DATA SSF AFLUENTE SSF EFLUENTE SSF AFLUENTE SSF EFLUENTE [mg/L]

\begin{tabular}{|c|c|c|c|c|}
\hline & & & & \\
\hline $15 / 09 / 05$ & 26,0 & 12,0 & 26,0 & 13,0 \\
\hline $19 / 09 / 05$ & 30,0 & 18,0 & 30,0 & 15,0 \\
\hline $26 / 09 / 05$ & 22,0 & 10,0 & 22,0 & 10,0 \\
\hline 03/10/05 & 32,0 & 4,0 & 32,0 & 12,0 \\
\hline $10 / 10 / 05$ & 54,0 & 24,0 & 54,0 & 16,0 \\
\hline $24 / 10 / 05$ & 26,0 & 8,0 & 26,0 & 4,0 \\
\hline $26 / 10 / 05$ & 20,0 & 8,0 & 20,0 & 12,0 \\
\hline $31 / 10 / 05$ & 12,0 & 4,0 & 12,0 & 6,0 \\
\hline 03/11/05 & 24,0 & 20,0 & 24,0 & 10,0 \\
\hline 08/11/05 & 22,0 & 14,0 & 22,0 & 16,0 \\
\hline $10 / 11 / 05$ & 6,0 & 8,0 & 6,0 & 18,0 \\
\hline $21 / 11 / 05$ & 76,0 & 26,0 & 76,0 & 12,0 \\
\hline 23/11/05 & 124,0 & 24,0 & 124,0 & 12,0 \\
\hline $28 / 11 / 05$ & 78,0 & 8,0 & 78,0 & 4,0 \\
\hline $30 / 11 / 05$ & 20,0 & 12,0 & 20,0 & 6,0 \\
\hline 05/12/05 & 36,0 & 10,0 & 36,0 & 4,0 \\
\hline 07/12/05 & 26,0 & 18,0 & 26,0 & 10,0 \\
\hline $12 / 12 / 05$ & 24,0 & 12,0 & 24,0 & 6,0 \\
\hline $14 / 12 / 05$ & 96,0 & 12,0 & 96,0 & 0,0 \\
\hline $19 / 12 / 05$ & 22,0 & 6,0 & 22,0 & 18,0 \\
\hline 01/02/06 & 20,0 & 4,0 & 20,0 & 4,0 \\
\hline
\end{tabular}


Tabela A.27 - Sólidos Suspensos Voláteis - Dosagem de $25 \mathrm{mg} \mathrm{FeCl}_{3} / \mathrm{L}$ no Reator $\mathrm{B}$

REATOR B

REATOR C

DATA SSV AFLUENTE SSV EFLUENTE SSV AFLUENTE SSV EFLUENTE [mg/L] $[\mathrm{mg} / \mathrm{L}]$ [mg/L]

\begin{tabular}{ccccc}
\hline $15 / 09 / 05$ & 96,0 & 15,0 & 96,0 & 40,0 \\
\hline $19 / 09 / 05$ & 100,0 & 30,0 & 100,0 & 42,0 \\
\hline $26 / 09 / 05$ & 76,0 & 64,0 & 76,0 & 26,0 \\
\hline $03 / 10 / 05$ & 138,0 & 46,0 & 138,0 & 42,0 \\
\hline $10 / 10 / 05$ & 146,0 & 46,0 & 146,0 & 50,0 \\
\hline $24 / 10 / 05$ & 92,0 & 28,0 & 92,0 & 38,0 \\
\hline $26 / 10 / 05$ & 78,0 & 26,0 & 78,0 & 30,0 \\
\hline $31 / 10 / 05$ & 68,0 & 28,0 & 68,0 & 42,0 \\
\hline $03 / 11 / 05$ & 86,0 & 30,0 & 86,0 & 36,0 \\
\hline $08 / 11 / 05$ & 80,0 & 34,0 & 80,0 & 36,0 \\
\hline $10 / 11 / 05$ & 66,0 & 22,0 & 66,0 & 18,0 \\
\hline $21 / 11 / 05$ & 148,0 & 34,0 & 148,0 & 50,0 \\
\hline $23 / 11 / 05$ & 202,0 & 40,0 & 202,0 & 48,0 \\
\hline $28 / 11 / 05$ & 118,0 & 18,0 & 118,0 & 40,0 \\
\hline $30 / 11 / 05$ & 112,0 & 28,0 & 112,0 & 32,0 \\
\hline $05 / 12 / 05$ & 142,0 & 32,0 & 142,0 & 48,0 \\
\hline $07 / 12 / 05$ & 82,0 & 28,0 & 82,0 & 30,0 \\
\hline $12 / 12 / 05$ & 112,0 & 30,0 & 112,0 & 28,0 \\
\hline $14 / 12 / 05$ & 310,0 & 26,0 & 310,0 & 26,0 \\
\hline $19 / 12 / 05$ & 64,0 & 20,0 & 64,0 & 40,0 \\
\hline $01 / 02 / 06$ & 68,0 & 20,0 & 68,0 & 32,0 \\
\hline & & & \\
\hline
\end{tabular}


Tabela A.28 - Sólidos Sedimentáveis - Dosagem de $25 \mathrm{mg} \mathrm{FeCl} / \mathrm{L}$ no Reator B

REATOR B REATOR C

\begin{tabular}{lcccc} 
DATA & $\begin{array}{c}\text { S }_{\text {SED }} \text { AFLUENTE } \\
{[\mathrm{mL} / \mathrm{L}]}\end{array}$ & $\begin{array}{c}\text { S }_{\text {SED }} \text { EFLUENTE } \\
{[\mathrm{mL} / \mathrm{L}]}\end{array}$ & $\begin{array}{c}\text { S SED } \\
\text { AFLUENTE } \\
{[\mathrm{mL} / \mathrm{L}]}\end{array}$ & $\begin{array}{c}\mathbf{S}_{\text {SED }} \text { EFLUENTE } \\
{[\mathrm{mL} / \mathrm{L}]}\end{array}$ \\
\hline $19 / 09 / 05$ & 1,3 & 0,0 & 1,3 & 0,0 \\
\hline $26 / 09 / 05$ & 3,0 & 0,1 & 3,0 & 0,0 \\
\hline $03 / 10 / 05$ & 2,0 & 0,1 & 2,0 & 0,0 \\
\hline $10 / 10 / 05$ & 2,2 & 0,1 & 2,2 & 0,0 \\
\hline $24 / 10 / 05$ & 1,4 & 0,0 & 1,4 & 0,0 \\
\hline $31 / 10 / 05$ & 0,9 & 0,1 & 0,9 & 0,0 \\
\hline $08 / 11 / 05$ & 1,4 & 0,0 & 1,4 & 0,0 \\
\hline $21 / 11 / 05$ & 3,0 & 0,1 & 3,0 & 0,0 \\
\hline $28 / 11 / 05$ & 3,5 & 0,0 & 3,5 & 0,0 \\
\hline $05 / 12 / 05$ & 3,5 & 0,0 & 3,5 & 0,0 \\
\hline $01 / 02 / 06$ & 1,6 & 0,1 & 1,6 & 0,0 \\
\hline
\end{tabular}


Tabela A.29 - pH - Dosagem de $25 \mathrm{mg} \mathrm{FeCl} / \mathrm{L}$ no Reator B

REATOR B

REATOR C

\begin{tabular}{llllc} 
DATA & \multicolumn{2}{c}{ REATOR B } & \multicolumn{2}{c}{ REATOR C } \\
\cline { 2 - 5 } & PH AFLUENTE & pH EFLUENTE & pH AFLUENTE & pH EFLUENTE \\
\hline $15 / 09 / 05$ & 6,5 & 5,9 & 6,5 & 6,5 \\
\hline $19 / 09 / 05$ & 6,5 & 6,2 & 6,5 & 6,8 \\
\hline $21 / 09 / 05$ & 6,5 & 6,5 & 6,5 & 7,0 \\
\hline $26 / 09 / 05$ & 6,7 & 6,6 & 6,7 & 7,0 \\
\hline $03 / 10 / 05$ & 6,8 & 6,5 & 6,8 & 7,0 \\
\hline $05 / 10 / 05$ & 6,6 & 6,4 & 6,6 & 6,6 \\
\hline $10 / 10 / 05$ & 6,6 & 6,3 & 6,6 & 6,7 \\
\hline $24 / 10 / 05$ & 6,7 & 6,5 & 6,7 & 7,0 \\
\hline $31 / 10 / 05$ & 6,6 & 6,6 & 6,6 & 6,7 \\
\hline $03 / 11 / 05$ & 6,7 & 6,4 & 6,7 & 6,7 \\
\hline $08 / 11 / 05$ & 6,7 & 6,5 & 6,7 & 6,9 \\
\hline $10 / 11 / 05$ & 7,2 & 6,8 & 7,2 & 7,1 \\
\hline $21 / 11 / 05$ & 6,7 & 6,7 & 6,7 & 7,0 \\
\hline $23 / 11 / 05$ & 7,2 & 6,9 & 7,2 & 7,0 \\
\hline $28 / 11 / 05$ & 7,2 & 6,9 & 7,2 & 7,2 \\
\hline $30 / 11 / 05$ & 7,2 & 6,7 & 7,2 & 6,9 \\
\hline $05 / 12 / 05$ & 7,3 & 6,9 & 7,3 & 7,0 \\
\hline $07 / 12 / 05$ & 7,1 & 6,9 & 7,1 & 7,0 \\
\hline $01 / 02 / 06$ & 6,8 & 6,7 & 6,8 & \\
\hline & & & & 7,0 \\
\hline
\end{tabular}


Tabela A.30 - Alcalinidade - Dosagem de $25 \mathrm{mg} \mathrm{FeCl} / 3$ L no Reator B

REATOR B

REATOR C

\begin{tabular}{ccccc} 
DATA & $\begin{array}{c}\text { ALCALINIDADE } \\
\text { AFLUENTE }[\mathrm{mg} \\
\left.\mathrm{CaCO}_{3} / \mathrm{L}\right]\end{array}$ & $\begin{array}{c}\text { ALCALINIDADE } \\
\text { EFLUNTE }[\mathrm{mg} \\
\left.\mathrm{CaCO}_{3} / \mathrm{L}\right]\end{array}$ & $\begin{array}{c}\text { ALCALINIDADE } \\
\text { AFLUENTE }[\mathrm{mg} \\
\left.\mathrm{CaCO}_{3} / \mathrm{L}\right]\end{array}$ & $\begin{array}{c}\text { ALCALINIDADE } \\
\text { EFLUENTE [mg } \\
\left.\text { CaCO }_{3} / \mathrm{L}\right]\end{array}$ \\
\hline $15 / 09 / 05$ & 147,0 & 95,0 & 147,0 & 151,0 \\
\hline $19 / 09 / 05$ & 143,0 & 128,0 & 143,0 & 131,0 \\
\hline $21 / 09 / 05$ & 115,0 & 141,0 & 115,0 & 160,0 \\
\hline $26 / 09 / 05$ & 143,0 & 132,0 & 143,0 & 156,0 \\
\hline $03 / 10 / 05$ & 251,0 & 252,0 & 251,0 & 250,0 \\
\hline $05 / 10 / 05$ & 285,0 & 262,0 & 285,0 & 289,0 \\
\hline $10 / 10 / 05$ & 188,0 & 179,0 & 188,0 & 202,0 \\
\hline $24 / 10 / 05$ & 112,0 & 116,0 & 112,0 & 106,0 \\
\hline $31 / 10 / 05$ & 78,0 & 76,0 & 78,0 & 75,0 \\
\hline $03 / 11 / 05$ & 112,0 & 126,0 & 112,0 & 111,0 \\
\hline $08 / 11 / 05$ & 128,0 & 113,0 & 128,0 & 115,0 \\
\hline $10 / 11 / 05$ & 131,0 & 129,0 & 131,0 & 138,0 \\
\hline $21 / 11 / 05$ & 149,0 & 118,0 & 149,0 & 147,0 \\
\hline $23 / 11 / 05$ & 152,0 & 141,0 & 152,0 & 167,0 \\
\hline $28 / 11 / 05$ & 153,0 & 121,0 & 153,0 & 146,0 \\
\hline $30 / 11 / 05$ & 145,0 & 135,0 & 145,0 & 152,0 \\
\hline $05 / 12 / 05$ & 150,0 & 134,0 & 150,0 & 151,0 \\
\hline $07 / 12 / 05$ & 114,0 & 93,0 & 114,0 & 103,0 \\
\hline $01 / 02 / 06$ & 111,0 & 110,0 & 111,0 & 125,0 \\
\hline & & & & \\
\hline
\end{tabular}


Tabela A.31 - DQO Total - Dosagem de $50 \mathrm{mg} \mathrm{FeCl} / / \mathrm{L}$ no Reator B REATOR B

REATOR C

DATA DQO AFLUENTE DQO EFLUENTE DQO AFLUENTE DQO EFLUENTE $[\mathrm{mg} / \mathrm{L}]$ $[\mathrm{mg} / \mathrm{L}]$ [mg/L] $[\mathrm{mg} / \mathrm{L}]$

\begin{tabular}{lllll}
\hline $29 / 03 / 06$ & 84 & 28 & 84 & 60 \\
\hline $03 / 04 / 06$ & 232 & 60 & 232 & 116 \\
\hline $05 / 04 / 06$ & 287 & 65 & 287 & 104 \\
\hline $10 / 04 / 06$ & 339 & 105 & 339 & 178 \\
\hline $12 / 04 / 06$ & 301 & 91 & 301 & 194 \\
\hline $17 / 04 / 06$ & 151 & 94 & 151 & 121 \\
\hline $19 / 04 / 06$ & 297 & 76 & 297 & 171 \\
\hline $24 / 04 / 06$ & 424 & 75 & 424 & 180 \\
\hline $26 / 04 / 06$ & 308 & 81 & 308 & 185 \\
\hline $03 / 05 / 06$ & 388 & 109 & 388 & 148 \\
\hline $08 / 05 / 06$ & 497 & 167 & 497 & 179 \\
\hline $10 / 05 / 06$ & 342 & 85 & 342 & 124 \\
\hline $15 / 05 / 06$ & 404 & 82 & 404 & 120 \\
\hline $17 / 05 / 06$ & 646 & 127 & 646 & 262 \\
\hline $22 / 05 / 06$ & 404 & 117 & 404 & 163 \\
\hline $24 / 05 / 06$ & 340 & 57 & 340 & 132 \\
\hline $29 / 05 / 06$ & 453 & 155 & 453 & 226 \\
\hline $31 / 05 / 06$ & 396 & 128 & 396 & 183 \\
\hline
\end{tabular}


Tabela A.32 - DQO Filtrada - Dosagem de $50 \mathrm{mg} \mathrm{FeCl}_{3} / \mathrm{L}$ no Reator B

REATOR B

REATOR C

DATA DQO AFLUENTE DQO EFLUENTE DQO AFLUENTE DQO EFLUENTE [mg/L] [mg/L] [mg/L]

\begin{tabular}{lllll}
\hline $29 / 03 / 06$ & 14 & 33 & 14 & 38 \\
\hline $03 / 04 / 06$ & 77 & 33 & 77 & 56 \\
\hline $05 / 04 / 06$ & 96 & 35 & 96 & 58 \\
\hline $10 / 04 / 06$ & 145 & 51 & 145 & 83 \\
\hline $12 / 04 / 06$ & 123 & 51 & 123 & 82 \\
\hline $17 / 04 / 06$ & 72 & 30 & 72 & 50 \\
\hline $19 / 04 / 06$ & 122 & 28 & 122 & 63 \\
\hline $24 / 04 / 06$ & 137 & 51 & 137 & 78 \\
\hline $26 / 04 / 06$ & 119 & 48 & 119 & 77 \\
\hline $03 / 05 / 06$ & 144 & 38 & 144 & 54 \\
\hline $08 / 05 / 06$ & 171 & 45 & 171 & 65 \\
\hline $10 / 05 / 06$ & 117 & 44 & 117 & 55 \\
\hline $15 / 05 / 06$ & 148 & 50 & 148 & 72 \\
\hline $17 / 05 / 06$ & 169 & 59 & 169 & 156 \\
\hline $22 / 05 / 06$ & 132 & 49 & 132 & 82 \\
\hline $24 / 05 / 06$ & 151 & 41 & 151 & 57 \\
\hline $29 / 05 / 06$ & 147 & 70 & 147 & 93 \\
\hline $31 / 05 / 06$ & 124 & 64 & & 124 \\
\hline
\end{tabular}


Tabela A.33 - $\mathrm{DBO}_{5,20^{\circ} \mathrm{C}}$ Total - Dosagem de $50 \mathrm{mg} \mathrm{FeCl} / \mathrm{L}$ no Reator B

REATOR B

REATOR C

\begin{tabular}{ccccc}
\cline { 2 - 5 } DATA & $\begin{array}{c}\text { DBO }_{5,20}{ }^{\circ} \mathrm{C} \\
\text { AFLUENTE } \\
{[\mathrm{mg} / \mathrm{L}]}\end{array}$ & $\begin{array}{c}\text { DBO }_{5,20}{ }^{\circ} \\
\text { EFLUENTE } \\
{[\mathrm{mg} / \mathrm{L}]}\end{array}$ & $\begin{array}{c}\text { DBO }_{5,20}{ }^{\circ} \mathrm{C} \\
\text { AFLUENTE } \\
\text { [mg/L] }\end{array}$ & $\begin{array}{c}\text { DBO }_{5,20}{ }^{\circ} \mathrm{C} \\
\text { EFLUENTE } \\
\text { [mg/L] }\end{array}$ \\
\hline $29 / 03 / 06$ & 117 & 18 & 117 & 35 \\
\hline $05 / 04 / 06$ & 138 & 23 & 138 & 52 \\
\hline $12 / 04 / 06$ & 120 & 21 & 120 & 58 \\
\hline $19 / 04 / 06$ & 109 & 18 & 109 & 57 \\
\hline $03 / 05 / 06$ & 205 & 35 & 205 & 63 \\
\hline $10 / 05 / 06$ & 164 & 24 & 164 & 47 \\
\hline $17 / 05 / 06$ & 259 & 36 & 259 & 105 \\
\hline $24 / 05 / 06$ & 145 & 30 & 145 & 55 \\
\hline $31 / 05 / 06$ & 204 & 52 & 204 & 76 \\
\hline
\end{tabular}

Tabela A.34 - $\mathrm{DBO}_{5,20^{\circ} \mathrm{C}}$ Filtrada - Dosagem de $50 \mathrm{mg} \mathrm{FeCl}_{3} / \mathrm{L}$ no Reator B

REATOR B

REATOR C

\begin{tabular}{ccccc}
\cline { 2 - 5 } DATA & $\begin{array}{c}\text { DBO }_{5,20^{\circ} \mathrm{C}} \\
\text { AFLUENTE } \\
\text { [mg/L] }\end{array}$ & $\begin{array}{c}\text { DBO }_{5,20^{\circ} \mathrm{C}} \\
\text { EFLUENTE } \\
\text { [mg/L] }\end{array}$ & $\begin{array}{c}\text { DBO }_{5,2 \circ^{\circ} \mathrm{C}} \\
\text { AFLUENTE } \\
\text { [mg/L] }\end{array}$ & $\begin{array}{c}\text { DBO }_{5,20}{ }^{\circ} \mathrm{C} \\
\text { EFLUENTE } \\
\text { [mg/L] }\end{array}$ \\
\hline $29 / 03 / 06$ & 14 & 5 & 14 & 13 \\
\hline $05 / 04 / 06$ & 37 & 10 & 37 & 22 \\
\hline $12 / 04 / 06$ & 39 & 5 & 39 & 27 \\
\hline $19 / 04 / 06$ & 38 & 3 & 38 & 24 \\
\hline $03 / 05 / 06$ & 60 & 14 & 60 & 28 \\
\hline $10 / 05 / 06$ & 57 & 8 & 57 & 20 \\
\hline $17 / 05 / 06$ & 82 & 15 & 82 & 60 \\
\hline $24 / 05 / 06$ & 64 & 4 & 64 & 23 \\
\hline $31 / 05 / 06$ & 59 & 20 & 59 & 36 \\
\hline
\end{tabular}


Tabela A.35 - Fósforo Total - Dosagem de $50 \mathrm{mg} \mathrm{FeCl}_{3} / \mathrm{L}$ no Reator B

\begin{tabular}{lcccc} 
& \multicolumn{2}{c}{ REATOR B } & \multicolumn{2}{c}{ REATOR C } \\
\cline { 2 - 5 } DATA & $\begin{array}{c}\text { P }_{\text {TOTAL }} \\
\text { AFLUENTE } \\
\text { [mg/L] }\end{array}$ & $\begin{array}{c}\text { P }_{\text {TOTAL }} \\
\text { EFLUENTE } \\
\text { [mg/L] }\end{array}$ & $\begin{array}{c}\text { P }_{\text {TOTAL }} \\
\text { AFLUENTE } \\
\text { [mg/L] }\end{array}$ & $\begin{array}{c}\text { P }_{\text {TOTAL }} \\
\text { EFLUENTE } \\
\text { [mg/L] }\end{array}$ \\
\hline $29 / 03 / 06$ & 1,9 & 1,2 & 1,9 & 4,8 \\
\hline $03 / 04 / 06$ & 4,0 & 2,4 & 4,0 & 2,2 \\
\hline $05 / 04 / 06$ & 4,2 & 4,0 & 4,2 & 3,7 \\
\hline $10 / 04 / 06$ & 5,7 & 2,9 & 5,7 & 4,2 \\
\hline $12 / 04 / 06$ & 4,7 & 3,1 & 4,7 & 3,5 \\
\hline $17 / 04 / 06$ & 2,8 & 2,7 & 2,8 & 2,0 \\
\hline $19 / 04 / 06$ & 4,2 & 1,8 & 4,2 & 2,9 \\
\hline $24 / 04 / 06$ & 5,2 & 3,2 & 5,2 & 4,0 \\
\hline $26 / 04 / 06$ & 4,5 & 2,4 & 4,5 & 3,8 \\
\hline $03 / 05 / 06$ & 5,6 & 3,4 & 5,6 & 3,6 \\
\hline $08 / 05 / 06$ & 6,9 & 4,4 & 6,9 & 3,8 \\
\hline $10 / 05 / 06$ & 5,9 & 4,4 & 5,9 & 3,3 \\
\hline $15 / 05 / 06$ & 6,3 & 3,8 & 6,3 & 3,4 \\
\hline $17 / 05 / 06$ & 6,3 & 4,7 & 6,3 & 4,8 \\
\hline $22 / 05 / 06$ & 6,0 & 3,6 & 6,0 & 3,6 \\
\hline $24 / 05 / 06$ & 5,1 & 2,9 & 5,1 & 4,0 \\
\hline $29 / 05 / 06$ & 5,8 & 3,7 & 5,8 & \\
\hline $31 / 05 / 06$ & 5,7 & 3,7 & 5,7 & 4,3 \\
\hline
\end{tabular}


Tabela A.36 - Ortofosfato - Dosagem de $50 \mathrm{mg} \mathrm{FeCl}_{3} / \mathrm{L}$ no Reator B REATOR B

REATOR C

\begin{tabular}{|c|c|c|c|c|}
\hline DATA & $\begin{array}{c}\mathrm{P}_{\mathrm{PO} 4-} \text { AFLUENTE } \\
{[\mathrm{mg} / \mathrm{L}]}\end{array}$ & $\begin{array}{l}P_{\text {PO4- }} \text { EFLUENTE } \\
{[\mathrm{mg} / \mathrm{L}]}\end{array}$ & $\begin{array}{l}P_{\text {PO4- }} \text { AFLUENTE } \\
{[\mathrm{mg} / \mathrm{L}]}\end{array}$ & $\begin{array}{c}P_{\text {PO4- }} \text { EFLUENTE } \\
{[\mathrm{mg} / \mathrm{L}]}\end{array}$ \\
\hline 29/03/06 & 1,6 & 0,9 & 1,6 & 1,2 \\
\hline 03/04/06 & 0,4 & 1,0 & 0,4 & 0,4 \\
\hline 05/04/06 & 1,4 & 0,9 & 1,4 & 1,5 \\
\hline $10 / 04 / 06$ & 1,7 & 1,1 & 1,7 & 1,8 \\
\hline $12 / 04 / 06$ & 2,0 & 2,1 & 2,0 & 2,2 \\
\hline $17 / 04 / 06$ & 1,7 & 1,2 & 1,7 & 2,0 \\
\hline $19 / 04 / 06$ & 1,1 & 0,8 & 1,1 & 1,2 \\
\hline $24 / 04 / 06$ & 1,3 & 0,1 & 1,3 & 1,3 \\
\hline $26 / 04 / 06$ & 2,3 & 0,8 & 2,3 & 2,7 \\
\hline 03/05/06 & 2,0 & 0,8 & 2,0 & 2,4 \\
\hline 08/05/06 & 2,0 & 0,4 & 2,0 & 1,6 \\
\hline $10 / 05 / 06$ & 2,4 & 0,7 & 2,4 & 2,1 \\
\hline $15 / 05 / 06$ & 2,4 & 0,9 & 2,4 & 2,1 \\
\hline $17 / 05 / 06$ & 2,8 & 0,5 & 2,8 & 2,4 \\
\hline $22 / 05 / 06$ & 2,4 & 0,4 & 2,4 & 2,4 \\
\hline $24 / 05 / 06$ & 1,9 & 0,3 & 1,9 & 2,4 \\
\hline $29 / 05 / 06$ & 1,8 & 0,4 & 1,8 & 1,7 \\
\hline $31 / 05 / 06$ & 2,4 & 0,4 & 2,4 & 2,6 \\
\hline 05/06/06 & 2,2 & 1,0 & 2,2 & 2,1 \\
\hline
\end{tabular}


Tabela A.37 - Sulfetos - Dosagem de $50 \mathrm{mg} \mathrm{FeCl} / / \mathrm{L}$ no Reator B

REATOR B

REATOR C

DATA CONCENTRAÇÃO DE SULFETOS CONCENTRAÇÃO DE SULFETOS EFLUENTE [mg/L]

\begin{tabular}{lll}
\hline $29 / 03 / 06$ & 2,8 & 2,5 \\
\hline $03 / 04 / 06$ & 2,4 & 2,4 \\
\hline $05 / 04 / 06$ & 2,5 & 2,6 \\
\hline $10 / 04 / 06$ & 3,3 & 3,0 \\
\hline $12 / 04 / 06$ & 3,1 & 3,3 \\
\hline $17 / 04 / 06$ & 3,3 & 2,5 \\
\hline $19 / 04 / 06$ & 2,8 & 2,5 \\
\hline $24 / 04 / 06$ & 2,5 & 2,9 \\
\hline $26 / 04 / 06$ & 2,9 & 3,0 \\
\hline $03 / 05 / 06$ & 3,3 & 2,4 \\
\hline
\end{tabular}

Tabela A.38 - Sólidos Totais - Dosagem de $50 \mathrm{mg} \mathrm{FeCl}_{3} / \mathrm{L}$ no Reator B

REATOR B

REATOR C

\begin{tabular}{ccccc} 
DATA & $\begin{array}{c}\text { ST AFLUENTE } \\
{[\mathrm{mg} / \mathrm{L}]}\end{array}$ & $\begin{array}{c}\text { ST EFLUENTE } \\
{[\mathrm{mg} / \mathrm{L}]}\end{array}$ & $\begin{array}{c}\text { ST AFLUENTE } \\
{[\mathrm{mg} / \mathrm{L}]}\end{array}$ & $\begin{array}{c}\text { ST EFLUENTE } \\
{[\mathrm{mg} / \mathrm{L}]}\end{array}$ \\
\hline $29 / 03 / 06$ & 260,0 & 200,0 & 260,0 & 220,0 \\
\hline $03 / 04 / 06$ & 440,0 & 240,0 & 440,0 & 240,0 \\
\hline $05 / 04 / 06$ & 500,0 & 280,0 & 500,0 & 320,0 \\
\hline $10 / 04 / 06$ & 400,0 & 200,0 & 400,0 & 280,0 \\
\hline $12 / 04 / 06$ & 380,0 & 300,0 & 380,0 & 300,0 \\
\hline $17 / 04 / 06$ & 300,0 & 240,0 & 300,0 & 280,0 \\
\hline $19 / 04 / 06$ & 360,0 & 180,0 & 360,0 & 240,0 \\
\hline $24 / 04 / 06$ & 500,0 & 260,0 & 500,0 & 320,0 \\
\hline $26 / 04 / 06$ & 400,0 & 280,0 & 400,0 & 300,0 \\
\hline $03 / 05 / 06$ & 460,0 & 240,0 & 460,0 & 240,0 \\
\hline $08 / 05 / 06$ & 540,0 & 300,0 & 540,0 & 240,0 \\
\hline
\end{tabular}


Tabela A.39 - Sólidos Totais Fixos - Dosagem de $50 \mathrm{mg} \mathrm{FeCl} / \mathrm{L}$ no Reator B

REATOR B

REATOR C

\begin{tabular}{lcccc} 
DATA & $\begin{array}{c}\text { STF AFLUENTE } \\
{[\mathbf{m g} / \mathbf{L}]}\end{array}$ & $\begin{array}{c}\text { STF EFLUENTE } \\
{[\mathbf{m g} / \mathbf{L}]}\end{array}$ & $\begin{array}{c}\text { STF AFLUENTE } \\
{[\mathrm{mg} / \mathrm{L}]}\end{array}$ & $\begin{array}{c}\text { STF EFLUENTE } \\
{[\mathrm{mg} / \mathrm{L}]}\end{array}$ \\
\hline $29 / 03 / 06$ & 140,0 & 120,0 & 140,0 & 120,0 \\
\hline $03 / 04 / 06$ & 260,0 & 160,0 & 260,0 & 140,0 \\
\hline $05 / 04 / 06$ & 300,0 & 200,0 & 300,0 & 200,0 \\
\hline $10 / 04 / 06$ & 180,0 & 60,0 & 180,0 & 100,0 \\
\hline $12 / 04 / 06$ & 180,0 & 180,0 & 180,0 & 160,0 \\
\hline $17 / 04 / 06$ & 180,0 & 160,0 & 180,0 & 160,0 \\
\hline $19 / 04 / 06$ & 240,0 & 160,0 & 240,0 & 200,0 \\
\hline $24 / 04 / 06$ & 240,0 & 140,0 & 240,0 & 160,0 \\
\hline $26 / 04 / 06$ & 220,0 & 180,0 & 220,0 & 160,0 \\
\hline $03 / 05 / 06$ & 180,0 & 100,0 & 180,0 & 80,0 \\
\hline $08 / 05 / 06$ & 240,0 & 160,0 & 240,0 & 100,0 \\
\hline
\end{tabular}

Tabela A.40 - Sólidos Totais Voláteis - Dosagem de $50 \mathrm{mg} \mathrm{FeCl}_{3} / \mathrm{L}$ no Reator B

REATOR B

REATOR C

DATA STV AFLUENTE STV EFLUENTE STV AFLUENTE STV EFLUENTE $[\mathrm{mg} / \mathrm{L}]$ $[\mathrm{mg} / \mathrm{L}] \quad[\mathrm{mg} / \mathrm{L}]$ $[\mathrm{mg} / \mathrm{L}]$

\begin{tabular}{lllll}
\hline $29 / 03 / 06$ & 120,0 & 80,0 & 120,0 & 100,0 \\
\hline $03 / 04 / 06$ & 180,0 & 80,0 & 180,0 & 100,0 \\
\hline $05 / 04 / 06$ & 200,0 & 80,0 & 200,0 & 120,0 \\
\hline $10 / 04 / 06$ & 220,0 & 140,0 & 220,0 & 180,0 \\
\hline $12 / 04 / 06$ & 200,0 & 120,0 & 200,0 & 140,0 \\
\hline $17 / 04 / 06$ & 120,0 & 80,0 & 120,0 & 120,0 \\
\hline $19 / 04 / 06$ & 120,0 & 20,0 & 120,0 & 40,0 \\
\hline $24 / 04 / 06$ & 260,0 & 120,0 & 260,0 & 160,0 \\
\hline $26 / 04 / 06$ & 180,0 & 100,0 & 180,0 & 140,0 \\
\hline $03 / 05 / 06$ & 280,0 & 140,0 & 280,0 & 160,0 \\
\hline $08 / 05 / 06$ & 300,0 & 140,0 & 300,0 & 140,0 \\
\hline
\end{tabular}


Tabela A.41 - Sólidos Suspensos Totais - Dosagem de $50 \mathrm{mg} \mathrm{FeCl} / \mathrm{L}$ no Reator B

REATOR B

REATOR C

\begin{tabular}{lcccc} 
DATA & $\begin{array}{c}\text { SST AFLUENTE SST EFLUENTE } \\
{[\mathrm{mg} / \mathrm{L}]}\end{array}$ & $\begin{array}{c}\text { SST AFLUENTE } \\
{[\mathrm{mg} / \mathrm{L}]}\end{array}$ & $\begin{array}{c}\text { SST EFLUENTE } \\
{[\mathrm{mg} / \mathrm{L}]}\end{array}$ \\
\hline $29 / 03 / 06$ & 178,0 & 38,0 & 178,0 & 64,0 \\
\hline $03 / 04 / 06$ & 174,0 & 48,0 & 174,0 & 60,0 \\
\hline $05 / 04 / 06$ & 204,0 & 32,0 & 204,0 & 58,0 \\
\hline $10 / 04 / 06$ & 150,0 & 60,0 & 150,0 & 82,0 \\
\hline $12 / 04 / 06$ & 136,0 & 56,0 & 136,0 & 88,0 \\
\hline $17 / 04 / 06$ & 74,0 & 58,0 & 74,0 & 60,0 \\
\hline $19 / 04 / 06$ & 132,0 & 42,0 & 132,0 & 54,0 \\
\hline $24 / 04 / 06$ & 236,0 & 42,0 & 236,0 & 76,0 \\
\hline $26 / 04 / 06$ & 134,0 & 38,0 & 134,0 & 64,0 \\
\hline $03 / 05 / 06$ & 188,0 & 72,0 & 188,0 & 42,0 \\
\hline $08 / 05 / 06$ & 262,0 & 106,0 & 262,0 & 60,0 \\
\hline $10 / 05 / 06$ & 204,0 & 60,0 & 204,0 & 58,0 \\
\hline $15 / 05 / 06$ & 184,0 & 50,0 & 184,0 & 46,0 \\
\hline $17 / 05 / 06$ & 378,0 & 84,0 & 378,0 & 82,0 \\
\hline $22 / 05 / 06$ & 224,0 & 64,0 & 224,0 & 78,0 \\
\hline $24 / 05 / 06$ & 184,0 & 54,0 & 184,0 & 74,0 \\
\hline $29 / 05 / 06$ & 244,0 & 98,0 & 244,0 & 98,0 \\
\hline $31 / 05 / 06$ & 212,0 & 70,0 & 212,0 & 70,0 \\
\hline & & & & \\
\hline
\end{tabular}


Tabela A.42 - Sólidos Suspensos Fixos - Dosagem de 50 mg FeCl $/ 2$ no Reator B

REATOR B

REATOR C

DATA SSF AFLUENTE SSF EFLUENTE SSF AFLUENTE SSF EFLUENTE

\begin{tabular}{ccccc} 
& {$[\mathrm{mg} / \mathrm{L}]$} & {$[\mathrm{mg} / \mathrm{L}]$} & {$[\mathrm{mg} / \mathbf{L}]$} & {$[\mathrm{mg} / \mathbf{L}]$} \\
\hline $29 / 03 / 06$ & 100,0 & 16,0 & 100,0 & 28,0 \\
\hline $03 / 04 / 06$ & 52,0 & 22,0 & 52,0 & 10,0 \\
\hline $05 / 04 / 06$ & 90,0 & 4,0 & 90,0 & 10,0 \\
\hline $10 / 04 / 06$ & 38,0 & 18,0 & 38,0 & 22,0 \\
\hline $12 / 04 / 06$ & 20,0 & 18,0 & 20,0 & 14,0 \\
\hline $17 / 04 / 06$ & 18,0 & 18,0 & 18,0 & 14,0 \\
\hline $19 / 04 / 06$ & 38,0 & 18,0 & 38,0 & 14,0 \\
\hline $24 / 04 / 06$ & 52,0 & 16,0 & 52,0 & 12,0 \\
\hline $26 / 04 / 06$ & 22,0 & 10,0 & 22,0 & 8,0 \\
\hline $03 / 05 / 06$ & 50,0 & 28,0 & 50,0 & 18,0 \\
\hline $08 / 05 / 06$ & 78,0 & 48,0 & 78,0 & 14,0 \\
\hline $10 / 05 / 06$ & 42,0 & 24,0 & 42,0 & 14,0 \\
\hline $15 / 05 / 06$ & 32,0 & 30,0 & 32,0 & 8,0 \\
\hline $17 / 05 / 06$ & 88,0 & 44,0 & 88,0 & 10,0 \\
\hline $22 / 05 / 06$ & 46,0 & 26,0 & 46,0 & 12,0 \\
\hline $24 / 05 / 06$ & 58,0 & 18,0 & 58,0 & 20,0 \\
\hline $29 / 05 / 06$ & 64,0 & 34,0 & 64,0 & 18,0 \\
\hline $31 / 05 / 06$ & 50,0 & 32,0 & 50,0 & 14,0 \\
\hline
\end{tabular}


Tabela A.43 - Sólidos Suspensos Voláteis - Dosagem de $50 \mathrm{mg} \mathrm{FeCl} / / \mathrm{L}$ no Reator B

REATOR B

REATOR C

\begin{tabular}{lcccc} 
DATA & $\begin{array}{c}\text { SSV AFLUENTE } \\
{[\mathbf{m g} / \mathbf{L}]}\end{array}$ & $\begin{array}{c}\text { SSV EFLUENTE } \\
{[\mathrm{mg} / \mathrm{L}]}\end{array}$ & $\begin{array}{c}\text { SSV AFLUENTE } \\
{[\mathrm{mg} / \mathrm{L}]}\end{array}$ & $\begin{array}{c}\text { SSV EFLUENTE } \\
{[\mathrm{mg} / \mathrm{L}]}\end{array}$ \\
\hline $29 / 03 / 06$ & 78,0 & 22,0 & 78,0 & 36,0 \\
\hline $03 / 04 / 06$ & 122,0 & 26,0 & 122,0 & 50,0 \\
\hline $05 / 04 / 06$ & 114,0 & 28,0 & 114,0 & 48,0 \\
\hline $10 / 04 / 06$ & 112,0 & 42,0 & 112,0 & 60,0 \\
\hline $17 / 04 / 06$ & 56,0 & 40,0 & 56,0 & 46,0 \\
\hline $19 / 04 / 06$ & 94,0 & 24,0 & 94,0 & 40,0 \\
\hline $24 / 04 / 06$ & 184,0 & 26,0 & 184,0 & 64,0 \\
\hline $08 / 05 / 06$ & 184,0 & 58,0 & 184,0 & 46,0 \\
\hline $10 / 05 / 06$ & 162,0 & 36,0 & 162,0 & 44,0 \\
\hline $15 / 05 / 06$ & 152,0 & 20,0 & 152,0 & 38,0 \\
\hline $17 / 05 / 06$ & 290,0 & 40,0 & 290,0 & 72,0 \\
\hline $22 / 05 / 06$ & 178,0 & 38,0 & 178,0 & 66,0 \\
\hline $24 / 05 / 06$ & 126,0 & 36,0 & 126,0 & 54,0 \\
\hline $29 / 05 / 06$ & 180,0 & 64,0 & 180,0 & 80,0 \\
\hline $31 / 05 / 06$ & 162,0 & 38,0 & 162,0 & 56,0 \\
\hline
\end{tabular}

Tabela A.44 - Sólidos Sedimentáveis - Dosagem de 50 mg FeCl $/ 2$ no Reator B

REATOR B

REATOR C

\begin{tabular}{ccccc} 
DATA & $\begin{array}{c}\mathbf{S}_{\text {SED }} \text { AFLUENTE } \\
{[\mathrm{mL} / \mathrm{L}]}\end{array}$ & $\begin{array}{c}\mathbf{S}_{\text {SED }} \text { EFLUENTE } \\
{[\mathrm{mL} / \mathrm{L}]}\end{array}$ & $\begin{array}{c}\mathbf{S}_{\text {SED }} \text { AFLUENTE } \\
{[\mathrm{mL} / \mathrm{L}]}\end{array}$ & $\begin{array}{c}\mathbf{S}_{\mathrm{SED}} \text { EFLUENTE } \\
{[\mathrm{mL} / \mathrm{L}]}\end{array}$ \\
\hline $03 / 04 / 06$ & 2,3 & 0,1 & 2,3 & 0,1 \\
\hline $10 / 04 / 06$ & 1,7 & 0,0 & 1,7 & 0,0 \\
\hline $12 / 04 / 06$ & 1,5 & 0,1 & 1,5 & 0,1 \\
\hline $17 / 04 / 06$ & 0,6 & 1,0 & 0,6 & 0,2 \\
\hline $19 / 04 / 06$ & 2,3 & 0,4 & 2,3 & 0,1 \\
\hline $24 / 04 / 06$ & 2,4 & 0,1 & 2,4 & 0,4 \\
\hline $26 / 04 / 06$ & 1,8 & 0,0 & 1,8 & 0,0 \\
\hline $03 / 05 / 06$ & 2,7 & 0,5 & 2,7 & 0,0 \\
\hline $08 / 05 / 06$ & 2,4 & 0,2 & 2,4 & 0,0 \\
\hline
\end{tabular}


Tabela A.45 - pH - Dosagem de 50 mg FeCl 3 /L no Reator B

REATOR B

REATOR C

\begin{tabular}{|c|c|c|c|c|}
\hline \multirow{2}{*}{ DATA } & & \\
\hline & pH AFLUENTE & pH EFLUENTE & pH AFLUENTE & pH EFLUENTE \\
\hline 29/03/06 & 6,4 & 6,7 & 6,4 & 6,9 \\
\hline 03/04/06 & 6,6 & 6,4 & 6,6 & 6,8 \\
\hline 05/04/06 & 6,5 & 6,4 & 6,5 & 6,5 \\
\hline $10 / 04 / 06$ & 6,5 & 6,5 & 6,5 & 7,0 \\
\hline $12 / 04 / 06$ & 6,5 & 6,5 & 6,5 & 7,1 \\
\hline $17 / 04 / 06$ & 6,2 & 6,2 & 6,2 & 6,7 \\
\hline $19 / 04 / 06$ & 6,4 & 6,3 & 6,4 & 6,9 \\
\hline $24 / 04 / 06$ & 6,3 & 6,0 & 6,3 & 6,8 \\
\hline $26 / 04 / 06$ & 6,7 & 6,2 & 6,7 & 7,0 \\
\hline 03/05/06 & 6,6 & 6,4 & 6,6 & 7,1 \\
\hline 08/05/06 & 6,5 & 6,3 & 6,5 & 7,0 \\
\hline $10 / 05 / 06$ & 6,9 & 6,3 & 6,9 & 6,9 \\
\hline $15 / 05 / 06$ & 7,0 & 6,3 & 7,0 & 6,8 \\
\hline $17 / 05 / 06$ & 6,6 & 6,2 & 6,6 & 6,8 \\
\hline 22/05/06 & 6,7 & 6,4 & 6,7 & 6,9 \\
\hline $24 / 05 / 06$ & 6,8 & 6,4 & 6,8 & 6,8 \\
\hline 29/05/06 & 6,5 & 6,1 & 6,5 & 6,8 \\
\hline $31 / 05 / 06$ & 6,8 & 6,6 & 6,8 & 6,9 \\
\hline
\end{tabular}


Tabela A.46 - Alcalinidade - Dosagem de $50 \mathrm{mg} \mathrm{FeCl} / 3 / \mathrm{L}$ no Reator B

REATOR B

REATOR C

\begin{tabular}{ccccc} 
DATA & $\begin{array}{c}\text { ALCALINIDADE } \\
\text { AFLUENTE }[\mathrm{mg} \\
\left.\mathrm{CaCO}_{3} / \mathrm{L}\right]\end{array}$ & $\begin{array}{c}\text { ALCALINIDADE } \\
\text { EFLUENTE }[\mathrm{mg} \\
\left.\mathrm{CaCO}_{3} / \mathrm{L}\right]\end{array}$ & $\begin{array}{c}\text { ALCALINIDADE } \\
\text { AFLUENTE }[\mathrm{mg} \\
\left.\mathrm{CaCO}_{3} / \mathrm{L}\right]\end{array}$ & $\begin{array}{c}\text { ALCALINIDADE } \\
\text { EFLUENTE }[\mathrm{mg} \\
\left.\mathrm{CaCO}_{3} / \mathrm{L}\right]\end{array}$ \\
\hline $29 / 03 / 06$ & 47,0 & 70,0 & 47,0 & 74,0 \\
\hline $03 / 04 / 06$ & 100,0 & 92,0 & 100,0 & 107,0 \\
\hline $05 / 04 / 06$ & 104,0 & 90,0 & 104,0 & 113,0 \\
\hline $10 / 04 / 06$ & 109,0 & 127,0 & 109,0 & 131,0 \\
\hline $12 / 04 / 06$ & 110,0 & 107,0 & 110,0 & 136,0 \\
\hline $17 / 04 / 06$ & 62,0 & 72,0 & 62,0 & 71,0 \\
\hline $19 / 04 / 06$ & 103,0 & 86,0 & 103,0 & 111,0 \\
\hline $24 / 04 / 06$ & 115,0 & 94,0 & 115,0 & 130,0 \\
\hline $26 / 04 / 06$ & 109,0 & 97,0 & 109,0 & 126,0 \\
\hline $03 / 05 / 06$ & 123,0 & 104,0 & 123,0 & 118,0 \\
\hline $08 / 05 / 06$ & 127,0 & 114,0 & 127,0 & 132,0 \\
\hline $10 / 05 / 06$ & 130,0 & 110,0 & 130,0 & 127,0 \\
\hline $15 / 05 / 06$ & 157,0 & 107,0 & 157,0 & 143,0 \\
\hline $17 / 05 / 06$ & 110,0 & 115,0 & 110,0 & 139,0 \\
\hline $22 / 05 / 06$ & 132,0 & 105,0 & 132,0 & 135,0 \\
\hline $24 / 05 / 06$ & 102,0 & 89,0 & 102,0 & 110,0 \\
\hline $29 / 05 / 06$ & 126,0 & 110,0 & 126,0 & 133,0 \\
\hline $31 / 05 / 06$ & 130,0 & 110,0 & 130,0 & 126,0 \\
\hline & & & & \\
\hline
\end{tabular}


Tabela B.1 - Valores de DQO anteriores ao experimento (Fonte: SABESP)

\begin{tabular}{|c|c|c|c|}
\hline \multirow{2}{*}{ Data: } & \multicolumn{3}{|c|}{ DQO [mg/L]: } \\
\hline & Afluente: & Saída: & Efic. [\%]: \\
\hline $08 / 05 / 03$ & 255 & 87 & 65,9 \\
\hline $14 / 05 / 03$ & 218 & 93 & 57,3 \\
\hline $19 / 05 / 03$ & 233 & 88 & 62,2 \\
\hline $27 / 05 / 03$ & 299 & 98 & 67,2 \\
\hline 05/06/03 & 225 & 81 & 64,0 \\
\hline $10 / 06 / 03$ & 347 & 97 & 72,0 \\
\hline $04 / 07 / 03$ & 285 & 95 & 66,7 \\
\hline $10 / 07 / 03$ & 366 & 91 & 75,1 \\
\hline $17 / 07 / 03$ & 381 & 79 & 79,3 \\
\hline $22 / 07 / 03$ & 401 & 85 & 78,8 \\
\hline $06 / 08 / 03$ & 316 & 87 & 72,5 \\
\hline $13 / 08 / 03$ & 394 & 80 & 79,7 \\
\hline $21 / 08 / 03$ & 291 & 92 & 68,4 \\
\hline $27 / 08 / 03$ & 338 & 86 & 74,6 \\
\hline 03/09/03 & 293 & 104 & 64,5 \\
\hline $10 / 09 / 03$ & 313 & 108 & 65,5 \\
\hline $16 / 09 / 03$ & 339 & 98 & 71,1 \\
\hline $23 / 09 / 03$ & 396 & 102 & 74,2 \\
\hline $07 / 10 / 03$ & 322 & 91 & 71,7 \\
\hline $15 / 10 / 03$ & 303 & 87 & 71,3 \\
\hline $20 / 10 / 03$ & 295 & 96 & 67,5 \\
\hline $30 / 10 / 03$ & 271 & 90 & 66,8 \\
\hline $04 / 11 / 03$ & 294 & 93 & 68,4 \\
\hline $11 / 11 / 03$ & 301 & 97 & 67,8 \\
\hline $21 / 11 / 03$ & 338 & 90 & 73,4 \\
\hline $25 / 11 / 03$ & 286 & 87 & 69,6 \\
\hline $04 / 12 / 03$ & 368 & 109 & 70,4 \\
\hline $09 / 12 / 03$ & 301 & 96 & 68,1 \\
\hline $17 / 12 / 03$ & 394 & 110 & 72,1 \\
\hline $08 / 01 / 04$ & 361 & 92 & 74,5 \\
\hline $13 / 01 / 04$ & 301 & 82 & 72,8 \\
\hline $23 / 01 / 04$ & 348 & 90 & 74,1 \\
\hline $27 / 01 / 04$ & 294 & 87 & 70,4 \\
\hline $04 / 02 / 04$ & 716 & 122 & 83,0 \\
\hline $11 / 02 / 04$ & 602 & 139 & 76,9 \\
\hline $05 / 03 / 04$ & 217 & 84 & 61,3 \\
\hline $17 / 03 / 04$ & 337 & 96 & 71,5 \\
\hline $23 / 03 / 04$ & 282 & 87 & 69,1 \\
\hline $29 / 03 / 04$ & 308 & 93 & 69,8 \\
\hline $02 / 04 / 04$ & 302 & 97 & 67,9 \\
\hline $12 / 04 / 04$ & 361 & 102 & 71,7 \\
\hline $20 / 04 / 04$ & 284 & 92 & 67,6 \\
\hline $26 / 04 / 04$ & 312 & 86 & 72,4 \\
\hline $06 / 05 / 04$ & 316 & 102 & 67,7 \\
\hline $13 / 05 / 04$ & 339 & 97 & 71,4 \\
\hline $19 / 05 / 04$ & 397 & 106 & 73,3 \\
\hline
\end{tabular}


Tabela B.2 - Valores de Turbidez anteriores ao experimento (Fonte: SABESP)

\begin{tabular}{|c|c|c|}
\hline \multirow{2}{*}{ Data: } & \multicolumn{2}{|c|}{ Turbidez } \\
\hline & Afluente: & Saída: \\
\hline $19 / 04 / 03$ & 204 & 48 \\
\hline $23 / 04 / 03$ & 236 & 58 \\
\hline $08 / 05 / 03$ & 193 & 100 \\
\hline $14 / 05 / 03$ & 184 & 79 \\
\hline $19 / 05 / 03$ & 106 & 67 \\
\hline $27 / 05 / 03$ & 99 & 45 \\
\hline $05 / 06 / 03$ & 231 & 73 \\
\hline $10 / 06 / 03$ & 148 & 90 \\
\hline $04 / 07 / 03$ & 266 & 79 \\
\hline $10 / 07 / 03$ & 245 & 102 \\
\hline $17 / 07 / 03$ & 260 & 83 \\
\hline $22 / 07 / 03$ & 294 & 96 \\
\hline $06 / 08 / 03$ & 196 & 82 \\
\hline $13 / 08 / 03$ & 217 & 78 \\
\hline $21 / 08 / 03$ & 203 & 87 \\
\hline $27 / 08 / 03$ & 234 & 91 \\
\hline $03 / 09 / 03$ & 208 & 87 \\
\hline $10 / 09 / 03$ & 276 & 94 \\
\hline $16 / 09 / 03$ & 247 & 101 \\
\hline $23 / 09 / 03$ & 283 & 97 \\
\hline $07 / 10 / 03$ & 215 & 76 \\
\hline $15 / 10 / 03$ & 208 & 81 \\
\hline $20 / 10 / 03$ & 198 & 79 \\
\hline $30 / 10 / 03$ & 148 & 87 \\
\hline $04 / 11 / 03$ & 216 & 72 \\
\hline $11 / 11 / 03$ & 228 & 76 \\
\hline $21 / 11 / 03$ & 273 & 84 \\
\hline $25 / 11 / 03$ & 239 & 91 \\
\hline $04 / 12 / 03$ & 267 & 81 \\
\hline $09 / 12 / 03$ & 283 & 84 \\
\hline $17 / 12 / 03$ & 318 & 92 \\
\hline $08 / 01 / 04$ & 302 & 69 \\
\hline $13 / 01 / 04$ & 321 & 64 \\
\hline $23 / 01 / 04$ & 273 & 70 \\
\hline $27 / 01 / 04$ & 243 & 67 \\
\hline $04 / 02 / 04$ & 416 & 174 \\
\hline $11 / 02 / 04$ & 348 & 97 \\
\hline $05 / 03 / 04$ & 261 & 84 \\
\hline $17 / 03 / 04$ & 215 & 88 \\
\hline $23 / 03 / 04$ & 213 & 77 \\
\hline $29 / 03 / 04$ & 274 & 87 \\
\hline $02 / 04 / 04$ & 263 & 84 \\
\hline $12 / 04 / 04$ & 281 & 80 \\
\hline $20 / 04 / 04$ & 275 & 96 \\
\hline $26 / 04 / 04$ & 339 & 101 \\
\hline $06 / 05 / 04$ & 273 & 76 \\
\hline $13 / 05 / 04$ & 301 & 88 \\
\hline $19 / 05 / 04$ & 284 & 76 \\
\hline
\end{tabular}


Tabela B.3 - Valores de SST anteriores ao experimento (Fonte: SABESP)

\begin{tabular}{|c|c|c|}
\hline \multirow{2}{*}{ Data: } & \multicolumn{2}{|c|}{ Sol. S. Totais [mg/L]: } \\
\hline & Afluente: & Saída: \\
\hline 13/08/03 & 81 & 36 \\
\hline $21 / 08 / 03$ & 72 & 33 \\
\hline $27 / 08 / 03$ & 78 & 30 \\
\hline $03 / 09 / 03$ & 91 & 47 \\
\hline 10/09/03 & 88 & 51 \\
\hline 16/09/03 & 73 & 39 \\
\hline $23 / 09 / 03$ & 84 & 50 \\
\hline 07/10/03 & 106 & 52 \\
\hline $15 / 10 / 03$ & 117 & 66 \\
\hline $20 / 10 / 03$ & 96 & 48 \\
\hline $30 / 10 / 03$ & 91 & 53 \\
\hline $04 / 11 / 03$ & 79 & 41 \\
\hline $11 / 11 / 03$ & 84 & 33 \\
\hline $21 / 11 / 03$ & 65 & 37 \\
\hline $25 / 11 / 03$ & 71 & 39 \\
\hline $04 / 12 / 03$ & 143 & 61 \\
\hline 09/12/03 & 171 & 65 \\
\hline $17 / 12 / 03$ & 213 & 72 \\
\hline 08/01/04 & 76 & 41 \\
\hline $13 / 01 / 04$ & 83 & 38 \\
\hline $23 / 01 / 04$ & 88 & 47 \\
\hline $27 / 01 / 04$ & 79 & 41 \\
\hline $04 / 02 / 04$ & 229 & 77 \\
\hline $11 / 02 / 04$ & 225 & 84 \\
\hline 05/03/04 & 111 & 49 \\
\hline $17 / 03 / 04$ & 102 & 51 \\
\hline $23 / 03 / 04$ & 94 & 42 \\
\hline 29/03/04 & 83 & 31 \\
\hline 02/04/04 & 65 & 37 \\
\hline $12 / 04 / 04$ & 83 & 46 \\
\hline 20/04/04 & 77 & 40 \\
\hline $26 / 04 / 04$ & 69 & 32 \\
\hline 06/05/04 & 114 & 51 \\
\hline $13 / 05 / 04$ & 116 & 48 \\
\hline $19 / 05 / 04$ & 102 & 54 \\
\hline
\end{tabular}


Tabela B.4 - Valores de DBO anteriores ao experimento (Fonte: SABESP)

\begin{tabular}{cccc}
\hline \multirow{2}{*}{ Data: } & \multicolumn{3}{c}{ DBO [mg/L]: } \\
\cline { 2 - 4 } & Afluente: & Saída: & Efic. [\%]: \\
\hline $02 / 01 / 02$ & 70 & 11 & 84,3 \\
\hline $16 / 02 / 02$ & 43 & 10 & 76,7 \\
\hline $14 / 03 / 02$ & 61 & 17 & 72,1 \\
\hline $03 / 04 / 02$ & 98 & 22 & 77,6 \\
\hline $23 / 05 / 02$ & 110 & 30 & 72,7 \\
\hline $24 / 06 / 02$ & 194 & 40 & 86,6 \\
\hline $10 / 07 / 02$ & 246 & 54 & 83,7 \\
\hline $24 / 08 / 02$ & 395 & 42 & 86,3 \\
\hline $04 / 09 / 02$ & 85 & 29 & 50,8 \\
\hline $10 / 10 / 02$ & 104 & 11 & 72,1 \\
\hline $12 / 11 / 02$ & 32 & 15 & 65,6 \\
\hline $17 / 12 / 02$ & 60 & 17 & 74,9 \\
\hline $16 / 01 / 03$ & 48 & 25 & 64,8 \\
\hline $14 / 02 / 03$ & 124 & 19 & 79,9 \\
\hline $07 / 03 / 03$ & 30 & 13 & 36,7 \\
\hline $10 / 04 / 03$ & 18 & 21 & 42,2 \\
\hline $08 / 05 / 03$ & 37 & 29 & 69,9 \\
\hline $05 / 06 / 03$ & 96 & 36 & 84,5 \\
\hline $10 / 07 / 03$ & 233 & 72 & 7,1 \\
\hline $06 / 08 / 03$ & 78 & 35 & 82,7 \\
\hline $03 / 09 / 03$ & 202 & 24 & 70,6 \\
\hline $07 / 10 / 03$ & 82 & 21 & 63,5 \\
\hline $04 / 11 / 03$ & 58 & 20 & 63,0 \\
\hline $04 / 12 / 03$ & 54 & 13 & 97,8 \\
\hline $08 / 01 / 04$ & 46 & & 77,2 \\
\hline $04 / 02 / 04$ & 57 &
\end{tabular}


Tabela B.5 - Valores de fósforo total anteriores ao experimento (Fonte: SABESP)

\begin{tabular}{|c|c|c|}
\hline \multirow{2}{*}{ Data: } & \multicolumn{2}{|c|}{$\mathbf{P}_{\text {TOTAL }}[\mathrm{mg} / \mathrm{L}]:$} \\
\hline & Afluente: & Saída: \\
\hline $02 / 01 / 02$ & 4,9 & 4,5 \\
\hline $16 / 02 / 02$ & 6,3 & 5,8 \\
\hline $14 / 03 / 02$ & 5,2 & 4,0 \\
\hline $03 / 04 / 02$ & 5,0 & 4,2 \\
\hline $23 / 05 / 02$ & 5,7 & 4,1 \\
\hline $24 / 06 / 02$ & 5,1 & 4,2 \\
\hline $10 / 07 / 02$ & 4,4 & 3,4 \\
\hline $24 / 08 / 02$ & 5,1 & 4,7 \\
\hline $04 / 09 / 02$ & 4,4 & 3,1 \\
\hline $10 / 10 / 02$ & 5,2 & 4,8 \\
\hline $12 / 11 / 02$ & 4,0 & 3,3 \\
\hline $17 / 12 / 02$ & 4,0 & 3,3 \\
\hline $16 / 01 / 03$ & 4,3 & 3,2 \\
\hline $14 / 02 / 03$ & 3,1 & 2,8 \\
\hline 07/03/03 & 2,8 & 2,2 \\
\hline $10 / 04 / 03$ & 2,5 & 2,2 \\
\hline $08 / 05 / 03$ & 2,3 & 2,1 \\
\hline 05/06/03 & 2,2 & 2,1 \\
\hline 10/07/03 & 3,9 & 3,2 \\
\hline $06 / 08 / 03$ & 5,7 & 4,3 \\
\hline 03/09/03 & 5,1 & 4,3 \\
\hline 07/10/03 & 4,2 & 3,8 \\
\hline $04 / 11 / 03$ & 3,4 & 3,1 \\
\hline $04 / 12 / 03$ & 4,1 & 3,6 \\
\hline $08 / 01 / 04$ & 3,1 & 2,4 \\
\hline 04/02/04 & 3,1 & 2,2 \\
\hline $23 / 03 / 04$ & 6,1 & 4,3 \\
\hline $26 / 04 / 04$ & 6,3 & 4,0 \\
\hline 06/05/04 & 4,2 & 3,8 \\
\hline
\end{tabular}




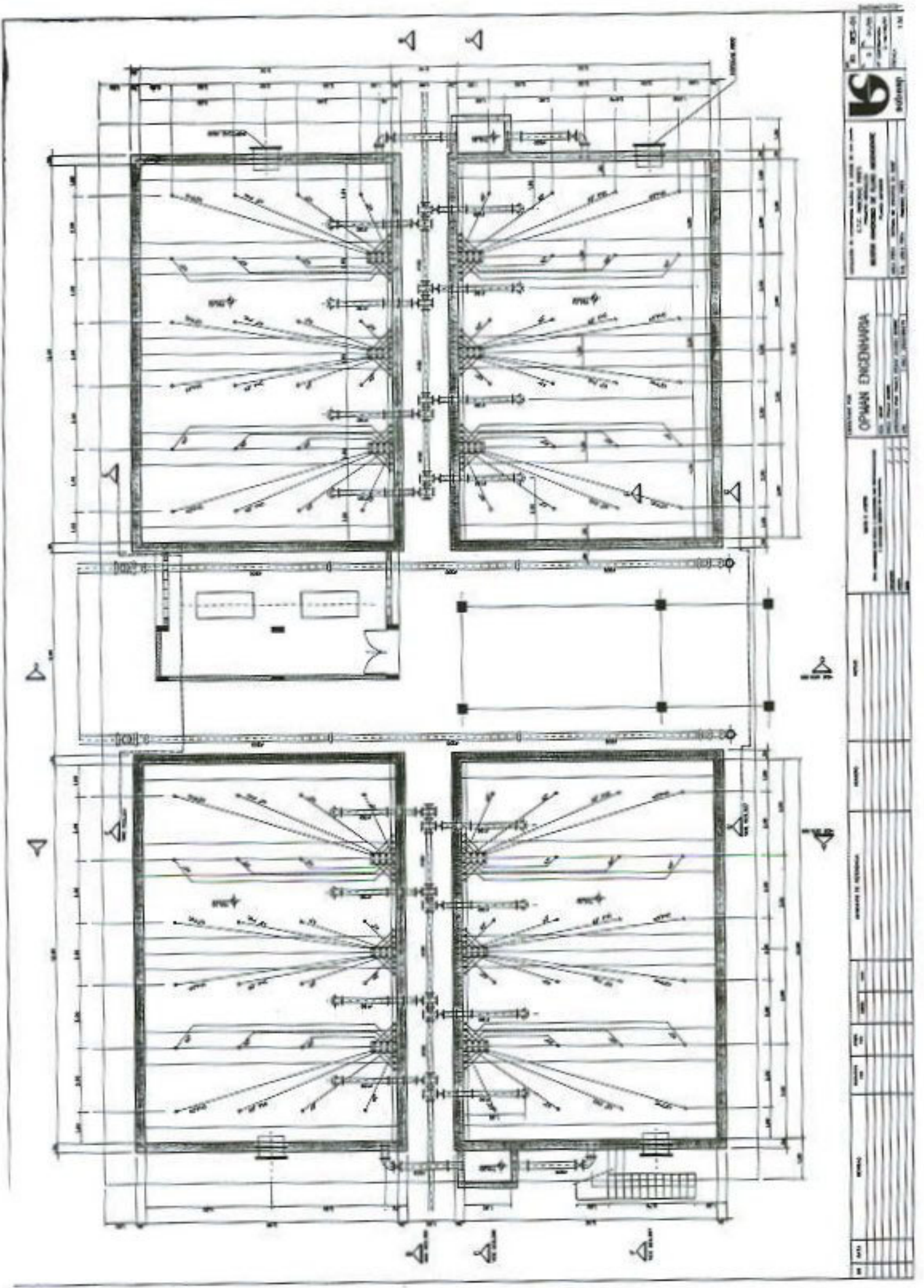

Figura C.1 - Planta do Fundo dos Reatores e Sala de Compressores (Fonte: SABESP) 


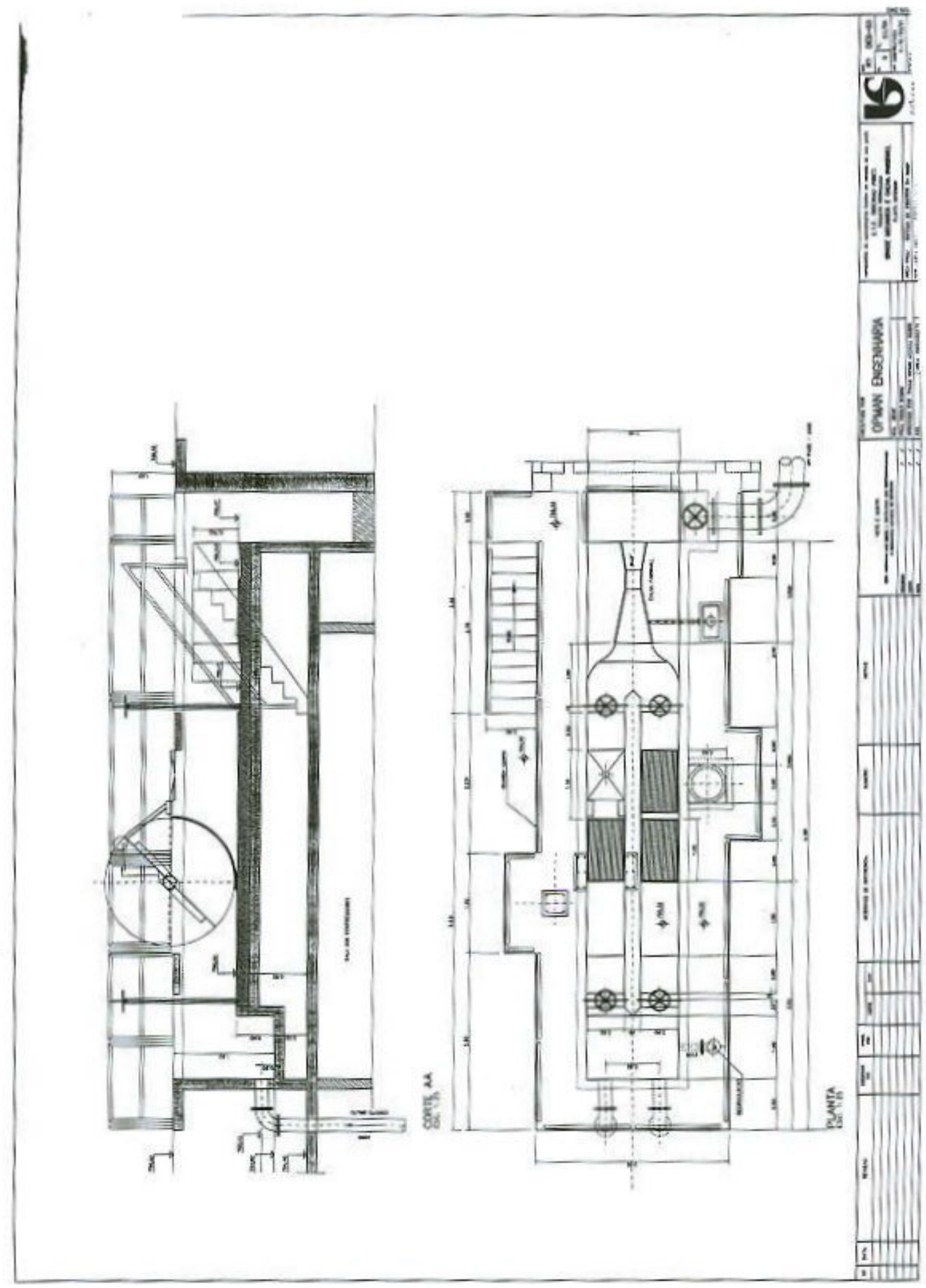

Figura C.2 - Tratamento Preliminar (Grade, Parshall e Caixa de Areia Aerada) (Fonte: SABESP) 


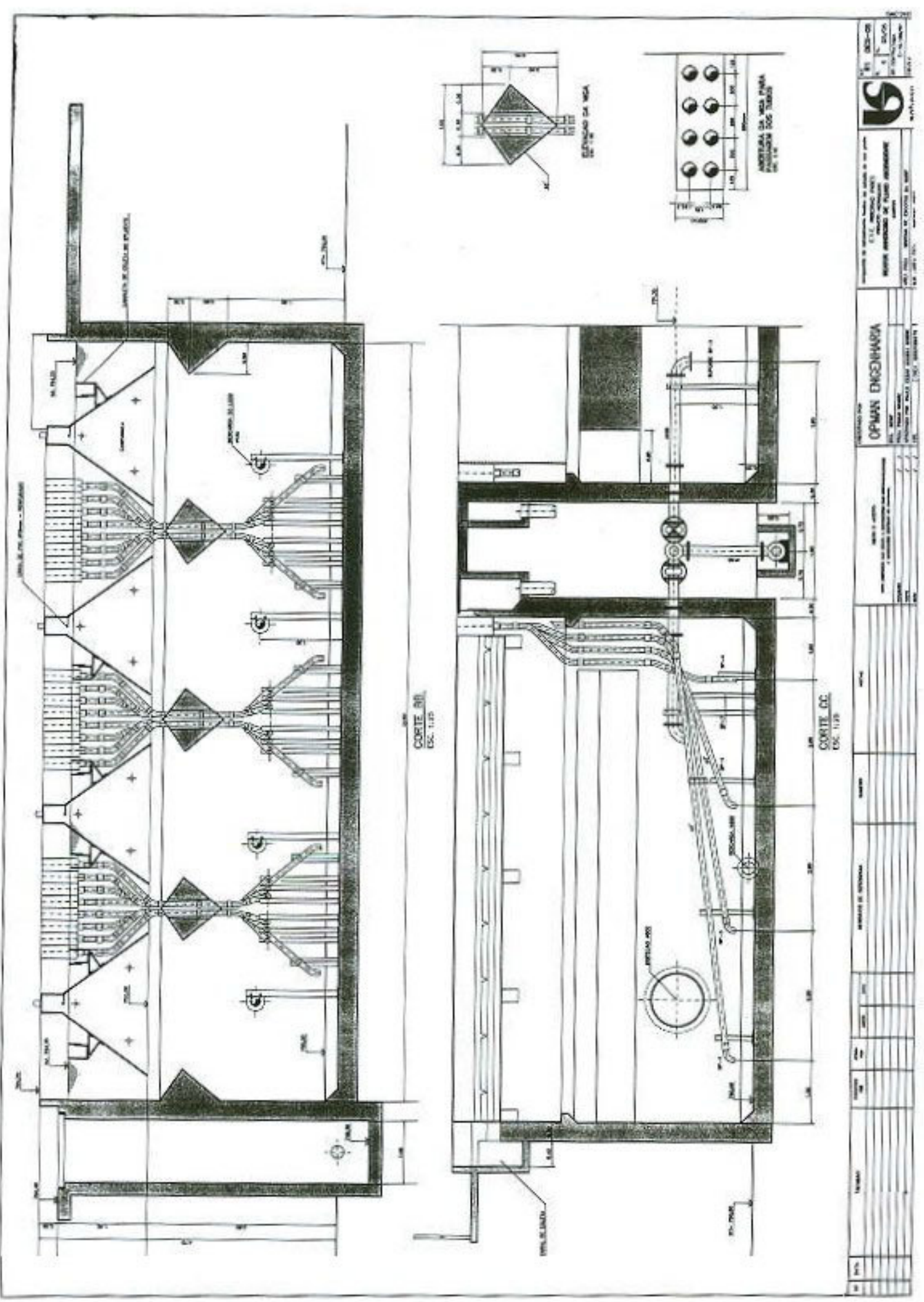

Figura C.3 - Vista em Corte dos Reatores UASB (Fonte: SABESP) 


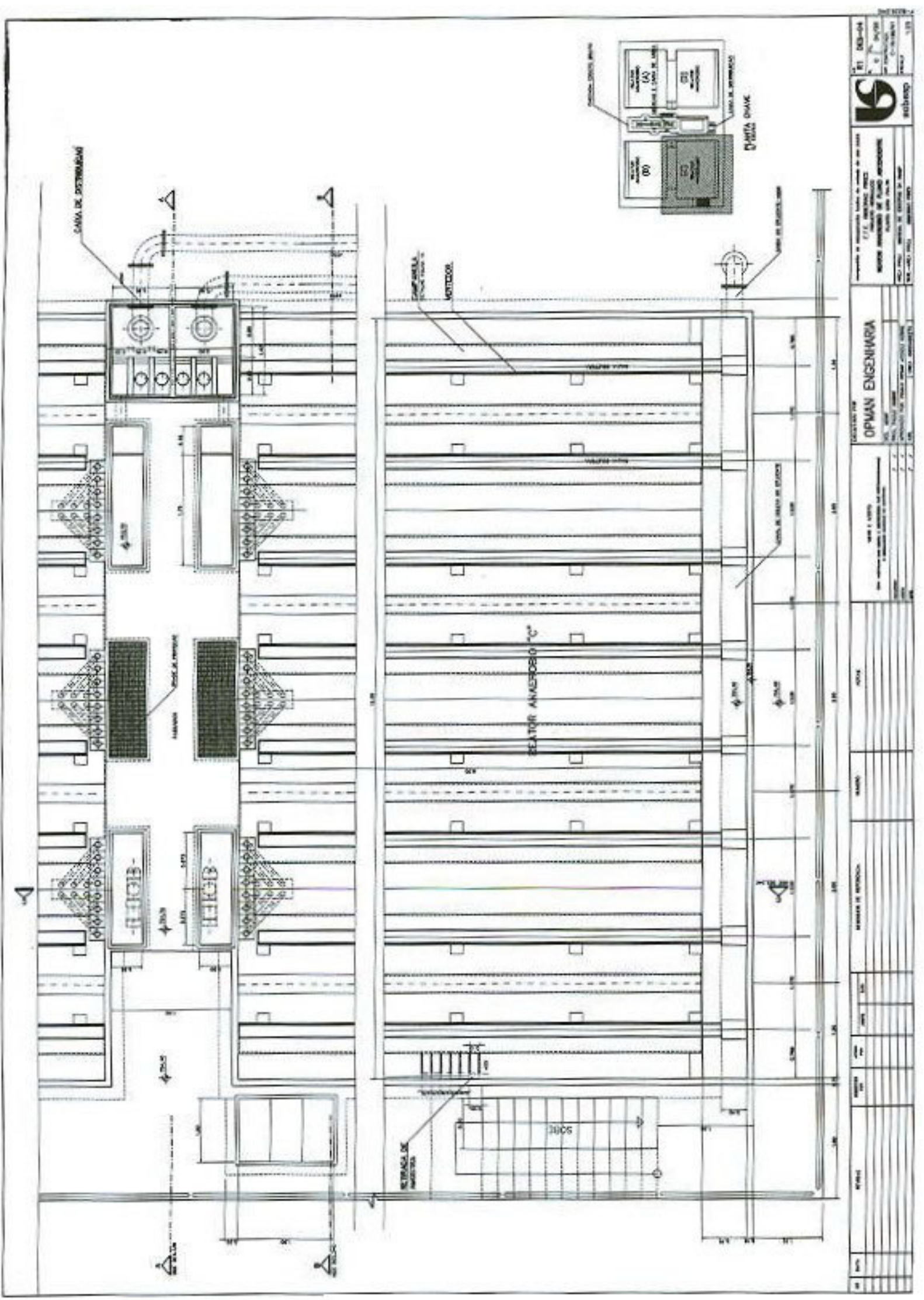

Figura C.4 - Planta dos Sistemas de Distribuição e de Coleta de Clarificado (Fonte: SABESP) 


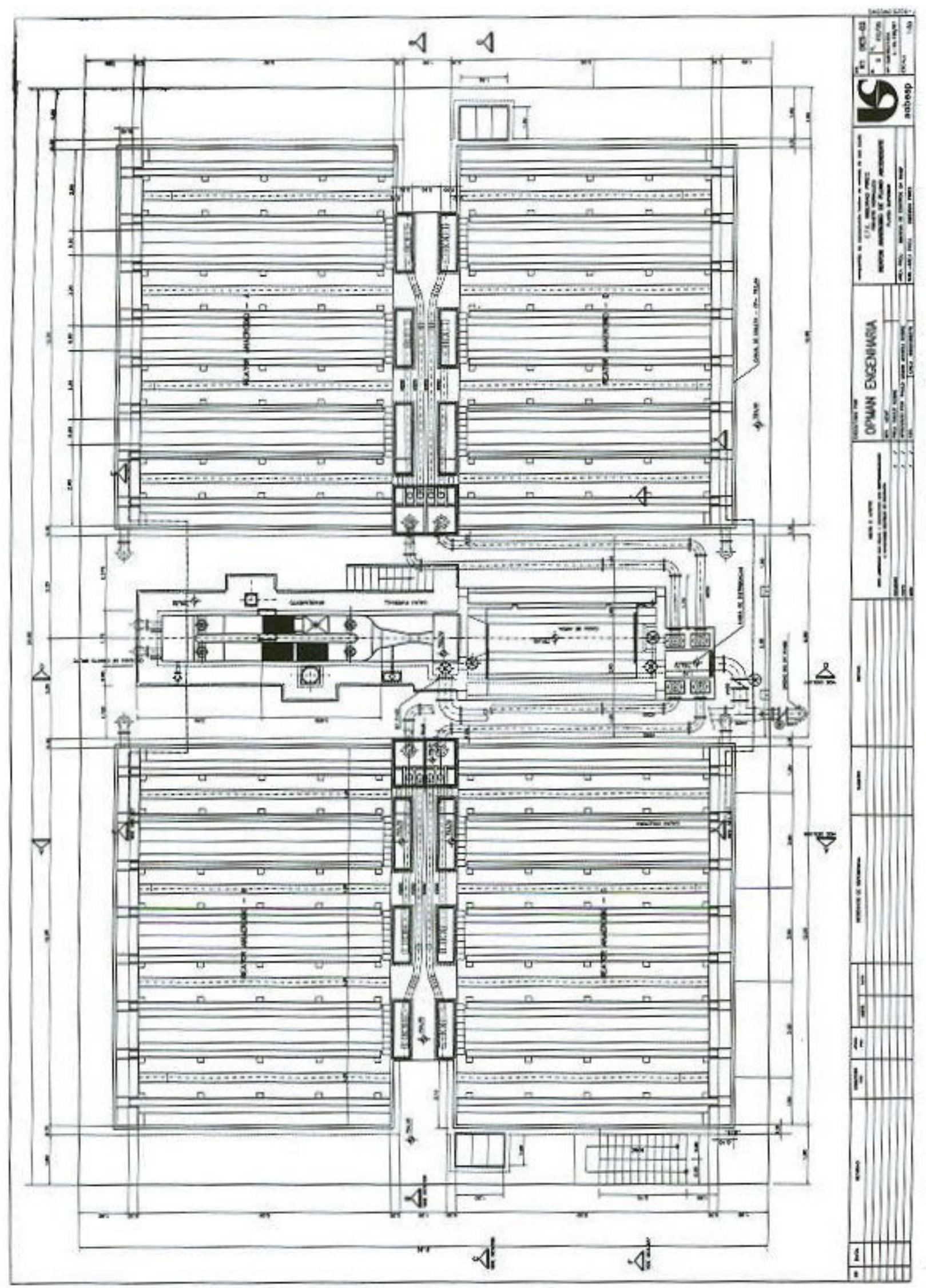

Figura C.5 - Planta Geral da ETE Ribeirão Pires (Fonte: SABESP) 
Tabela D.1 - Concentrações de sólidos no manto de lodo: reator B em 11/05/05

Reator B - 11/05/05

\begin{tabular}{ccccccc}
\hline $\begin{array}{c}\text { Altura a } \\
\text { partir do } \\
\text { fundo do } \\
\text { reator [m]: }\end{array}$ & ST [mg/L] & STF [mg/L] & STV [mg/L] & SST [mg/L] & SSF [mg/L] SSV [mg/L] \\
\hline $\mathbf{3 , 0}$ & 460 & 300 & 160 & 264 & 204 & 60 \\
\hline $\mathbf{2 , 0}$ & 53400 & 29660 & 23740 & 54636 & 36768 & 17868 \\
\hline $\mathbf{1 , 0}$ & 96460 & 55840 & 40620 & 150320 & 54196 & 96124 \\
\hline
\end{tabular}

Tabela D.2 - Concentrações de sólidos no manto de lodo: reator C em 11/05/05

Reator C - 11/05/05

\begin{tabular}{ccccccc}
\hline $\begin{array}{c}\text { Altura a } \\
\text { partir do } \\
\text { fundo do } \\
\text { reator [m]: }\end{array}$ & ST [mg/L] & STF [mg/L] & STV [mg/L] & SST [mg/L] & SSF [mg/L] SSV [mg/L] \\
\hline $\mathbf{3 , 0}$ & 700 & 240 & 460 & 380 & 228 & 152 \\
\hline $\mathbf{2 , 0}$ & 70020 & 39500 & 30520 & 70520 & 29032 & 41488 \\
\hline $\mathbf{1 , 0}$ & 82540 & 50100 & 32440 & 119128 & 52312 & 66816 \\
\hline
\end{tabular}

Tabela D.3 - Concentrações de sólidos no manto de lodo: reator B em 01/06/05

Reator B - 01/06/05

\begin{tabular}{ccccccc}
\hline $\begin{array}{r}\text { Altura a } \\
\text { partir do } \\
\text { fundo do } \\
\text { reator [m]: }\end{array}$ & ST [mg/L] & STF [mg/L] & STV [mg/L] & SST [mg/L] & SSF [mg/L] SSV [mg/L] & SS \\
\hline $\mathbf{3 , 0}$ & 340 & 220 & 120 & 200 & 80 & 120 \\
\hline $\mathbf{2 , 0}$ & 56640 & 31800 & 24840 & 62000 & 34700 & 27300 \\
\hline $\mathbf{1 , 0}$ & 87520 & 50160 & 37360 & 85500 & 46680 & 38820 \\
\hline
\end{tabular}


Tabela D.4 - Concentrações de sólidos no manto de lodo: reator C em 01/06/05

Reator C - 01/06/05

\begin{tabular}{ccccccc}
\hline $\begin{array}{c}\text { Altura a } \\
\text { partir do } \\
\text { fundo do } \\
\text { reator [m]: }\end{array}$ & ST [mg/L] & STF [mg/L] & STV [mg/L] & SST [mg/L] & SSF [mg/L] SSV [mg/L] \\
\hline $\mathbf{3 , 0}$ & 360 & 240 & 120 & 120 & 60 & 60 \\
\hline $\mathbf{2 , 0}$ & 92120 & 52380 & 39740 & 93940 & 51520 & 42420 \\
\hline $\mathbf{1 , 0}$ & 17120 & 8940 & 8180 & 18000 & 9220 & 8780 \\
\hline
\end{tabular}

Tabela D.5 - Concentrações de sólidos no manto de lodo: reator B em 15/08/05

Reator B - 15/08/05

\begin{tabular}{ccccccc}
\hline $\begin{array}{c}\text { Altura a } \\
\text { partir do } \\
\text { fundo do } \\
\text { reator [m]: }\end{array}$ & ST [mg/L] & STF [mg/L] & STV [mg/L] & SST [mg/L] & SSF [mg/L] SSV [mg/L] \\
\hline $\mathbf{3 , 0}$ & 62900 & 34520 & 28380 & 60620 & 32230 & 28390 \\
\hline $\mathbf{2 , 0}$ & 67520 & 36780 & 30740 & 66640 & 35650 & 30990 \\
\hline $\mathbf{1 , 0}$ & 77500 & 44540 & 32960 & 80290 & 43360 & 36930 \\
\hline
\end{tabular}

Tabela D.6 - Concentrações de sólidos no manto de lodo: reator C em 15/08/05

Reator C - 15/08/05

\begin{tabular}{ccccccc}
\hline $\begin{array}{c}\text { Altura a } \\
\text { partir do } \\
\text { fundo do } \\
\text { reator [m]: }\end{array}$ & ST [mg/L] & STF [mg/L] & STV [mg/L] & SST [mg/L] & SSF [mg/L] SSV [mg/L] \\
\hline $\mathbf{3 , 0}$ & 82300 & 46460 & 35840 & 80500 & 44160 & 36340 \\
\hline $\mathbf{2 , 0}$ & 96480 & 54860 & 41620 & 99150 & 53450 & 45700 \\
\hline $\mathbf{1 , 0}$ & 126580 & 77800 & 48780 & 151760 & 81560 & 70200 \\
\hline
\end{tabular}


Tabela D.7 - Concentrações de sólidos no manto de lodo: reator B em 05/10/05

Reator B - 05/10/05

\begin{tabular}{ccccccc}
\hline $\begin{array}{c}\text { Altura a } \\
\text { partir do } \\
\text { fundo do } \\
\text { reator [m]: }\end{array}$ & ST [mg/L] & STF [mg/L] & STV [mg/L] & SST [mg/L] & SSF [mg/L] SSV [mg/L] \\
\hline $\mathbf{3 , 0}$ & 56320 & 30060 & 26260 & 320 & 290 & 30 \\
\hline $\mathbf{2 , 0}$ & 580 & 380 & 200 & 55540 & 29620 & 25920 \\
\hline $\mathbf{1 , 0}$ & 67660 & 37600 & 30060 & 66540 & 37160 & 29380 \\
\hline
\end{tabular}

Tabela D.8 - Concentrações de sólidos no manto de lodo: reator C em 05/10/05

Reator C - 05/10/05

\begin{tabular}{ccccccc}
\hline $\begin{array}{c}\text { Altura a } \\
\text { partir do } \\
\text { fundo do } \\
\text { reator [m]: }\end{array}$ & ST [mg/L] & STF [mg/L] & STV [mg/L] & SST [mg/L] & SSF [mg/L] SSV [mg/L] \\
\hline $\mathbf{3 , 0}$ & 340 & 220 & 120 & 160 & 160 & 160 \\
\hline $\mathbf{2 , 0}$ & 68740 & 38300 & 30440 & 72920 & 39340 & 72920 \\
\hline $\mathbf{1 , 0}$ & 54520 & 31100 & 23420 & 54160 & 30420 & 54160 \\
\hline
\end{tabular}

Tabela D.9 - Concentrações de sólidos no manto de lodo: reator B em 06/02/06

Reator B - 06/02/06

\begin{tabular}{ccccccc}
\hline $\begin{array}{r}\text { Altura a } \\
\text { partir do } \\
\text { fundo do } \\
\text { reator [m]: }\end{array}$ & ST [mg/L] & STF [mg/L] & STV [mg/L] & SST [mg/L] & SSF [mg/L] SSV [mg/L] & SS \\
\hline $\mathbf{3 , 0}$ & 776 & 526 & 250 & 540 & 330 & 210 \\
\hline $\mathbf{2 , 0}$ & 40740 & 22860 & 17880 & 41000 & 22290 & 18710 \\
\hline $\mathbf{1 , 0}$ & 69860 & 42260 & 27600 & 67520 & -4391 & 71911 \\
\hline
\end{tabular}


Tabela D.10 - Concentrações de sólidos no manto de lodo: reator C em 06/02/06

Reator C - 06/02/06

\begin{tabular}{ccccccc}
\hline $\begin{array}{c}\text { Altura a } \\
\text { partir do } \\
\text { fundo do } \\
\text { reator [m]: }\end{array}$ & ST [mg/L] & STF [mg/L] & STV [mg/L] & SST [mg/L] & SSF [mg/L] SSV [mg/L] \\
\hline $\mathbf{3 , 0}$ & 400 & 280 & 120 & 100 & 40 & 60 \\
\hline $\mathbf{2 , 0}$ & 101280 & 62780 & 38500 & 106170 & 60650 & 45520 \\
\hline $\mathbf{1 , 0}$ & 108220 & 67020 & 41200 & 120870 & 68100 & 52770 \\
\hline
\end{tabular}

Tabela D.11 - Concentrações de sólidos no manto de lodo: reator B em 17/05/06

Reator B - 17/05/06

\begin{tabular}{ccccccc}
\hline $\begin{array}{c}\text { Altura a } \\
\text { partir do } \\
\text { fundo do } \\
\text { reator [m]: }\end{array}$ & ST [mg/L] & STF [mg/L] & STV [mg/L] & SST [mg/L] & SSF [mg/L] SSV [mg/L] \\
\hline $\mathbf{3 , 0}$ & 25880 & 13900 & 11980 & 25210 & 13980 & 11230 \\
\hline $\mathbf{2 , 0}$ & 37660 & 20660 & 17000 & 36600 & 20210 & 16390 \\
\hline $\mathbf{1 , 0}$ & 73660 & 40540 & 33120 & 71310 & 39300 & 32010 \\
\hline
\end{tabular}

Tabela D.12 - Concentrações de sólidos no manto de lodo: reator C em 17/05/06

Reator C - 17/05/06

\begin{tabular}{ccccccc}
\hline $\begin{array}{c}\text { Altura a } \\
\text { partir do } \\
\text { fundo do } \\
\text { reator [m]: }\end{array}$ & ST [mg/L] & STF [mg/L] & STV [mg/L] & SST [mg/L] & SSF [mg/L] SSV [mg/L] \\
\hline $\mathbf{3 , 0}$ & 380 & 320 & 60 & 150 & 190 & -40 \\
\hline $\mathbf{2 , 0}$ & 33140 & 19780 & 13360 & 29110 & 17840 & 11270 \\
\hline $\mathbf{1 , 0}$ & 104000 & 63120 & 40880 & 112330 & 65280 & 47050 \\
\hline
\end{tabular}


Hidrograma típico de vazões de esgoto sanitário afluente à ETE Ribeirão Pires

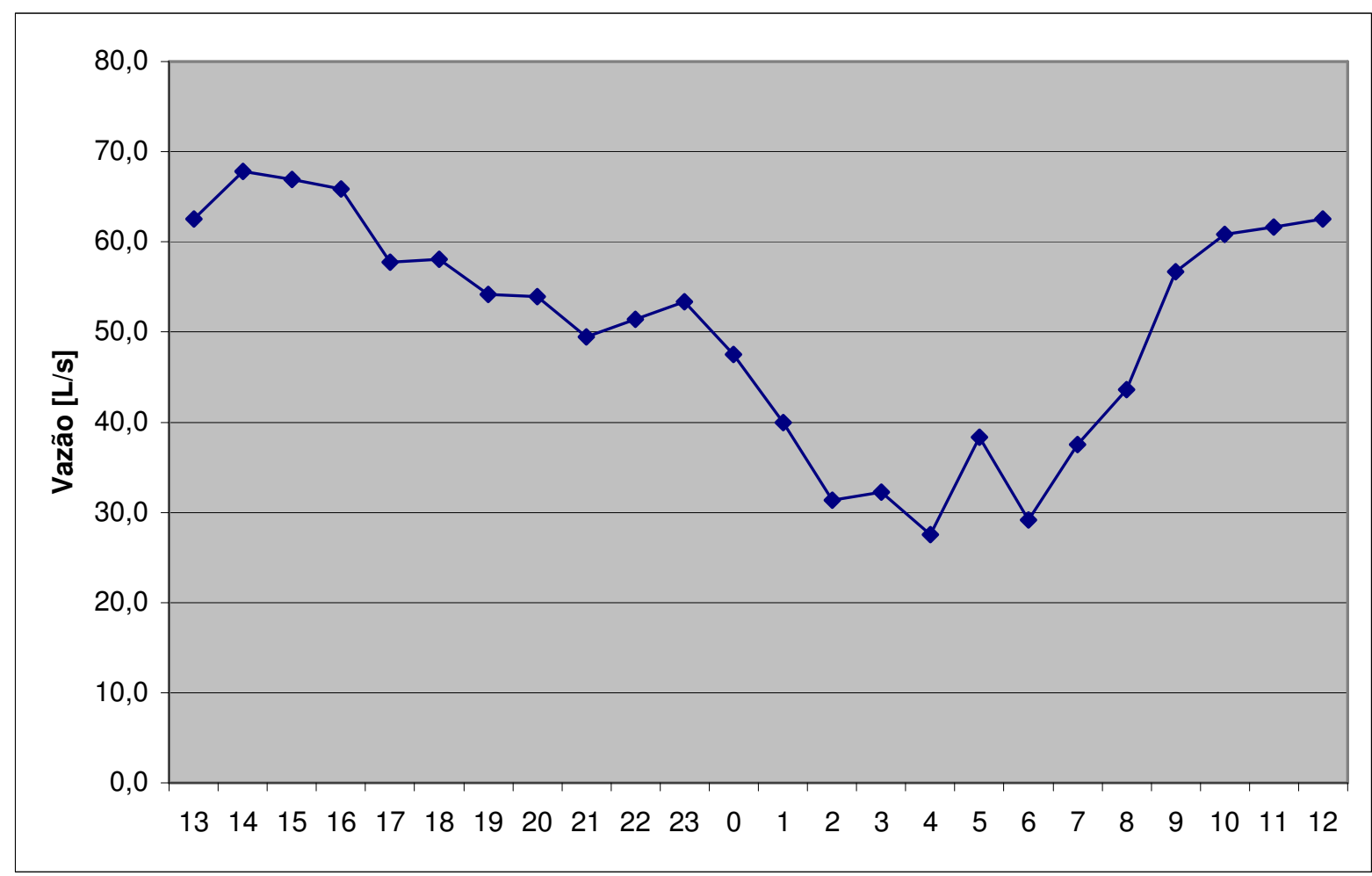

Figura E.1 - Hidrograma de vazões de esgoto sanitário afluente à ETE Ribeirão Pires (dia 30/05/05) 


\section{LISTA DE REFERÊNCIAS}

ALEM SOBRINHO, P.; JORDÃO, E. P. Pós-Tratamento de Efluentes de Reatores Anaeróbios - Uma Análise Crítica. In: Pós-tratamento de efluentes de reatores anaeróbios. PROSAB - PROGRAMA DE PESQUISA EM SANEAMENTO BÁSICO 2, p. 490-513, 2001.

APHA - American Public Health Association; AWWA - American Water Works Association; WPCF - Water Pollution Control Federation. Standards Methods for the Examination of Water and Wastewater. American Public Health Association, Washington, 20th ed., 2000.

DERISIO, J. C., Introdução ao Controle de Poluição Ambiental. CETESB, 1992.

Dentel, S. K. and J. M. Gossett. Coagulation of Organic Suspensions with Salts. Journal of Water Pollution Fed., 59, 101, 1987

DI BERNARDO, L., Métodos e Técnicas de Tratamento de Água. Volumes 1 e 2 , ABES, Rio de Janeiro, 1993.

Environment and Society in Florida - CRC Press, Boca Raton, Florida - 1997

FRANCl et. Al, 2004. Tratamento Terciário do Efluente de uma Estação de Tratamento de Esgoto Sanitário do Tipo UASB + Biofiltros Aerados Submersos Através de Processo Físico-Químico. ABES.

JORDAO, E. P, PESSOA, C. A. Tratamento de Esgotos Domésticos Concepções Clássicas de Tratamento de Esgotos. 1. ed. São Paulo: CETESB, 1975. v. 1.

METCALF \& EDDY, INC. Wastewater Engineering - Treatment, Disposal and Reuse. $3^{\text {rd }}$ ed., McGraw-Hill, 1991. 
PAKIN, G. F. e OWEN, WILLIAM - Fundamentals of Anaerobic Digestion of Wastewater Sludges, J. Environmental Engineering, ASCE,v. 112, m. 5,867 - 921, 1986.

PROSAB - PROGRAMA DE PESQUISA EM SANEAMENTO BÁSICO (1999) Tratamento de Esgotos Sanitários por Processo Anaeróbio e Disposição Controlada no Solo, McGraw-Hill.

SANTOS, HÉLIO RODRIGUES, Aplicação de Coagulantes no Afluente de reator Anaeróbio de Leito Expandido Alimentado com Esgoto Sanitário. São Carlos, 2001. Dissertação de Mestrado - Escola de Engenharia de São Carlos, Universidade de São Paulo. 151p.

SEDLAK, R. The Soap and Detergent Association, Phosphorus and Nitrogen Removal From Municipal Wastewater - Principles and Practices, Second Edition, Lewis Publishers, Estados Unidos, 1991.

SOUZA, MARCOS EDUARDO, Fatores que Influenciam a Digestão Anaeróbia. Revista DAE, Vol. 44 nr. 137, pág. 88 a 94, 1984.

SINELLI, P. H. Remoção de Fósforo de Efluente de Tratamento Anaeróbio por Processo Físico-Químico. São Paulo, 2002. Dissertação de mestrado - Escola Politécnica, Universidade de São Paulo. 128p.

SINELLI, P. H. et al. Remoção de Fósforo de Efluente de Tratamento Anaeróbio por Processo Físico-Químico. Cancun, 2002. Artigo do XXVIII Congreso Interamericano de Ingenieria Sanitaria y Ambiental - Cancun, México Out. 2002.

USEPA, Design manual - Phosphorus Removal, 1987

VAN HAANDEL, A. C. \& LETTINGA, G. Anaerobic Sewage Treatment.. West Sussex, England, 1994.John Wiley \& Sons. 
VON SPERLING, M. Introdução à Qualidade das Águas e ao Tratamento de Esgotos - Princípios do Tratamento Biológico de Águas Residuárias. Departamento de Engenharia Sanitária e Ambiental - Universidade federal de Minas Gerais, vol. 1, 1996. 